\title{
Effects of environmental exposures on childhood respiratory symptoms and function
}

Citation for published version (APA):

Cuijpers, C. (1995). Effects of environmental exposures on childhood respiratory symptoms and function. [Doctoral Thesis, Maastricht University]. Datawyse / Universitaire Pers Maastricht.

https://doi.org/10.26481/dis.19950629cc

Document status and date:

Published: 01/01/1995

DOI:

10.26481/dis.19950629cc

Document Version:

Publisher's PDF, also known as Version of record

\section{Please check the document version of this publication:}

- A submitted manuscript is the version of the article upon submission and before peer-review. There can be important differences between the submitted version and the official published version of record.

People interested in the research are advised to contact the author for the final version of the publication, or visit the DOI to the publisher's website.

- The final author version and the galley proof are versions of the publication after peer review.

- The final published version features the final layout of the paper including the volume, issue and page numbers.

Link to publication

\footnotetext{
General rights rights.

- You may freely distribute the URL identifying the publication in the public portal. please follow below link for the End User Agreement:

www.umlib.nl/taverne-license

Take down policy

If you believe that this document breaches copyright please contact us at:

repository@maastrichtuniversity.nl

providing details and we will investigate your claim.
}

Copyright and moral rights for the publications made accessible in the public portal are retained by the authors and/or other copyright owners and it is a condition of accessing publications that users recognise and abide by the legal requirements associated with these

- Users may download and print one copy of any publication from the public portal for the purpose of private study or research.

- You may not further distribute the material or use it for any profit-making activity or commercial gain

If the publication is distributed under the terms of Article $25 \mathrm{fa}$ of the Dutch Copyright Act, indicated by the "Taverne" license above, 


\section{Effects of environmental exposures on childhood respiratory symptoms and function}





\title{
EFFECTS OF ENVIRONMENTAL \\ EXPOSURES ON CHILDHOOD
}

\section{RESPIRATORY SYMPTOMS AND}

\author{
FUNCTION
}

PROEFSCHRIFT

ter verkrijging van de graad van doctor

aan de Rijksuniversiteit Limburg te Maastricht,

op gezag van de Rector Magnificus, Prof. mr. M.J. Cohen, volgens het besluit van het College van Decanen,

in het openbaar te verdedigen

op donderdag 29 juni 1995

om 14.00 uur

door

Carin Culjpers

geboren te Venray op 21 oktober 1965 

Promotores:
Prof. dr. E.F.M. Wouters
Prof. dr. F. Sturmans
Co-promotores:
Dr. G.M.H. Swaen
Dr. GJ. Wesseling
Beoordelingscommissie: Prof. dr. J.A. Knottnerus (voorzitter) Dr. J. Britton (University of Nottingham, United Kingdom) Prof. dr. J. Kleinjans Prof. dr. J.M.J.P. van der Linden Dr. B. Aijcken (Rijksuniversiteit Groningen)

GIP-DATA KONINKLUJKE BIBLIOTHEEK, DEN HAAG

Cuijpers, Carin

Effects of environmental exposures on childhood respiratory symptoms and function / Carin Cuijpers. Maastricht: Universitaire Pers Maastricht. - III. Thesis Aijksuniversiteit Limburg Matastricht. - With ref. With summary in Dulch.

ISBN 90.5278-189.3

Subject headings: emironmental exposures / respiratory impedance; children.

Lay-out: Thum Aarts, Epidemiologie RL, Maastricht Omslag: Serva Slangen, Maastricht

Produktie Datawyse | Universitaire Pers Maastricht 
Voor mijn ouders

Aan oma 


\section{CONTENTS}

page

Chapter 1: General introduction $\quad 7$

Childhood asthma

Environmental air pollution and respiratony health 8

Outdoor air pollution 8

Indoor air pollution $\quad 10$

$\begin{array}{lr}\text { Method's } & 12\end{array}$

Central aims of the thesis $\quad 15$

$\begin{array}{lr}\text { Structure of the thesis } & 15\end{array}$

Chapter 2: Frequency Dependence of Oscillatory Resistance in Healthy Primary School Children.

Chapter 3: Fespiratory Impedance in 1776 Dutch Primary School Children, With and Without Chironic Respiratory Symptoms.

Chapter 4: Asthma-related Symptoms and Lung Function in Primary School Children.

Chapter 5: Adverse Effects of the Indoor Environment on Respiratory Health in Primary School Children.

Chapter 6: How Does Parental Smoking Affect Respiratory Impedance in Children.

Chapter 7: Acute Respiratory Effects of Low Level Summer Smog in Primary School Children.

Chapter 8: Inter-regional Differences in the Prevalence of Asthma Among Primary School Chilldren in the Netherlands

Chapter 9: General Discussion and Conclusions $\quad 125$

Asthma $\quad 125$

Environmental risk factors $\quad 126$

$\begin{array}{lr}\text { Indoor } & 126\end{array}$

$\begin{array}{ll}\text { Outdoor } & 127 \\ & 128\end{array}$

$\begin{array}{lr}\text { The forced Oscillation Technique } & 128\end{array}$

Chapter 10: Samenvatting 133

Dankwoord

Curriculum Vitae

Lijst van Publicaties 


\section{Chapter 1}

\section{GENERAL INTRODUCTION}

\section{CHILDHOOD ASTHMA}

Asthma is by far the most common chronic disease in children. Asthma can be defined as a disease characterized by wide variations over short periods of time in resistance to flow in intra pulmonary airways, which manifests itself by episodes of wheezy breathlessness with intervals of relative or complete absence of symptoms." Pathophysiologicaly, asthma is characterized by bronchoconstriction and inflammation. ${ }^{2}$ The clinical diagnosis of asthma is of limited value for epidemiological purposes and the fundamental issue of how to define and operationalize asthma in this area therefore remains unresolved. Most epidemiologic studies resort to identify asthma on the basis of its main manifestation, i.e. wheezy breathlessness and the subordinate symptoms shortness of breath and chronic cough, by means of a questionnaire. In addition, asthma can be operationalized as a positive answer to the question whether the subject has asthma, sometimes quantified by a further question on whether this has been confirmed by a doctor and/or a physiological measurement of increased bronchial responsiveness. ${ }^{3}$ Problems which are inherent to a symptom-based definition of asthma are that asthma presents a heterogeneous clinical picture and that it shares many symptoms with other conditions. Ambiguity in the definition of asthma and the lack of a well standardized instrument for detecting the condition, makes it difficult to obtain a clear picture of the distribution of the disease or to give a valid estimate of its prevalence. ${ }^{3}$

Internationally reported prevalence rates for asthma in school age children vary from $11-20 \% .{ }^{4} \mathrm{~A}$ growing body of data suggest that there is a genuine increase in the prevalence of childhood asthma, which can not simply be explained by a change in diagnostic criteria, and which in turn may reflect a more general change in the prevalence of atopy. ${ }^{5-9}$ Some studies even reported an increase in asthma mortality. ${ }^{10,11}$ One of the problems with childhood asthma is that its diagnosis is frequently missed. ${ }^{4}$ Several studies have reported underdiagnosis and misclassification and consequently undertreatment of childhood asthma. ${ }^{12-14}$ The reason for the inadequacy in the diagnosis of asthma in children is not clear but may, in part, be explained by the fact that the young asthmatic child often presents itself with cough as the primary symptom rather than wheeze. ${ }^{4}$ In the Netherlands most epidemiological studies on asthma in childhood are conducted among primary school children. In these studies about $25 \%$. 
$30 \%$ of the children are reported to have one or more respiratory symptoms, in the previous twelve months. Combinations of asthma-like symptoms have been seen in $10 \%-15 \%$ and the (life-time) prevalence of (doctor-diagnosed) asthma in these children is estimated to be $5 \%-6 \%$. $15-17$

The most important etiological factor in the development of childhood asthma is that of allergen sensitization, with over $90 \%$ of the asthmatics demonstrating hypersensitivity to one or more allergen. The development of allergen sensitization is largely influenced by the level of genetic susceptibility and induced inflammation. ${ }^{18}$ important adjuvant factors which have been suggested to promote sensitization to an allergen in an individual are environmental tobacco smoke, environmental air pollution and viral infections. ${ }^{19}$ The possibility that these factors may increase the response to some allergens is intriguing, but their specific role in the etiology of asthma is still unclear. In the past decades a large number of studies focused on the potential effects on respiratory health, resulting from exposure to indoor as well as outdoor air pollutants. A brief overview of the current insights into this matter is presented in part two of this chapter.

\section{ENVIRONMENTAL AIR POLLUTION AND RESPIRATORY HEALTH}

\section{Outdoor Air Pollution}

In the evaluation of the potential health effects related to exposure to outdoor air pollution, long term effects resulting from chronic exposure to ambient levels and acute effects resulting from episodic exposure need to be distinguished. To investigate these effects a multidisciplinary approach is needed, using animal toxicology, epidemiology, controlled human exposure studies and more recently molecular and cell biology. The majority of the studies addressed the possible effects of a few indicator components being; sulphur dioxide $\left(\mathrm{SO}_{2}\right)$, nitrogen dioxide $\left(\mathrm{NO}_{2}\right)$, ozone $\left(\mathrm{O}_{3}\right)$, particulate matter (PM) and acid aerosols. The large database resulting from these studies offers some insight into the links between air pollution and asthma. In a recent review of the literature on this topic Wardlow stated that air pollution theoretically could both, increase the risk of developing asthma and exacerbate existing asthma. ${ }^{20}$ Several possible mechanisms by which air pollutants affect asthma were mentioned; a direct toxic effect, modification of the immune response to make it more susceptible to an immunological trigger, a direct irritant effect on hypersensitive airways and generation of both non-specific and allergen specific airway hyperreactivity possibly through provoking airway inflammation.

Controlled human exposure studies have shown that inhalation of high concentrations of $\mathrm{SO}_{2}$ can cause acute adverse effects on the respiratory system. $\mathrm{SO}_{2}$ is known to induce bronchoconstriction and airway hypersensitivity, since the $1970 \mathrm{~s}$. ${ }^{21}$ Asthmatics appear to respond to exposures around $0.5 \mathrm{ppm}\left(1430 \mu \mathrm{g} / \mathrm{m}^{3}\right)$, but under conditions of heavy exercise and mouth breathing lower concentrations may provoke a wheezy prolonged exposure. Healthy individuals do not suffer any major adverse effect, unless levels of $\mathrm{SO}_{2}$ are well in excess of $1 \mathrm{ppm}\left(2860 \mu \mathrm{g} / \mathrm{m}^{3}\right)$. ${ }^{26}$ At the moment there is only limited insight in the effects of $\mathrm{SO}_{2}$ on severe, liable asthmatics or young children,
resulting from experimental studies.

Under controlled conditions inhalation of $\mathrm{O}_{3}$ (at levels which also occur regularly in ambient air) can cause impairment in lung function, which appear to be a restrictive 
rather than an obstructive defect. ${ }^{20}$ Ozone also has been demonstrated to cause an increase in responsiveness to both specific and non-specific bronchoconstrictors, which is likely to be due to the pro-inflammatory effects of ozone. ${ }^{20}$ No marked difference in acute response between asthmatic and normal subjects has been reported, although there is considerable variation between individuals in their response. ${ }^{22}$ Factors that predict individual sensitivity to ozone have yet to be identified, although it is clear that increasing age is associated with decreased responsiveness to ozone. ${ }^{23}$ The effects induced by ozone exposure depend on the total dose received and increases proportional to the amount of exercise..$^{23}$

The database on human health effects due to exposure to $\mathrm{NO}_{2}$ lacks consistency and reproducibility, as some studies did were others failed to show any effect of $\mathrm{NO}_{2}$ inhalation. ${ }^{20,23}$ Overall, the evidence suggests that an effect if any on asthmatics is likely to be small.

Laboratory studies concerning particulate air pollutants have generally failed to show pathologic effects of exposures at current outdoor levels, possibly because of their focus on single pollutants or because they studied the wrong agents. ${ }^{24}$

Short-term inhalation studies with acid aerosols $\left(\mathrm{H}_{2} \mathrm{SO}_{4}\right)$ show that any effect on asthmatics or healthy individuals is transient, of limited magnitude and occurs only at high concentrations, which are rarely encountered in ambient air. ${ }^{20}$ Asthmatics appear to be more susceptible than healthy subjects and children more than adults. Laboratory studies are useful to investigate the potential of individual air pollutants to cause adverse effects, to study the mechanism of action and allowing calculation of dose-response curves. However, they never can accurately mimic the effects of real air pollution with its combination of interacting circumstances and effects of prolonged exposure. ${ }^{20}$ In epidemiology, adverse effects are measured directly in humans exposed in their natural environment, but it is difficult to identify the exact causative agents with any certainty.

A few historical air pollution episodes have highlighted the detrimental effects of air pollution on health, during which persons with asthma were noted to be specifically affected (Meuse valley 1933, Donora Pennsylvania 1948). However, during the London smog (1952) and the more recent smog-episode in the Ruhr (1985), no increased susceptibility of asthmatic persons, compared to healthy ones, could be demonstrated. ${ }^{3}$ In general, episodic exposure offers unique opportunities to study acute changes in health status. In the past few years also in the Netherlands several investigators reported effects on lung function and respiratory symptoms in primary school children, due to exposure to air pollution episodes with only moderately elevated levels of air pollutants. ${ }^{25-29}$ However, in severel studies no adverse effects on pulmonary function were found in children exposed to similar or even higher levels of air pollutants. ${ }^{30-31}$ In contrast to episodic air pollution, some epidemiological studies have been initiated by the episodic occurrence of asthma attacks. ${ }^{3}$ These include; 'Tokyo-Yokohama asthma ${ }^{32}$ which has never been adequately explained, 'New Orleans asthma',33 which has been attributed to high levels of airborne pollen and spores, "Yokkaichi asthma episode, ${ }^{34}$ which was believed to be caused by the concentrated sulphuric acid mists emitted from a titanium oxide manufacturing plant, epidemics of asthma following thunderstorms ${ }^{35}$ and the epidemic of asthma in Barcelona ${ }^{36}$, which has been attributed to pollution by soybean allergen.

In general, many epidemiological studies have demonstrated small, transient, but consistent effects of air pollution on respiratory health of children and adults, even at moderate concentrations of air pollutants. ${ }^{37-47}$ Exposure to $\mathrm{SO}_{2}$ and oxidant air pollution 
consistently resulted in adverse effects on asthma (panel studies of asthmatics) and appeared to increase visits to the emergency room, although the effect on asthma admissions is variable. ${ }^{20}$ In a recent study from Germany, traffic load was reported to be significantly associated with a reduced puimonary function and increased respiratory symptoms in 10 year old chilldren. ${ }^{48}$ However, no significant increase in the prevalence of asthma and the response to cold air challenge could be demonstrated in this cross-sectional study.

At the moment there is a growing interest in the potential health effects of particulate ailr pollution, especially $\mathrm{PM}_{10}$ : on human morbidity and mortality. Pope et al. found daily $P M_{10}$ levels to be related to respiratory symptoms, peak expiratory flow rates and use of medication for asthma in symptomatic and asymptomatic chidren. ${ }^{49,50}$ Very recently these investigators reported small degrees of impairment in pulmonary function in adults to be associated with small changes in $P M_{10}$ exposure. ${ }^{51}$ in Seatle increases in $\mathrm{PM}_{10}$ levels have been associated with more emergency room visits for asthma. ${ }^{52}$ Studies in several geographical areas of the world have consistently shown statistically significant associations between mortality and daily concentrations of particulate matter in the air, at levels around the current $\mathrm{PM}_{10}$ level. ${ }^{53}$ Recently, a prospective cohort study reported the mortality rate, adjusted for other health risk factors, to be associated with the level of particulate air pollution. ${ }^{54}$ The consistency of the observed associations is certainly suggestive for causality. However, until now the toxicological evidence to demonstrate biological plausibility is lacking. ${ }^{55}$

There are almost no studies which specifically address the relative prevalence of asthma in low and high pollution areas. In a few studies concerning the long-term exposure to ambient levels of air pollutants, an increased prevalence of (chronic) respiratory symptoms was found. ${ }^{56-58}$ However, recently von Mutius et al. ${ }^{59}$ reported that they did not find differences in the lifetime prevallence of asthma, wheezung and bronchial hyperresponsiveness between children from eastern Germany (chronically exposed to heawy air pollution) compared to children from western Germany (less polluted). The lifetime prevalence of bronchitis was found to be higher in eastern than in western Germany. Sofar no study has specifically addressed the relationship between the incidence of bronchial hyperresponsiveness and air pollution. The question of air pollution increasing the prevalence of asthma therefore remains an open question. $^{20}$

In a pilot study, conducted in 1988, we investigated differences in the prevallence of asthma and asthma-like symptoms in relation to long-term exposure to ambient air" pollution. The investigated children lived in two different regions of the Netherlands; the south (regarded as polluted) and the morth (less polluted). The reported prevalence off all respiratory symptoms was on the average a factor 2 higher in the southern region than in the morthern regions $(p \leq 0.05)$, with the exception of asthma-attacks. Doctors consultation and school absenteeism, specific for respiratory symptoms, were also higher in the southern part. However, the prevalence data were not collected at the same time in both regions, no objective health measurements, e.g. lung function, were made and no specific data on air quality were collected. Therefore, no firm conclusions about a relationship between air pollution and respiratory heaith in these children could be drawn. ${ }^{60}$

\section{Indoor Air Pollution}

The importance of the indoor environment has been increasingly recoginized over the past three decades. Reduced building ventilation for the purpose of energy 
conservation and the fact that people spend the majority of their time indoors have increased both the concentration and the duration of exposure to the many identified pollutants. Cigarette smoke is an important and frequent cause of indoor air pollution. In the Netherlands still about $34 \%$ of the adult population (males $38 \%$, females $31 \%$ ) are smokers. ${ }^{6.1}$ The effects of parental smoking on acute respiratory illnesses has evidently been shown in infancy (up to the first year or two of life), with the mother's smoking making a greater contribution than the father's smoking. ${ }^{62,63}$ The evidence for effects on respiratory symptoms or pulmonary function in older children is less clear. The results of a large number of cross-sectional studies point at an excess prevalence of 30 to 80 percent of chronic respiratory symptoms in children of smokers. ${ }^{62}$ Regarding the effects on lung function, mainly determined by spirometry, less consistent results emerged. Some investigators did and others did not find effects on lung function related to passive smoking. ${ }^{62,63}$ There are three factors which may be responsible for this inconsistency in the data; (1) passive smoking determined by questionnaire is a crude estimate of exposure, (2) confound ing by active smoking or, (3) lack of power of the study to detect such small effects on lung function (in the order of 1 to $5 \%$ ). Similar to the studies among infants the observed health effects in older children were most obvious for maternal smoking and less obvious for paternal smoking. Inconsistent findings have been reported on gender differences in susceptibility to environmental tobacco smoke exposure. ${ }^{63-66}$ Recently, it has been suggested that the flow rates in the terminal part of the spirogram may be the most sensitive to passive smoke exposure, which might be interpreted as evidence of damage to the smaller airways. ${ }^{67}$ Whether this may progress to more severe impairment of ventilatory function as has been observed in some longitudinal studies ${ }^{68,69}$ is not clear. An interesting observation which has recently been reported by Frischer et al. ${ }^{70}$ is that exposure to maternal smoking can increase the variability of the peak expiratory flow rate (PEFR) and thus might contribute to the development of asthma.

A second important factor of the indoor environment is dampness. In the Netherlands the climate is moist and home dampness is a frequently reported problem. About 10$15 \%$ of the present housing stock deal with dampness problems. ${ }^{71}$ it has been hypothesized that a damp home environment promotes the development of mould growth and housedust mites which produce inhalation allergens. These in turn may be responsible for an increase in chronic airway symptoms such as wheeze and cough. Several cross-sectional, epidemiological studies have reported an association between damp housing and respiratory symptoms in children, in particular chronic cough and wheeze. ${ }^{72-78}$ Whether exposure to mould and/or housedust mites is responsible for this observed association is still an open question. A relationship of damp housing with lung function abnormalities is however less evident. Weak negative effects have been found on flow rates in the terminal part of the spirogram (MMEF), once again suggesting an effect on the smaller ainways. ${ }^{73,76}$ However, some investigators failed to find an effect on pulmonary function from exposure to home dampness. ${ }^{79,80}$ Recent results from a large cross-sectional study among Canadian school children indicate that home dampness is significantly associated with the prevalence of current asthma and the prevalence of wheezing without a diagnosis of asthma. ${ }^{81}$

A third indoor environmental factor which has received considerable attention in the past, is directly or indirectly measured nitrogen dioxide, mainly from gas household appliances (e.g. gas stoves). It appears that in the Netherlands the use of unvented kitchen geysers (= gas-heated hot-water supplies, without flue, located in the kitchen) 
contribute most to the indoor $\mathrm{NO}_{2}$ level. Short-term peaks, lasting several minutes, of about $4000 \mu \mathrm{g} / \mathrm{m}^{3}$ and one hour mean concentrations of $2000 \mu \mathrm{g} / \mathrm{m}^{3}$ have been reported in Dutch kitchens. Weekly averages measured in kitchens with an unvented kitchen geyser were in the range of $120-143 \mu \mathrm{g} / \mathrm{m}^{3}{ }^{82}$ Reduced efficacy of lung defense and airway injury have been postulated as mechanism for the effects of nitrogen dioxide on respiratory health. ${ }^{83}$ The results of epidemiological studies on this topic are inconclusive. In the past, the presence of gas stoves has been associated with an increased history of respiratory illness before the age of two years and small but significant lower levels of pulmonary function, in children. ${ }^{84}$ More recently, a significant association between gas cooking appliances and the prevalence of asthma in childhood was reported. ${ }^{81}$ In contrast, others failed to find a clear association between nitrogen dioxide exposure and respiratory symptoms and/or pulmonary function in children.. ${ }^{80,85-B 7}$ Recently, Infante-Rivard ${ }^{88}$ reported a dose-response relationship of quantitative measurements of nitrogen dioxide with childhood asthma. However, Dijkstra et al. ${ }^{79}$ only found a weak negative association between MMEF in children and quantitatively determined nitrogen dioxide exposure in the home. No clear associations with reported respiratory symptoms and lung growth was found. The inconsistency in the results may, in part, be explained by misclassification of exposure and disease and to the (often) small study sizes. ${ }^{83}$

In general, information about the presence of indoor factors and the occurrence of respiratory symptoms, is obtained by means of a questionnaire. Inherent to the subjective nature of questionnaire reporting is that the observed associations between exposure to the indoor factors and the occurrence of symptoms must be considered liable to information bias. Therefore it is important to develop and use more objective measures of individual exposure and effect, e.g. sensitive lung function measurements. Despite the huge body of knowledge concerning the adverse effects of outdoor and indoor environmental exposures on respiratory health in general and asthma in particular, still many issues remain to be resolved. In the studies on this topic discussed in this thesis three outcome variables of respiratory health are used. These are questionnaire derived asthma-like symptoms, flow-volume indices obtained by spirometry and impedance characteristics of the respiratory system measured by means of the Forced Oscillation Technique. As both lung function techniques measure different characteristics of the respiratory system they may give a broader insight into the potential health effects, resulting from to outdoor and indoor environmental exposures.

\section{METHODS}

In the third part of this chapter the techniques used to measure respiratory health of the investigated children are discussed in more detail.

\section{The Questionnaire}

The prevalence of asthma-like (chronic respiratory) symptoms is evaluated by means of a written questionnaire, completed by the parents of the children. The questionnaire is a Dutch version of the children"s questionnaire of the World Health Organisation published by Florey and Leeder. ${ }^{89}$ The reproducibility of the answers of the Dutch questionnaire has been found to be good to very good for almost all questions, especially for wheeze and attacks of shortness of breath with wheeze and asthma and 
bronchitis diagnosed by a physician, Cohen's Kappa values ranging from 0.60 to 0.96 . $^{90}$ The reproducibility of chronic cough was less (a Kappa value of 0.28 ). By means of the questionnaire the lifetime prevalence and the period prevalence ( = within the previous year) of the key symptoms, chronic cough, wheeze, (attacks of) shortness of breath (with wheeze) are determined. The questionnaire further contains questions on age and gender of the child, medical consumption, family history, smoking habits of persons inside the house, domestic animals, presence of indoor nitrogen dioxide sources (gas appliances), home dampness and other home characteristics, and the parental educational levels. The parents received the questionnaire by mail and mailed it back after completion.

At the end of each chapter of this thesis the main questions used in the analysis, are specified in an Appendix.

\section{Spirometry}

Spirometry is the most widely accepted method for lung function measurement, due to its wide availability, good reproducibility and the ease with which measurements are performed and interpreted. A disadvantage of spirometry is that the results depend on the effort made by the subject and therefore is less suitable for measurements in small children. Furthermore, forced inspirations and expirations may alter bronchial tone and can modify the airway obstruction. The commonly used spirometry indices; the forced expiratory volume in one second $\left(F E V_{1}\right)$ and the peak expiratory flow rate (PEFR) are mainly indicating large airway flow obstruction and are less sensitive indicators of small airway obstruction. ${ }^{91}$

In the studies presented in this thesis, spirometry was performed according to the ECCS-protocol ${ }_{19}^{92}$ with the exception that five instead of three acceptable manoeuvres had to be collected out of a maximum of eight attempts. Measurements were performed with the child in standing position using a dry spirometer (Vitalograph Ltd., Buckingham, England). From the valid manoeuvres the highest values for the forced vital capacity (FVC), the forced expiratory volume in one second $\left(F E V_{1}\right)$ and peak expiratory flow (PEF) were selected. The forced expiratory flow between 25 and $75 \%$ of the vital capacity (FEF $25.75 \%$ ) was selected from the measurement with the highest sum value for the FVC and the $\mathrm{FEV}_{1}{ }^{92}$ These values were used in the analyses.

\section{The Forced Oscillation Technique}

The application of the forced oscillation technique (FOT), to measure respiratory impedance, is not yet widely accepted. The measurements are non-invasive and do not require active cooperation from the subject. They are performed during spontaneous quiet breathing and can therefore be of special value in young children, as has been demonstrated by several investigators. ${ }^{93-99}$ By the forced oscillation technique information on mechanical characteristics of the respiratory system is obtained. ${ }^{100}$ By applying a complex acoustic signal the frequency dependent behaviour of the respiratory system can be measured over an extended frequency spectrum. ${ }^{101}$ Respiratory impedance can be partitioned into a real part or resistance $\left(R_{r s}\right)$ and an imaginary part or reactance $\left(x_{\mathrm{rs}}\right)$. The total resistance consists of the resistance of the central airways, the peripheral airways and the chest wall. At low frequencies $X_{r s}$ is negative because it is determined mainly by the capacitance of the respiratory system. At high frequencies the inertial properties dominate $X_{r s}$ which is then positive. The frequency at which $X_{r s}=0$ is called resonant frequency $\left(f_{0}\right)$ : the influences of capacitance and inertia on $\mathrm{X}_{\mathrm{rs}}$ cancel out at the resonant frequency. In adult patients 
with Chronic Obstructive Pulmonary Disease (COPD) and asthma it has been demonstrated that resistance values are increased at low frequencies and resistance markedly decrease with increasing frequency. This is called (negative) frequency dependence of resistance (FD). Reactance values are more negative and consequently resonant frequency is increased in patients with airflow obstruction. ${ }^{102}$ in asthmatic children similar changes in respiratory impedance were reported after histamine and methacholine challenges. ${ }^{103,104}$ However, by several investigators negative frequency dependence of oscillatory resistance has been suggested to be a normal finding in young healthy children. ${ }^{93,96,98,99}$ Two examples of a result of an impedance measurement are presented, in Figure ta for a symptom-free eight year old girl, and in Figure $1 \mathrm{~b}$ for an asthmatic 8 year old girl. It can be seen that in the asthmatic girl there is a decrease in resistance with increasing frequency (negative frequency dependence of resistance) whereas in the symptom-free girl the resistance curve slightly increases with increasing frequency. In the asthmatic girl (1b) reactance is more negative than in the symptom-free girl (1a) and consequently the resonant frequency is increased in the asthmatic girl. If environmental factors adversely affect respiratory impedance outcomes, we would expect to find values for resistance and reactance to be affected in the direction as presented in Figure $1 b$ for the asthmatic girl.

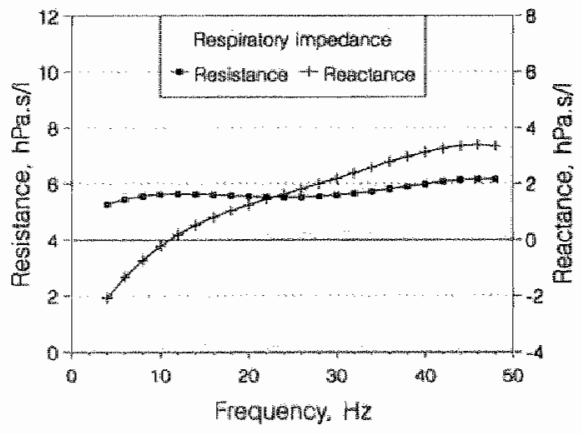

Figure 19. Results of a respiratory impedance measurement for a symptom-free ${ }_{n} 8$ year old girl.

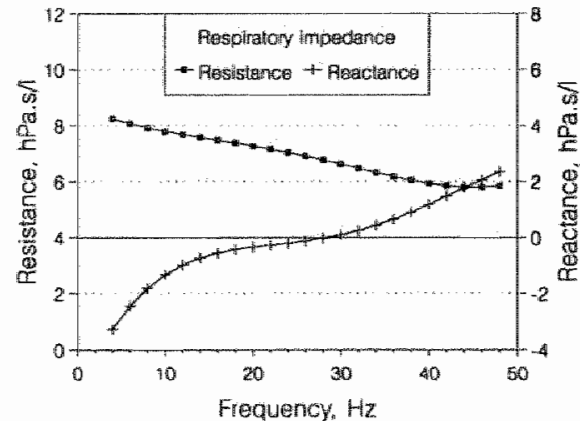

Figure 1b. Results of a respiratory impedance measurement for a asthmatic 8 year old girt.

Brochard et al. ${ }^{105}$ used the FOT in an occupational setting, studying the effects of exposure to inhaled irritants. They found that the slope of the resistance versus frequency curve was a sensitive index capable of separating subjects free of any exposure to respiratory irritants from subjects with low respiratory risk. The use of $\mathrm{He}-\mathrm{O}_{2}$ improved the specificity of this index. Besides, the change in the slope of frequency dependence of resistance between air and $\mathrm{He}-\mathrm{O}_{2}$ breathing, appeared to be more sensitive to detect early airway abnormalities caused by smoking or occupational hazards than the maximal expiratory flow volume curve (MEFV). At about the same time an interesting finding was reported by Peslin et al. ${ }^{97}$ These investigators observed that the slope of the resistance versus frequency curve was significantly lower 
in children from a polluted area compared to children from a non-polluted area. It was suggested that this finding could represent the only and early manifestation of peripheral airway obstruction. Because the FOT can easily be applied and is capable of detecting early airway abnormalities, it has been suggested to be an adequate test for epidemiological studies and occupational medicine applications. ${ }^{101}$ Very recently a study has been conducted using the FOT in different occupational settings. ${ }^{106}$ In the present thesis the FOT was used in different epidemiological settings, studying asthma related problems due to exposure to environmental pollutants, in open populations of school children.

\section{CENTRAL AIMS OF THE THESIS}

1 To investigate the prevalence of chronic respiratory (asthma-like) symptoms and lung function characteristics in Dutch primary school children.

The prevalence of childhood asthma is discussed in the context of national and international prevalence rates, and with respect to recognition, classification and treatment by physicians.

2 Respiratory morbidity and lung function abnormalities in children are studied in relation to indoor and outdoor environmental exposures.

3 New is the application of the Forced Oscillation Technique (FOT) in open populations of school children. Impedance values are studied in relation to height, weight, gendler and reponted asthma-like symptoms. Investigated is the diagnostic value of the impedanice parameters. Throughout the thesis the suitability of the FOT in epidemiological (open populations) research on respiratory health problems in children in relation to indoor and outdoor environmental exposures, is evaluated.

\section{STRUCTURE OF THE THESIS}

As outlined before, the FOT is a non-invasive method to determine mechanical characteristics of the respiratory system, during normal breathing. No active cooperation of the subject is required and information on the localisation of respiratory abnormalities may be directly obtained. The technique has mainly been used in clinical practice in patients with various disease entities. Recently it has been demonstrated that the FOT is a sensitive method to obtain quantitative and qualitative information on the response of the respiratory system to bronchoactive agents. ${ }^{107}$ The advantages of the FOT observed in clinical practice raised the question whether this technique would also be a suitable tool in epidemiological research. In the studies presented in this thesis the technique of forced oscillations is used to measure respiratory input impedance in children.

In chapter 2 respiratory resistance and reactance values, in 371 healthy children, are analyzed in relation to height (age) and gender. It is investigated to what extent negative frequency dependence of oscillatory resistance, which has been suggested to be a sensitive index of air flow obstruction in adults, exists in these children.

In chapter 3 a more sophisticated approach is presented for analyzing respiratory impedance measurements of 1776 children. For each individual child resistance and reactance curves are described as a function of frequency using linear and quadratic regressions. The linear curves are described for the total frequency range $(4-48 \mathrm{~Hz})$ 
and for the sub-sections $4-12 \mathrm{~Hz}$ and $8-28 \mathrm{~Hz}$. Curve parameters $(\gamma, \beta$ and $\alpha$ ) and the on-line parameters are compared between symptom-free children and children with asthma, chronic cough or rest-symptoms. Discussed is the diagnostic value of the individual impedance parameters.

Chapter 4 describes a study of the prevalence of asthma-like symptoms such as wheeze, cough, shortness of breath and attacks of shortness of breath with wheeze; in 482 primary school children living in Maastricht. Evalluated is the recognition of asthma by physicians and the subsequent drug prescription. In addition, it is investigated whether children reporting asthma related symptoms differ in terms of their lung function values, spirometry and respiratory impedance from symptom-free children.

Chapter 5 presents a cross-sectional study of the association between respiratory morbidity and changes in lung function, and various aspects of the home environment in 470 Dutch primary school children. The aim of the study is to investigate which of the indoor environmental factors, home dampness, passive smoking, urvented kitchen geysers and pets is most obviously related to the respiratory health of the children. Besides the four key symptoms for current asthma; chronic cough, shortness of breath, wheeze and attacks of shortness of breath with wheeze, changes in lung function as determined by the FOT and spirometry, are used as outcome variables.

In chapter 6 effects of parental tobacca smoke on respiratory impedance in 1776 children is studied in more detail. Exposure to maternal , paternal and parental smoking are analyzed independently. The existence of a dose-response relationship and gender differences in susceptibility to parental smoke exposure are investigated.

In chapter 7 exposure to outdoor air pollution, i.e. summer-smog, is discussed. In a group of 212 children comparisons between baseline and episode are made regarding acute respiratory symptoms and changes in lung function, measured by the FOT and spirometry. The baseline measurements were performed during a period with low air pollution levels. Re-examination of the same children took place after a summer-smogepisode, characterised by 8-hour ozone levels $>120 \mu \mathrm{g} / \mathrm{m}^{3}\left(\max .163 \mu \mathrm{g} / \mathrm{m}^{3}\right)$ and 1 hour ozone levels $>160 \mu \mathrm{g} / \mathrm{m}^{3}$ (max. $\left.215 \mu \mathrm{g} / \mathrm{m}^{3}\right)$.

In chapter $\mathbf{B}$ an inter-regional study on the prevalence of asthma-like symptoms and respiratory impedance in primary school children is presented. Comparisons are made between the very south of the Netherlands (Melick-Herkenbosch/Asenray, province of Limburg) and the very north of the Netherlands (Leek, province of Groningen). Differences in outdoor air pollution and the distribution of indoor environmental factors are discussed as possible risk factors for the observed differences in asthma prevalence and respiratory impedance values between the regions.

\section{REFERENCES}

1. Chatk T.HH. Defirition and clinical categories of asthma. In: Asthma (3rd edn), eds. Clark TJH: Godfrey S, and Lee TH. Chapmann \& Hall, London 1992, (chapter 1).

2. Anderson HR. Epidemiology of asthma. Br J Hospital Medioine 1992; 47: 99-103.

3. Burney PGJ. Epidemiology. In: Asthma (3rd edn), eds, Clark TJH, Godfrey S, and Lee TH. Chapmann \& Hall, London 1992, (chapter 9 ).

4. Godfey S. Childhood asthma lin: Asthma (3rd edn), eds. Clark TJH, Godfrey S, and Lee TH. Chapmann \& Hall, London 1992, (chapter 18).

5. Burney PGJ, Chinn S, Rona RJ. Has the prevalence of asthma increased in children? Evidence from the national study of thealth and growth 1973-1986. Br Med J 1990; 300: 1306-1310 
6. Britton J. Asthma changing prevalence. Br Med J 1992; 304: 857-858.

7. Burr ML, Butland $B K_{,}$King $S$, Vaughan-Williams $E$. Changes in asthma prevalence: two surveys 15 years apart. Arch Dis Child 1989; 64: 1452-1456.

8. Ninan TK, Fussell G. Respiratory symptoms and atopy in Aberdeen schoolchildren: evidence from two surveys 25 years apart. Br Med J 1992; $304: 873-875$.

9. Yunginger JW, Reed CE, O'Connel EJ, Meiton LJ, O'Fallon WM, Silverstein MD. A communitym based study of the epidemiology of asthma. Incidence rates, 1964-1983. Am Rev Respir Dis 1992; 146: 888-894.

10. Burney PGJ. Asthma mortality in England and Wales: Evidence for a further increase, 1974-84. Lancet 1986; ii: 323-326.

11. Sears MR, Rea HH, Fenwick J, et al. Deaths from asthma in New Zealand. Arch Dis Child 1986: $61: 6-10$.

12. Lee DA. Winslow NR, Speight ANP. Hey EN. Prevalence and spectrum of asthma in childhood. Br Med J 1983: 286: 1256-1258.

13. Wilson NM. Wheezy bronchitis revisited (controwersy). Arch Dis Child 1989; 64: 1194-1199.

14. Speight ANP, Lee DA. Hey EN. Underdiagnosis and undertreatment of asthma in childhood. B: Med J 1983; 286: 1253-1256.

15. Akkerman I, Dijkstra L, Houthuijs D, Brunekreef, Biersteker $K$. Evaluation of a questionnaire on respiratory sympioms in children. I Reproducibility of the answers. T Soc Gezondheidsz 1989; 67: 183-187 (in Dutch).

16. Steenbekkers A, Boer de A, Brunekreef B, Hoek G, Rijcken B, Groot B. A comparison of two questionnaires on respiratory symptoms in children. I Comparison of the prevalences. T Soc Gezondheidsz 1990; 68: 478-482 (in Dutch).

17. Rijcken B. Two questionnaires on respiratory symptoms for epidemiological studies in the youth health service. T Soo Gezondheidsz 1989; 67: 271-274 (in Dutch).

18. Clough $\mathrm{JB}$. Pre- and post-natal events leading to allergen sensitization. Clin Exp Allergy 1993 ; 23: $462-465$.

19. Popp W, Zwick H, Streyrer K et al. Sensitization depends on environmental factors. Allergy 1989; 44: 572-575.

20. Wardlaw AJ. The role of air pollution in asthma. Review. Clin Exp Allergy 1993; 23: 81-96.

21. Farely JM. Inhaled toxicants and alrway hyperresponsiveness. Annu Rev Pharmacol Toxicol $1992^{*}$ 32: 67-88.

22. Koenig JQ, Covert DS, Marshall SG, Van-Belle G. Pierson WE. The effects of azone and nitrogen dioxide on pulmonary function in healthy and asthmatic adolescents. Am Rev Respir Dis 1987" 136: $1152-1157$.

23. Folinsbee Lu. Human health effects of air pollution. Environ Health Perspec 1992; 100: $45 \cdot 56$.

24. Schenker M. Air pollution and mortality (editorials). New Engl J Med 1993; 329: 1807-1808.

25. Dassen W, Brunekreef B, Hoek G, Holschreuder P. Staatsen B, Groot de H, Schouten E, Blersteker K. Decline in children's pulmonary function during an air pollution episode. JAPCA 1986: 36: 1223 1227.

26. Brunekreef $B$, Lumens $M$, Hoek $G$, Hotschreuder $P$. Fischer $P$. Biersteker K. Pulmonary function changes associated with an air pollution episode in january 1987. JAPCA 1989; 39: 1444-1447.

27. Hoek G. Brunekreef B. Acute effects of a winter air pollution episode on pulmonary function and respiratory symptoms in children. Arch Envirom Health 1993; 48: $27-32$.

28. Roemer $W$. Hoek $G$, Brunekreef $B$. Effect of ambient winter air pollution on respiratory health of children with chronic respiratory symptoms. Am Rev Respir Dis 1993; 147; 118-124.

29. Hoek $G$, Fischer $P_{\text {, }}$ Brunekreef $B$, Lebret $E_{4}$ Hofschreuder $P_{v}$ Meninen MG. Acute effects of ambient ozone on pulmonary function of children in the Netherlands. Am Rev Respir Dis 1993; 147: 111117.

30. Vedal $S$, Schenker MB, Munoz A, Sarnet JM, Baiterman S, Speizer FE. Daily air pallution effects on children"s respiratory symptoms and peak expiratory flow. Am J Public Health 1987; 77: 694698.

31. Stebbings $\mathrm{JH}$, Fogleman DG, McClain KE, Townsend MC. Effect of the Pittsburgh air pollution episode upon pulmonary function in schoolchildren. JAPCA 1976; 26: 547-553.

32. Huber TE, Joseph SW, Knoblock $E$, Redfearn RL, Karakawa JA. New enwironmental disease (rokohama asthma). Arch Ind Hyg Occ Med 1954; 10: 399-408. 
33. Salvagio J, Seabury J, Schoenhardt A. New Orleans asthma. J Allergy Clin Immunol 1971; 48 : $96-114$.

34. Kitagawa T. Cause analysis of the Yokkaichi asthma episode in Japan. JAPCA 1984; 34: 743-746.

35. Harries MG, Lacey J, Tee RD, Cayley GR, Newman-Taylor Ad. Didymella exifialis and late summer asthma. Lancet 1985; i: 1063-1066.

36. Anto $J M_{i}$ Suyner $J$, Rodriguez-Plosin $A$, Suarez-Cervera $M$, Vazquez $L$ Community outbreaks of asthma associated with soybean dust. New Engl J Med 1989; 320: 1097-1102.

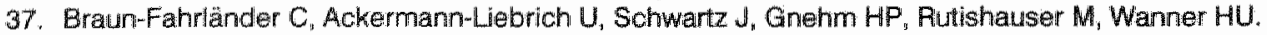
Air pollution and respiratory symptoms in preschool children. Am Rev Fespir Dis 1992; 145: 42-47.

38. Castillejos M, Gold DR, Dockery D, Tosteson T, Baun T, Speizer F. Effects af ambient ozone on respiratory function and symptoms in Mexico City school children. Am Rev Respir Dis 1992; 145 : $276-282$.

39. Higgins ITT, D'Arcy JB, Gibbons DI, Awol EL, Gross KB. Effect of exposure to ambient ozone on ventilatory lung function in children. Am Rev Respir Dis 1990; 141:1136-1146.

40. Krzyzanowsiki M, Quackenboss du, Lebowitz MD. Relation of peak expiratory flow rates and symptoms to ambient ozone. Avch Environ Health 1992; 47: $107-115$.

41. Ostro BD, Lipsett Ma, Wiener MB, Selner $\mathrm{JC}$. Asthmatic responses to airborne acid aerosols. Am $\mathrm{J}$ Public Health 1991; 81: 694-702.

42. Pönkä A. Absenteeism and respiratory disease among children and adults in Helsinki in relation to low-level air pollution and temperature. Environ Research 1990; 52: 34-46.

43. Pónkä A. Asthma and low-lewel air pollution in Helsinki. Arch Enwiron Health 1991; 46: 262-270.

44. Schmitzberger $\mathrm{R}$, Rohmberg $\mathrm{K}_{\text {" }}$ Büchelle $\mathrm{H}_{*}$ Puchegger $\mathrm{A}$, Schmitzberger-Natzmer $\mathrm{D}$, Kemmler Q. Panosch B. Effects of air pollution on respiratory tract of children. Pediat Pulmonol 1993; 15: 68.74 .

45. Spektor DM, Lippmenn M, Lioy PJ, Thurston GD, Citak K, James DJ, Bock N, Speizer FE, Hayes C. Effects of ambient ozone on respiratory function in active normal children. Am Rev Respir Dis $1988 ; 137: 313-320$.

46. Spektor DM, Lippmann $M_{1}$ Thurston GD, Lioy PJ, Stecko J, O'Connor G, Garshick E, Speizer FE, Hays C. Effects on ambient ozone on respiratory function in healthy adults exercising outdoors. Am Hev Respir Dis 1988; 138: 821-828.

47. Tseng RYM, Li CK. Low level atmospheric sulphur dioxide pollution and childhood asthma. Ann Allergy 1990; 65: 397-383.

48. Wijst $M$, Reitmeir $P$, Dold $S$, Wulff, Nicolai $T$, Loeffelholz-Colberg von EF, Mutius $E$. Road traffic and adverse effects on respiratory health in childrem. $\mathrm{Br}$ Med J 1993; 307: 586-600.

49. Pope CA, Dockery DW. Spengler JD, Rlaizenne M. Respiratory health and PM 10 pollution: $A$ daily time series analysis. Am Rev Respir Dis $1991 ; 144: 668-674$.

50. Pope CA. Dockery DW. Acute health effects of $\mathrm{PM}_{10}$ pollution on symptomatic and asymptomatic children. Am Rev Respir Dis 1992; 145: 1123-1128.

51. Pope CA, Kanner FE. Acute effects of $\mathrm{PM}_{10}$ pollution on pulmonary function af smokers with mild to moderate COPD. Am Rev Respir Dis 1993; 147: 1336-1340.

52. Schwartz d, Slater D, Larson TV, Pierson WE, Koenig JQ. Particulate air pollution and hospital emergency room wisits for asthma in Seatle. Am Rev Respir Dis 1993; 147: 826-831.

53. Schwartz J. Particulate air pollution and daily mortality: a synthesis. Public Health Rov 1991-92; $(1-4): 39-60$.

54. Dockery DW, Pope CA, Xu $X$, Spengler JD, Ware JH, Fay ME, Ferris BG, Speizer FE. An association between air pollution and mortality in six U.S. cities. New Engl J Med 1993; 329: 1753. 1759 .

55. Schenker M. Air pollution and mortality. Ediotorial. New Engll J Med 1993; 329: 1807-1808.

56. Detels F, Sayre JW. Coulson AH, Rokaw SN, Massey FJ, Tashkin DP, Wu M. The ULCA population studies of chronic obstructive disease. iv. Respiratory effect of long term exposure to photochemical oxidants, nitrogen dioxide and sulphates on current and nwer smokers. Am Rev Pespir Dis 1981: 124: $873-880$.

57. Ferris BG. Higgins IT, Peters JM, Ganse WF, Goldman MD. Chronic no-specific respiratory disease, Berlin, New Hampshire 1961-1967. A cross-sectional study. Am Rev Respir Dis 1971; 104: 232-244.

58. Chapman RS, Caffiore DC, Hasselblad V. Prevalence of persistent cough and phlegm in young adults in relation to long term ambient sulphur dioxide exposure. Am Rev Respir Dis 1985; 1132: $261-267$. 


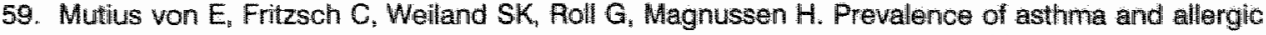
disorders among children in united Germany: a descrpitive comparison. Br Med J1992; 305: 1395. 1399.

60. Cuijpers CEJ, Mertens PLIM, Meyers JHM. Luchtwegklachten in Melick, Herkenbosch, Asenray en Echth. GGD Midden-Limburg, Foermond \& Rijksuniversiteit Limburg. Maastricht, 1988.

61. Stichting Volksgezondheid en Roken. Roken in Nederland, Jaarverslag 1992. (Annual report on smoking figures in The Netherlands).

62. Fielding JE, Phenow KJ. Health effects of involurtary smoking. New Engl J Med $1988 ; 319: 1452-$ 1460.

63. Tager IB. Health effects of "passive smoking' in children. Chest 1989; 96:" $116+1164$.

64. Rona $\mathrm{FJ}$, Chinn S. Lung function, respiratory illness, and passive smoking in British primary school children. Thorax 1993; 48: 21-25.

65. Murray $\mathrm{AB}$, Morrison BJ. Passive smoking by asthmatics: its greater effects on boys than on girls and on older than on younger children. Pediatrics 1989; 84: 451-459.

66. Vedal $S$ "Schenker MB, Samet $J M_{n}$ Speizer FE. Fisk factors for childhood respiratory disease: analysis of pulmonary function. Am Rev Respir Dis 1984; 130: 187-192.

67. Strachan DP, Jarvis MJ, Feyerabend $\mathrm{C}$. The relationship of salvary Cotinine to respiratory symptoms, spirometry and exelrcise-induced brochospasm in seven-year old children. Am Rev Respir Dis 1990; 142: 147-151.

68. Tager IB, Weiss ST, Munoz A, Rosner $B$, Speizer F. Longitudinal study of the effects of maternal smoking on pulmonary function in children. New Engl $\downarrow$ Med 1983; 309: 699-703.

69. Sherrill DL, Martinez FD, Lebowitz MD, Holdaway MD. Flannery EM, Herbison GP, Stanton WR, Silva PA, Sears MR. Longitudinal effects of passive smoking on pulmonary function in New Zeeland children. Am Rev Respir Dis 1992; 145: 1136-1141.

70. Frischer $\pi$, Kühr $J$, Meinert $R$, Karmaus $W$, Urbanek $R$. Influence of maternal smoking on variability of peak expiratory flow rate in school children. Chest 1993; 104: 1133-37.

71. Stumpel R. Environment and Health (Milieu en Gezondheid). WNAA Nederlandse Vereninging van Artsen, Utrecht 1989. (p.97-98).

72. Strachan DP, Sanders $\mathrm{CH}$. Damp housing and childhood asthma; respiratory effects of indoor air temperature and relative humidity. J. Epidemiol Commun Health 1989; 43: 7-14.

73. Brunekreef $B$. Associations between questionnaire reports of home dampness and childhood respiratory symptoms. Sel Total Environ 1992; 127: 79-89.

74. Waegemaekers $M$, Wageningen van $\mathbb{N}$, Brunekreef $B$, Boleij SM. Respiratory symptoms in damp homes. A pilot study. Allergy 1989; 44: 192-198.

75. Platt SD, Martin CJ, Hunt SM, Lewis CW. Damp housing, mould growth and symptomatic health state. Br Med J 1989; $298: 1673-1678$.

76. Brunekreef B, Dockery DW, Speizer FE, Ware JH, Spengler JD, Ferris BG. Home dampness and respiratory morbidity in children. Am Rev Respir Dis 1989; 140: 1363-1367.

77. Martin CJ, Platt SD. Hunt S. Housing conditions and ill health. Br Med $\mathbb{N} 1987 ; 294: 1125-1127$.

78. Dales RE, Zwanenburg H, Brunett, Franklin CA. Respiratory health effects an home dampness and molds among canadian children. Am ل Epidemiol 1991; 134: 196-203.

79. Dikstra L, Houthuils D, Brunekreef B, Akkerman I, Boleij JSM. Respiratory health effects of the indoar environment in a population of Dutch children. Am Rev Respir Dis 1990; 142:1172-1178.

80. Strachan DP. Damp housing and childhood asthma: validation of reporting of symptoins. $\mathrm{Br}$ Med $J 1988 ; 297: 1223-1226$.

81. Delkker $C$. Dales $R$, Bartlett $S$, Brunekreef $B$, Zwanenburg H. Chilldhood asthma and the indoor environment. Chest 1991" 100: $922-926$.

82. Brunekreef B. Verontreiniging van de binnenlucht (Indoor Air Pollution) (chapter 25). In: Medische Milieukunde (Environmental Health). eds. Stumpel ARJ, Doel van den R. Bohn, Scheltema \& Holkema, Utrecht/Antwerpen, 1989.

83. Samet $\mathrm{JM}$, Utell M.J. The risk of nitrogen dioxide: what have we learned from epiderniological and clinical studies? Tox Indus Health 1990; 6 : $247-262$.

84. Speizer FE, Ferris $B_{\text {, }}$ Bishop YMM, Spengler J. Respiratory disease rates and pulmonary function in children associated with $\mathrm{NO}_{3}$ exposure. Am Rev Respir Dis 1980; 121: 3-10.

85. Ware JH, Dockery DW, Spiro A, Speizer FE. Ferris BG. Passive smoking, gas cooking and respiratory thealth of children living in six cities. Am Rev Respir Dis 1984; 129: 366-374. 
86. Hosein HR, Corey $\mathrm{P}$, Robertson $\mathrm{MMCD}$. The effect of domestic factors on respiratory symptoms and FEV, Int J Epidemiol 1989; 18: 390-396.

87. Neas LM, Dockery DW, Ware JH, Spengler JD, Speizer FE Ferris BG. Association of indoor nitrogen dioxide with respiratory symptoms and pulmonary function in children. Am J Epidemiol $1991: 134: 204219$.

88. Intante-Fivard C. Childhood asthma and indoor environmental risk factors. Am J Epidemiol 1993; 137: $83.4-844$.

89. Florey C. du V, Leeder SR. Methods for cohort studies of chronic airflow limitation, (chapter 3). WHO regional publications, European series No. 12. London 1882, United Kingdom, pr12.

90. Brunekreef $B$, Groot $B$, Fijcken $B$, Hoek $G_{v}$ steenbekkers $A$, Boer de A. Reproducibility af childhood respiratory symptom questions. Eur Respir J 1992; 5: 930-935.

91. Weiss ST. Environmental tobacco smoke and asthma. (editorial). Chest 1993; 104: 991-992.

92. Quanjer PhH. Standardized lungfunction testing. Bull Eur Physiopathol Respir 1983; 19 (suppl.5): $1=95$.

93. Clément J,Dumoulin B,Gubbelmans R, Hendriks KP, Woestijne van de KP. Reference values of total respiratory resistance and reactance between 4 and $26 \mathrm{~Hz}$ in children and adolescents aged 4-20 years. Buil Eur Physiopathol Respir 1987; 23: 441-448.

94. Cogswell JJ. Forced oscillation technique for determination of resistance to breathing in children. Arch Dis Child 1973; 48: 259-266.

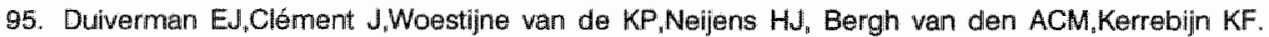
Forced oscillation technique. Reference values for resistance and reactance over af firequency spectrum of $2-26 \mathrm{~Hz}$ in healthy children aged 2.3-12.5 years. Bull Eur Physiopathol Respir 1985; 21: $174-178$.

96. Hantos Z,Daróczy B,Gyurkovits K. Total respiratory impedance in healthy children. Pediatr Pulmonol 1985; 1: $91-98$.

97. Peslin $A$,Gallina $C_{*}$ Teculescu D,Pham QT. Fespiratory input and transfer impedances in children 9-13 years old. Bull Eur Physiopathol Respir 1987; 23: 107-112.

98. Solymar $\mathrm{L}$, Aronsson $\mathrm{PH}$, Bake $\mathrm{B}, \mathrm{Bjure} \mathrm{J}$. Respiratory resistance and impedance magnitude in healthy children aged 2-18 years. Pediatr Pulmonol 1985; 1: 134-140.

99. Stanescu D, Moavero NE, Veriter $C_{i}$ Birasseur $L$. Frequency dependence of respiratory resistance in healthy children. J Appl Physiol 1979; 47: 268-272.

100. Làndsér FJ. Nagels J, Demedts M, Billiet L, Woestijne van de KP. A new method to determine frequency characteristics of the respiratory system. J Appl Physiol 1976; $41: 101-106$.

101 Wouters EFM. Total respiratory impedance measurement by forced oscillations: a noninvasive method to assess bronchial response in occupational medicine. Exp Lung Research 1990; 16 : 25-40.

102. Wosseling G.J, Vanderthoven-Augustin IML, Wouters EFM. Forced oscillation technique and spirometry in cold air provocation tests. Thorax 1993; 48: 254-259.

103. Duivermen Eu, Neijens HJ. Strik van $\mathrm{A}$, Snee-Smaalen van der $M$, Kerrebijn KF. Bronchial responsiweness in asthmatic children aged 3 to 8 years measured by the forced pseudo random noise ascillometry. Bull Eur Physiopathol Respir 1986; 22: 27-34.

104. Duiverman EJ, Neijens $H J$, Snee-Smaalen van der $M_{2}$ Kerrebijn KF. Comparison of forced oscillometry and forced expirations for measuring dose related responses to inhaled methacholine in asthmatic children. Bull Eur Physiopathol Respir 1986" 22: 433-436.

105. Brochard L. Pelle $G$, Palmas de $J_{\text {, Brochard }} \mathrm{P}_{\text {, Carre }} \mathrm{A}_{3}$ Lorino H Harf $\mathrm{A}$. Density and frequency dependence of resistance in early aimay obstruction. Am Rev Respir Dis 1987; 135: $579-584$.

106. Jorna THIM. Analysis of Respiratory impaiment due to occupational exposure. Thesis, University Press, Maastricht, 1994. ISBN 90-5278-162-1

107. Wesseling G.J. Respiratory impedance measurements in clinical lung function testing. Thesis. University Press, Maastricht 1993. ISBN 90-5278-073-0. 


\section{Chapter 2}

\section{FREQUENCY DEPENDENCE OF OSCILLATORY RESISTANCE IN HEALTHY PRIMARY SCHOOL CHILDREN}

CEJ Cuijpers, GJ Wesseling, GMH Swaen, EFM Wouters 


\section{FREQUENCY DEPENDENCE OF OSCILLATORY RESISTANCE IN HEALTHY PRIMARY SCHOOL CHILDREN}

\section{ABSTRACT}

With the use of the forced oscilation technique, respiratory input impedance was measured in 371 healthy children, aged $5-12$ years.

How impedance values varied with height (age) and gender and to what extent negative frequency dependence of oscillatory resistance existed in these children was investigated.

Negative frequency dependence of resistance between 8 and $28 \mathrm{~Hz}$ was a common finding in all height categories. With increasing height, resistance decreased and reactance increased in all children. Below $140 \mathrm{~cm}$ of height, resistance values at $8 \mathrm{~Hz}$ were higher, and reactance values at $8 \mathrm{~Hz}$ were more negative in girls than in boys. At heights above $140 \mathrm{~cm}$ the reverse was found. Resonant frequency was found to be higher in boys than in girls. The incidence of negative frequency dependence of resistance (FD) decreases during growth. Over heilghts of $130-160 \mathrm{~cm}$, more negative FD existed in boys than in girls.

It can be concluded that negative FD between 8 and $28 \mathrm{~Hz}$ can be found in healthy children up to 12 years of age, most pronounced in boys, not necessarily implicating puimonary pathology.

\section{INTRODUCTION}

With the use of the forced oscillation technique (FOT), the impedance of the respiratory system can be measured in a non-invasive and effort-independent manner. The technique used in this study, was developed by Landser et al. "The resistance $\left(R_{r s}\right)$ and reactance $\left(X_{r s}\right)$ of the respiratory system can be measured simultaneously at various frequencies, by means of complex oscillations superimposed at the mouth during spontaneous quiet breathing.

It has been shown that the forced oscillation technique is well suited for measurements in children. ${ }^{2-12}$ Negative frequency dependence of ascillatory resistance has been suggested to be a sensitive index of airflow obstruction in adults, ${ }^{13.15}$ but it may be a normal finding in young children. ${ }^{2,5,10,11}$ The age (or height) at which negative frequency dependence of resistance (FD) disappears in normal children has been the 
subject of conflicting reports and little is known of differences in impedance values between girls and boys.

The present study was conducted to evaluate the frequency dependent behavior of the respiratory system in children. Respiratory input impedance was measured in 371 primary school children, aged from 5 to 12 years. We studied how resistance and reactance values varied with height and in which children negative frequency dependence of respiratory resistance exists. Values in boys and girls were analysed separately.

\section{METHODS}

470 Dutch children, aged 5.2 to 12.1 years, participated in the study. They were recruited from two primary schools in the Maastricht area. The parents completed a questionnaire on the respiratory health of their children. 371 Children (172 boys, 199 girls) reported by their parents to be without any past or present symptoms of recurrent cough or wheezing, were selected for further investigation. The mean value for their FVC and FEV in percent predicted (according to the ECCS) ${ }^{16}$ was $100.4( \pm 12.3)$ and $92.1( \pm 13.0)$ respectively for boys, and $98.5( \pm 11.6)$ and $89.0( \pm 10.8)$ respectively for girls. Written informed consent to examine the children was obtained from the parents. The study was approved by the local medical ethics committee.

Weight and height were recorded for all children. The mechanical characteristics of the respiratory system were studied using the forced oscillation technique. This technique was described in detail by Wouters. ${ }^{17}$ Briefly, the apparatus consists of a loudspeaker attached to a tube leading to a Fleisch screen type pneumotachograph, adjacent to the mouthpiece (Figure 1).

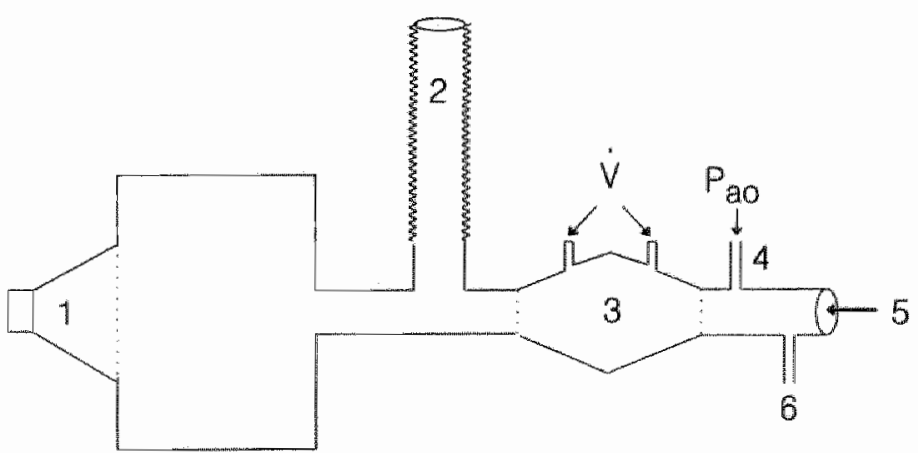

Figure 1. Setup of the measurement, with the forced oscillation technique; $1=$ loudspeaker; 2 = impedance tube; 3 = pneumotachograph; $4=$ bias flow: $5=$ mouth piece; $6=$ pressure transducer.

A bias flow is introduced through a side-tube to reduce the $\mathrm{CO}_{2}$ build-up at the mouth. A complex signal consisting of sinusoidal pressure oscillations containing all harmonics of $4 \mathrm{~Hz}$ up to $52 \mathrm{~Hz}$, appearing with random phase shift, is applied by the loudspeaker. 
The peak to peak amplitude of this pseudo-random noise signal is less than $2 \mathrm{cmH}_{2} \mathrm{O}$. Mouth pressure, measured from a lateral port close to the mouth peace and flow obtained from the pneumotachograph are measured with identical differential pressure transducers (Validyne MP 450). Pressure and flow signals are fed without filtering into a Fourier analyzer, by dividing pressure by flow: the system calculates an impedance value for each of the investigated frequencies. To filter out the disturbing signals produced by the breathing of the child, an ensemble averaging is performed during 8 seconds.

The impedance is partitioned into a real part, resistance $\left(R_{r s}\right)$ and an imaginary part or reactance $\left(X_{r s}\right)$. The real part $\left(R_{r s}\right)$ is the equivalent of the total resistance in a resistance-inductance-capacitance $(\mathbb{R}-\mathrm{L}-\mathrm{C})$ circuit. The reactance $\left(X_{\mathrm{TS}}\right)$ depends on the elastic and inertial properties of the respiratory system. The frequency at which $X_{r s}$ equals zero is called the resonant frequency $\left(f_{0}\right)$. To evaluate the accuracy of the measurement a coherence function is estimated at each frequency. This indicates the amount of noise generated by the child's spontaneous breathing, present in the measured signals. Measurements with coherence values lower than 0.95 at more than three frequencies were rejected. Landser et al. ${ }^{18}$ have demonstrated that measurements with a coherence function exceding 0.95 the error of the measurements due to the presence of noise or non-linearities is less than $10 \%$.

All measurements were performed with the child seated, wearing a nose clip and the cheeks and the floor of the mouth being supported with the hands of either the investigator or the child itself. Each child performed at least three valid impedance measurements. In this study we retained the oscillatory resistance at $8 \mathrm{~Hz}\left(\mathrm{R}_{\mathrm{rsB}}\right)$ and at $28 \mathrm{~Hz}\left(\mathrm{R}_{\mathrm{rs} 28}\right)$, the reactance at $8 \mathrm{~Hz}\left(\mathrm{X}_{\mathrm{rs} 8}\right)$, the $\mathrm{f}_{0}$ and the $F D$ of $\mathrm{R}_{\mathrm{rs}}$. The latter was defined as $\mathrm{A}_{\mathrm{rs} 28}$ minus $\mathrm{R}_{\mathrm{rs} 6}$ divided by 20 . Further, the relationship between FD and height, for boys and girls separately, was investigated.

\section{Statistical Analysis}

The children were divided into 6 height categories. In each category the mean and standard deviation (SD) of $R_{r S 8}, X_{r s 8}, R_{r s 28}, f_{0}$ and $F D$ were calculated, for boys and girls separately. Differences in impedance parameters between boys and girls were tested, using the unpaired Student's t-test. Linear regression analyses were carried out of FD vs height (model; $Y=a+B x+e$, with $Y=F D$ and $x=$ height). For the analyses the SPSS statistical package (SPSS Inc., Chicago, III., USA) and Statgraphics (Statistical Graphics Corp., Rockville, Maryland, USA) were used.

\section{RESULTS}

In Table 1 the physical characteristics of the 371 children without respiratory symptoms or complaints are summarized. There is a small but significant difference in age $(p<0.05)$ between boys and girls in the height category from 120 and $129 \mathrm{~cm}$. In the height category of $130-139 \mathrm{~cm}$ there were smal differences in height $(p<0.05)$ and weight $(p<0.001)$ between boys and girls.

The mean values $( \pm S D$ ) of the impedance parameters are presented in Tables 2 and 3 . In all children resistance values decrease, and reactance values increase with increasing height. $R_{r s 8}$ decreases from $7.04 \pm 0.88(\leq 120 \mathrm{~cm})$ to $4.65 \pm 0.60$ $\mathrm{cmH}_{2} \mathrm{O} /(\mathrm{L} / \mathrm{s})(\geq 160 \mathrm{~cm})$ in boys and from $8.38 \pm 1.40$ to $4.01 \pm 1.21 \mathrm{cmH}_{2} \mathrm{O} /(\mathrm{L} / \mathrm{s})$ in girls. $R_{\text {rs } 28}$ decreases from $6.07 \pm 0.78$ to $4.96 \pm 0.75 \mathrm{cmH}_{2} \mathrm{O} /(\mathrm{L} / \mathrm{s})$ in boys and from 
$7.70 \pm 1.52$ to $4.52 \pm 1.25 \mathrm{cmH}_{2} \mathrm{O} /(\mathrm{L} / \mathrm{s})$ in girls. $X_{\mathrm{rsg}}$ increases from $-1.55 \pm 0.36$ to $-0.38 \pm 0.48 \mathrm{H}_{2} \mathrm{O} /(\mathrm{L} / \mathrm{s})$ in boys and from $-2.29 \pm 1.02$ to $-0.29 \pm 0.24 \mathrm{cmH}_{2} \mathrm{O} /(\mathrm{L} / \mathrm{s})$ in girls. $f_{0}$ decreases from $23.9 \pm 1.5$ to $10.3 \pm 6.2 \mathrm{~Hz}$ in boys and from $22.1 \pm 8.8$ to $8.4 \pm 3.5 \mathrm{~Hz}$ in girls.

Table 1. Physical characteristics of 371 children without respiratory symptoms and complaints, (mean $\pm \mathrm{SD}$ ).

\begin{tabular}{|c|c|c|c|c|c|c|c|c|}
\hline \multirow{2}{*}{$\begin{array}{l}\text { Height } \\
\mathrm{cm}\end{array}$} & \multicolumn{4}{|c|}{ Boys $(n=172)$} & \multicolumn{4}{|c|}{ Girls $(n=199)$} \\
\hline & $n$ & Age, years & Weight, kg & Height, $\mathrm{cm}$ & $n$ & Age, years & Weight, $\mathrm{kg}$ & Helight, $\mathrm{cm}$ \\
\hline$<120$ & 4 & $6.0 \pm 0.8$ & $21.0 \pm 1.8$ & $116.8 \pm 1.9$ & 4 & $6.5 \pm 0.6$ & $19.8 \pm 2.5$ & $116.5 \pm 2.4$ \\
\hline $120-129$ & 30 & $6.6 \pm 0.8$ & $24.5 \pm 2.2$ & $124.8 \pm 2.6$ & 43 & $7.1 \pm 1.0^{\star 4}$ & $24.5 \pm 3.1$ & $125.6 \pm 2.8^{4}$ \\
\hline $130-139$ & 57 & $8.1 \pm 1.1$ & $30.2 \pm 3.7$ & $135.5 \pm 2.9$ & 55 & $8.4 \pm 1.1$ & $28.0 \pm 2.9^{*}$ & $134.2 \pm 2.9^{\circ}$ \\
\hline $140-149$ & 47 & $9.6 \pm 1.0$ & $34.6 \pm 4.6$ & $144.4 \pm 3.1$ & 56 & $9.8 \pm 0.9$ & $35.3 \pm 5.5$ & $144.3 \pm 2.8$ \\
\hline $150-159$ & 27 & $10.6 \pm 0.9$ & $39.9 \pm 4.5$ & $153.8 \pm 2.7$ & 26 & $10.8 \pm 0.6$ & $40.4 \pm 5.1$ & $154.1 \pm 2.9$ \\
\hline$\geq 160$ & 7 & $11.6 \pm 0.5$ & $54.4 \pm 8.6$ & $166.6 \pm 5.7$ & 15 & $1 \| .0 \pm 0.7^{*}$ & $47.8 \pm 3.7^{17}$ & $162.9 \pm 3.0$ \\
\hline
\end{tabular}

Significance levels boys compared to girls: * $p<0.05 ; \uparrow p<0.01 ; * p<0.001$.

Table 2. Impedance values (mean $\pm \mathrm{SD}) \mathrm{F}_{\mathrm{rsg}}, \mathrm{F}_{\mathrm{rs} 28^{\prime}}, \mathrm{X}_{\mathrm{rse}}$ and $\mathrm{FD}\left(\mathrm{cmH}_{2} \mathrm{O} /(\mathrm{L} / \mathrm{s})\right)$ and $\mathrm{f}_{0}(\mathrm{~Hz})$ for 172 boys without respiratory symptoms and complaints, divided over six height categiories.

\begin{tabular}{llllll}
\hline $\begin{array}{l}\text { Height } \\
\mathrm{cm}\end{array}$ & & \multicolumn{5}{c}{ Boys $(n=172)$} \\
\cline { 2 - 6 } & $\mathrm{R}_{\text {rss }}$ & $\mathrm{X}_{\text {rs }}$ & $\mathbb{R}_{\mathrm{rs} 28}$ & $f_{0}$ & FD \\
\hline$<120$ & $7.04 \pm 0.88$ & $-1.55 \pm 0.36$ & $6.07 \pm 0.78$ & $23.9 \pm 1.5$ & $-0.049 \pm 0.027$ \\
$120-129$ & $6.85 \pm 1.63$ & $-1.33 \pm 0.67$ & $6.31 \pm 1.33$ & $18.4 \pm 7.1$ & $-0.027 \pm 0.048$ \\
$130-139$ & $6.29 \pm 1.39$ & $-1.03 \pm 0.56$ & $6.05 \pm 1.08$ & $15.8 \pm 5.8$ & $-0.012 \pm 0.047$ \\
$140-149$ & $5.90 \pm 1.38$ & $-1.10 \pm 0.65$ & $5.36 \pm 1.06$ & $17.1 \pm 6.0$ & $-0.027 \pm 0.046$ \\
$150-159$ & $4.92 \pm 1.19$ & $-0.72 \pm 0.43$ & $4.84 \pm 1.15$ & $13.1 \pm 5.5$ & $-0.004 \pm 0.041$ \\
$\geq 160$ & $4.65 \pm 0.60$ & $-0.38 \pm 0.48$ & $4.96 \pm 0.75$ & $10.3 \pm 6.2$ & $0.015 \pm 0.039$ \\
\hline
\end{tabular}

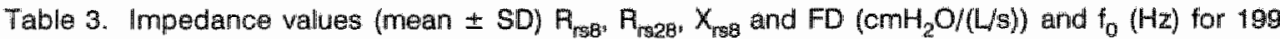
girls without respiratory symptoms and complaints, divided over six height categories.

\begin{tabular}{|c|c|c|c|c|c|}
\hline \multirow{2}{*}{$\begin{array}{l}\text { Height } \\
\mathrm{cm}\end{array}$} & \multicolumn{5}{|c|}{ Girls $(n=199)$} \\
\hline & $\mathrm{P}_{\mathrm{rssi}}$ & $x_{\text {rse }}$ & $\mathrm{F}_{\mathrm{ra}}$ & $f_{0}$ & $\mathrm{FD}$ \\
\hline$<120$ & $8.38 \pm 1.40$ & $-2.29 \pm 1.02$ & $7.70 \pm 1.52$ & $22.1 \pm 8.8$ & $-0.034 \pm 0.056$ \\
\hline $120-129$ & $7.15 \pm 1.54$ & $-1.58 \pm 0.57$ & $6.54 \pm 1.20$ & $18.2 \pm 6.2$ & $-0.030 \pm 0.049$ \\
\hline $130-139$ & $6.45 \pm 1.28$ & $-1.13 \pm 0.51$ & $6.56 \pm 1.28^{\text {. }}$ & $14.2 \pm 4.5$ & $0.005 \pm 0.046^{*}$ \\
\hline $140-149$ & $5.87 \pm 1.23$ & $-0.90 \pm 0.55$ & $5.95 \pm 1.09^{*}$ & $13.5 \pm 6.0^{4}$ & $0.004 \pm 0.040^{4}$ \\
\hline $150-159$ & $4.64 \pm 1.00$ & $-0.41 \pm 0.40^{t}$ & $5.27 \pm 0.99$ & $9.6 \pm 5.0$ & $0.032 \pm 0.037^{\dagger}$ \\
\hline$\geq 160$ & $4.01 \pm 1.21$ & $-0.29 \pm 0.24$ & $4.52 \pm 1.25$ & $8.4 \pm 3.5$ & $0.026 \pm 0.021$ \\
\hline
\end{tabular}

Significance levels boys compared to girls: * $<0.05 ; \uparrow<0.01 ; * 0.001$ 
Negative $F D$ of $R_{r s}$ was observed in all height categories with a higher incidence in the smallest children ( $88 \%$ ) than in the tallest children (14\%). During growth FD decreases, i.e. becomes less negative. The percentage of children with negative FD decreases with increasing height, from $100 \%$ to $29 \%$ in boys and from $75 \%$ to $7 \%$ in girls.

Below $140 \mathrm{~cm}$ girls have higher $R_{\mathrm{rsB}}$ values than boys, the reverse is found above 140 $\mathrm{cm} . \mathrm{P}_{\mathrm{rs} 28}$ is higher for girls at all heights, except for heights above $160 \mathrm{~cm}$. Between 130 and $139 \mathrm{~cm}(p<0.05)$ and between 140 and $149 \mathrm{~cm}(p<0.01)$ the differences in $R_{\mathrm{rs} 2 \mathrm{~B}}$ between boys and girls are significant. Below $140 \mathrm{~cm}$ girls have more negative $X_{r s}$ values than boys, the reverse is found in children above $140 \mathrm{~cm}$ of height. However, the difference is statistically significant only between $150-159 \mathrm{~cm}(p<0.01)$. In the taller children $t_{0}$ is higher in bays than in girls (between 140 and $149 \mathrm{~cm} ; \mathrm{p}<0.01$, between 150 and $159 \mathrm{~cm} p<0.05$ ). The differences in FD between boys and girls are statistically significant between 130 and $139 \mathrm{~cm}(p<0.05)$, between 140 and $149 \mathrm{~cm}(p<0.001)$ and between 150 and $159 \mathrm{~cm}(p<0.01)$. Above $160 \mathrm{~cm}$ no statistically significant differences in FD are found between boys and girls (Figure 2).

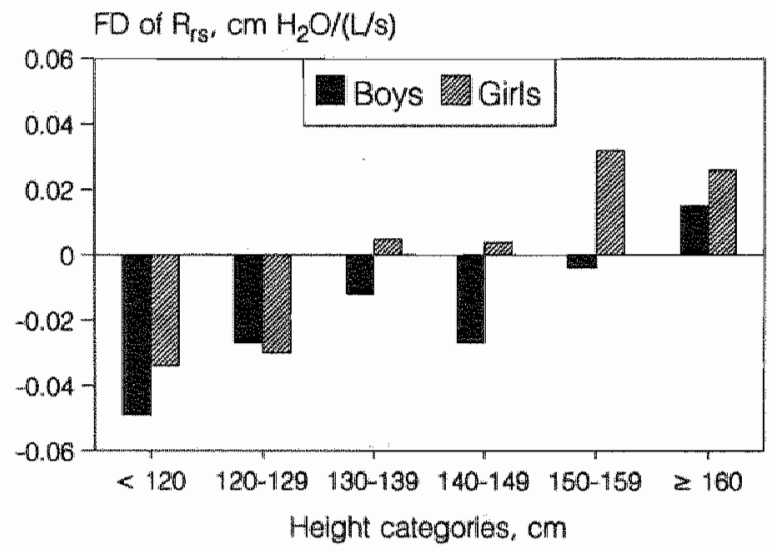

Figure 2. The degree of frequency dependency (FD) of resistance $\left(R_{r s}\right)$ for boys and girls, over the six height categories.

Figures 3 and 4 present the results of linear regression of frequency dependence of resistance and height, for boys and girls separately. In both groups the slope of the decrease in frequency dependence with increasing height is statistically significant, for boys $F D=-0.12+7.4310^{-4}$ height $+3.0710^{-4}, p=0.016$ and for girls $F D=$ $-0.22+1.5510^{-4}$ height $+2.5510^{-4}, p=0.000$ ). The mean height at which negative frequency dependence of resistance disappears is about $135 \mathrm{~cm}$ in girls against 160 $\mathrm{cm}$ in boys. 


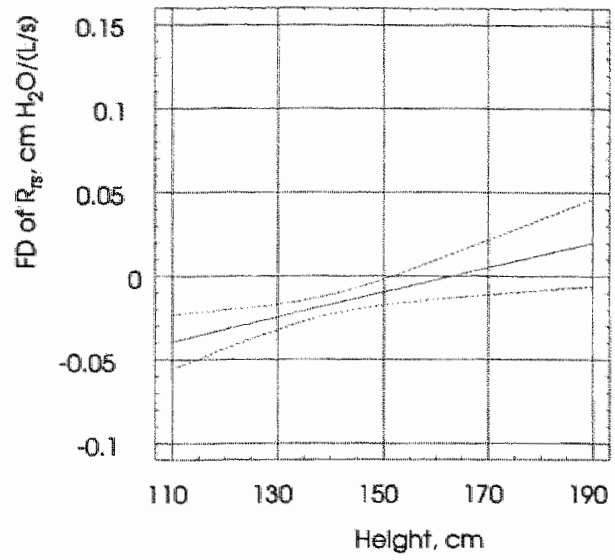

Figure 3. Regression of frequency dependency $(F D)$ of resistance $\left(R_{\mathrm{rs}}\right)$ on height in boys.

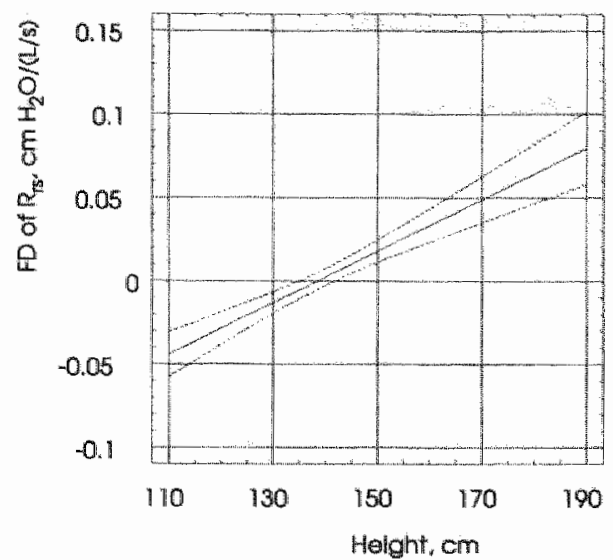

Figure 4. Regression of frequency dependence (FD) of resistance $\left(\mathrm{F}_{\mathrm{rs}}\right)$ on height in girls.

\section{DISCUSSION}

In this study we analysed the impedance of the respiratory system in 371 presumably healthy children, using the technique of forced oscillations. The children were considered to be free from pulmonary diseases based on a questionnaire completed by the parents of the children, since no complaints of cough, wheeze or (attacks of) shortness of breath were reported and their values for FVC and $F E V_{1}$ in percent predicted were in the normal range. In these children negative frequency, dependence of oscillatory resistance, i.e. a decrease in resistance with increasing frequency, was a common finding. Therefore it is believed that negative frequency dependence of resistance (FD) does not necessarily implicate pathology in children of this age. Negative FD has been suggested to reflect the shunt effect of bronchial distensibility or compliance on the peripheral impedance. ${ }^{19}$ In the presence of obstruction of the peripheral airways it is aggravated, but it may also be found in healthy adults, be it in mild form. ${ }^{15,20,21}$ The finding of negative FD in presumably healthy children suggests that in children the resistance of the peripheral airways makes up a larger part of the total respiratory resistance than in adults. This is in keeping with the observations of Hogg et al. ${ }^{22}$ who demonstrated that the peripheral airways are disproportionally narrow in the early years of life.

Our alternative explanation for the negative frequency dependence of resistance may be the shunt produced by the upper airways. Part of the flow applied at the mouth is lost in the motions of the upper airway walls, most notably the cheeks. Supporting the cheeks as was done by the children in this study, approximately haives the artifact resulting from the upper airway shunt. Then again, it is not very likely that the negative FD observed in children is the result of the upper airway shunt. The use of a head generator as was proposed by Peslin et al. ${ }^{23}$ does not fully eliminate the FD. Caubergs and van der Woestijne ${ }^{24}$ concluded that this upper airway shunt occurring in input impedance measurements at the mouth as with the technique used in the present study 
is not necessary an inconvenience for diagnostic purposes allowing a separation between healthy subjects and patients with airflow obstruction.

Our results are in agreement with those reported by others. ${ }^{2,5,10,11}$ Clement et al. ${ }^{2}$ measured oscillatory $R_{r s}$ and $X_{r s}$ between 4 and $26 \mathrm{~Hz}$ in 403 healthy children aged $4-20$ years. These authors also observed negative frequency dependence of resistance, which decreased during growth. From their graphics it can be gathered that FD exists in children up to about 13 years of age. Stanescu et al. ${ }^{11}$ used forced oscillations from 4 to $9 \mathrm{~Hz}$. In their study $F D$ (defined as $R_{r s 4}$ minus $R_{r s 9}$ ) was found to be maximum at the age of $3-4$ years $(\mathrm{Ht}=105-110 \mathrm{~cm})$ with a progressive decrease to reach a minimum at $12-13$ years $(\mathrm{Ht}=155-160)$. They calculated (by extrapolation) that resistance became independent of frequency at about 15-16 years ( $\mathrm{Ht}=165-170 \mathrm{~cm})$. Solymar et al ${ }^{10}$ studied respiratory impedance at $4 \mathrm{~Hz}$ in 218 healthy children $(2-18$ years) and at 2, 4 and $12 \mathrm{~Hz}$ in an aselect subpopulation of 61 of these children. They found negative FD between 2 and $12 \mathrm{~Hz}$ in children up to $160 \pm 5 \mathrm{~cm}$ of height. In the largest children $(\mathrm{Ht}=190 \pm 5 \mathrm{~cm}), R_{\mathrm{rs}}$ values obtained at all three frequencies were almost similar. Hantos et al. ${ }^{5}$ also observed negative frequency dependence of resistance, between 3 and $10 \mathrm{~Hz}$ in children aged $4-16$ years, although of a lesser magnitude as Stanescu et al. "1. and Solymar et al. 10

Little is known of the differences in impedance data between boys and girls. In our study negative $F D$ of $\mathrm{F}_{\mathrm{rs}}$ occured more in boys than in girls. From the height of $130-160$ $\mathrm{cm}$ the difference in FD between boys and girls was statistically significant $(\mathrm{p}<0.05)$. Above the height of $160 \mathrm{~cm}$ (mean age $11.2 \mathrm{yr}$ ) no differences in FD between boys and girls were observed. $R_{\mathrm{rs} g}$ values were higher, and $X_{\mathrm{rse}}$ values more negative in girls than in boys below $140 \mathrm{~cm}$ of height (mean age $8.3 \pm 1.11$ ). At heights above 140 $\mathrm{cm}$ the reverse was found. Boys had higher $t_{0}$ than girls, the differences were significant at heights above $140 \mathrm{~cm}$. With measurements of $R_{\mathrm{rs}}$ at a single frequency of $10 \mathrm{~Hz}$ in 102 subjects free of respiratory disease Gimeno et al. ${ }^{25}$ demonstrated that $R_{r s}$ is significantly related to height, possibly through a relationship to lung volume (FRC) but not to sex, age and weight, which is in accordance with our observations.

The observed differences in $F D$ of $R_{p s}$ between boys and girls may partly be explained by a more rapid growth of the smaller airways in girls than in boys during childhood and adolescence as reported by Pagtakhan et al. ${ }^{28}$ In accordance with this are results reported by Dockery et al. ${ }^{27}$ "which also imply that preadolescent girls have ainways relatively larger to lung size than boys, suggesting relatively lower peripheral resistance and thus less frequency dependence of resistance in young girls than in young boys. Clément et al ${ }^{2}$ did not report differences in FD between boys and girls. However, they did find higher $\mathbb{R}_{r s}$ values in girls under the age of 9 than in boys. The reverse was found after the age of 12 years. Reactance values did not differ between both sexes which is at variance with our results. Stanescu et al. ${ }^{11}$ found no significant differences in $F_{r s}$ values between boys and girls of 314 years. Solymar et al. ${ }^{10}$ and Hantos et al. ${ }^{5}$ did not differentiate between boys and girls.

Our data on negative FD of resistance are at variance with those reported by Duiverman et al. ${ }^{4}$ and Peslin et al. ${ }^{9}$ Duiverman et al. ${ }^{4}$ investigated 255 healthy Dutch children aged $2.3-12.5$ years. They found negative frequency dependence of $R_{r s}$ only in boys up to about 5 years of age and not in girls of the same age or in older children. In contrast to our results $R_{\text {rs }}$ values were found to be significantly higher in boys than in girls, at the age of 4 years. At about 8 years of age, differences between both sexes were no longer significant. At the age of 12 years $R_{r s}$ values were again significantly higher in boys. $X_{r s}$ values were more negative in boys than in girls at all ages. 
Consequently, this implies a higher resonant frequency in boys at all ages, which is in accordance with our findings. Peslin et al. ${ }^{9}$ studied the input and transfer impedance in 69 healthy children over the frequency range of $4-30 \mathrm{~Hz}$. Neglative frequency dependence of $R_{\mathrm{rs}}$ was only observed below $16 \mathrm{~Hz}$ in children between 130 and 139 $\mathrm{cm}$ of height, while resistance tended to increase with frequency in taller chilliren. These investigators did not report differences between boys and girls.

Differences in impedance values observed between our study and those of others, may in part be explained by differences in technique. Frequency dependence of resistance was not uniformly defined in the various studies, but essentially all investigators pointed at a decrease in resistance with increasing frequency. Further, differences in selection criteria may have played a role.

In summary, we conclude that the forced oscillation technique is well suited for use in primary schoolchildren. The method provides information on the mechanical characteristics of the respiratory system in a non-invasive and effort-independent way. Negative frequency dependence of resistance between 8 and $28 \mathrm{~Hz}$ can be found in healthy children up to 12 years of age, most pronounced in boys, not necessarily implicating pulmonary pathology.

\section{REFERENCES}

1. Làndsér FJ, Nagels J, Demedts $M$, Billiet $L$, Woestijne van de KP. A new method to determine frequency characteristics of the respiratory system. I Appl Physiol 1976; 41: 101-106.

2. Clément $J$, Dumoulin $B$, Gubbelmans $R$, Hendriks KP, Woestijne van de KP. Reference values of total respiratory resistance and reactance between 4 and $26 \mathrm{~Hz}$ in childiren and adolescents aged 4-20 years. Bull Eur Physiopathol Respir 1987; 23: 441-448.

3. Cogswell $\mathrm{u}$. Forced ascillation technique for determination of resistance to breathing in children. Arch Dis Child 1973; 48: 259-266.

4. Duiverman EJ, Clément $J$ "Woestijne van de KP, Neijens HJ, Bergh van den ACM, Kerrebijn KF. Forced oscillation technique. Reference values for resistance and reactance over a frequency spectrum of 2-26 Hz in healthy children aged 2.3-12.5 years. Bull Eur Physiopathol Respir 1985: 21: $171-178$.

5. Hantos Z, Daróczy B. Gyurkovits K. Total respiratory impedance in healthy children. Pediatr Pulmonol 1985; 1: 91 -98.

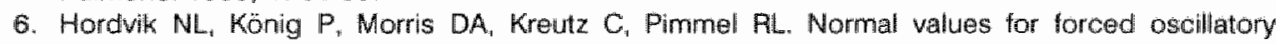
respiratory resistance in children. Pediatr Pulmonol 1985; 1: 145-148.

7. Mansell $A$, Levison $H$, Kruger $K$, Tripp TL. Measurement of respiratory resistance in children by forced ascillations. Am Rev Respir Dis 1972; 106: 710-714.

B. Nussbaum $E$, Galant SP. Measurement of total respiratory resistance in children by a modified forced oscillation method. Pediatr Res 1984; 8: 139-145.

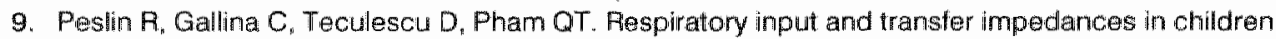
9-13 years old. Bull Eur Physiopathol Respir 1987; 23: 107-112.

10. Solymar L. Aronsson $\mathrm{PH}$, Bake B. Bjure J. Respiratory resistance and impedance magnitude in healthy children aged 2-18 years. Pedialr Pumonol 1985; $1: 134.140$.

11. Stanescu D, Moavero NE, Veriter $C$. Brasseur L. Frequency dependence of respiratory resistance in healthy children. I Appl Physiol 1979; 47:268-272.

12. Milliams SP. Fullton JM. Tsai MJ, Pimmel RL, Collier AM. Pespiratory impedance and derived parameters in young children by forced random noise. J Appl Physiol 1979; 47: 169-174.

13. Clément $J$ Làndsér FJ, Woestijne van de KP. Total resistance and reactance in patients with respiratory complaints with and without airway obstruction. Chest 1983; 83: 215-2:20.

14. Cutillo AG, Renzetti AD. Mechanical behavior of the respiratory system as a function of frequency in health and disease. Bull Eur Physiopathol Respir 1983: 19: 293-326. 
15. Landser $F J$, Clement $\mathrm{J}$, Woestine van de $\mathrm{KP}$. Normal values of total respiratory resistance and reactance determined by forced osciflations. Inffuence of smoking. Chest 1982; $81: 586-591$.

16. Quanjer PH. Standardized lung function testing. Bull Eur Physiopathol Respir 1983; 10: 1-95.

17. Wouters EFM, Làndsér FJ, Polko AH, Visser BF. Physiological analysis of extended spectrum oscillometry. Fespiration 1988; 54: 263-270.

18. Ländsér FJ, Nagels J, Clément J. Woestijne van de KP. Errors in the measurement of total respiratory resistance and reactance by forced oscillations. Respir Physiol 1976; 28: 289-301.

19. Mead J. Contribution of compliance of airways to frequency-dependent behavior of lungs. J Appl Physiol 1969; 26: 670-673.

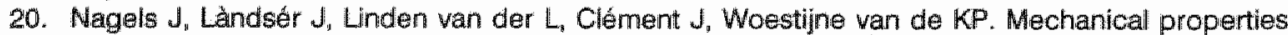
of lungs and chest wall during spontaneous breathing. J Appl Physiol 1980; 49:408-416.

21. Peslin $R_{3}$. Hannthart $B$, Pino J. Mechanical impedance of the chestit in smokers and non-smokers. Bull Eur Physiopathol Respir 1981; 17: 93-105.

22. Hogg JC, Williams J. Age as a factor in the distribution of lower ainway conductance and the pathologic anatomy of obstructive lung disease. N Engl J Med 1970; 282: 1283-1287.

23. Peslin R, Duvivier $C_{s}$ Gallina $C$. Total respiratory input and transfer impedance in humans. J Appl Physiol 1985; 59: 492-501.

24. Cauberghs $M_{n}$ Woestijne van de KP. Effects of upper airway shunt and series properties on respiratory impedance measurements. J Appl Physiol 1989; 66: 2274-2279.

25. Gimeno F, Weele wan der LTh, Koeter GH, Altena R. Forced oscillation technique. Reference values for total respiratory resistance obtained with the Siemens Sirgnost FD5. Ann Allergy 1992; 68: 155158.

26. Pagtakhan RD, Bjelland JC, Landau LI, Loughlin G, Kaltenborn W, Seeley G, Taussig M. Sex differences in growth patterns of the airways and lungparenchyma in children. J Appl Physiol 1984; 56: $1204-1210$.

27. Dockery DW, Berkey CS, Ware $\mathrm{JH}_{\mathrm{a}}$ Speizer FE, Ferris BG jr. Distribution of forced vital capacity and forced expiratory volume in one second in children 6 to 11 years of age. Am Rev Respir Dis 1983 ; 128: $405-412$. 


\section{Chapter 3}

\section{RESPIRATORY IMPEDANCE IN 1776 DUTCH PRIMARY SCHOOL CHILDREN, WITH AND WITHOUT CHRONIC RESPIRATORY SYMPTOMS}

CEJ Cuijpers, AGH Kessels, PLJM Mertens, GJ Wesseling, GMH Swaen, ME de Kok, J Broer, F Sturmans, EFM Wouters 


\section{RESPIRATORY IMPEDANCE IN 1776 DUTCH PRIMARY SCHOOL CHILDREN, WITH AND WITHOUT CHRONIC RESPIRATORY SYMPTOMS}

\section{ABSTRACT}

Using the forced oscillation technique, respiratory impedance was measured in 1776 Dutch children, aged 6 to 12 years. Besides the commonly used parameters of resistance and reactance, additional impedance parameters ( $\gamma$ 's, $\beta$ 's and $\alpha$ 's) were obtained by using linear and quadratic regression to describe individual resistance and reactance curves as a function of frequency. Investigated was whether impedance values in children with chronic respiratory complaints ( 4 groups) differed from those observed in symptom-free children. Furthermore, the diagnostic value of the individual impedance parameters was evaluated.

Statistically significant differences in impedance values were found in girls with symptoms suggesting asthma compared to symptom-free girls, but not in 'asthmatic' boys compared to symptom-free boys. No clear differences were observed in children with 'chronic cough' or 'rest symptoms' compared to symptom-free children. The results obtained by the additional impedance parameters were comparable to those of the commonly used measures. The diagnostic value of the impedance parameters appeared to be low, no cut-off points were found, which clearly discriminate between symptomatic and symptom-free children. However, these results may indeed reflect absence of functional abnormalities in symptomatic children at this age.

In the present study, the suitability of the impedance measurements, using the FOT, in an open population of children, appeared to be good since the measurements were rapidly and easily to perform for the child as well as the investigator. However, to obtain more insight into its diagnostic abilities for epidemiologic purposes, further longitudinal studies in children, with a larger contrast in disease status or with help of bronchial provocation tests, will be necessary.

\section{INTRODUCTION}

By the technique of forced oscillations (FOT) mechanical properties and the frequency dependent behaviour of the respiratory system can be determined. The FOT yields values for the total resistance and reactance of the respiratory system. Because measurements are non-invasive, independent of effort, and require little or no coope- 
ration from the subject, they can easily be performed in young children. Hitherto, respiratory impedance has been studied in adults ${ }^{1-4}$ as well as in children, ${ }^{5-15}$ mainly by means of complex oscillations superimposed at the mouth during spontaneous quiet breathing. In adult patients with airflow obstruction, higher resistance $\left(\mathrm{R}_{\mathrm{rg}}\right)$ values (especially at lower frequencies), a decrease in resistance with increasing frequency (negative frequency dependence of resistance, $F D$ ), decreased reactance $\left(X_{r s}\right)$ values and consequently increased resonant frequency $\left(f_{0}\right)$, have been observed when compared with normal subjects. ${ }^{1-4}$ in children, several investigators reported negative frequency dependence of resistance to be a common finding up to twelve years of age, which disappears with growth, $5,8,13,14$ whereas others did not find negative frequency dependence of resistance in healthy children. ${ }^{7,12}$

Recently, we reported respiratory resistance and reactance values at 8 and $28 \mathrm{~Hz}$, in normal children aged 6 to 12 years $(n=371) .{ }^{16}$ All impedance parameters were significantly related to height, varied between sexes and negative frequency dependence of resistance between $8-28 \mathrm{~Hz}$ was a common finding in these children, most pronounced in (young) boys. Furthermore, we have reported statistically significant, but small differences in impedance values between children with $(n=110)$ and without $(n=360)$ asthma-like symptoms. ${ }^{17}$ The analyses of the data of these children were however, restricted in the sense that not all information of the resistance and reactance curves was used, but only mean values at single frequencies in the frequency range from 8-28 $\mathrm{Hz}$. At present more information on the impedance versus frequency curves $(4-48 \mathrm{~Hz})$ can be obtained, due to computerization of the impedance data.

The aims of the present study were to come to an optimal use of the impedance data and to further analyse the relation between respiratory symptoms and the impedance of the respiratory system in a large cohort of primary school children. Using linear $(Y$ $\left.=\beta_{f} f+\alpha_{i}\right)$ and quadratic $\left(\gamma=\gamma_{q}{ }^{2}+\beta_{q} f+\alpha_{q}\right)$ regression, individual resistance and reactance curves were described as a function of frequency (f), for 1776 Dutch primary school children. To determine whether certain sub-sections of the total frequency range contained more specific information the linear curves were described for the total frequency range $(4-48 \mathrm{~Hz})$ and for the sub-sections, $4-12 \mathrm{~Hz}$ and $8-28 \mathrm{~Hz}$. The following parameters were chosen to characterize the curves: $\beta_{\|,}, \alpha_{1,} \gamma_{\mathrm{q}}, \beta_{\mathrm{q}}$ and $\alpha_{\mathrm{q}}$, for both resistance $\left(R_{r s}\right)$ and reactance curves $\left(X_{\mathrm{rs}}\right)$. It was investigated whether children with chronic cough or symptoms of asthma differed from symptom-free children, in the curve parameters and in more frequently used on-line impedance parameters, i.e. resistance at $8 \mathrm{~Hz}\left(\mathrm{R}_{\mathrm{rs}}\right)$, reactance at $8 \mathrm{~Hz}\left(\mathrm{X}_{\mathrm{rs} \theta}\right)$, resonant frequency $\left(\mathrm{f}_{0}\right)$ and frequency dependence of resistance (FD). Since our previous studies ${ }^{16,17}$ indicated gender differences in respiratory impedance outcomes in children, the present analyses were performed for boys and girls separately.

\section{METHODS}

From March 1993 to June 1993 we conducted a survey on respiratory health in 1968 primary school children in two different regions of the Netherlands. The prevallence of respiratory symptoms was evaluated using a written questionnaire, completed by the parents of the children. Respiratory impedance measurements were performed using a forced oscillation technique. ${ }^{10}$ Data collection was carried out by trained technicians, at the same time in both regions with similar methods and according to a standard protocol. 


\section{Population}

In cooperation with two local health services 1968 children were approached, from 19 primary schools, 1281 children living in the south of the Netherlands (Limburg) and 687 children living in the north of the Netherlands (Groningen).

Informed consent to examine the children was obtained from the parents of 1226 $(95.7 \%)$ children, in Limburg and from the parents of $658 .(95.8 \%)$ children in Groningen, resulting in a total response of $1884(95.7 \%)$ children.

\section{The Questionnaire}

The prevalence of respiratory symptoms was evaluated by means of a written questionnaire, completed by the parents of the children. The questionnaire is a Dutch version of the children's questionnaire of the World Health Organisation published by Florey and Leeder. ${ }^{19}$ The reproducibility of the answers off the Dutch questionnaire has been found to be good to very good for almost all questions especially for the questions on wheeze and shorness of breath with wheeze with Cohen's kappa values ranging from 0.60 to 0.96 . The reproducibility of (chronic) cough was less (kappa $=$ 0.28 ). ${ }^{20}$ The questionnaires were distributed in the participating schools two weeks before the team who performed the lung function measurements visited the school. At the time of the lung function measurement the questionnaires were collected.

\section{The Forced Oscillation Technique}

The mechanical characteristics of the respiratory system were measured using the technique of forced oscillations, accordling to the method described by Làndsér et al. ${ }^{2}$ The technique has been described in detail previously. ${ }^{22}$ Briefly, a pseudo-random noise signal, consisting of sinusoidal pressure oscillations, containing all harmonics of $2 \mathrm{~Hz}$ up to $48 \mathrm{~Hz}(4,6,8, \ldots .48)$, was applied at the mouth of the seated child. During the measurements the child breathed quietly and wore a nose clip. The cheeks and the floor of the mouth were firmly supported with the hands of either the investigator or the chill itself. Mouth pressure and mouth flow were measured with identical differential pressure transducers (Validyne MP 458), and fed into a Fourier analyzer, dividing pressure by flow: the system calculates an impedance value for each of the investigated frequencies. The impedance is partitioned into a real part, resistance $\left(R_{\mathrm{rS}}\right)$ and an imaginary part or reactance $\left(X_{r s}\right)$. The real part $\left(R_{r s}\right)$ is the equivalent of the total resistance in a resistance-inductance-capacitance (R-L-C) circuit. The reactance $\left(X_{\mathrm{r}}\right)$ depends on the elastic and inertial propenties of the respiratory system. The frequency at which $X_{r s}$ equals zero is called the resonant frequency $\left(f_{0}\right)$. To evaluate the rellability of the measurement a coherence function is estimated at each frequency. This indicates the amount of noise generated by the child's spontaneous breathing, present in the measured signals.

Each child performed at least five valid impedance measurements according to the recommendations, which have recently been set up by an international working group on standardization of impedance measurements in children. ${ }^{18}$

\section{Analyses}

Based on the information obtained by the questionnaires four groups of children were distinguished; 1) children who were free from past and present (chronic) respiratory symptoms (symptom free), 2) children who reported chronic cough (cough for at least three months a year) but no other (chronic) respiratory symptoms (chronic cough), 3) children who reported at least two of the four asthma-like symptoms (chronic cough. 
shortness of breath during exercise, wheeze and attacks of shortness of breath with wheeze) in the previous year, to include wheeze or attacks of shortness of breath with wheeze (suggesting asthma), and 4) children with one or more past or present respiratory symptoms, but who did not meet the inclusion criteria of group 2 or 3 (rest group) (see Appendix).

Làndsér et al. ${ }^{23}$ have demonstrated that in measurements with a coherence function exceeding 0.95 the error of the measurements due to the presence of noise or nonlinearities is less than $10 \%$. Therefore only values of $R_{r s}$ and $X_{r s}$ with a coherence function equal to or exceeding 0.95 were retained in the analysis. For each child linear regression curves $\left(\gamma=\beta_{\mathrm{f}} \mathrm{f}+\alpha_{1}\right)$ over the frequency ranges $4-48 \mathrm{~Hz}, 4-12 \mathrm{~Hz}$ and $8-28$ $\mathrm{Hz}$ and quadratic regressions $\left(\gamma=\gamma_{\mathrm{q}} f^{2}+\beta_{\mathrm{q}} f+\alpha_{q}\right)$ over the frequency range $4-48 \mathrm{~Hz}$ were fitted to describe respiratory resistance and reactance as a function of frequency. The curves were characterized by the following parameters: $\beta_{1, R^{\prime}}, \alpha_{1, R^{\prime}} \gamma_{q, R^{\prime}}, \beta_{q, A^{\prime}}, \alpha_{q, R^{\prime}}$ $\beta_{1, x}, \alpha_{1, x}, \gamma_{q, X}, \beta_{q, X}$ and $\alpha_{q, X}$. Differences in these curve characteristics and in the on-line impedance parameters $\left(R_{\mathrm{rs} 8}, X_{\mathrm{rsa}}, f_{0}\right.$ and $\left.F D\right)$, between symptom-free children and children from the different symptom-groups were tested using unpaired t-tests (crude data) and multiple linear regression analyses. In the latter differences in impedance values between the groups were adjusted for the influences of age, height, and weight. The analyses were performed for boys and girls separately.

To use an impedance parameter to discriminate between children with and without chronic respiratory complaints, a cut-off point has to be chosen that appoints all possible values of the (concerning) parameter to either a positive or a negative test result. Using the information of the questionnaire (clinical symptoms), for each cut-off point the sensitivity and the specificity can be determined, which will be dependent on the value of this cut-off point. The relation between the sensitivity and specificity for the various values of the cut-off points was investigated with help of receiver operator characteristic (ROC) curves. In a ROC curve the sensitivity of an impedance index is plotted by the complement of the specificity. Ideally, both sensitivity (Se) and specificity (Sp) of a diagnostic parameter is $100 \%$, in this case the curve approaches the upper left hand corner $(\mathrm{Se}=\mathrm{Sp}=100 \%)$. The more the curve deviates from this point, the less discriminative the parameter is. ROC curves were constructed for all investigated impedance parameters, each symptom subgroup (chronic cough, 'asthma'; rest group) was compared separately to the symptom-free group. For all children curve parameters of the linear-and quadratic-regressions over the frequency range $4-48 \mathrm{~Hz}$ were investigated, and those of the linear curves for the ranges $8-28 \mathrm{~Hz}$, and $4-12 \mathrm{~Hz}$. Furthermore, the children were divided by gender (boys, girls) and height (4 categories: $<120 \mathrm{~cm}, 120-139 \mathrm{~cm}, 140-159 \mathrm{~cm} \geq 160 \mathrm{~cm}$ ), and ROC-curves were constructed again. The analyses were performed using SPSS-X statistical package. ${ }^{24}$

\section{RESULTS}

Completed questionnaires were returned by 1885 (98.8\%) parents. Of $1792(91.1 \%)$ children valid impedance measurements were obtained. The combination of a fully completed questionnaire and valid impedance measurements was available for 1776 $(90 \%)$ children. In Table 1 the numbers of children distributed over the four 'symptom groups' are shown. The distribution was almost similar for boys and for girls. 
Table 1. Numbers (n) and percentages (\%) of children in the different symptom-groups; symptom-free. chronic cough, asthma, and rest-group, for boys and girls separately and overall.

\begin{tabular}{|c|c|c|c|c|c|c|c|c|c|c|}
\hline \multirow{2}{*}{$\begin{array}{l}\text { Groups } \\
\text { Gender }\end{array}$} & \multicolumn{2}{|c|}{ Symptomfree } & \multicolumn{2}{|c|}{ Chronic cough } & \multicolumn{2}{|c|}{ Asthma } & \multicolumn{2}{|c|}{ Rest group } & \multicolumn{2}{|l|}{ Total } \\
\hline & $n$ & $\%$ & $n$ & $\%$ & $n$ & $\%$ & $n$ & $\%$ & $\mathrm{r}$ & $\%$ \\
\hline Boys & 472 & 52 & 41 & 5 & 110 & 12 & 283 & 31 & 906 & 100 \\
\hline Girts & 447 & 52 & 37 & 4 & 88 & 10 & 298 & 34 & 870 & 100 \\
\hline Total & 919 & 52 & 78 & 4 & 198 & 11 & 581 & 33 & 1776 & 100 \\
\hline
\end{tabular}

The results from the t-tests (crude dlata) and the regression analysis (adjusted data), in which impedance values between the different symptom-groups and the symptomfree children were compared, showed good agreement. For girls with ashtma-like symptoms compared to symptom-free girls, statistically significant differences were observed for almost all investigated impedance parameters (Table 2).

Table 2. Crude and adjusted differences in impedance parameters, between asthmatic and symptomfree children, boys and girls separately, and $\mathrm{I}_{2}$, interaction between disease status and gender (=asthmatic vs symptom-free children, differences between boys and girls).

\begin{tabular}{|c|c|c|c|c|c|}
\hline \multirow[t]{2}{*}{ parameters } & \multicolumn{2}{|c|}{$\Delta$ crude } & \multicolumn{2}{|c|}{$\Delta$ adjusted } & \multirow{2}{*}{$I_{2}$, interaction } \\
\hline & Boys & Girls & Boys & Girls & \\
\hline$\beta_{\text {I. }}$ & -0.006 & $-0.025^{\ddagger}$ & -0.004 & $-0.024^{*}$ & $-0.019^{t}$ \\
\hline$a_{1, R}$ & $0.378^{*}$ & $1.146^{*}$ & 0.242 & $1.078^{\sharp}$ & $0.837^{\star}$ \\
\hline$\beta_{1, x}^{1, x}$ & 0.000 & -0.001 & -0.001 & -0.001 & $-1.28 E-04$ \\
\hline$a_{1, x}$ & -0.093 & $-0.440^{*}$ & 0.007 & $-0.384^{*}$ & -0.392 \\
\hline$R_{\mathrm{rgB}}^{1, \mathrm{~A}}$ & 0.222 & $0.723^{\#}$ & 0.042 & $0.622^{\text {t }}$ & $0.580^{*}$ \\
\hline$x_{\text {部昌 }}$ & -0.0555 & $-0.43^{t}$ & 0.034 & -0.428 & $-0.462^{t}$ \\
\hline $\mathrm{FD}$ & 0.002 & $-0.023^{\#}$ & 0.006 & $-0.020^{\dagger}$ & $-0.026^{\dagger}$ \\
\hline$f_{0}$ & 0.821 & $1.920^{*}$ & 0.318 & $1.642^{4+}$ & 1.324 \\
\hline$\beta_{\mathrm{q}, \mathrm{A}}$ & -0.002 & $-0.016^{7}$ & $2.50 E-04$ & $-0.015^{*}$ & $-0.015^{t}$ \\
\hline$\alpha_{\mathrm{q}, \mathrm{p}} \mathrm{p}$ & 0.160 & 0.310 & 0.059 & 0.261 * & 0.202 \\
\hline$\alpha_{a, x}, x$ & -0.056 & $-0.396^{\ddagger}$ & 0.009 & $-0.354^{*}$ & $-0.363^{t}$ \\
\hline
\end{tabular}

\# $p \leq 0.10 ; * p \leq 0.05 ; \uparrow p \leq 0.01 ; \neq p \leq 0.001$

The results for the parameters of the linear and quadratic curves were quite comparable, and of a similar magnitude and direction as those obtained by the more commonly used on-line parameters $\left(\mathrm{A}_{\mathrm{rs} \theta}, \mathrm{X}_{\mathrm{rsB}} \mathrm{FD}\right.$ and $\left.\mathrm{f}_{0}\right)$. The linear curve characteristics of the sub-sections $4-12 \mathrm{~Hz}$ and $8-28 \mathrm{~Hz}$ also were comparable to those over the totall frequency range $(4-48 \mathrm{~Hz})$, only the difference in $\beta_{1, A}$ for both frequency ranges was no longer significant. In contrast, significant differences (t-tests) between boys with asthma-like symptoms and symptom-free ones were observed for $\alpha_{1, \mathrm{~A}, 4-48}$ and $\alpha_{1, \mathrm{R}, 4-12}$, only ( $p \leq 0.10$ ). After adjusting the data by regression analysis these differences were no longer significant. Although the differences between boys with asthma-like symptoms and symptom-free boys were smaller and not significant, in general the direction 
of the difference was comparable to that observed in girls (Table 2). To investigate whether differences between children with asthma-like symptoms and symptom-free children differ between boys and girls, interaction-terms (I) were entered into the regression analysis. For almost all investigated impedance parameters statistically significant interaction terms were found between symptom status and gender (Table 2).

For the children with chronic cough and the children with rest symptoms no clear patterns were observed when the impedance values were compared with those of the symptom-free children. However, we did find significant differences in a small part of the impedance parameters. In girls with chronic cough, $\beta_{1, R 4-48}$ was significantly different in the t-test $(p \leq 0.10)$, but no longer in the regression analysis and in girls of the restgroup differences were significant for $\beta_{1, R 4-48}(p \leq 0.05), \alpha_{1, R 4-48}(p \leq 0.05)$, and for $\beta_{1 \times 4-48}$ $(p=0.0 \leq 0,10)$, in t-test and regression analysis. In boys with chronic cough no significant effects were observed, but in boys of the rest group significant differences: were found for $A_{r s 8}(p \leq 0.05)$ and $F D(p \leq 0.10)$ (only in t-tests), and for $\gamma_{q, R}(p \leq 0.05)$ (in t-test and regression analysis).

\section{Diagnostic Value of the FOT}

Figure 1a and Figure 2a present the results of two different ROC-curves. The examples have been arbitrarily chosen: $\beta_{1, R}$ over the whole frequency range $(4-48 \mathrm{~Hz})$, and $\beta_{1, A}$ over the frequency range $8-28 \mathrm{~Hz}$, for the total group of children investigated. Ideally, the ROC-curve should approach the upper left hand corner $(\mathrm{Se}=\mathrm{Sp}=100 \%$ ).

From Figures 1a and $2 a$ it can be seen that the curves are around the diagonal, which means that for none of these parameters a cut-off point can be found which discriminates between symptom-free children and children with (chronic) respiratory symptoms. This can also be demonstrated by the frequency distribution as presented in Figures $1 b$ and $2 \mathrm{~b}$, which show large overlap for the different groups of children. For all other investigated impedance parameters, resulting from the linear, considering all three frequency ranges, and the quadratic regressions as well as for $R_{r s 8}, X_{r s 8}, F D$ and $f_{0}$ similar results were obtained.

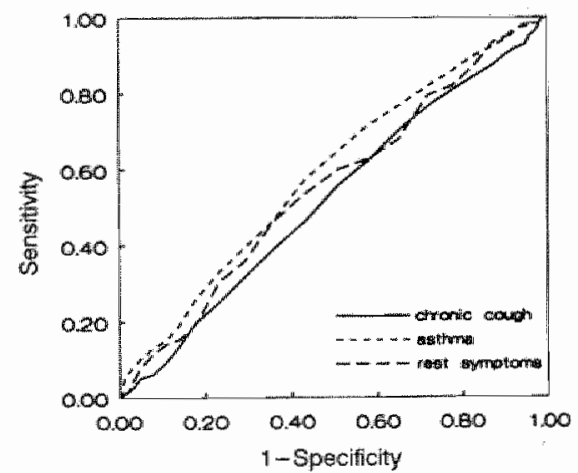

Figure 1a. ROC curve for $\beta_{1 \text { f }}$ over the whole frequency range $(4-48 \mathrm{~Hz})$, children with chronic cough, asthma or 'rest symptoms' were compared separately to the symptom-free ones.

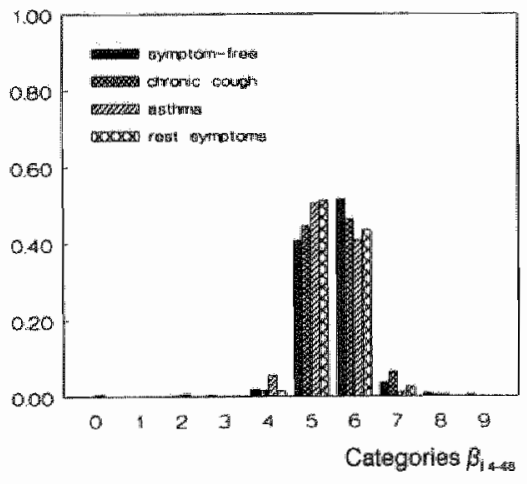

Figure $1 \mathrm{~b}$. Frequency distribution of $\beta_{1, \mathrm{p}}(4-48$ $\mathrm{Hzl}$, for symptom-firee children, chilldren with chronic cough, asthma or 'rest symptoms'. 


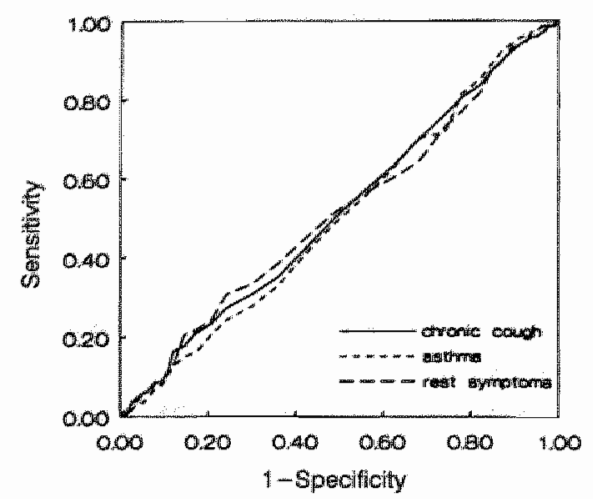

Figure 2a. FOC curve for $\beta_{1, A}$ over the frequency range $28 \mathrm{~Hz}$, children with chronic cough, asthma or "rest symptoms' were compared separately to the symptom-free ones.

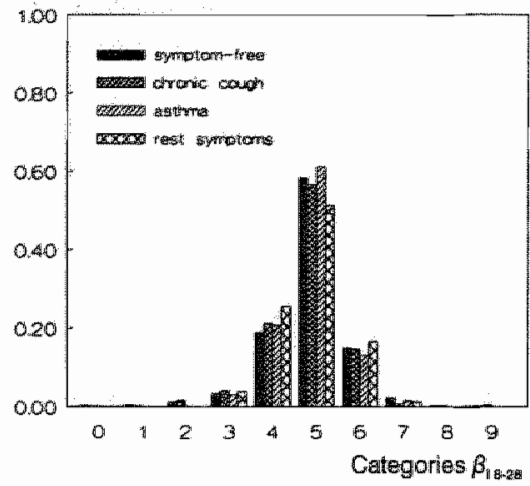

Figure 2b. Frequency distribution of $\beta_{1_{n}}(8-28$ $H z$ ), for symptom-free children, children with chronic cough, asthma or 'rest symptoms'.

When the total group was stratified for gender and height (4 categories), again no cutoff points with clear diagnostic value, for none of the different symptom-subgroups were found (Figure 3). Again the example is arbitrarily chosen, since all parameters showed similar results.

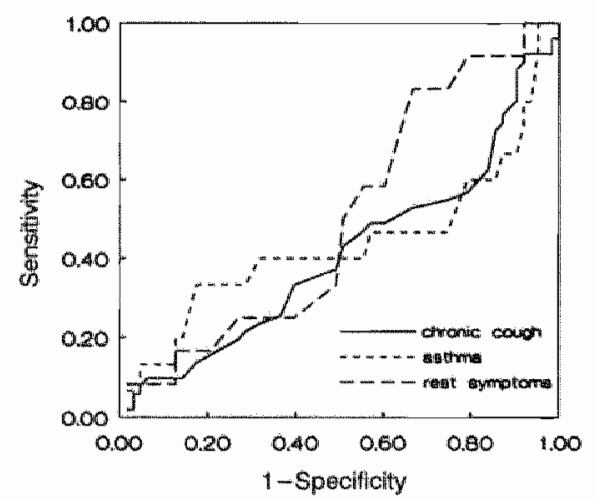

Figure 3a. ROC curve for $\beta_{1,2}$ over the whole frequency range $4-48 \mathrm{~Hz}$, for boys in height category one, boys with chronic cough, asthma or 'rest symptoms' were compared separately to the symptom-free ones.

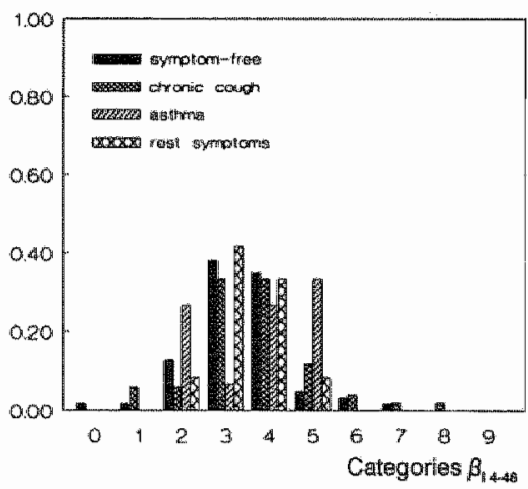

Figure $3 \mathrm{~b}$. Frequency distribution of $\beta_{l, \mathrm{~A}}$ (4-48 $\mathrm{Hz}$ ), for boys in height category

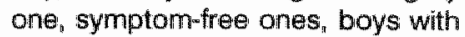
chronic cough, asthma or "rest symptoms'. 


\section{DISCUSSION}

In the present study, respiratory impedance was studied in 1776 Dutch children, aged 6 to 12 years. Of these children $919(52 \%)$ were free of any past or present respiratory symptoms, $78(4 \%)$ were reported to suffer only from chronic cough $198(11 \%)$ were found to have symptoms suggesting asthma, and $581(33 \%)$ were reported to have one or more past or present respiratory symptoms, excluding chronic cough and 'asthma". In girls with symptoms of asthma but not in boys, statistically significant differences in almost all investiglated impedance parameters were found compared with symptom-free children. When children with chronic cough or with "the rest symptoms' were compared to the symptom-firee children, no clear differences were observed, in boys nor in girls. In order to investigate the ability of the Impedance parameters to classify children according to the three different symptom-groups, we performed ROC-Curve analyses. The diagnostic value of the impedance parameters was found to be low, since no clear cut off points, which discriminate between symptomatic and symptom-free children, were observed. Stratification for height and gender did not fundamentally change the results. Applying linear and quadratic regression was found to give no further information than using simpler parameters only, and did not add to the diagnostic value of the impedance parameters.

The findings of statistically significant differences in respiratory impedance values found in girls with symptoms of asthma compared to symptom-free girls, but not in girls with chronic cough or with 'rest symptoms' suggests that only reported asthmanlike symptoms, in girls, are accompanied by altered physiology of the respiratory system. In absolute terms the observed effects were small, but they had a plausible direction and were comparable to our previous findings. ${ }^{17}$ Although the differences in boys observed in the present study, in general, were comparable to those found in girls, they were smaller and not statistically significant. A gender difference in respiratory impedance outcomes has been reported betore. ${ }^{5}, 1,16$ In a previous study we showed that negative frequency dependence of resistance ( $F D$ of $P_{r s}$ ) between 8 and $28 \mathrm{~Hz}$, can be found in thealthy children up to 12 years of age, not necessarily implicating pulmonary pathology. "This observation was most pronounced in boys, since negative $F D$ of $R_{r s}$ was found in boys up to the height of $160 \mathrm{~cm}_{1}$ whereas in girls it was found up to the height of $130 \mathrm{~cm}$. It was suggested that differences in airway diameter and in the growth rate of the smaller airways could, at laast in part, explain these observations. ${ }^{16}$ Negative frequency dependence of resistance may either be determined by an increase in the resistance of the peripheral airways ${ }^{3}$ or result from an upper airway artifact that is not fully corrected for by supporting the cheeks as was done in our study. ${ }^{25}$ To correct for this error various investiglators have made use of a head generator ${ }^{12,26}$ but this complicates the technique and for diagnostic purposes the conventional technique used in this study is considered adequate. ${ }^{25,26}$ The impedance values obtained in the present study were largely in line with our previous results, although in the present study no clear differences were observed between symptomfree girls and symptom-free boys. The interaction between disease status and gender was, however, found to be statistically significant "which means that differences between children with and without synptoms were different for boys than for girls. This may suggest a more pronounced airflow obstruction in girls than in boys with asthmalike symptoms at the time of the forced ascillation procedure. Influences of respiratory manoeuvres can be neglected during impedance measurements. ${ }^{5,7,16}$ Based on the cross-sectional design, it can only be hypothesized that the measured changes in 
impedance reflect a more persistent airflow obstruction in this group of 'asthmatic' girls. Besides differences in the incidence of asthma in this age-category (boys predominating $2.2: 1.0 \%$, there does not appear to be any difference in severity of childhood asthma between boys and girls. ${ }^{27}$

With the use of computerization of the impedance data in the present study, we set out to obtain more extended information on individual impedance values. Using linear and quadratic regression, individual resistance and reactance curves were described as a function of frequency. In contrast to the mean values at single frequencies used in our previous studies, these parameters reflect information on respiratory impedance over the total frequency rangle, $4-48 \mathrm{~Hz}$, and the sub-sections $4-12 \mathrm{~Hz}$ and $8-28 \mathrm{~Hz}$. In the analyses, the curve characteristics ( $\gamma$ 's, $\beta$ 's and $\alpha$ 's) were studied additionally to the commonly used on-line parameters $\mathrm{R}_{\mathrm{rs} 8^{\prime}}, \mathrm{X}_{\mathrm{rs}}, \mathrm{f}_{0}$ and FD. The results of all investigated parameters were quite comparable and had a plausible direction. Especially the magnitude and direction of the differences for $\beta$ and $\alpha$ of the linear $\mathrm{R}_{\mathrm{rs}}$ curve $(4-48 \mathrm{~Hz})$ compared well with our previous findings. No additional information was obtained by the linear curves considering the subsections $4-12 \mathrm{~Hz}$ and $8-28 \mathrm{~Hz}$. Using quadratic regression to describe resistance and reactance curves as a function of frequency, was of no additional value when compared to the linear curves. The fact that the results of the (simpler) on-line and the more sophisticated impedance parameters largely agree with each other, support the use of the on-line indicator parameters, and allow comparison of the present with previous results.

A second aim of the study was to evaluate the diagnostic value of the impedance parameters. Respiratory impedance measured by the FOT, has been studied in children with respiratory disorders (asthma, cystic fibrosis), yet little is known about its diagnostic value. ${ }^{6,28}$ For none of the impedance parameters a cut-off point was found with acceptable values of sensitivity and specificity, which discriminates between symptom-free children and children with chronic cough, 'asthma', or the rest-group. These results did not change when the analyses were stratified for height (4 categories) and gender. That in the latter case more irregular curves emerged, can probably be ascribed to the fact that after stratification, small numbers remained in the different subgroups. One possible explanation for our results is that, based on a cross-sectional measurement, the FOT is not sensitive enough to identify children who suffer from chronic cough, 'asthma' or any other (chronic) respiratory symptoms. In the comparisons of symptom-free with symptomatic children, only in the case of girls presenting with symptoms suggesting asthma significant differences with symptom-free girls were found. The distributions of the impedance values for both groups largely overlap, and the differences of the mean only become significant because of the large numbers of children. These findings strongly suggest that the individual impedance values would have low diagnostic value. To define the symptom groups in this study we used reported symptoms in the previous year ( 12 month prevalence) and compared them with an impedance measurement at a single moment, when the children were at school. This may have resulted in a certain bias since the children with the severest abnormalities at the time of the measurements may have been kept away from school, thus diminishing the differences between the groups. Characteristic for asthma is that symptoms alternate with intervals of relative or complete freedom from symptoms, during these symptom-free intervals the lung function can be completely normal. ${ }^{29}$ This can, in part, explain the lack of discriminative ability of the impedance indices as abserved in the present study. Furthermore, the symptom based asthma definition used gave no insight into asthma severity of the children. In the present analyses no 
questions were included concerning the use of medication. In an earlier study ${ }^{17}$ we have shown that in children diagnosed as having asthma by a doctor and using antiasthma medication lung function abnormalities were less pronounced than in those children with symptoms suggesting asthma not on anti-asthma medication, which means that the use of medication may have obscured differences in the present study. Alternatively, if as some have suggested ${ }^{1-3,30-32}$ the forced oscillation technique has the diagnotsic sensitivity to detect airway abnormalities, the absence of differences in impedance between children with and children without respiratory complaints may indeed reflect absence of functional abnormalities.

Recently, Buhr et al. ${ }^{30}$ studied 60 healthy and 66 asthmatic children aged $5-8$ years using the technique of forced oscillations, body plethysmography and spirometry. Fixing specificity to $95 \%$ they computed sensitivities of $66 \%$ for the forced oscillation technique, $68 \%$ for body plethysmography and $76 \%$ for spirometry. The relatively low sensitivity of all three technicues of lung function measurement was ascribed to the mild disease status of the asthmatic children studied. They concluded that the diagnostic value of the three investigated techniques was similar, but that the value of spirometry is limited by cooperation in these young children, since $29 \%$ of the investigated children failed to perform valid spirometry. Duiverman et al... ${ }^{31,32}$ used the FOT to determine individual bronchial responsiveness in several groups of asthmatic children after histamine and methacholine challenges. They found that bronchial responsiveness as determined by the FOT compared well to that obtained by maximum or partial flow volume curves. Furthermore, it appeared that bronchial responsiveness measured by the FOT in young children showed good $24 \mathrm{~h}$ within-patient reproducibility. ${ }^{31}$

The present study is, as far as we know, the first one in which the diagnostic value of the FOT was evaluated in an open population of children. Respiratory impedance measurements were easy and rapid to perform for the child as well as the investigator. The impedance outcomes appeared to be related to gender, and significant but small differences between symptomatic and symptom-free children were found in girls only. We found the diagnostic value of the impedance parameters to be low. The use of linear and quadratic regression to describe individual resistance and reactance curves as a function of frequency, did not give additional information on it's discriminative abilities as compared to more simpler measures at single frequencies. However, lack of measurable functional differences between symptomatic and symptom-free children at this age, may also explain the observations. Future studies, with a longitudinal design and with a larger contrast in disease status or with help of bronchial provocation tests, can probably give more insight into the diagnostic ability of the FOT for epidemiologic purposes.

\section{ACKNOWLEDGEMENTS}

The authors wish to thank the teachers of the cooperating schools, the children and their parents for participating in the study. We thank Jlos Slangen for his valuable contribution to the statistical analysis and Rene Cardynaalls for his help to handle the enormous impedance data files. This study was conducted in a successful collaboration of the Department of Public Health, Regional Services of Roermond, Groningen and the University of Maastricht. 


\section{APPENDIX}

4 Did your child cough, usually in the morning, during the autumn and winter season?

5. Did your child cough, usually during day-fime or at night, during the autumn and winter season?

6 Did your child cough on most days, for at least 3 months a year?

7 Has your child ever been troubled by shortness of breath when playing outside or climbing the stairs?

8 Has your child been troubled by shortness of breath when playing outside or climbing the stairs, in the previous year?

9 Has your child's chest ever sounded wheezy?

10 Has your child's chest sounded wheezy, in the previous year?

11 Has your child ever had attacks of shortness of breath with wheeze?

12 Has your child had attacks of shortness of breath with wheeze, in the previous year?

symptom free: children who are free from all above described past or present chronic respiratory symptoms

chronic cough: children who report chronic cough (6), but none of the other chronic respiratory symptoms

asthma: children who repont at least two of the four asthma-like symptoms $(6$, 8,10 and 12 ) in the previous year, to include 10 or 12 ,

rest group: children who report one or more past or present respiratory symptoms (4-12) but who do not meet the inclusion criteria for chronic cough or asthma

\section{REFERENCES}

1. Van Noord JA, Wellens W, Clarysse $I_{\text {, Cauberghs }} \mathrm{M}_{2}$ Van de Woestijne KP, Demedts M. Total respiratory resistance and reactance in patients with asthma, chronic bronchitis and emphysema. Am Rev Hespir Dis 1991: 143: 922-927.

2. Wesseling GJ, Vanderhoven-Augustin IML, Wouters EFM. Forced oscillation technique and spirometry in cold air prowocation test:. Thorax 1993 "48: 254-259.

3. Clément $J$, Làndsér $F J$, Van de Woestijne KP. Total resistance and reactance in patients with respiratory complaints with and without airway obstruction. Chest 1983; 83: 215-220.

4. Chalker $\mathrm{RB}$, Celli $\mathrm{BR}$, Habib $\mathrm{RH}$, Jackson $\mathrm{AC}$. Respiratory input impedance from 4 to $256 \mathrm{~Hz}$ in normals and chronic airflaw obstruction: Comparisons and correlations with spirometry. Am Rev Respir Dis 1992; 146: 570-576.

5. Clement $J$, Dumoulin $B$, Gubbelmans $R$, Hendriks KP, Woestiine van de KP. Reference values of total respiratory resistance and reactance between 4 and $26 \mathrm{~Hz}$ in children and adolescents aged 4-20 years. Bull Eur Physiopathol Respir 1987; 23: 441-448.

6. Cogswell JJ. Forced oscillation technique for determination of resistance to breathing in children. Archiv Dis Child 1973; 48: 259-266.

7. Duivermant EJ, Clément J, Woestijne van de KP, Neijens HJ, Bergh van den ACM, Kerrebijn KF. Forced oscillation technique. Reference values for resistance and reactance over a frequency spectrum of 2-26 Hz in healthy children aged 2.3-12.5 years. Bull Eur Physiopathol Respir 1985; 21: $171-178$.

8. Hantos $Z$, Daróczy $B$, Gyurkovits $K$. Total respiratory impedance in healthy children. Pediatr Pulmonol 1985; 11: 91-98. 
9. Hordwik NL König P, Morris. DA, Kreutz C, Pimmel RL. Normal values for forced oscillatory respiratory resistance in children. Pediat Pulmonol 1985; 1: 145-148.

10. Mansell $\mathrm{A}_{*}$ Levison $\mathrm{H}_{2}$ Kruger $\mathrm{K}$, Tripp TL. Measurement of respiratory resistance in children by forced oscillations. Am Rev Respir Dis 1972; 106: 710-714.

11. Nussbaum E, Galant SP. Measurement of total respiratory resistance in children by a modified forced oscillation method. Pediatr Res 1984; 8: 139-145.

12. Peslin $R$, Gallina $C$, Teculescu $D$, Pham QT. Respiratory imput and transfer impedances in children 9-13 years old. Bull Eur Physiopathol Respir 1987; 23: 107-112.

13. Solymar $L$. Aronsson $\mathrm{PH}_{3}$ Bake $\mathrm{B}$, Bjure J. Respiratory resistance and impedance magnitude in healthy children aged 2-18 years. Pediatr Pulmonol 1985; 1: 134-140.

14. Stanescu $D$, Moavero $N E_{\text {, Veriter }} C$, Brasseur $L$. Frequency dependence of respiratory resistance in healthy children. J Appl Physiol 1979; 47: 268-272

15. Williams SP, Fullton JM, Tsai MJ, Pimmel RL, Collier AM. Respiratory impedance and derived parameters in young children by forced random noise. I Appl Physiol 1979; 47: 169-174.

16. Cuijpers CEJ "Wesseling GJ, Swaen GMH, Wouters EFM. Frequency dependence of oscillatory resistance in healthy primary school children. Respiration 1993; 60: 149-154.

17. Cuijpers CEJ, Wesseling GJ Swaen GMH, Sturmans F. Wouters EFM. Asthma related symptoms and lungfunction in primary school children. J Asthma 1994: 31: 301.312.

18. Woestijne van de KP, Desager KN, Duiverman EJ, Marchal F. Recomrnendations for measurement of the respiratory impedance input impedance by means of the forced oscillations method. Eur Respir Rev 1994; 4: 235-237.

19. Florey $\mathrm{C}$ du $V_{1}$ Leeder SR. Methods for cohort studies of chronic airflow limitation, (chapter 3). WHO reglional publications, European series No. 12. London, United Kingdiomi 1982.

20. Brunekreef B, Groot B, Rijcken B, Hoek $G_{1}$ Steenbekkers A, Boer de A. Repradticibility of child hood respiratory symptom questions. Eur Respir J 1992; 5: 930-935.

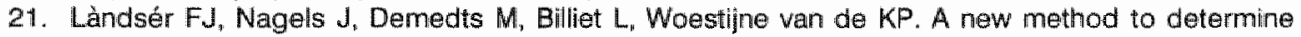
frequency characteristics of the respiratory system. J Appl Physiol 1976; 41: 101-106.

22. Wouters EFM, Làndsér FJ, Polko AH, Visser BF. Physiological analysis of extended spectrum oscillometry. Hespiration 1988; 54 : 263-270.

23. Ländsér FJ, Nagels J, Clement J, Woestijne van de KP. Errors in the measurement of total respiratory resistance and reactance by forced oscillations. Respir Physiall 1976; 28: 289-301.

24. SPSS® Inc., $1990,444 n$ Michigan Avenue, Chicago, lllinois 60611.

25. Peslin $A$, Duvivier $C$, Gallina $C$, Cervantes $P$. Upper airway artifact in respiratory impedance measurments. Ann Rev Respir Dis 1985; 132: 712-714.

26. Gowaerts $E_{\text {s }}$ Cauberghs $M$, Demedts $M$, Van de Woestijne KP. Head generator versus conventional technique in respiratory input impedance measurements. Eur Respir Fev 1994; 4: 143-149.

27. Godfrey S. Childhood asthima. In: Clark TJH, Godfrey S, Lee TH, Eds. Asthma (3rd edn), Chapmann \& Hall, London 1992, (chapter 18, p556-558).

28. König P. Hordvik NL, Pimmel RL. Forced random noise resistance determination in childhood asthma. Chest 1984; B6: 884-890.

29. Clark TJH. Definition and clinical categories of asthma. Im: Clark TJH, Godfrey S, Lee TH, Eds. Asthma (3rd edr), Chapmann \& Hall, London 1992, (chapter i).

30. Buhr $W$, Reimnitz $P$, Jorres $R$, Berdel $D$. Sensitivity and specificity of polyfrequent oscillation method. body plethysmography and spirometry in asthmatics aged 5 to 8 years. Pneumologie 1990; 40 : 1196-1198.

31. Duiverman EJ, Neijens $H J$, Strik wan $A$, Snee-Smaalen wan der $M$, Kerrebijn KF. Bronchial responsiveness in asthmatic children aged 3 to 8 years measured by the forced pseudo random noise oscillometry. Bull Eur Physiopathol Respir 1986: 22: 27-34.

32. Duiverman EJ. Neijens $H J^{\prime}$, Snee-Smaalen van der $M$, Kerebijn KF. Comparison of forced oscillometry and forced expirations for measuring dose related responses to inhaled methacholine in asthmatic children. Bull Eur Physiopathol Respir 1986; 22: 433-436. 



\section{Chapter 4}

\section{ASTHMA-RELATED SYMPTOMS AND LUNG \\ FUNCTION IN PRIMARY SCHOOL CHILDREN}

CEJ Cuijpers, GJ Wesseling, GMH Swaen, F Sturmans, EFM Wouters 


\section{ASTHMA-RELATED SYMPTOMS AND LUNG FUNCTION IN PRIMARY SCHOOL CHILDREN}

\section{ABSTRACT}

The aim of the present study was to determine the prevalence of asthma-related symptoms in a group of primary school children, by means of a questionnaire completed by their parents, and their lung function using spirometry and the forced oscillation technique (FOT). Also investigated were diagnostic labeling and medical prescription. We approached 535 children, from two primary schools in Maastricht, the Netherlands. Completed questionnaires were received from 482 children $(90 \%)$. Valid lung function values were obtained in 470 of these children $(98 \%)$.

The lifetime prevalence of wheeze and attacks of shortness of breath with wheeze was $29 \%$ and $19 \%$, respectively. The period prevalence of wheeze was $15 \%, 13 \%$ reported chronic cough, and $10 \%$ attacks of shortness of breath with wheeze. The doctordiagnosed asthma and bronchitis prevalence was $6 \%$ and $19 \%$, respectively. Of the children diagnosed as having asthma $69 \%$ used antiasthma medication; none of the children diagnosed as having bronchitis used antiasthma medication. A symptombased asthma prevalence of $11 \%$ was calculated. Statistically significant differences in spirometric and FOT indices were found between the children with and without complaints:

In conclusion, among the 482 investigated children a relatively high prevalence of unrecognized or misclassified, and therefore undertreated, asthma-related symptoms were found. These observations were confirmed by the lung function data, in that we found significant differences in spirometric and FOT indices between children with and without complaints.

\section{INTAODUCTION}

Asthma is an important health problem in children. This chronic disease is characterized by periods with chest tightness, wheezing, and cough. Most definitions of asthma include airway hyperresponsiveness and variable airflow obstruction as key findings. ${ }^{1-3}$ According to the American Thorasic Society, the major symptoms of asthma are attacks of dyspnea, wheezing, and cough. ${ }^{2}$ It has been argued that for the epidemiological assessment of asthma in children, wheezing must be a key symptom, with cough and 
shorthess of breath being related, but subordinate symptoms. ${ }^{4}$ Reported asthma prevalence rates in Europe vary widely. This can be partly explained by the lack of uniformity in defining asthma, which makes it difficult to compare prevalence figures on an international scale. ${ }^{\gamma}$ It is also believed that asthma is often misclassified, resulting from the misconception that wheezy bronchitis and asthma are different disease entities, contrary to the evidence that both are part of a single disease entity with a spectrum of severity, ${ }^{5.7}$ and despite increased medical efforts in the field of childhood asthma the disease is still thought to be underdiagnosed and undertreated. $4,8,9$ Recently, studies from the United Kingdom, Australia and the United States reported that the proportion of the child population with asthma is increasing. ${ }^{10}$

Among primary school children in the Netherlands, respiratory symptoms are frequently reported. In studies published so far, about $25-30 \%$ of the children are reported to have one or more respiratory symptoms. Combinations of respiratory complaints were found in $10-15 \%$ of the children. The prevalence of asthma in these children is estimated to be $5-6 \%{ }^{16-18}$

The aims of the present, purely descriptive, study were: to determine the prevalence of asthma-related symptoms such as wheeze, cough, and shortness of breath, among primary school children living in the south of the Netherlands (Maastricht), to evaluate the recognition of asthma by physicians and the subsequent drug prescription, and to investigate whether children reporting asthma-related symptoms differ in terms of lung function from symptom-free children.

\section{METHODS}

\section{Population}

The study population consisted of 535 children aged 6-12 years. The children were recruited from two randomly selected primary schools, which are llocated in a \pm 15 year-old residential area on the outskirts of Maastricht. The parents of these children were approached by a letter given to the children at school. For each participating child, written informed consent was obtained from the parents. The study was approved by the local medical ethics committee.

\section{The Questionnaire}

The prevalence of respiratory symptoms was evaluated by a written questionnaire, completed by the parents of the children. The questionnaire is a Dutch version of the children's questionnaire of the World Health Organization (WHO), by Florey and Leeder. ${ }^{19}$ The reproducibility of the answers of the Dutch questionnaire has been found to be good to very good for almost all questions, especially for wheeze and attacks of shortness of breath with wheeze and asthma and bronchitis diagnosed by a physician, Cohen's kappa values ranging from 0.60 to $0.96 .{ }^{20}$ The reproducibility of (chronic) cough was less (a kappa value of 0.28 ). The major questions for this report are summarized in the Appendix.

By means of the questionnaire, the lifetime prevalence of wheeze and (attacks of) shortness of breath (with wheeze), and the period prevalence (= within the previous year) of the key symptoms, chronic cough, wheeze, and (attacks of) shortness of breath (with wheeze), were determined.

The parents who agreed to participate in the study received the questionnaire by mail, and mailed it back after completion. 


\section{Lung Function Measurements}

Spirometry was performed during morning and afternoon school hours, according to the protocol of the European Community for Coal and Steel (ECCS) ${ }^{21}$ with the exception that five instead of three acceptable maneuvers had to be collected out of a maximum of eight attempts. We used the vitalograph-compact dry spirometer (Vitalograph Ltd., Buckingham, England), with the child standing. The measurement with the highest sum value of the forced vital capacity (FVC) and the forced expiratory volume in $1 \mathrm{sec}$. $\left(\mathrm{FEV}_{1}\right)$ was used in the analysis.

The technique of forced oscillations used in this study was similar to the method described by Làndsér et al. ${ }^{22}$ With this technique values for the total resistance $\left(R_{\mathrm{rg}}\right)$ and reactance $\left(X_{r s}\right)$ of the respiratory system are obtained. ${ }^{23}$ In this report values for the resistance at $8 \mathrm{~Hz}\left(\mathrm{R}_{\mathrm{rSB}}\right)$ and the reactance at $8 \mathrm{~Hz}\left(\mathrm{X}_{\mathrm{rSB}}\right)$, the frequency dependence of resistance ( $F D$ ) defined as the difference between the resistance at $28 \mathrm{~Hz}\left(\mathrm{R}_{\mathrm{rs} 28}\right)$ and $\mathrm{R}_{\mathrm{rs} 8}$ divided by 20 , and the resonant frequency $\left(f_{0}\right.$, the frequency at which $X_{r s}=0$ ) are discussed.

\section{Analyses}

First, lifetime prevalence and period prevalence of the asthma-related respiratory symptoms (chronic cough, wheeze, and attacks of shortness breath with wheeze) were calculated for the total group and for the subgroups stratified for age, gender, and [age + gender], because it has been demonstrated that the prevalence of asthma varies with age and gender. Only two age levels were chosen to prevent subgroups from becoming too small. Next we calculated the "symptom-based" prevalence of asthma, in the children who reported at least two of the key symptoms within the previous year, to include wheeze or attacks of shortness of breath with wheeze. Further, we investigated which of the symptoms were the most frequently reported among the children diagnosed as having asthma and bronchitis and whether they used any form of antiasthma medication - anti-inflammatory, bronchodilator, or any other treatment especially prescribed for these particular symptoms.

Finally, the lung function values of children with and without asthma-related symptoms were compared. We distinguished six symptom subgroups: chronic cough, shortness of breath during exercise, recent wheeze, attacks of shortness of breath with wheeze, asthma diagnosed by a doctor, and asthma according to our symptom based definition.

Therefore, we used multiple linear regression analysis. In addition to the symptom variable, the regression model contained the variables height, gender, age, and weight. According to Dockery et al. ${ }^{24}$, a log transformation was carried out for the spirometric variables, height, age, and weight to normalize the residuals. No log transformation was carried out for the impedance variables because some of these data are negative. Consequently, differences in spirometry values were expressed in terms of percentage whereas differences in impedancevalues were expressed as absolute values. The basic form of the regression model was:

$$
\begin{aligned}
\ln (\text { hung function })= & \text { constant }+ \text { symptom }+ \text { gender }+\ln (\text { height })+\ln (\text { age })+\ln (\text { weight }) \\
& + \text { "error" }
\end{aligned}
$$

and for the impedance indices without the logarithmic transformation. For the analysis the SPSS-X statistical package was used. ${ }^{25}$ 


\section{RESULTS}

\section{The Questionnaire}

A total of 482 questionnaires $(90 \%)$ were completed. We have no information about the reasons why $10 \%$ did not return a completed questionnaire. The age distribution of the children is shown in Figure 1. There were 226 boys and 256 girls. Table 1 gives an overview of the prevalence of the key symptoms and asthma and bronchitis diagnosed by a doctor, in the total group $(n=482)$.

age years

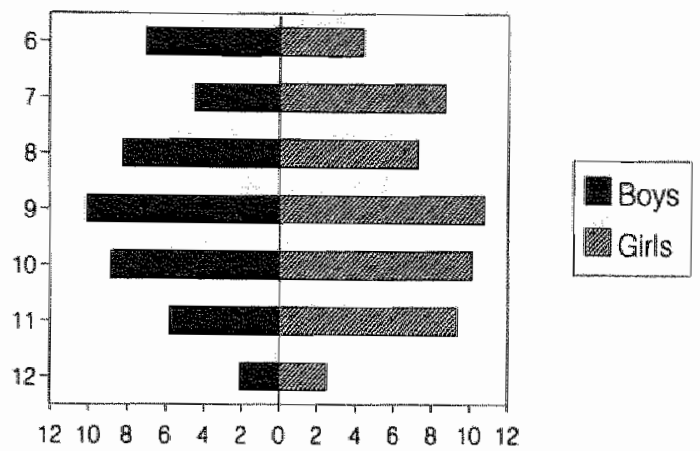

percerliage of total study popullation

Figure 1. Percent distribution of age for the total study population $(n=482)$; percentages for boys $(n=226)$ and girls $(n=256)$ are shown separately.

Table 1. Lifetime and period prevalence of the k8y symptoms in 482 primary school children.

\begin{tabular}{lrr}
\hline Symptom & $n$ & $\%$ \\
\hline Chronic cough & 63 & 13 \\
Ever exerciseminduced shortness of breath & 74 & 15 \\
Exercise-induced shortness of breath in the previous year & 59 & 12 \\
Ever wheeze & 141 & 29 \\
Wheeze in the previous year & 72 & 15 \\
Ever attacks of shortness of breath with wheeze & 90 & 19 \\
Attacks of shortness of breath with wheeze in the previous year & 46 & 10 \\
Ever doctor-diagnosed asthma & 28 & 6 \\
Antiasthma medication & 19 & 4 \\
Ever doctor-diagnosed bronchitis & 108 & 22 \\
\hline
\end{tabular}

Lifetime prevalence. A total of 153 parents (32\%) reported that their child had ever had wheeze and/or attacks of shortness of breath with wheeze, $141(29 \%)$ reported ever wheeze and $90(19 \%)$ reported ever attacks of shortness of breath with wheeze; $78(51 \%)$ of these children reported a combination of both symptoms. 
- Period prevalence. A total of 110 parents (23\%) reported that their child had one or more of the key symptoms within the previous year. Chronic cough was reported in $63(13 \%)$ children, $59(12 \%)$ reported shortness of breath during exercise, $72(15 \%)$ reported wheeze and, $46(9.5 \%)$ reported attacks of shortness of breath with wheeze; $59(54 \%)$ of these children reported a combination of at least two symptoms.

- Doctor-diagnosed prevalence of asthma and bronchitis. A total of $28(6 \%)$ children (18 boys, 10 girls) were ever diagnosed by a doctor as having asthma, and 108 children $(22 \%)$ were ever diagnosed as having bronchitis. However, 15 of the bronchitis children also had a diagnosis of asthma and were further considered asthmatic "leaving out $93(19 \%)$ bronchitis children. As 153 children were reported to have symptoms at any time, and $121(28+93)$ had been diagnosed as having asthma or bronchitis at any time, a diagnosing rate of $79 \%$ results.

- The symptom-based prevalence of asthma. A total of $54(11.2 \%)$ children (31 boys, $23 \mathrm{girls}$ ) reported at least two of the key symptoms within the previous year, to include wheeze or attacks of shortness of breath with wheeze. This is almost twice as high as the doctor-diagnosed prevalence of asthma $(6 \%)$.

- Symptom combinations in asthma and bronchitis children. From Table 2 it can be concluded that among the asthma children wheeze, shortness of breath, and attacks of shortness of breath with wheeze are the most frequently reported $(71-79 \%)$; aboult $25 \%$ of the bronchitis children also reportted at least two of the key symptoms, including wheeze or attacks of shortness of breath with wheeze, suggesting asthma.

Table 2. Reported symptoms and medication in the doctor-diagnosed asthma $(n=28)$ and bronchitis $(n=93)$ children.

\begin{tabular}{lll}
\hline Symptom & $\begin{array}{l}\text { Asthma } \\
(n=28) \\
\%\end{array}$ & $\begin{array}{l}\text { Bronchitis } \\
(n=93) \\
\%\end{array}$ \\
\hline Chronic cough & 54 & 26 \\
Shortness of breath & 75 & 24 \\
Wheeze & 79 & 37 \\
Attacks of shortness of breath with wheeze & 71 & 23 \\
Antiasthrna medication & 69 & 0 \\
Any pulmonary medication & 11 & 13 \\
\hline
\end{tabular}

- Medical prescription. Most of the children diagnosed as having asthma (69\%) use some form of antiasthma medication. Three of the asthmatic children (11\%) who did not use antiasthma medication reported that they did use other pulmonary medication (e.g., antibiotics). When bronchitis is diagnosed, no antiasthma medication is prescribed and only $13 \%$ are using (or have used) any other form of pulmonary medication.

- Stratification by age and gender. Tables $3 \mathrm{~A}$ and $3 \mathrm{~B}$ show the results of the stratified analysis by gender, age (6-9 and 10-12), and gender + age. Stratification for age alone does not result in clear differences in the prevalence of the key symptoms or in the 
prevalence of asthma and bronchitis diagnosed by a doctor. From the stratification by gender it can be seen that the prevalence of most of the key symptoms and diagnosed by a doctor are higher in boys than in girls. Stratification by age and gender results in a higher prevalence of the key symptoms, doctor-diagnosed asthma and bronchitis, in young boys (6-9) than in older boys (10-12) and higher than in young girls $(6-9)$.

Table 3 A. Prevalence of the key symptoms and asthma and bronchitis diagnosed by a doctor stratified by age and gender, separately.

\begin{tabular}{|c|c|c|c|c|c|c|c|c|}
\hline \multirow[b]{2}{*}{ Symptom } & \multicolumn{2}{|c|}{$\begin{array}{l}\text { Boys } \\
(n=226)\end{array}$} & \multicolumn{2}{|c|}{$\begin{array}{l}\text { Girls } \\
(n=256)\end{array}$} & \multicolumn{2}{|c|}{$\begin{array}{l}6-9 \text { years } \\
(n=295)\end{array}$} & \multicolumn{2}{|c|}{$\begin{array}{l}10-12 \text { years } \\
(n=187)\end{array}$} \\
\hline & $n$ & $\%$ & $n$ & $\%$ & $\pi$ & $\%$ & n & $\%$ \\
\hline Chronic cough & 34 & 15.0 & 29 & 11.3 & 44 & 14.9 & 19 & 10.2 \\
\hline SOB previous year & 36 & 15.9 & 23 & 9.0 & 35 & 11.9 & 24 & 12.6 \\
\hline Wheeze previous year & 35 & 15.5 & 37 & 14.5 & 42 & 14.2 & 30 & 16.0 \\
\hline Attacks SOB + whz previous year & 28 & 12.4 & 18 & 7.0 & 30 & 10.2 & 46 & 8.6 \\
\hline Ever doctor-diagnosed asthma & 18 & 8.0 & 10 & 3.9 & 17 & 5.8 & 11 & 5.9 \\
\hline Antiasithma medication & 13 & 5.8 & 7 & 2.7 & 12 & 4.1 & $B$ & 4.3 \\
\hline Ever doctor-diagnosed bronchitis & 60 & 26.5 & 48 & 18.8 & 66 & 22.4 & 42 & 22.5 \\
\hline
\end{tabular}

Table 3B. Prevalence of the key symptoms and asthma and bronchitis diagnosed by a doctor stratified by age + gender.

\begin{tabular}{|c|c|c|c|c|c|c|c|c|}
\hline \multirow[b]{3}{*}{ Symptom } & \multicolumn{4}{|c|}{ Boys } & \multicolumn{4}{|c|}{ Girls } \\
\hline & \multicolumn{2}{|c|}{$\begin{array}{l}6 \cdot 9 \text { years } \\
(n=145)\end{array}$} & \multicolumn{2}{|c|}{$\begin{array}{l}10-12 \text { years } \\
(n=81)\end{array}$} & \multicolumn{2}{|c|}{$\begin{array}{l}6-9 \text { years } \\
(n=150)\end{array}$} & \multicolumn{2}{|c|}{$\begin{array}{l}10-12 \text { years } \\
(n=106)\end{array}$} \\
\hline & $n$ & $\%$ & $n$ & $\%$ & $n$ & $\%$ & $n$ & $\%$ \\
\hline Chronic cough & 25 & 17.2 & 9 & 11.1 & 19 & 12.7 & 10 & 9.4 \\
\hline SOB prewious year & 24 & 16.6 & 12 & 14.8 & 11 & 7.3 & 12 & 11.3 \\
\hline Wheeze previous year & 21 & 14.5 & 14 & 17.3 & 21 & 14.0 & 16 & 15.4 \\
\hline Attacks SOB + whe previous year & 19 & 13.1 & 9 & 11.1 & 11 & 7.3 & 7 & 6.6 \\
\hline Ever doctor-diagnosed asthma & 11 & 7.6 & 7 & 8.6 & 6 & 4,0 & 4 & 3.8 \\
\hline Antiasthma medication & 8 & 5.5 & 5 & 6.2 & 4 & 2.7 & 3 & 2.8 \\
\hline Ever doctor-diagnosed bronchitis & 38 & 26.2 & 22 & 27.2 & 28 & 18.7 & 20 & 18.9 \\
\hline
\end{tabular}

$\mathrm{SOB}=$ shortness of breath; $\mathrm{SOB}+$ whz $=$ shortness of breath with wheeze

\section{Lung Function}

Valid lung function measurements were obtained in 470 of the 482 children (98\%). Using simple linear regression analysis, differences in lung function were studied for several symptom subgroups, each time compared to the symptom-free group $(n=360)$. The results of four of the subgroup comparisons are presented in Table 4: asthma according to our symptom-based definition $(n=54)$, asthma diagnosed by a doctor $(n=26)$, chronic cough $(n=59)$ and attacks of shortness of breath with wheeze $(n=42)$. 
Table 4. Resultt from the multiple linear regression analysis, differences in spirometric values in terms of percentage and impedance values as absolute differences, for four symptom sub groups.

\begin{tabular}{|c|c|c|c|c|c|c|}
\hline & & \multicolumn{2}{|c|}{ Asthma symptoms $(n=54)$} & \multicolumn{3}{|c|}{ Asthma $(n=26)$} \\
\hline \multicolumn{2}{|c|}{ Lung function } & Difference & C.I. & Difterence & C.I. & \\
\hline \multicolumn{7}{|c|}{ Spirometry: } \\
\hline FVC & $\%$ & 0.0 & $-2.8 /$ & 4.1 & 0.41 & $7.9^{*}$ \\
\hline $\mathrm{FEV}_{i}$ & $\%$ & -3.0 & $-6.0 / \quad 0.0$ & -0.3 & $-4.4 /$ & 3.8 \\
\hline PEF & $\%$ & -6.7 & $-10.8 /-2.7^{4}$ & -2.9 & $-8.6 /$ & 2.8 \\
\hline $\mathrm{FEF}_{25.75 \%}$ & $\%$ & -9.2 & $-15.0 /-3.4^{\dagger}$ & -9.4 & $-17.4 /$ & $1.3^{*}$ \\
\hline \multicolumn{7}{|c|}{ Impedance: } \\
\hline $\mathrm{A}_{\text {rse }}$ & $\mathrm{cmH}_{2} \mathrm{Or}(\mathrm{L} / \mathrm{s})$ & 0.21 & $-0.10 / 0.53$ & 0.32 & $-0.12 /$ & 0.77 \\
\hline$X_{r s 6}$ & $\mathrm{cmH}_{2} \mathrm{Or}(\mathrm{L} / \mathrm{s})$ & -0.33 & $-0.49 /-0.17^{4}$ & -0.30 & $-0.521-$ & $-0.09^{*}$ \\
\hline $\mathbb{f}_{0}$ & $\mathrm{~Hz}$ & 1.80 & $0.40 / 3.20^{*}$ & 1.3 & $-0.70 \%$ & 3.20 \\
\hline $\mathrm{FD}$ & $\mathrm{CmH}_{2} \mathrm{O} /(\mathrm{L} / \mathrm{s})$ & -0.02 & $-0.03 /-0.01^{4}$ & -0.01 & $-0.03 /$ & 0.00 \\
\hline
\end{tabular}

\begin{tabular}{|c|c|c|c|c|c|}
\hline \multirow{2}{*}{\multicolumn{2}{|c|}{ Lung function }} & \multicolumn{2}{|c|}{ Chronic cough $(n=59)$} & \multicolumn{2}{|c|}{ Attacks SOB + wheeze $(n=42)$} \\
\hline & & Difference & C.1. ${ }^{a}$ & Difference & C.1. ${ }^{a}$ \\
\hline \multicolumn{6}{|c|}{ Spirometry: } \\
\hline FWC & $\%$ & -2.1 & $-4.8 / \quad 0.5$ & 0.2 & $-2.9 / 3.3$ \\
\hline FEV & $\%$ & -3.7 & $-6.5 /-0.8^{1 / 2}$ & -4.0 & $-7.3 /-0.7$ \\
\hline PEF & $\%$ & -7.0 & $-10.9 /-3.1$ & -6.6 & $-11.2 /-2.1^{\dagger}$ \\
\hline $\mathrm{FEF}_{25.75 \%}$ & $\%$ & -6.5 & $-12,1 / \omega-0.9^{1}$ & -12.4 & $-18.8 /-5.9^{\dagger}$ \\
\hline \multicolumn{6}{|c|}{ Impedance: } \\
\hline $\mathrm{A}_{\mathrm{r}: \mathrm{B}}$ & $\mathrm{CmH}_{2} \mathrm{O} /(\mathrm{L} / \mathrm{s})$ & $-0,08$ & $-0.23 / \quad 0.39$ & 0.28 & $-0.08 / 0.63$ \\
\hline$x_{r s \theta}$ & $\mathrm{CmH}_{2} \mathrm{O} /(\mathrm{L} / \mathrm{s})$ & -0.26 & $-0.41 /-0.10^{\dagger}$ & -0.38 & $-0.56 /-0.21$ \\
\hline$f_{0}^{150}$ & $\mathrm{~Hz}$ & 0.98 & $0.36 / 2.33$ & 2.10 & $0.58 / 3.68^{*}$ \\
\hline FD & $\mathrm{cmH}_{2} \mathrm{O} /(\mathrm{L} / \mathrm{s})$ & -0.01 & $-0.02 / 0.00^{*}$ & -0.02 & $-0.03 / 0.00^{t}$ \\
\hline
\end{tabular}

In all instances the symptom-free group $(n=360)$ is used as the reference group.

* $p<0.05 ;+p<0.01 ; \neq p<0.001$

$a \quad=90 \%$ conficlence interval

$\mathrm{SOB}=$ shortmess of breath

Comparison of the FOT indices of children with and without asthma-related symptoms revealed that the largest differences were found in the reactance at $8 \mathrm{~Hz}$ and in the frequency dependence of resistance, especially in the children with attacks of shortness of breath with wheeze in whom also a significant increase in resonant frequency was found. Differences in PEF and $\mathrm{FEF}_{25.75 \%}$ were also largest in the children from this group. In the children who met our criteria for asthma, the differences in lung function indices compared with children without asthma-related symptoms were even larger than in children with previously diagnosed asthma. The results of the comparisons for the children with shortness of breath during exercise $(n=56)$ and recent wheeze $(n=69)$ are not shown in Table 4, but they are comparable to the findings in the children with chronic cough. 


\section{DISCUSSION}

In this study we investigated the prevalence of asthma-related symptoms using a validated questionnaire completed by the parents of 482 primary school children and we found a symptom-based asthma prevalence of $11.2 \%$. Questionnaire studies of asthma may be flawed by low return rates. ${ }^{26}$ However, in the present study a response rate of $90 \%$ was achieved. In the 482 investigated primary school children, a high lifetime prevalence and period prevalence of asthma-related symptoms of $32 \%$ and $23 \%$, respectively, was found. In $6 \%$ of the children, a diagnosis of asthma had been made by a doctor. Of these children $69 \%$ used antiasthma medication. The doctordiagnosed prevalence of bronchitis was $19 \%$ and none of these children used antiasthma medication. Stratification of the data by age and gender revealed that the prevalence of the key symptoms and asthma and bronchitis diagnosed by a doctor was the highest among young boys (6-9 years).

The results of this study are in agreement with the statement that asthma in children is still underdiagnosed and undertreated. Based on the definition that reporting at least two of the key symptoms to include wheeze or attacks of shortness of breath with wheeze constitutes asthma, an estimated asthma prevalence of $11 \%$ is found, as opposed to a doctor-diagnosed asthma prevalence of $6 \%$. Furthermore, about onequarter of the bronchitis children meet our symptom-based criteria for asthma, which suggests that some of the children are misclassified. Diagnostic labeling by a doctor as either asthma or bronchitis apparently determines whether antiasthma medication is prescribed.

Table 5 gives an overview of recently reported national and international studies. In the Dutch studies children aged 6-12 years were investigated by means of the same ${ }^{16,17}$ or a comparable ${ }^{18}$ questionnaire. Overall, it appears that the prevalence of the key symptoms, especially for chronic cough (although this symptom has a moderate reproducibility) and bronchitis diagnosed by a doctor, is relatively high in our study. Comparing our data stratified by age, gender and (age + gender) with those of Rijcken, ${ }^{18}$ relatively high prevalence rates for all symptoms are found in our study. However, our study population may not be representative of the total country, and we realize that the sample size may be too small to draw firm conclusions. We emphasize that the present study was not aimed at detecting region-specific triggers of asthma nor to study the changes in asthma prevalence over time.

Compared with international rates, the prevalence of ever wheeze is somewhat higher than reported by athers, ${ }^{4,10,12,27,28}$ with the exception of the Melbourne study. ${ }^{14}$ The prevalence of wheeze in the previous year is, again with the exception of the Melbourne study, comparable. However, because of differences in methodology, manner of defining asthma, age range of the children (most studies did not report stratified results), and population selection, no further interpretation is possible. 
Table 5. Comparison of national prevalence studies on respiratory symptoms and asthma in children (ages 6.12 years) and international studies, varying ages.

\begin{tabular}{|c|c|c|c|c|c|c|c|}
\hline \multirow[b]{2}{*}{ Study (nationial) } & \multirow{2}{*}{$\begin{array}{l}\text { Chronic } \\
\text { cough }\end{array}$} & \multicolumn{2}{|c|}{ Whesze } & \multirow{2}{*}{$\begin{array}{l}\text { SOB } \\
\text { prew. yr }\end{array}$} & \multirow{2}{*}{$\begin{array}{l}\text { SoB twhe } \\
\text { prev yr }\end{array}$} & \multirow{2}{*}{$\begin{array}{l}\text { Diagnosed } \\
\text { Asthma }\end{array}$} & \multirow{2}{*}{$\begin{array}{l}\text { Diagnosed } \\
\text { Bronchitis }\end{array}$} \\
\hline & & ever & prew yr & & & & \\
\hline \multirow{5}{*}{ 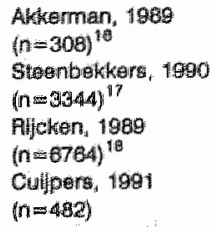 } & 5.7 & 200 & 94. & 10. & 0.1 & 4.6 & $15 \%$ \\
\hline & & & & & & & \\
\hline & 4.7 & 17.9 & 10.1 & 5.8 & 5.9 & 4.0 & 17.9 \\
\hline &., 4 & - & 9.6 & 3.8 & 5.6 & - & - \\
\hline & 13.1 & 29.3 & 14,9 & 12.2 & 9.5 & 5.8 & 22.4 \\
\hline & & \multicolumn{2}{|c|}{ Wherze } & & & Diagnosed & Age \\
\hline Intamational & Place & ever & prov. yr & & & Asthma & years \\
\hline \multicolumn{8}{|l|}{ Ninan, 1989} \\
\hline $\begin{array}{l}\text { Hilil, } 1989 \\
(\mathrm{~m}=\mathrm{m}, 3805)^{\circ} \\
\text { Johnston, } 1985\end{array}$ & Notungham & - & 11.5 & & & 5.9 & $5-11$ \\
\hline $\begin{array}{l}(n=7337)^{27} \\
\text { Burt, } 198.8\end{array}$ & S-West London & 17.0 & 15.0 & & & 5.0 & $5-13$ \\
\hline $\begin{array}{l}(\mathrm{n}=965)^{1.2} \\
\text { Seninhauser. } 1990\end{array}$ & South Wates & 22.3 & 15.2 & & & 12.0 & 12 \\
\hline $\begin{array}{l}(n=4156)^{26} \\
\text { Riobertison, }\end{array}$ & Scthweiz & 16.5 & 9.1 & & & 6.0 & $1-16$ \\
\hline 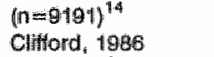 & Melboume & 37.7 & 21.1 & & & 23.1 & $7,12,15$ \\
\hline$(n \ln 2503)^{4}$ & Southampton: & 18.8 & 12.1 & & & 9.5 & $7-11$ \\
\hline
\end{tabular}

In the present study lung function measurements have been performed using an effortdependent (spirometry) and an effort-independent method (the technique of forced oscillations). Spirometry is the most widely accepted method for lung function measurements owing to its reproducibility, the ease with which the measurements are performed and interpreted, and its wide availability. In this study, the highest differences in spirometric indices between children with and children without asthma-related symptoms were found in PEF and in $\mathrm{FEF}_{25-75 \%}$. Application of the technique of forced oscillations is less common. The measurements are performed during spontaneous quiet breathing and can therefore be of special value in young children. The technique yields values for the total resistance and reactance of the respiratory system. The total resistance $\left(\mathrm{R}_{\mathrm{rs}}\right)$ comprises the resistance of the airways, the lungs, and the chest wall. The reactance $\left(X_{r s}\right)$ is determined by the inertial and capacitative properties of the respiratory system. In young children a decrease in $R_{r s}$ with increasing frequency is usually observed. ${ }^{29}$ This negative frequency dependence of resistance tends to disappear with age and growth and does not necessarily implicate pulmonary pathology. ${ }^{29-32}$ In adults negative frequency dependence of resistance (FD) is considered an abnormal finding ${ }^{33-35}$ and together with increased $\mathrm{A}_{\mathrm{rs}}$ and $\mathrm{t}_{\mathrm{p}}$ values, and decreased $X_{r s}$ values is considered a marker of airflow obstruction.

In the present study values for resistance and reactance were compared between groups of children with and without asthma-related symptoms, controlled for age, height, gender, and weight. It was observed that the indices from forced oscillation measurements are in all instances significantly different in children with compiaints, suggesting that this technique may have special value in epidemiological surveys such 
as the present study. The finding of significant differences in the various lung function indices used in this study between groups of children with and without complaints supports the relatively high prevalence rates of asthma-related symptoms in our study population. The lung function data also support our earlier statement that asthme is still underdiagnosed. Analysis of the children with the key symptoms suggestive of asthma shows that even larger abnormalities in lung hunction indices are found than in those children previously diagnosed as having asthma. This may partly be explained by use of antiasthma drugs in children diagnosed as having asthma, because we did not control for this in the analysis. However, the results are in agreement with those reported by Flach and Brunekreef ${ }^{36}$ who also studied the relationship between respiratory symptoms (measured by the WHO questionnaire) and lung function (measured by spirometry) in primary school children. They found that children with chronic cough, doctor-diagnosed asthma, and/or (attacks of shortness off breath with) wheeze had significantly lower lung function values than children without symptoms. Also, children in whom wheezing (but no doctor-diagnosed asthma) or attacks of shortness of breath with wheezing (but no doctor-diagnosed asthma) were reported, had significantly lower lung function values than control children. These findings also suggest underdiagnosis of asthma in these children.

From a study among a general practice population of 187 children diagnosed as having asthma since 1984, Jones and Sykes, ${ }^{37}$ reported that as many as $45 \%$ of the asthmatic children may have had "bronchitis" diagnosed and treated instead of asthma. These investigators therefore suggested that a repeated diagnosis of "bronchitis" merely detracts from underlying asthma. Furthermore, they found that asthma is more likely to be missed or labeled as bronchitis in children who cough repeatedly than in children who wheeze occasionally. This suggestion is supported by the findings of our study. Recent studies from the United Kingdom, ${ }^{10-13}$ Australia, $^{14}$ and the United States ${ }^{15}$ reported on a "real" increase (over time) in the prevallence of asthma, despite possible artifacts introduced by changes in recognition or labeling, which may reflect a more general change in the prevalence of atopy. Robertson et al. ${ }^{14}$ found a high prevalence of current respiratory symptoms suggestive of asthma and a large increase in the prevalence of a history of wheeze or asthma in 7-vear old Melbourne schoolchildren over the past 26 years. An intriguing finding of the study of Yunginger et al. ${ }^{15}$ was that the increase in asthma incidence rates seen from 1964 to 1983 in Rochester, Minnesota, occurred only in children and adolescents (1-14 year of age) and not in infants and adults, which emphasizes that asthma is a particular childhood problem. In summary, in this cross-sectional survey of asthma-related symptoms in 482 primary schoolchildren aged 6-12 years, an estimated asthma prevalence of $11 \%$ is calcullated. Definitive causes for this relatively high prevalence need to be established in future studies. In children with symptoms, lung function values measured by splrometry and forced oscillation technique differed significantly from those of children without complaints, especially in the children with key symptoms suggestive of asthma, including also children labeled as having bronchitis. Apparently this labeling has a major influence on the subsequent treatment of these children. From our data it can be concluded that underdiagnosis, misclassification and undertreatment of asthma are still common in these children. 


\section{ACKNOWLEDGEMENTS}

We thank all parents, children, and schools that participated in the study. We thank our colleagues Jos Slangen and Fons Kessels for their valuable contribution to the statistical analysis.

\section{APPENDIX}

Overview of the major questions from the questionnaire used in this report.

No. Question

(6) Did your child cough on most days, for at least 3 months a year?

(7) Has your child ever been troubled by shortness of breath when playing outside or climbing the stairs?

(8) Has your child been troubled by shortness of breath when playing outside or climbing the stairs, in the previous year?

(9) Has your child's chest ever sounded wheezy?

(10) Has your child's chest sounded wheezy, in the previous year?

(11) Has your child ever had attacks of shortness of breath with wheeze?

(12) Has your child had attacks of shortness of breath with wheeze, in the previous year?

(16) Has the child ever had asthma diagnosed by a doctor?

(18) Is your child at this moment using antiasthma medication?

(19) Has the child ever had bronchitis diagnosed by a doctor?

\section{REFERENCES}

1. Gregg I. Epidemiologic aspects. In: Asthma (2nd edn), eds. Clark TJH, Godfrey S. Chapman and Hall London 1983, 242-278.

2. American Thoracic Society (ATS). Standards for the diagnosis and care of patients with chronic obstructive pulmonary disease (COPD) and asthma, (chapter 2). ATS, november 1986.

3. Anderson HR. is the prevalence of asthma changing? Arch Dis Child 1989; 64: 172-175.

4. Clifford $\mathrm{AD}$, Fadford M, Howell JB, Holgate ST. Prevalence of respiratory symptoms among 7 and 11 year ofd schoolchildren and association with asthma. Arch Dis Child 1989; 64: 1118-1125.

5. Lee DA, Winslow NR, Speight ANP, Hey EN. Prevalence and spectrum of asthma in childhood. Br Med J 1983; 286: 1256-1258.

6. Williams $H$, MCNicol KN. Prevalence, natural history, and relationship of wheezy bronchitis and asthma in children. An epidemiological study. Br Med J 1969; $4: 321-325$.

7. Wilson NM. Wheezy bronchitis revisited (controwersy). Arch Dis Child 1989; 64: 1194-1 199.

8. Speight ANP, Lee DA, Hey EN. Underdiagnosis and undertreatment of asthma in childhood. Br Med $\ 1983 ; 286 ; 1253-1256$.

9. Hill RA, Standen P.d, Tattersfield AE. Asthma "Wheezing, and school absence in primary schools. Arch Dis Child 1989; 64: 246-251.

10. Ninan TK, Russell G. Respiratory symptoms and atopy in Aberdeen schoolchildren: evidence from two surveys 25 years apart. Br Med J 1992; 304: 873-875.

11. Burney PGJ, Chinn S, Rona RJ. Has the prevalence of asthma increased in children? Evidence from the national study of health and growth 1973-1986. Bir Med J 1990; 300: 1306-1310 
12. Burr $M L$, Butland $B K$, King $S$, Vaughan-Willams $E$. Changes in asthma prevalence: two surveys 15 years apart. Arch Dis Child 1989: 64: 1452-1456.

13. Fleming DM, Crombie DL. Prevalence of asthma and hay fever in England and Wales. Br Med $\mathrm{d}$ 1987; 294: 279-283.

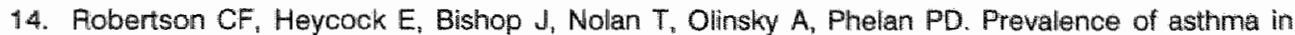
Melbourne schoolchildren: changes over 26 years. Br Med J 1991; 302: 111641118.

15. Yunginger JW, Reed CE, O'Connel EJ, Melton LJ, O'Fallon WM, Silverstein MD. A community-based study of the epidemiology of asthma. Incidence rates, 1964-1983. Am Rev Respir Dis 1992; 146: 888-894.

16. Akkerman I. Dijkstra L, Houthuijs D, Brunekreef, Biersteker K. Evaluation of a questionnaire on respiratory symptoms in children. I Reproducibility of the answers. T Soc Gezondheidsz 1989; 67: 183-187 (in Dutch).

17. Steenbekkers $A$, Boer de $A$, Brunekreef $B$, Hoek $G$, Aijcken $B$, Groot $B$. A comparison of two questionnaires on respiratory symptoms in children. I Comparison of the prevalences. $T$ Soc Gezondheidsz 1990; 68: 478-482 (in Dutch).

18. Rijcken $\mathbb{B}$. Two questionnaires on respiratory symptoms for epidemiological studies in the youth health service. T Soc Gezondheidsz 1989; 67: 271-274 (in Dutch).

19. Florey C. du V., Leeder SR. Methods for cohort studies of chronic airflow limitation. (chapter 3). WHO regional publications, European series No. 12. London, United Kingdom 1982; 112.

20. Brunekreef B, Groot B. Rijcken B, Hoek G, Steenbekkers A, Boer de A. Reproducibility of childhood respiratory symptom questions. Eur Respir J 1992; 5: 930-935.

21. Quanjer Ph.H. Standardized lungfunction testing. Bull Eur Physiopathol Resp 1983; 19(suppl. 5): $1-95$.

22. Làndisér $F J_{\text {g }}$ Nagels $J$, Demedis $M$, Billiet $L$, Woestijne van de KP. A new method to determine frequency characteristics of the respiratory system. J Appl Physiol 1976; 41: 101-106.

23. Wouters EFM, Lândsér FJ, Polko AH. Visser BF. Physiological analysis of extended spectrum oscillometry. Respiration 1988; 54: 263-270.

24. Dockery DW, Berkey CS, Ware JH, Speizer FE, Ferris BG, Jr. Distribution of FVC and FEV, in children 6 to 11 year of age. Am Rev Respir Dis 1983; 128: 405-412.

25. SPSSe Inc., 1990, 444n Michigan Avenue, Chicago, Illinois 60611.

26. Mark $H_{n}$, lohnston $P$, Abbey $H_{2}$ Talamo $R C$. Prevalence of asthma and health service utilization of asthmatic children in an inner city. J All Clin Immunol 1982; 70: 367-372.

27. Johnston IDA, Bland JM, Anderson $H_{R}$. Ethnic variation in respiratory morbidity and lung function in childhood. Thorax 1987; 42; 542-548.

28. Sennhauser FH, Güntert B. Prävalenz des asthma bronchiale im kindesalter in der Schweiz: Die bedeutung von symptomatik und diagnose. Schweiz med Wochenschr 1992; 122: 189-193.

29. Stanescu D. Moavero NE, Veriter C. Brasseur L. Frequency dependence of respiratory resistance in healthy children. J Appl Physiol 1979: 47: 268-272.

30. Clément J, Dumoulin B, Gubbelmans R, Hendriks KP. Woestijne van die KP. Peference values of total respiratory resistance and reactance between 4 and $26 \mathrm{~Hz}$ in children and adolescents eqged 4-20 years. Bull Eur Physiopathol Respir 1987; 23: 441-448.

31. Solymar $L$, Aronsson PH, Bake $B$, Bjure J. Respiratory resistance and impedance magnitude in healthy children aged 2-18 years. Pediatr Pulmonol 1985; 1: 134-140.

32. Cuijpers CEJ, Wesseling $G$, Swaen GMH, Wouters EFM. Frequency dependence ofl oscillatory resistance in healthy primary school children. Respiration 1993; 60: 149-154.

33. Clément $J$, Làndsér FJ, Woestijne van de KP. Total resistance and reactance in patients with respiratory complaints with and without airway obstruction. Chest 1983: B3: 215-220.

34. Cutillo $\mathrm{AG}$, Renzetti $\mathrm{AD}$. Mechanical behavior of the respiratory systerm as a function of frequency in health and disease. Bull Eur Physiopathol Respir 1983; 19: 293-326.

35. Làndsér $F J$, Clement $J$, Woestijne van de KP. Normal values of total respiratory resistance and reactance determined by forced oscillations. Influence of smoking. Chest 1982; 81: 586-591.

36. Flach $\mathrm{KC}$. Brunekreef $\mathrm{B}$. Respiratory symptoms and lung function in children aged 6 to 12 years. T Soc Gezondheidsz 1991; 69: 159-164 (in Dutch).

37. Jones A, Sykes A. The effect of symptom presentation on delay in asthma diagnosis in children in general practice. Respir Med 1990; 84: 139-142. 



\section{Chapter 5}

\section{ADVERSE EFFECTS OF THE INDOOR ENVIRONMENT ON RESPIRATORY HEALTH IN PRIMARY SCHOOL CHILDREN}

CEJ Cuijpers, GMH Swaen, GJ Wesseling, F Sturmans, EFM Wouters 


\section{ADVERSE EFFECTS OF THE INDOOR ENVIRONMENT ON RESPIRATORY HEALTH IN PRIMARY SCHOOL CHILDREN}

\section{ABSTRACT}

Exposure to various factors from the indoor environment on respiratory health of 470 Dutch primary school children was studied. We investigated which of the factors, such as hame dampness, passive smoking, unvented kitchen geysers, or pets, affected children's respiratory health the most, and whether airway sensitivity to these indoor exposures differed between boys and girls. Information on respiratory morbidity and characteristics of the housing was obtained by a written questioninaire, completed by the parents of the children. Lung function of the children was measured at school, by forced oscillation technique (FOT) and spirometry.

In boys, all investigated lung function parameters were significantly affected by exposure to passive smoking during the child's entire life. Although mostly nonsignificant, all of the reported asthma-like symptoms were related especially to maternal smoking, with a trend of a dose-response relationship. Furthermore, damp stains $(p<0.05)$ and mould growth (n.s.) were associated with chronic cough and with small, but significant impairments in part of the lung function parameters. No consistent patterns were observed with unvented kitchen geysers and pets. Although passive smoking (cumulative dose) in girls was also associated with lung function impairments, the effects were smaller than those in boys and not all significant. Associations between the asthma-like symptoms and the dose of maternal and paternal smoking also were less consistent. Furthermore, no associations were found with the dampness indicators and with pets, but unvented kitchen geysers were significantly related to impairments in some of the impedance indices.

This study shows detrimental effects of several indoor factors on the prevalence of chronic respiratory symptoms and lung function in children, which are most pronounced for passive smoking, and somewhat less pronounced for dampness and the presence of unvented kitchen geysers. Airway sensitivity to these exposures appeared to be higher in boys than in girls. 


\section{INTRODUCTION}

Public concern over health effects of the indoor environment has arisen, since it has been recognized that most people spend $75-90 \%$ (or even more) of their lives indoors. ${ }^{1}$ Since World War II, the number of potential sources for indoor air pollution has increased whereas for energy saving reasons the level of ventilation has decreased. There has been a shift in attention for potential health effects from outdoor air to indoor air. Hitherto, interest has mainly been focused on the potential hazards of tobacco smoke, home dampness, humidiffer use, and nitrogen dioxide $\left(\mathrm{NO}_{2}\right)$, mainly produced by combustion appliances. Exposure to these indoor factors has been associated with an increased prevalence of respiratory and other symptoms in children ${ }^{2-10}$ and adults ${ }^{7,11.12}$, although the evidence for passive smoking (in respect to effects on lung function) and $\mathrm{NO}_{2}$ (in general) is somewhat inconsistent. ${ }^{13.14}$ Some investigators have reported that airway sensitivity to passive smoking is higher in girls, ${ }^{15-17}$ whereas others have found that boys are more susceptible. ${ }^{18-21}$ In general, the effects were more consistent with maternal than with paternal or parental smoking. A recent study has suggested that when asthmatic children are exposed to less cigarette smoke the asthma will be less severe, manifested by an improvement in lung function as determined by spirometry and less reported wheeze and medication use. ${ }^{22}$ Information about indoor factors and the occurrence of (respiratory) symptoms is generally obtained by means of a (written) questionnaire. Because of the subjective mature of questionnaire reporting, observed associations between the presence of indoor factors and the occurrence of symptoms must be considered to be prone to reporting bias. Therefore objective measures of exposure and effect must be developed and used. ${ }^{23}$ By now, several studies have been conducted in which the exposure measurement and/or the effect outcome has been objectively determined. $4 \cdot 7,11,23,24$ In some of these studies, which mainly addressed the effects of home dampness (mould) on respiratory health in children, conflicting results were found in that reported respiratory symptoms appeared to be related to dampness whereas (most of) the lung function data were not. ${ }^{4,5,23}$ Whether this discrepancy is caused by the occurrence of reporting bias in the questionnaire data or that the selected lung function technique was an invalid method to determine the effects of damp housing is not clear.

The present paper describes a cross-sectional study on the association between respiratory morbidity and changes in lung function, and various aspects of the home environment, among 470 Dutch primary school children. The prevalence of respiratory symptoms and information on the indoor environment were determined by means of a written questionnaire. Lung function was measured by spirometry and by the forced oscillation technique (FOT). The FOT allows the characterization of the mechanical properties of the respiratory system. This technique is rapid and demands only passive cooperation which makes it especially suited for use in children and in epidemiological studies. The FOT has been used in many studies in children, ${ }^{25,26}$ adults $^{27-30}$ and animals. ${ }^{31}$ We investigated which of the indoor factors (passive smoking, home dampness, unvented kitchen geysers, and pets) were most obviously related to respiratory symptoms or lung function impairments, and whether differences in susceptibility, between boys and girls, existed. 


\section{METHODS}

\section{Population}

The study population consisted of 535 children 6 to 12 years of age. The children were recruited from two primary schools located in Maastricht. Written informed consent was obtained from the parents for each participating child. The study was approved by the local medical ethics committee.

\section{The Questionnaire}

Information on the presence of indoor environmental factors and the prevalence of chronic respiratory symptoms was evaluated by means of a written questionnaire, completed by the parents of the children. The questionnaire is a Dutch version of the children's questionnaire of the World Health Organization by Florey and Leeder. ${ }^{32,33}$ In addition to the occurrence of respiratory symptoms, the parents were asked about age and gender of the child, medical consumption, family history, smoking habits of persons inside the house, domestic animals, presence of indoor nitrogen dioxide sources (gas appliances), home dampness and other home characteristics, as well as their education level. In this report the questionnaire data will be reported only partially. Four key symptoms for current asthma were chosen as outcome variables (chronic cough, shortness of breath, wheeze and attacks of shortness of breath with wheeze, reported in the previous twelve months). The indoor exposure variables selected were the presence of damp stains, mould growth, passive smoking by the father, mother, or other house-mates, unvented kitchen geysers (geysers, gas-heated hot-water supplies, without flue, located in the kitchen, an important source of nitrogen dioxide in Dutch homes) and the presence of pets (cat, dog, birds, and rodents). The major questions discussed in this report are given in the Appendix.

The parents who agreed to participate in the study received the questionnaire by mail, and mailed it back after completion.

\section{Lung Function Measurements}

- Spirometry. The lung function measurements were taken at school during school hours by trained technicians. Weight and height of the children were measured at the time of the pulmonary function test. Spirometry was performed according to the ECCSprotocol, ${ }^{34}$ with the exception that for each child five instead of three acceptable manoeuvres had to be collected out of a maximum of eight attempts, using a dry spirometer (Vitalograph Ltd., Buckingham, England), with the child standing. From the valid manoeuvres the highest values for the forced vital capacity (FVC), the forced expiratory volume in one second $\left(F E V_{1}\right)$ and peak expiratory flow (PEF) were selected. The forced expiratory flow between 25 and $75 \%$ of the vital capacity $\left(\mathrm{FEF}_{25-75 \%}\right)$ was selected from the curve with the highest sum value for FVC and FEV ${ }_{t}{ }^{34}$

- Forced Oscillation Technique. The technique of forced oscillations (FOT) used in this study was similar to the method described by Landser et al. ${ }^{35}$ The measurements were performed during spontaneous quiet breathing and enable the assessment of mechanical characteristics of the respiratory system. The technique, extensively described previously, ${ }^{36,37}$ yields values for the total resistance and reactance of the respiratory system. Measurements are made using a pseudo-random noise signal, consisting of sinusoidal pressure oscillations containing all harmonics of 4 to $52 \mathrm{~Hz}$, 
applied by a loudspeaker at the mouth. All measurements were performed with the child seated, wearing a nose clip and the cheeks and the floor of the mouth being supported with the hands of either the investigator or the child itself. Each child performed at least three valid impedance measurements. To evaluate the accuracy of the measurement a coherence function is estimated at each frequency. This indicates the amount of noise generated by the child's spontaneous breathing, present in the measured signals. In the present study impedance measurements with coherence values $<0.95$ at $8,28 \mathrm{~Hz}$ or at more than three frequencies were rejected. Làndsér et al. ${ }^{38}$ demonstrated that for measurements with a coherence function exceeding 0.95 the error of the measurement due to the presence of noise or noniinearities is less than $10 \%$.

The total resistance $\left(\mathrm{R}_{\mathrm{rs}}\right)$ comprises the resistance of the airways, the lungs, and the chest wall. The reactance $\left(X_{r s}\right)$ is determined by the inertial and capacitative properties of the respiratory system. In normal aduits, resistance values increase slightly with increasing frequency. Reactance is usually negative at lower frequencies and becomes positive at frequencies between 5 and $10 \mathrm{~Hz}$ (resonant frequency, $\mathrm{f}_{0}$ ). In the presence of airway obstruction there is a large increase in resistance values especially at low frequencies, which decreases with increasing frequency (negative frequency dependence of resistance, FD). Reactance values are more negative and resonant frequency is increased in patients with airflow obstruction. ${ }^{29}$ These observations can be explained by a high peripheral resistance in parallel with the compliance of the airways. ${ }^{28}$ In cases of high peripheral resistance, the resonant frequency is determined predominantly by airway compliance and inertia. ${ }^{28}$ In healthy children negative frequency dependence of resistance, between $8-28 \mathrm{~Hz}$, is a common finding which progressively decreases during growth, advancing the values found in healthy adults. $37,39,40$ For the present report the mean values for the resistance and the reactance at $8 \mathrm{~Hz}\left(\mathrm{R}_{\mathrm{rs}}, \mathrm{X}_{\mathrm{rs} 8}\right)$, the frequency dependence of resistance (FD) defined as the difference between the resistance at $28 \mathrm{~Hz}\left(R_{\mathrm{rs} 28}\right)$ and $R_{\mathrm{rs} 8}$ divided by 20 , and the resonant frequency ( $f_{0}$, the frequency at which $X_{r s}=0$ ), were used. If exposure to the investigated indoor factors results in adverse effects on respiratory impedance, one would expect an increase in resistance and in resonant frequency, more negative reactance values and negative frequency dependence of resistance, reflecting airflow obstruction. ${ }^{28,29}$

\section{Anailyses}

The four key symptoms for current asthma were used as outcome variables. For damp housing, the items 'damp stains' and 'mould growth', in the past 2 years, were evaluated independently (see Appendix).

First, simple cross-tabulation was used to estimate unadjusted odds ratios for the key symptoms for asthma associaled with exposure to mould growth or damp stains and the other indoor factors; passive smoking, unvented kitchen geysers, and pets. Next, adjusted odds ratios for the key symptoms associated with the indoor factors were estimated, using multiple logistic regression. The models contained the independent variables age, gender, damp stains or mould growth (both were investigated independently), (parental) smoking, the presence of unvented kitchen geysers (nitrogen dioxide source) and education level of the father. To investigate differences in susceptibility between boys and girls, the analyses were performed by gender.

Parental smoking was evaluated in three independent ways; first the total number of smokes (cigarettes +cigars + pipes)/day inside the home (father+mother+other(s)), 
divided into three categories, less than 11 , from 11 to 20 , and more than 20 . Each group was compared to the "no smoking' group. Second, the amount of maternal and paternal smoking was separated (same categorization). Third, the number of years smoked by the father or the mother (during the child's life), in "years of passive smoking' (cumulative exposure), was divided by the child's age, resulting in three categories: less than 0.10 no passive smoking, $0.10-0.95$ part of their life passive smoking, greater than 0.95 during their entire life passive smoking. The education level of the father as obtained by questionnaire, was categorized from eight possible education levels into two groups: a low and a high level group.

Finally, exposure to the indoor factors damp stains or mould growth, passive smoking (only the cumulative dose), unvented kitchen geysers, and pets were related to the spirometry and impedance data, by means of multiple linear regression, first for the total group and thereafter the analysis was performed by gender. The models also contained the variables height, age, gender, and education level of the father. According to Dockery et al. ${ }^{41}$ spirometric variables, height, age, and weight were Intransformed before analysis, to normalize the residuals. No log transformation was carried out for the impedance variables because parts of these data have negative values. Consequently, the effects on spirometry were expressed as the percentage difference in lung function between 'exposed' and 'nonexposed' children, whereas the effects on respiratory impedance were expressed as absolute differences (in $\mathrm{cmH}_{2} \mathrm{O} /(\mathrm{L} / \mathrm{s})$ or $\left.\mathrm{Hz}\right)$. For the analysis the SPSS-X statistical package was used. ${ }^{42}$

\section{RESULTS}

Of 470 children ( $88 \%$ ) a combination of two sets of valid lung function data, spirometry and impedance, and a completed questionnaire is available. The age distribution for the 222 boys and 248 girls was comparable. Prevalence rates (in the previous year) of the key symptoms suggestive for asthma, were between 9 and $15 \%$, and except for wheeze 1.4 to 1.9 times higher in boys than in girls (Table 1).

Table 1. Prevalence of the key symptorns of asthma in the previous year, in all 470 investigated children, and for boys $(n=222)$ and girls $(n=248)$ separately.

\begin{tabular}{|c|c|c|c|c|c|c|}
\hline \multirow[t]{2}{*}{ Asthma symptoms } & \multicolumn{2}{|c|}{ Total group } & \multicolumn{2}{|c|}{ Boys } & \multicolumn{2}{|c|}{ Girls } \\
\hline & $\mathrm{n}$ & $\%$ & m & $\%$ & n & $\%$ \\
\hline Chronic cough & 59 & 12.6 & 33 & 14.9 & 26 & 10.5 \\
\hline Shortness of breath & 56 & 11.9 & 35 & 15.8 & 21 & 8.5 \\
\hline Wheere & 69 & 14.7 & 33 & 14.9 & 36 & 14.5 \\
\hline Attacks of $\mathrm{SOB}+$ whereze & 42 & 8.9 & 26 & 11.7 & 16 & 6.5 \\
\hline Free of symptoms & 360 & 76.6 & 165 & 74.3 & 195 & 78.6 \\
\hline
\end{tabular}

* Defined as cough on most days for at least three months a year. $\mathrm{SOB}=$ shortness of breath

Three hundred sixty (77\%) children were free from these symptoms, of them 165 were boys and 195 were girls. Visible damp stains and mould growth are reported in 148 
(31.5\%) and $110(23.4 \%)$ cases respectively. A breakdown by the four different response categories can be seen in Table 2 .

Table 2. Frequencies of the indoor factors damp stains, mould growth, unvented kitchen geysers, dogs and parental smoking, in the homes of the 470 investigated children.

\begin{tabular}{lrc}
\hline Indoor factor & $n$ & $\%$ \\
\hline Damp stains: & 321 & 68.3 \\
never & 90 & 19.1 \\
sometimes & 28 & 6.0 \\
often & 30 & 6.4 \\
always & & \\
Mould growth: & 358 & 76.2 \\
never & 67 & 14.3 \\
sometimes & 16 & 3.4 \\
often & 27 & 5.7 \\
always & 94 & $20.0 *$ \\
Damp + mould & 56 & 11.9 \\
Unvented kitchen geyser & 85 & 18.1 \\
Cats & 143 & 30.4 \\
Dogs & 192 & 40.9 \\
Birds & 165 & 35.1 \\
Rodents & & \\
Malternal smoking: & 267 & 56.8 \\
never smoked & 83 & 17.7 \\
O-10 smokes/day & 86 & 18.3 \\
11-20 smokes/day & 14 & 3.0 \\
> 20 smokes/day & 20 & 4.3 \\
missing & & \\
Paternal smoking: & 249 & 53.0 \\
never smoked & 111 & 23.6 \\
0-10 smokes/day & 47 & 10.0 \\
11-20 smokes/day & 13 & 2.8 \\
> 20 smokes/day & 50 & 10.6 \\
missing & & \\
\hline
\end{tabular}

* All possible combinations

a Meant are geysers (gas-heated hot-water supplies) without flue, located in the kitchen

A combination of damp stains and mould growth was reported in 94 (20\%) cases. Unvented kitchen geysers were present in $12 \%$ of the respondent families and a dog in $30 \%$ of the families. Of the mothers $183(38.9 \%)$ were smokers, and of the fathers $171(36.4 \%)$ were smokers, the distribution over the three smoking categories $(>0$, $11-20$, and $<1$ ) is given in Table 2. The information on smoking habits for $50(10.6 \%)$ fathers was missing in contrast to that for $20(4.3 \%)$ of the mothers.

The unadjusted odds ratios indicated a relationship between (one or more of the) respiratory symptoms and damp stains, mould growth, parental smoking habits, the presence of a dog and unvented kitchen geysers (data not presented). The outcomes of the multiple logistic regression analysis, by gender, resulting in the adjusted odds ratios, are presented in Table 3a for boys and $3 \mathrm{~b}$ for girls. As mentioned in the analysis part, damp stains and mould growth were evaluated separately, which resulted in two 
different regression models, per gender; one containing damp stains and one model containing mould growth, in addition to the factors passive smoking, unvented kitchen geysers, pets and education level of the father. The OR's for passive smoking, unvented kitchen geysers, pets, and education level of the father differed only slightly between both models, therefore, for these factors only the OR's resulting from the model containing damp stains are presented. For damp stains there were almost no difference between the categories 'sometimes', 'often' and 'always', therefore these were combined and compared to the 'never' category.

Table 3A. Flesults of the Multiple Logistic Regression Analysis in Boys.

\begin{tabular}{|c|c|c|c|c|c|c|c|c|}
\hline \multirow[b]{2}{*}{ Indoor factor } & \multicolumn{2}{|c|}{$\begin{array}{l}\text { Chronic cough } \\
(n=33)\end{array}$} & \multicolumn{2}{|c|}{$\begin{array}{l}\text { Shortness of } \\
\text { breath }(n=35)\end{array}$} & \multicolumn{2}{|c|}{$\begin{array}{l}\text { Wheeze } \\
(n=33)\end{array}$} & \multicolumn{2}{|c|}{$\begin{array}{l}\text { Attack of } S O B+ \\
\text { wheeze }(n=26)\end{array}$} \\
\hline & O.R. & $\mathrm{C} . \mathrm{l}$ & O.R. & C.l. & O.R. & C.I. & O.R. & C.I. \\
\hline \multicolumn{9}{|l|}{ Passive smoking (T): } \\
\hline$<11$ smakes/day & 0.97 & $0.30 / 3.14$ & $\sqrt[1]{1.04}$ & $0.35 / 3.13$ & 1.04 & $0.35 / 3.07$ & 1.62 & $0.50 / 5.23$ \\
\hline $11-20$ smokes/day & 1.61 & $0.50 / 5.17$ & 2.70 & $1.07 / 6.77^{*}$ & 1.76 & $0.56 / 5.54$ & 2.04 & $0.55 / 7.51$ \\
\hline$>20$ smokes/day & 1.65 & $0.55 / 4.91$ & 1.72 & $0.58 / 5.09$ & 0.72 & $0.21 / 4.86$ & 1.60 & $0.45 / 5.72$ \\
\hline \multicolumn{9}{|l|}{ Passive smoking: } \\
\hline Whole life & 1,96 & $0.60 / 6.44$ & 4.04 & $1.21 / 13.45^{*}$ & 1.09 & $0.34 / 3.49$ & 1.40 & $0.40 / 4.86$ \\
\hline Part of their life & $1 . \| 11$ & $0.38 / 3.25$ & 1.64 & $0.54 / 5.04$ & 0.58 & $0.19 / 1.73$ & 0.60 & $0.18 / 2.02$ \\
\hline Damp slains (yes/mo) & 3.01 & $1.31 / 6.92^{*}$ & 0.81 & $0.34 / 1.92$ & 0.56 & $0.22 / 1.44$ & 0.32 & $0.10 / 4.0 \|^{*}$ * \\
\hline $\begin{array}{l}\text { Unvented kitchen geyse } \\
9.48\end{array}$ & & 1.700 .591 & 4.88 & $2.18 \quad 0.731$ & 6.50 & $1.860 .56 /$ & 6.14 & $2.430 .63 /$ \\
\hline Dog & 1.48 & $0.61 / 3.63$ & 0.99 & $0.40 / 2.44$ & 1.23 & $0.48 / 3.15$ & 1.78 & $0.65 / 4.92$ \\
\hline $\begin{array}{l}\text { Education level }(F) \\
\text { (low ws high) }\end{array}$ & 1.06 & $0.45 / 2.49$ & 0.57 & $0.24 / 1.38$ & 0,48 & $0.18 / 1.23$ & 0.34 & $0.11 / 1.05^{*}$ \\
\hline Age 5-7 ws $10+$ & 1.29 & $0.7 / / 2.34$ & 0.87 & $0.51 / 1.51$ & 0.76 & $0.43 / 1.34$ & 0.82 & $0.44 / 1.53$ \\
\hline $5-7$ w5 8-9 & 1.04 & $0.59 / 1.83$ & 0.96 & $0.56 / 1.66$ & 0.84 & $0.48 / 1.48$ & 0.92 & $0.50 / 1.69$ \\
\hline \multicolumn{9}{|l|}{ Mould growth: } \\
\hline always & 3.36 & $0.80 / 14.10$ & 2.26 & $0.54 / 9.49$ & 0.95 & $0.16 / 5.46$ & 1.23 & $0.20 / 7.51$ \\
\hline oftem & 1.59 & $0.28 / 9.11$ & 0.41 & $0.04 / 3.76$ & 0.46 & $0.05 / 4.47$ & - & \\
\hline sometimes & 2.26 & $0.83 / 6.15$ & 0.99 & $0.32 / 3.01$ & 0.50 & $0.13 / 1.89$ & 0.43 & $0.09 / 2.07$ \\
\hline
\end{tabular}

Note. The presented adjusted odds ratios all come from the regression model containing damp stains, except for mould growth for which the OR comes from the regression madel containing mould growth instead of damp stain.

\# $=\mathrm{p} \leq 0.10(90 \% \mathrm{C} . \mathrm{l})$

$*=p \leq 0.05(95 \%$ C.I.)

$*=$ the OR was near zero; empty cells 
Table 3B. Results of the Multiple Logistic Regression Analysis in Girls.

\begin{tabular}{|c|c|c|c|c|c|c|c|c|}
\hline \multirow[b]{2}{*}{ Indoor factor } & \multicolumn{2}{|c|}{$\begin{array}{l}\text { Chronic cough } \\
(n=26)\end{array}$} & \multicolumn{2}{|c|}{$\begin{array}{l}\text { Shortness of } \\
\text { breath }(n=21)\end{array}$} & \multicolumn{2}{|c|}{$\begin{array}{l}\text { Whereze } \\
(n=36)\end{array}$} & \multicolumn{2}{|c|}{$\begin{array}{l}\text { Aittack of } \mathrm{SOB}+ \\
\text { wheeze }(n=16)\end{array}$} \\
\hline & O.R. & C.l. & O.R. & C.l. & O.R. & C.ll. & O.R. & C.ll. \\
\hline \multicolumn{9}{|l|}{ Passive smoking $(T)$ : } \\
\hline$<11$ smokes/day & 0.80 & $0.22 / 2.93$ & 1.88 & $0.54 / 6.58$ & 1.62 & $0.62 / 4.25$ & 3.23 & $0.79 / 13.17$ \\
\hline $11-20$ smokes/day & 0.84 & $0.26 / 2.74$ & 1.24 & $0.34 / 4.58$ & 0.49 & $0.14 / 1.66$ & 1.24 & $0.26 / 5.99$ \\
\hline$>20$ smokes/day & 0.81 & $0.19 / 3.39$ & 0.35 & $0.04 / 3.13$ & 0.92 & $0.27 / 3.21$ & - & -7 \\
\hline \multicolumn{9}{|l|}{ Passive smoking: } \\
\hline Whole life & 1.30 & $0.41 / 4.12$ & 1.58 & $0.41 / 6.13$ & 0.91 & $0.34 / 2.40$ & 0.95 & $0.19 / 4.86$ \\
\hline Part of their life & 0.70 & $0.20 / 2.44$ & 1.78 & $0.44 / 7.18$ & 0.86 & $0.32 / 2.34$ & 1.42 & $0.30 / 6.78$ \\
\hline Damp stains (yes/mo) & 1.41 & $0.52 / 3.83$ & 0.87 & $0.25 / 2.95$ & 1.48 & $0.62 / 3.54$ & 0.90 & $0.21 / 3.88$ \\
\hline \multicolumn{2}{|c|}{$\begin{array}{l}\text { Unvented kitchen geyser } \\
6.42\end{array}$} & $1.910 .57 /$ & 6.35 & 0.880 .171 & 4.70 & $2.831 .13 /$ & $7.07^{* x^{4}}$ & $1.08 \quad 0.18$ \\
\hline $\operatorname{Dog}$ & 1.26 & $0.47 / 3.36$ & 1.15 & $0.38 / 3.47$ & 1.32 & $0.54 / 3.21$ & 2.12 & $0.61 / 7.36$ \\
\hline $\begin{array}{l}\text { Education level (F) } \\
\text { (low ws high) }\end{array}$ & 3.80 & $1.43 / 10.14 *$ & 1.68 & $0.56 / 5.06$ & 0.73 & $0.29 / 1.83$ & 3.54 & $1.48 / 10.58^{*}$ \\
\hline Age 5-7 ws $10+$ & 1.32 & $0.71 / 2.47$ & - & $-\neq$ & 0.92 & $0.53 / 1.59$ & 0.92 & $0.35 / 2.42$ \\
\hline $5-7$ ws $8-9$ & 1.27 & $0.65 / 2.48$ & - & -+ & 0.71 & $0.40 / 1.25$ & 0.40 & $0.16 / 0.97^{k}$ \\
\hline \multicolumn{9}{|l|}{ Mould growth: } \\
\hline always & 0.79 & $0.07 / 8.34$ & - & $-\ddagger$ & 2.69 & $0.48 / 15.21$ & - & $-^{+}$ \\
\hline often & - & $-\#$ & 1.93 & $0.16 / 22.74$ & 0.79 & $0.06 / 10.66$ & - & $-\frac{}{+1}$ \\
\hline sometimes & 0.21 & $0.03 / 1.79$ & 0.81 & $0.16 / 4.13$ & 0.54 & $0.14 / 2.11$ & 0.44 & $0.05 / 4.36$ \\
\hline
\end{tabular}

Note. The presented adjusted odds ratios all come from the regression model containing damp stains, except for mould growth for which the OR comes from the regression model containing mould growth instead of damp stain.

* $=p \leq 0.10(90 \%$ C.I.)

$=p \leq 0.05(95 \%$ C.I.)

\# = the OR was near zero; empty cells

Considering the adjusted data of the overall sample (not presented), indications for an association were similar as with the crude OR's. However, clear patterns between the key symptoms and the indoor exposures were difficult to detect. The results changed markedly by doing the analysis by gender. Therefore, further presentation of the data will be focused on the results for boys and girls separately.

In boys (Table 3a) damp stains were significantly related to chronic cough $(\mathrm{O}=3.01$, $\mathrm{p}<0.05)$, but not to the other key symploms. For the mould growth categories OA's also were larger than 1, with chronic cough (ns), but not with the other symptoms. Elewated $(>1)$, but nonsignificant, OR's were found for unvented kitchen geysers with all key symptoms. The presence of a dog seemed to be associated, nonsignificant: with attacks of shortness of breath with wheeze and with chronic cough. Attacks of shortness of breath with wheeze were reported significantly more often in boys with a father in the higher education level category. Passive smoking, expressed as the total number of smokes, smoked by father + mother + other(s), per day inside the house, 
was related to most of the key symptoms, except to wheeze, with a trend of a doseresponse relationship. When the effects of maternal and paternal smoking were studied separately, the associations with the key symptoms were most obvious, and suggestive for a dose-response relation, with maternal smoking, whereas the results with paternal smoking were less consistent (Table 4a). However, it needs to be mentioned that subgroups became relatively small (especially in the heavily simoking category $>20$ smokes/day) and most of the associations were non-significant (wide confidence intervals). Passive smoking (undifferentiated) during the boy's entire life (cumulative dose) was related to all key symptoms, except to wheeze. Passive smoking during a part of the boy"s life was associated with shortness of breath, only.

Tabie AA. Pesults of the Multiple Logistic Regression Analysis in Boys.

\begin{tabular}{|c|c|c|c|c|c|c|c|c|}
\hline \multirow[b]{2}{*}{ Indoor factor } & \multicolumn{2}{|c|}{$\begin{array}{l}\text { Chronic cough } \\
(n=33)\end{array}$} & \multicolumn{2}{|c|}{$\begin{array}{l}\text { Shortness of } \\
\text { breath }(n=35)\end{array}$} & \multicolumn{2}{|c|}{$\begin{array}{l}\text { Wheeze } \\
(n=33)\end{array}$} & \multicolumn{2}{|c|}{$\begin{array}{l}\text { Attack of } S O B+ \\
\text { wheeze }(n=26)\end{array}$} \\
\hline & O.R. & C.1. & OR. & C.I. & O.R. & C.l. & O.R. & C.I. \\
\hline \multicolumn{9}{|l|}{ Maternal smoking (D): } \\
\hline$<11$ smokes/day & 1.37 & $0.47 / 4.04$ & 1.61 & $0.58 / 4.50$ & 1.39 & $0.48 / 4.04$ & 1.36 & $0.42 / 4.44$ \\
\hline $11-20$ smokes/day & 2.55 & $1.03 / 6.34^{H}$ & 2.80 & $1.13 / 6.95^{*}$ & 1.49 & $0.48 / 4.67$ & 3.21 & $1,45 / 8.99^{\prime}$ \\
\hline$>20$ smokes/day & 1.54 & $0.24 / 9.82$ & 4.58 & $1.19 / 17.65^{*}$ & 1.41 & $0.15 / 13.46$ & 2.11 & $0.20 \times 22.02$ \\
\hline \multicolumn{9}{|l|}{ Paternal smoking: } \\
\hline$<11$ smokes/day & 1.56 & $0.62 / 3.88$ & 1.14 & $0.48 / 2.70$ & 1.27 & & 1.64 & $0.60 / 4.46$ \\
\hline 11-20 smokes/day & 1.47 & $0.39 / 5.47$ & 0.48 & $0.10 / 2.36$ & 0.44 & $0.09 / 2.22$ & 1.62 & $0.42 / 6.29$ \\
\hline$>20$ smokes/day & 0.70 & $0.06 / 9.00$ & 1.82 & $0.14 / 23.96$ & 3.05 & $0.22 / 42.06$ & - & -+ \\
\hline
\end{tabular}

Note. Maternal and paternal smoking were analyzed separately, with presented OAs resulting from the logistic model containing damp stains.

Table 4B. Results of the Multiple Logistic Regression Analysis in Girls.

\begin{tabular}{|c|c|c|c|c|c|c|c|c|}
\hline \multirow[b]{2}{*}{ Indoor lactor } & \multicolumn{2}{|c|}{$\begin{array}{l}\text { Chronic cough } \\
(n=26)\end{array}$} & \multicolumn{2}{|c|}{$\begin{array}{l}\text { Shortness of } \\
\text { breath }(n=21)\end{array}$} & \multicolumn{2}{|c|}{$\begin{array}{l}\text { Wheeze } \\
(n=36)\end{array}$} & \multicolumn{2}{|c|}{$\begin{array}{l}\text { Attack of SOB }+ \\
\text { wheeze }(n=16)\end{array}$} \\
\hline & D.A. & C.l. & O.A. & C.I. & O.R. & C.I & O.R. & C.1. \\
\hline \multicolumn{9}{|l|}{ Maternal smoking: } \\
\hline$<11$ smokes day & 0,78 & $0.22 / 2.79$ & 1.15 & $0.33 / 4.01$ & 1.32 & $0.49 / 3.53$ & 1.92 & $0.50 / 7.46$ \\
\hline 11-20 smokes/day & 0.70 & $0.20 / 2.44$ & 0.23 & $0.03 / 1.90$ & 0.42 & $0.11 / 1.53$ & 0.22 & $0.02 / 2.03$ \\
\hline - 20 smokes/day & - & $-\omega^{*}$ & 3.76 & $0.25 / 57.63$ & 6.86 & $0.49 / 95.80$ & - & $-{ }^{+}$ \\
\hline \multicolumn{9}{|l|}{ Paternal smoking: } \\
\hline$<11$ smokes/day & 1.06 & $0.07 / 6.68$ & 2.85 & $1.10 / 7.35^{*}$ & 0.97 & $0.37 / 2.54$ & 1.41 & $0.38 / 5.31$ \\
\hline 11-20 smokes/day & 1.30 & $0.26 / 6.64$ & 0.93 & $0.10 / 8.26$ & 0.88 & $0.18 / 4.37$ & 0.71 & $0.07 / 6.75$ \\
\hline$>20$ smokesiday & 0.79 & $0.07 / 6.68$ & 1.53 & $0.16 / 15.11$ & 2.37 & $0.50 / 11.26$ & - & $-*$ \\
\hline
\end{tabular}

Note. Maternal and paternal smoking were analyzed separately, with presented ORs resulting from the logistic model containing damp stains.

$=0 \leq 0.10$ (90\% C.l.)

* = the OR was near zero; empty cells 
In girls (Table $3 b$ ) no significant associations were observed for damp stains with one of the key symptoms, although for chronic cough and wheeze the OR was larger than 1 ( 1.41 and 1.48 , respectively). Also no clear pattern was observed for mould growth and the key symptoms, due to the small numbers the OR was near zero in several mould categories. For unvented kitchen geysers a significant association was found with wheeze $(\mathrm{OR}=2.83, p<0.10)$ and a nonsignificant association with chronic cough $(O R=1.91)$. The presence of a dog was related to attacks of shortness of breath with wheeze, only $(O R=2.12, n s)$. For a low education level of the father significant associations were found with chronic cough $(O R=3.80, p<0.05)$ and attacks of shortness of breath with wheeze $(O R=3.45, p<0.10)$, and nonsignificant with shortness of breath (OR=1.68). For passive smoking (total number of smokes inside the house) less consistent associations were observed than in boys. Smoking less than 10 smokes/day appeared to be associated (nonsignificant) with shortness of breath, wheeze, and attacks of shortness of breath with wheeze. However, in the higher smoking categories no clear associations were found. Even after separating the effect of maternal and paternall smoking, no clear patterns could be observed (Table 4b). Like in boys, groups became small, confidence intervals wide, and in some instances OR's were near zero. The associations for passive smoking expressed as a cumulative dose also were less consistent than in boys, since only the OR of chronic cough $(O R=1.30)$ and of shortness of breath $(O R=1.58)$ exceeded 1 (nonsignificant). The results of the linear regression analysis for spirometry are summarized in Table 5A for boys, and in Table 5B for girls, and for respiratory impedance in Table 6A for boys, and in Table 6B for girls. In boys, passive smoking during the child's entire life (cumulative dose) was significantly associated with impairments in all spirometry parameters; a decrease of $-3.0 \%$ in FVC $(p<0.10),-6.0 \%$ in FEV,$-10.9 \%$ in PEF and $-15 \%$ in $\mathrm{FEF}_{25-75 \%}(\mathrm{p}<0.05)$. The impairments associated with passive smoking during a part of the boy's life were smaller but still all significant $(-3.2 \%,-3.7 \%$ and $-5.6 \%, p<0.05$, and $-5.2 \% ; p<0.10$ respectively).

Table 5A. Results of the Linear Regression Analysis in Boys.

\begin{tabular}{|c|c|c|c|c|c|c|c|c|c|}
\hline \multirow[b]{2}{*}{ Indion lactors } & \multicolumn{2}{|c|}{$\mathrm{F} / \mathrm{C}$} & \multicolumn{2}{|c|}{ FEV } & \multicolumn{3}{|c|}{ PEF } & \multicolumn{2}{|c|}{ 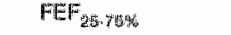 } \\
\hline & D旗 & C.I. & Diff $\%$ & C. 1 & Diff \% & C.ll. & & Difl & C.I. \\
\hline \multicolumn{10}{|c|}{ Passive smoking: } \\
\hline Whole life & $-3,0$ & -6.4 .40 .4 & -60 & $-10.5 /-15^{*}$ & -100 & -16.2 & $5.7^{*}$ & $=-15.0$ & $-23.6 /-6.1$ \\
\hline Pant of life & -32 & $-8.8 / 0.5^{*}$ & -3.7 & -7.710 .4 & -5.6 & $-10.3 \%=$ & $0.9 *$ & -52 & $-11.98 \quad 15$ \\
\hline Damp stains & -1.0 & $-3.6 / 16$ & $-\pi .6$ & $-4.5 / 11.3$ & -3.1 & -6.5 & 0.3 & $=0$ & -0.712 .8 \\
\hline Mould girowsth & 0.2 & -2.603 .0 & -1.0 & -42121 & -2.3 & -5.9 & 1.4 & $-1 x$ & $-7.5 / 1.1$ \\
\hline Geyser & 0.6 & $-4,1 / 5,3$ & 1.7 & -3.716 .9 & 40 & -2.2 & 10.1 & 2.2 & $-12.2 \mathrm{~B}$ \\
\hline Education, F & 0.8 & $-2.1 / 3.7$ & -1.4 & -4.61 .8 & -27 & -5.9 & 0.4 & -4.6 & $-10.010 .7^{4}$ \\
\hline
\end{tabular}

Note. Between lung function wariables (spirometry) and incloor factors (expressed as percentage difterence between "axposed" anch "nonexposed"?

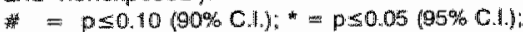

a = The number of years of passive smoking divided by the chili ils age, children were included if this ratlo was $>0.1$ and $<0.96$, (ratio $>0.95$, these chidren were in the group of childreri who "(passive) smoked their whole llte" and if the ratio was $\leq 0.4$, these children were treated as 'never (passive) smoking').

$\mathrm{b}=$ Meant are geysers (gas-hoated hot-water supplles) without flue, located in the kitchen:

$F=$ educational lewel father 
Passive smoking during the boy's entire life also was significantly associated with impairments in all respiratory impedance indices; an increase in $R_{r s 8}(0.565$ $\left.\mathrm{cmH}_{2} \mathrm{O} /(\mathrm{L} / \mathrm{s}), p<0.05\right)$ and $f_{0}(1.94 \mathrm{~Hz}, p<0.05)$ and a decrease in $X_{\mathrm{rs} 8}(-0.270$ $\left.\mathrm{cmH}_{2} \mathrm{O} /(\mathrm{L} / \mathrm{s}), \mathrm{p}<0.05\right)$ and $\mathrm{FD}\left(-0.012 \mathrm{cmH}_{2} \mathrm{O} /(\mathrm{L} / \mathrm{s}), \mathrm{p}<0.10\right)$. As with spirometry values impairments were smaller for passive smoking during a part of the boy's life, and significant for $X_{\text {rs: }}$ only $\left(-0.192 \mathrm{cmH}_{2} \mathrm{O} /(\mathrm{L} / \mathrm{s}), \mathrm{p}<0.05\right)$ (Table $\left.5 \mathrm{~b}\right)$.

Table 5B. Results of the Linear Regression Analysis in Girls.

\begin{tabular}{|c|c|c|c|c|c|c|c|c|}
\hline \multirow[b]{2}{*}{ Indoor iactors } & \multicolumn{2}{|c|}{ FVC } & \multicolumn{2}{|c|}{$\mathrm{FEV}_{\mathrm{s}}$} & \multicolumn{2}{|c|}{ PEF } & \multicolumn{2}{|c|}{$F E F_{25-75 \%}$} \\
\hline & Diff & C.l. & Diff : & $\mathrm{Cll}$ & Diff \% & c.l. & D䑴 \% & Cl. \\
\hline \multicolumn{9}{|c|}{ Pussive smoking: } \\
\hline Whole life & 0.2 & $-3.3 / 3.8$ & -2.7 & $-5.690 .2^{4}$ & -1.0 & $-5,7 / 38$ & -0.7 & $-13.4 / 0.0^{*}$ \\
\hline Pari of life & -0.7 & $-4.3 / 26$ & -24 & $-5.3 / 0.5$ & 24 & $-23 l^{\prime} 7.2^{*}$ & -4.6 & - \\
\hline Damp steting & 0.4 & $-2.8 / 3.6$ & 0.9 & $-2.3 / 4.0$ & 2.8 & $-1.5 / 7.1$ & 4.1 & $-1.019 .2^{8}$ \\
\hline Mould growth & 0.2 & $-2.6 / 3.0$ & -0.9 & $-3.6 / 1.8$ & 0.6 & $-31 / 43$ & -1.9 & $-7.2 / 3.3$ \\
\hline Geysor & -0.6 & $-2.3 / 4.1$ & -0.8 & $-2.5,0.8$ & -1.2 & $-3.5 / \quad 1.2$ & -11.8 & -5.011 .5 \\
\hline Eutucietillom, F & -2.5 & $-5.1 / 0.1^{*}$ & -2.5 & $-5.0,0.1^{*}$ & $-4,0$ & $-7,4 /-0,5$ & -2.3 & $-7.2 / 2.6$ \\
\hline
\end{tabular}

Notte. Betweren lung function variables (spirometry) and indaor factors (expressed as percentagle difference between "iexposed" and "nomexposed").

For legorod seo Table $5 \mathrm{~A}$

Small impairments in spirometry and impedance indices were observed with damp stains and with mouid growth, significant for damp stains and PEF $(-3.1 \%, p<0.05)$, $\mathrm{R}_{\mathrm{rsB}}\left(0.271 \mathrm{cmH}_{2} \mathrm{O} /(\mathrm{L} / \mathrm{s}), \mathrm{p}<0.05\right), \mathrm{X}_{\mathrm{rsB}}\left(-0.096 \mathrm{cmH}_{2} \mathrm{O} /(\mathrm{L} / \mathrm{s}), \mathrm{p}<0.10\right)$ and $\mathrm{t}_{0}(1.04 \mathrm{~Hz}$, $p<0.10)$. Non of the lung function indices in boys was related to unvented kitchen geysers. Low education level of the father appeared to be associated with, in general, worse pulmonary function values, significantly $(p<0.10)$ for $P E F, F E F_{25-75 \%}, X_{r s 8}$, and FD.

Table 6A. Hesults of the Linear Regression Arnalysis in Boys.

\begin{tabular}{|c|c|c|c|c|c|c|c|c|}
\hline \multirow[b]{2}{*}{ Indoor lactors } & \multicolumn{2}{|c|}{$\mathrm{P}_{\mathrm{r} g \mathrm{o}} \mathrm{omH}_{2} \mathrm{O} /(\mathrm{L} / \mathrm{s})$} & \multicolumn{2}{|c|}{$\mathrm{X}_{\mathrm{n} \leq \mathrm{g}}, \mathrm{cmH}_{2} \mathrm{Or}(\mathrm{L} / \mathrm{s})$} & & \multicolumn{2}{|c|}{$\mathrm{FD}, \mathrm{cmH}_{2} \mathrm{O} /(\mathrm{L} / \mathrm{s})$} \\
\hline & DHith abs. & C.li. & Diff abs. & C.l. & Difl ab & C.I. & Diffl abs. & Cils. \\
\hline \multicolumn{9}{|c|}{ Pagialve simoking: } \\
\hline Whole ife & 0.565 & $0.0721 .058^{*}$ & -0.270 & $-0.490 \%-0.051^{x}$ & 1.94 & $-0.13 / 4.01$ & -0.012 & $-0.02810 .002^{2}$ \\
\hline Part of 11 f $^{\mathrm{B}}$ & 0.232 & -0.2090 .672 & -0.192 & $-0.3890 .004^{*}$ & 0.57 & $-1.28 / 2.42$ & -0.0007 & -0.0220 .008 \\
\hline Clannp stains & 0.271 & $-0.047 / 0.598$ & -0.090 & -0.2100 .024 & 1.04 & $-0.09 / 2.17^{4}$ & -0.007 & -0.048 .0 .004 \\
\hline Mould growith & 0.151 & -0.19030 .494 & -0.031 & -0.18 때, 122 & 0.20 & $-1.25 / 1.65$ & - & $-3^{4}$ \\
\hline Geyserit & -0.220 & $-0.797 / 0.357$ & 0.062 & -0.1920 .319 & -0.44 & $-2.56 / 2.29$ & $-0,000$ & $-0.025 / 0.014$ \\
\hline Education, $F$ & 0.217 & $-0.136 / 0.569$ & -0.114 & $-0.2410 .0 .010^{1}$ & 0.95 & -0.5442 .43 & $-0,010$ & -0.02010 .000 \\
\hline
\end{tabular}

Nota. Between fung tunction warkables (mpedance) and indoor factors (differencess batween "gxpase" and "nonexposed" expressed in absolute valuesil.

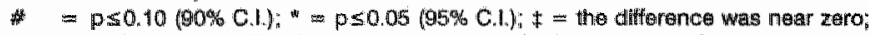

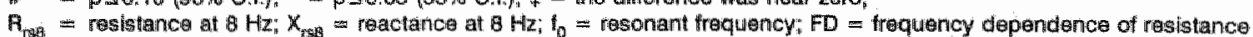

a the number of years of passive smoking divided by the chlid's age, children were includied if this ratio wass $>0.1$ and $<0.96$, (ratio $>0.95$, these children were in the group of chiletren who '(passive) smoked their whole Ifle' and the the ratio was $\leq 0.1$, these children were treated as "nover (passiwe) smoking).

b. meant are geyars (gas-fzeated hot water supples) without Hue, located in the kitehen.

$\mathrm{F}=$ educational leval tather 
Table 6B. Results of the Linear Regression Anallysis in Girls.

\begin{tabular}{|c|c|c|c|c|c|c|c|c|}
\hline \multirow[b]{2}{*}{ Indoor lactors: } & \multicolumn{2}{|c|}{$\mathbb{R}_{\mathrm{rssis}} \mathrm{cm} \mathrm{H}_{2} \mathrm{O} /(\mathrm{L} / \mathrm{s})$} & \multicolumn{2}{|c|}{$x_{m}, \mathrm{cmH}_{2} \mathrm{O}(\mathrm{L} / \mathrm{s})$} & \multicolumn{2}{|l|}{$\mathbb{t}_{\mathrm{p}} \mathrm{Hz}$} & \multicolumn{2}{|c|}{$\left.\mathrm{FD}, \mathrm{cm} \mathrm{H}_{\mathrm{i}} \mathrm{O} / \mathrm{L} / \mathrm{s}\right)$} \\
\hline & Diti abs. & C.l. & Difft abs: & C.l. & Diff ato & s. C.I. & Duts abs: & o.l. \\
\hline \multicolumn{9}{|c|}{ Passiva smoking: } \\
\hline Whote lite & 0.239 & $-0.130: 0.606$ & -0.201 & $-0.402 / 0.000^{\circ}$ & 1,63 & $0.118 .75 \%$ & -0.010 & mosol-a and \\
\hline Pant of lite & 0.077 & $-0.289 / 4.43$ & -0.092 & -0.29210 .108 & 0.25 & -0.6672 .37 & -0.009 & $-0.0200,002^{\text {ty }}$ \\
\hline Damp stains & $-0.3+15$ & $-0.647 / 0.017^{-4}$ & 0.158 & $0.02 \% 10.339^{*}$ & -0.69 & -2.060 .69 & 0.009 & -0.001 .0 .049 \\
\hline Moutd growth & -0.058 & 0.3460 .230 & 0.419 & $-0.0130 .252^{2}$ & -0.36 & $-1.54,0.83$ & 0.005 & -0.0050 .015 \\
\hline Geysen & 0.095 & -0.0840 .273 & -0.080 & $-0,16210,003$ & 0.66 & $-0.00 / 1.39^{4}$ & -0.004 & -0.0100 .002 \\
\hline Educartion, $F$ & -0.146 & -0.41540 .123 & 0.019 & $-0.128 / 0.166$ & -0.57 & -1.080 .55 & 0.000 & $0,0020.010$ \\
\hline
\end{tabular}

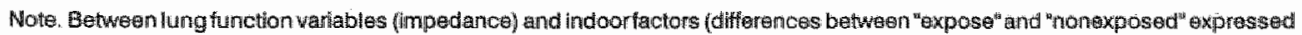
in absolute values).

For legend see Table 6 .

The results in girls again differed from those just described in boys. Passive smoking (cumulative dose) was associated with impairments in spirometry and impedance values, although in absolute terms they were smaller than in boys, and not all significant: $F E V_{1}-2.7 \%, p<0.10, P E F-1.0 \%$ (n.s.) "FEF $25-75 \%-2.7 \%, p<0.05, A_{r s i 8}$ $0.239 \mathrm{cmH}_{2} \mathrm{O} /(\mathrm{L} / \mathrm{s})(\mathrm{n} . \mathrm{s}), f_{0} 1.63 \mathrm{~Hz}, \mathrm{p}<0.05, X_{\mathrm{rss}}-0.201, p<0.05$, and $\mathrm{FD}-0.016$ $\mathrm{cmH}_{2} \mathrm{O} /(\mathrm{L} / \mathrm{s}), \mathrm{p}<0.05$. In contrast to the observations in boys, in girls no lung function impairments were found with respect to damp stains and mould growth. Moreover, impedance values were significantly 'better' in the damp stains group. For unventilated kitchen geysers significant impairments were found for $X_{\mathrm{rs}}\left(-0.080 \mathrm{cmH}_{2} \mathrm{O} / \mathrm{L} / \mathrm{s}\right.$ ), $p<0.10$ and $f_{0}(0.66 \mathrm{~Hz}, P<0.05)$. Low education levell of the father was significantly associated with impairments in almost all spirometry indices, but not with impairments in impedance indices.

Pets were omitted from the linear models, since they showed no effect on lung function.

\section{DISCUSSION}

In this study the effects of several factors from the indoor environment on respiratory morbidity and lung function were investigated in 470 Dutch primary school children. Passive smoking was significantly related to symptoms and lung function impairments, and more so in boys than in girls. The most consistent associations were found with the lung function parameters of both spirometry and impedance. The effects seemed to be related to duration of exposure, since the largest impairments in lung function were observed in children exposed during their entire life. Although often nonsignificant the OR's suggest a dose-response relationship between the asthma-like symptoms and maternal (but not paternal) smoking in boys, but not in girls. In boys, damp stains and mould growth were related to smail, mostly nonsignificant, effects on lung function indices and to chronic cough. Although elevated (>1) OR's suggested an adverse effect of unvented kitchen geysers on symptoms, they were nonsignificant and not confirmed by clear lung function impairments, since only reactance and resonant frequency in girls were significantly affected. Of the pets studied, only the presence of a dog seemed to be related to some of the key symptoms, but not to any of the lung function parameters. A low education level of the father was related to symptoms 
in girls, and to impairments (nonsignificant) in spirometry (both genders), but not to impedance indices.

The results of the present study are strongly suggestive of a gender difference in airway sensitivity to passive smoking, with boys being at a disadvantage. Taken as a whole, from the available data no consistent gender-specific pattern in the effects of passive smoking on lung function emerges, since some investigators found that girls, but others found that boys were more susceptible. ${ }^{15-21}$ Two studies with clearly contrasting results are those of Martinez et al. ${ }^{20}$ and Forastiere et al. ${ }^{16}$ Both studied the relationship between passive smoking and bronchial responsiveness (BR) in children. Where Martinez et al. found that BR was significantly related to parental smoking, with the strongest relationship in boys and in children with a history of asthma, ${ }^{20}$ Forastiere et al. found that it was difficult to detect a relationship in the overall sample, but did find a strong positive association in girls. ${ }^{16}$ In a short review of the literature on the effects of passive smoking, Tager ${ }^{15}$ mentioned that in general girls are more likely to be affected than boys. However, several studies reported the opposite results. ${ }^{18-21}$ Although Murray et al. ${ }^{18}$ studied asthmatic children, their results largely agree with our findings. They found adverse effects of passive smoking in both sexes, with boys being more severely affected than girls and pulmonary function progressively impaired with the duration of passive smoking. In accordance with the latter, we found the largest and most consistent effects on lung function in children exposed to parental smoking during their entire life. Recently Strachan et al. ${ }^{43}$ studied effects on respiratory health of passive tobacco smoke exposure, using salivary cotinine as a quantitative biochemical marker. They found small but potentially important reductions in the ventilatory function of children, but no clear associations with most respiratory symptoms. Their findings suggest that end-expiratory flow rates may be the most sensitive to passive smoke exposure, which might be interpreted as an effect on small airways. In the present study, the largest impairment in spirometry was found for the $F E F_{25-75 \% \text {, }}$ but in boys relatively large effects on PEF, FEV $\|_{1}$ and all impedance indices were observed as well. The question about the longterm consequences of the observed deficits in pulmonary function remains unanswered. However, since we clearly observed a progressive effect with duration of exposure, it is plausible that the observed damage on the children's airways could result in more severe impairment of pulmonary function later in life. In the present study for boys, indications of a dose-effect relationship, with the amount of maternal smoking and the asthma-like symptoms were found, whereas less clear associations were found with paternal smoking. On this topic, effects of maternal versus paternal smoking, the literature again is inconsistent; although most studies reported predominance of the maternal smoking effect, a number of studies have observed a supplemental effect of, or an effect confined to, paternal smoking. ${ }^{15}$ In the Netherlands about $34 \%$ of the adult population are smokers, somewhat more men $(38 \%)$ than women $(31 \%),{ }^{44}$ In the present study, slightly more mothers $(38.9 \%)$ smoked inside the house than fathers (36.4\%), and more mothers were in the middle smoking category (11-20 smokes) whereas more fathers were in the lower smoking category ( $<11$ smokes). The reason for this can be that we asked for the numbers of smokes (cigarettes + pipes + cigars) smoked inside the house, and still more fathers are working outside the house. Furthermore, the proportion of fathers of whom the information on smoking habits was missing was somewhat larger than the proportion of mothers with missing data on smoking. The chance that the observed effects were caused by active smoking by the child is probably neglectable in this age- 
category (Dutch figures indicate that in the age group of $10-12$ years about $2-3 \%$ of the children are smokers ${ }^{44}$ ).

Unvented gas household appliances, especially unvented kitchen geysers are potential sources of nitrogen dioxide inside the home, ${ }^{45}$ which may be associated with respiratory symptoms in children. ${ }^{46}$ In this study, we found unvented kitchen geysers to be related to most key symptoms without clear effects on spirometric values. These results are consistent with earlier reports. ${ }^{45,46}$ However $_{\text {" we did find an adverse }}$ relationship between part of the impedance values in girls and unvented kitchen geysers; reactance values were significantly lower and resonant frequency was significantly higher in girls exposed to an unvented kitchen geyser. Although nonsignificant, small impairments of spirometry indices were also observed in girls, the largest in $\mathrm{FEF}_{25-75 \%}$. Together with the affected impedance indices this could be an indication of obstruction of the small airways. However, since in absolute terms the effects were small and not found in boys, who are supposed to have a higher airway sensitivity, it is difficult to judge whether the observation is caused by chance or that in this case girls are more sensitive. It would seem likely that unvented kitchen geysers are particularly located in old(er) houses, which could have influenced the observed relationship, yet, the imvestigated children lived in a relatively new residential area of the city, where the majority of the houses were built after 1980 .

Several studies have demonstrated that chronic cough whether, accompanied by wheeze, was the symptom strongest related with damp housing ${ }^{4,8,23,45}$ This is in agreement with our findings, as chronic cough in boys was the only symptom significantly related to damp stains, in girls the relationship was indicative but not significant. In boys, exposure to mould growth was related to chronic cough, shortness of breath, and attacks of shortness of breath with wheeze, albeit not significantly, and in girls it was nonsignificantly related to wheeze only. Furthermore, small impairments in spirometry and impedance values were found, again in boys, with damp stain and mould growth. In girls the 'opposite effects' were observed. Our results agree, in part, with the recent findings of others, ${ }^{6,23,45}$ since in most studies no clear association between home dampness and lung function was found. Furthermore, as far as we know, no differences in airway sensitivity in respect to home dampness, between boys and girls have been reported. The assumption has been put forward by Strachan ${ }^{4}$, that exposure to home dampness may cause an increased symptom prevalence, without affecting the lung function. However, he also acknowledged that on biological grounds this seems unlikely, as the most plausible causal links between dampness and respiratory disease implicate functional abnormalities of the ainways, resulting from increased exposure to airborne allergens or intercurrent infections. ${ }^{4,5}$ In another study Strachan et al. ${ }^{47}$ found highly significant associations between damp and mould in the house and respiratory morbidity in children as reported by their parents, but these relations were not found with recorded general practice consultations for wheeze or lower respiratory tract iliness. Based on these results they warned of the influence of reporting bias on the observed associations between home dampness and respiratory health, in studies which rely solely on information obtained by questionnaires. However, while small and not always significant, the effects on lung function and reported symptoms found in the present study were consistent and certainly suggestive of an adverse relationship in boys, between home dampness and respiratory health.

Of the pets studied, only the presence of a dog was associated with attacks of shortness of breath with wheeze (both genders), but not with lung function parameters. The latter is in agreement with the results of Hosein et al. ${ }^{24}$ who also did not find any 
relationship between pets and respiratory health. However, a clear association would have prompted parents to remove the pet(s), resulting in an underestimation of the effect.

Since information on the exposure variables as well as respiratory morbidity was obtained by means of questionnaire, responder bias cannot be ruled out as a cause for the observed associations. In general, it has been stated that parents of symptomatic children, searching for etiologic factors may be more aware of indoor air problems than parents of asymptomatic children. ${ }^{B}$ With passive smoking, the observations in the present study of consistent effects on symptoms as well as on lung function, argue against reporting bias as an explanation of the findings. Moreover, public awareness of the adverse effects of passive smoking would more likely result in underreporting of symptoms or of the amount of smoking (because of parents' guilt feelings), resulting in underestimation of the effects. The potential role of home dampness as a risk factor for respiratory illness, has not received much public attention in the area in which the present study was conducted. Together with the fact that symptoms and lung function were altered in the same direction, at least in boys, this argues against the fact that the results were caused solely by reporting bias. The occurrence of reporting bias with unvented kitchen geysers is more likely, since indications of an adverse effect were found with symptoms, whereas pulmonary function was only marginally affected. However, taken as a whole it is difficult to judge to what extent public awareness of potential risk factors for the respiratory health of children may have influenced the results. In future studies objective measures of exposure need to be developed and used, in addition to more objective measures of the effects.

In summary, in this study we found that passive smoke exposure during the child's entire life, is most consistently related to respiratory symptoms and to lung function impairments in primary school children. Smaller and less consistent effects were found with home dampness and unvented kitchen geysers. Although future studies are necessary to further clarify this issue, our results are certainly suggestive of a larger airway sensitivity in boys, than in girls. The clinical relevance of the observed effects associated with the investigated indoor factors still remains to be determined, but they affect large groups of people, and broad public education about the potential health effects therefore should become a major issue of 'health gain'.

\section{ACKNOWLEDGEMENTS}

The authors thank all parents, children and schools in the study. We thank Jos Slangen and Fons Kessels for their valuable contribution to the statistical analysis. 


\section{APPENDIX}

Overview of the major questions from the questionnaire, used in this report.

Nr. Question

6 Did your child cough on most days, for at least 3 months a year? $(y / n)$.

8 Has your child been troubled by shortness of breath when playing outside or climbing the stairs, in the previous year? $(y / n)$.

10 Has your child's chest sounded wheezy, in the previous year? $(\mathrm{y} / \mathrm{n})$.

12 Has your child had attacks of shortness of breath with wheeze, in the previous year? $(\mathrm{y} / \mathrm{n})$.

56 Did you ever have damp stains in your home in the past two years? (never, sometimes, often, always).

57 Did you ever have mould growth in your home in the past two years? (never, sometimes, often, always).

62 How is the hot-water supply arranged in the present house? Unvented geyser inside the kitchen? $(y / n)^{*}$

69 Which pets do you have (or did you have) inside the home?

Cat $(y / n), \operatorname{dog}(y / n)$, bird $(y / n)$, rodent $(y / n)$, other.....

74 Does the mother of the child smoke at the moment?

1) No, never smoked

2) No, stopped smoking in 19.. (fill in date)

3) Yes, started smoking in 19.. (fill in date)

75 How many does the mother, on the average, smoke per day inside the house? (Number of smokes/day).

76 Does the father of the child smoke at the moment?

1) No, never smoked

2) No, stopped smoking in 19.. (fill in date)

3) Yes, started smoking in 19.. (fill in date)

77 How many does the father, on the average, smoke per day inside the house? (Number of smokes/day).

78 How many other house-mates do smoke inside the home of the child? (Do not count father and mother).

79 How many do these house-mates, on the average smoke, per day inside the home? (Number of smokes/day).

80 What is for the mother the highest obtained school (leaving) certificate? (Eight possible levels).

81 What is for the father the highest obtained school (leaving) certificate? (Eight possible levels).

* = one of the possibilities 


\section{REFERENCES}

1. Lebowtz MD. Health effects of indoor pollutants. Ann Rev Public Health 1983; 4: 203-221.

2. Martin Cud Platt SD, Hunt SM. Housing conditions and ill health. Br Med J 1987; 294: 1125-1127.

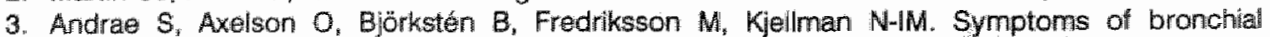
hyperreactivity and asthma in relation to environmental factors. Arch Dis Child 1988; 63: 473-478.

4. Strachan DP. Damp housing and childhood asthma: validation of reporting of symptoms. Br Med 1988; 297: $1223-1226$.

5. Strachan DP, Sanders CH. Damp housing and childhood asthma; respiratory effects of indoor air temperature and relative humidity. J Epidemiol Commun Health $1989 ; 43: 7-14$.

6. Brunekreef B, Dockery DW, Speizer FE, Ware لJH, Spengler JD, Ferris BG. Home dampness and respiratory morbidity in ohildren. Am Fey Fespir Dis 1989; 140: 1363-1367.

7. Waegemaekers $M$, Wageningen van $N$, Brunekreef $B$, Boleil SM. Respiratory symptoms in damp homes. A pilot study. Allergy 4989; 44: 192-198.

8. Dales RE, Zwanenburg $H$, Bumett $A$, Franklin CA. Respiratory health effects of home dampness: and moulds among canadian children. Am J Epidemiol 1991; 134: 196-203.

9. Dekker $C$, Dales $R$, Bartlett $S$, Brunekreef $B$, Zwanenburg $H$. Childhood asthma and the indoor environment. Chest 1991; 100: 922-26.

10. Infante-Fivard C. Childhood asthma and indoor environmental risk factors. Am $J$ Epidemiol 1993; $137: 834-44$.

11. Platt SD, Martin CJ, Hunt SM, Lewis CH. Damp housing, mould growth and symptomatic health state. Br Mad J 1989; 298: 1673-1678.

12. Dales RE, Burnett $R$, Zwanenburg $H$. Adverse health effects among adults exposed to home dampness and moulds. Am Rev Respir Dis 1991; 143: 505-509.

13. Fielding JE, Phenow KJ. Health effects of involuntary smoking. New Eng J Med 1988; 319: 14521460.

14. Samet JM, Utell MJ. The risk of nitrogen dioxide; what have we learned from epidemiological and clinical studies? Tox Indus Health 1990 6: 247-262.

15. Tager IB. Health effects of "passive smoking" in children. Chest 1989; 96: 1161-1164.

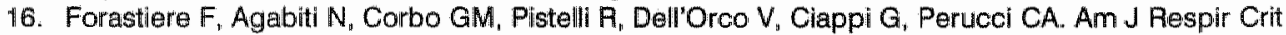
Carre Med 1994; 149:365-370.

17. Vedal S, Schenker MB, Samet $\mathrm{JM}_{\text {" }}$ Speizer FE. Risk factors for childhood respiratory disease: analysis of pulmonary function. Am Rev Respir Disi 984; 130: 187-192.

18. Murray AB, Morrison BJ. Passive smoking by asthmatics; its greater effects on boys than on girls and on older than on younger children. Pediatrics 1989; 84: 451-459.

19. Rona Rw, Chinn S. Lung function, respiratory Illness; and passive smoking in British primary school children. Thorax 1993; 48: $21-25$.

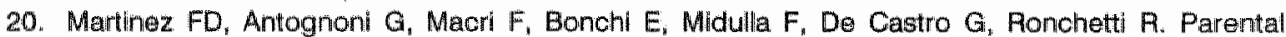
smoking enhances bronchial responsiveness in nine-year.old children. Am Riev Respir Dis 1988: 138: 518.523

21. Sherrill DL, Martinez FD, Lebowitz MD, Holdaway MD, Flannery EM, Herbison GP, Stanton WR. Silva PA, Sears MP. Longitudinal effects of passive smoking on pumoneny function in New Zealand children. Am Rev Respir Dis 1992; 145: 1136-1141.

22. Murray $\mathrm{AB}$, Morrison $\mathrm{BJ}$. The decrease in severity of asthma in children of parents who smoke since the parents have been exposing them to less cigarette smoke. J All Clin immunol 1993;91:102-110.

23. Brunekreef $B$. Associations between questionnaire reports of home dampness and childhood respiratory symptoms. Sol Total Environ 1992; 127: 79-89.

24. Hosein HA, Corey $P$. Robertson JMCD. The effects of domestic factors on respiratory symptoms and FEV, Int $J$ Epidemiol 1989; 18: 390-396.

25. Pesilin $R$, Gallina $C$, Teculescu $D$, Pham QT. Respiratory input and transfer impedances in children 9-13 years old. Bull Eur Physiopathol Respir 1987; 23: 107-112.

26. Duivermen EJ, Clément J, Woestijne varn de KP, Neijens HJ, Bergh van den ACM, Kerrebijn KF. Forced oscillation technique. References values for resistance and reactance over a frequency spectrum of 2-26 Hz in healthy children aged 2.3-12.5 years. Bull Eur Physiopathol Respir 1985; 21: 171.178 . 
27. Noord van JA, Wellens W, Clarysse 1, Cauberghs M, Woestigne van de KP, Demedts M. Total respiratory resistance and reactance in patients with asthma, chronic bronchitis and emphysema. Am Rev Respir Dis 1991; 143: 922-927.

28. Wesseling GJ, Vanderhoven-Augustin IML, Wouters EFM. Forced oscillation technique and spirometry in cold air provocation tests. Thorax 1993; 48: 254-259.

29. Clement $J$ Landser Fل Woestijne van de KP. Total resistance and reactance in patients with respiratory complaints with and without airway obstruction. Chest 1983; 83: 215-220.

30. Chalker RB. Celli BR, Habib $\mathrm{RH}$. Jackson AC. Respiratory input impedance from 4 to $256 \mathrm{~Hz}$ in normals and chronic airflow obstruction: Comparisons and correlations with spirometry. Am Rev Respir Dis 1992; 146: 570-576.

31. Oostveen $E$, Zwart $A_{n}$ Peslin $R_{8}$ Duvivier $C$. Respiratory transfer impedance and derived mechanical properties of conscious rats. J Appl Physiol 1992; 73: 1598-1607.

32. Florey C du V, Leeder SA. Methods for cohort studies of chronic airflow limitation, (chapter 3). WHO regional publications, European series No. 12. London, United Kingdom, 1982, p 112.

33. Brunekreef B, Groot B, Rijcken B, Hoek G, Steenbekkers A, Boer de A. Reproducibility of childhood respiratory symptom questions. Eur Respir J 1992; 5: 930-935.

34. Quanjer PhH. Standardized lungfunction testing. Bull Eur Physiopathol Respir 1983; 19 (suppl. 5): $11-95$.

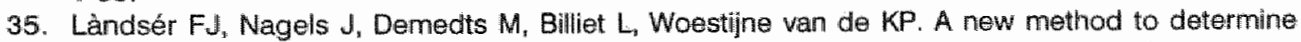
frequency characteristics of the respiratory system. J Appl Physiol 1976; 41: 101-106.

36. Wouters EFM, Làndsér FJ, Polko AH, Visser BF. Physiological analysis of extended spectrum oscillometry. Respiration 1988: $54: 263-270$.

37. Cuijpers CEJ "Wesseling GJ, Swaen GMH, Wouters EFM. Frequency dependence of oscillatory resistance in healthy primary school children. Respiration 1993; 60: 149-154.

38. Làndsér FJ, Nagels $J$, Clément $J$, Woestijne van de KP. Errors in the measurement of total respiratory resistance and reactance by forced oscillations. Fespir Physiol 1976: 28: 289-301.

39. Stanescu D. Moavero NE, Veriter $C$, Brasseur L. Frequency dependence of respiratony resistance in healthy children. J Appl Physiol 1979; 47: 268-272.

40. Clément J, Dumoulin B, Grubbelmans R, Hendriks KP, Woestijne van de KP. Reference values of total respiratory resistance and reactance between 4 and $26 \mathrm{~Hz}$ in children and adolescents aged 4-20 years. Bull Eur Physiopathol Respir 1987; 23: 441-448.

41. Dockery DW, Berkey CS, Ware $\mathrm{JH}$, Speizer FE, Ferris jr BG. Distribution of FVC and FEV, in children 6 to 11 year of age. Am Rev Respir Dis 1983"128: 405-412.

42. SPSS@ Inc, 1990, 444n Michigan Avenue, Chicago, Illinois 60611, USA.

43. Strachan DP, Martin JJ, Feyerabend $C$. The relationship of salivary cotinine to respiratory symptoms, spirometry, and exercise-induced bronchospasm in seven-year-old children. Am Rev Respir Dis 1990; 142: 147-151.

44. Stichting Volksgezondheid en Roken. Roken in Nederland, Jaarverslag 1992 (Annual report on smoking figures in The Netherlands).

45. Dijkstra L, Houthuijs D, Brunekreef B, Akkerman 1 , Boleil SM. Pespiratory health effects of the indoor environment in a population of Dutch children. Arn Rev Fespir Dis 1990, 142: 1172-1178.

46. Neas LM, Dockery DW, Ware JH, Spengler JD, Speizer FE. Ferris ir BG. Associations of indoor nitrogen dioxide with respiratory symptoms and pulmonary function in children. Am al Epidemiol 1991: 134: 204-19.

47. Strachan DP, Eltom RA. Relationship between respiratory morbidity in children and the home enwironment. Family Practice 1986; 3: 137-142. 



\section{Chapter 6}

\section{HOW DOES PARENTAL SMOKING AFFECT RESPIRATORY IMPEDANCE IN CHILDREN?}

CEJ Cuijpers, AGH Kessels, PLJM Mertens, GJ Wesseling, GMH Swaen, ME de Kok, \lrcorner Broer, F Sturmans, EFM Wouters 


\title{
HOW DOES PARENTAL SMOKING AFFECT RESPIRATORY IMPEDANCE IN CHILDREN?
}

\begin{abstract}
The results are presented of a cross-sectional study of the relationship between parental smoking and impedance properties of the respiratory system in 1776 Dutch children. Effects of maternal, paternal and parental smoking were studied independently, and gender differences in susceptibility to parental smoke exposure were investigated. Information on parental smoking habits and several confounding factors, was obtained by means of a written questionnaire. Respiratory impedance was measured using the forced oscillation technique.

In girls maternal smoking was significantly associated with a number of impedance parameters, whereas in boys very few parameters were affected. Although less obvious than with maternal smoking, there were some significant effects of paternall smoking on respiratory impedance, in boys rather than in girls. The affected impedance parameters mainly were measures of respiratory reactance. With (combined) parental smoking effects were less pronounced, but quite comparable to those found with maternal smoking. The observed effects mainly occurred if the parent(s) smoked 10 or more smokes per day inside the house, and were even more significant when 'cumulative dose' was used to quantify parental smoke exposure. Both results suggest the existence of a dose-responise association.

The present study provides further evidence, adding to earlier reports on adverse health effects of passive smoking, which should convince the still relatively large number of parents who are smokers (still $44 \%$ of the children are exposed), to quit smoking on behalf of their children's respiratory health.
\end{abstract}

\section{INTRODUCTION}

Exposure of infants and children to environmental tobacco smoke (ETS), caused by active parental smoking, has been shown to affect their respiratory health. ${ }^{i-4}$ The most consistent findings are those of (acute) respiratory illnesses in infancy, up to the first year or two of life. ${ }^{2,5}$ In older children, the majority of the studies did find a significant relationship between ETS exposure and reported respiratory symptoms, whereas lung function abnormalities were demonstrated by many, but not by all investigators. ${ }^{12}$ 
Although the observed changes in respiratory function, associated with ETS exposure, were often statistically significant they were also small and of unknown prognostic importance. ${ }^{4}$ Until now the dose-effect relationship is incompletely understood. When the effect of parental smoking was studied for mother and father separately, most studies reported predominance of a maternal smoking effect. ${ }^{1}$ However, a supplemental effect or an effect confined to paternal smoking has been reported as well. ${ }^{1}$

In several cross-sectional studies, gender differences in susceptibility to ETS exposure have been noted. The results however are inconsistent, since some investigators reported boys, ${ }^{6-8}$ whereas others reported girls to be more susceptible. ${ }^{19,10}$ Strachan et al. ${ }^{11}$ studied respiratory health effects in children due to ETS exposure, using salivary cotinine as a quantitative biochemical marker of passive tobacco smoke exposure. They found the flow rates in the terminal part of the spirogram ( $F E F_{75-85}$, $\mathrm{FEF}_{75}$ ) to be the most sensitive to passive smoke exposure, independent of gender, probably reflecting damage of the small ainways. Since the results of a few longitudinal studies showed a reduced lung function growth rate. ${ }^{12-15}$ it is plausible that this small airway damage could later progress to more severe impairment in pulmonary function, although the evidence is not yet clear. Interesting observations were reported recently by Wang et al. ${ }^{15}$ who prospectively studied the timing of the maternal smoking effect. Based on their results they suggested that among school aged children decrements in pulmonary function associated with maternal smoking appeared to be a combination of a persistent deficit related to earlier (including in utero) exposure and an additional deficit related to current exposure. In the majority of the longitudinal studies $^{12,14,15}$ no gender differences were found.

Parental smoking also has been reported to be associated with increased prevalence of airway hyperresponsiveness and skin-test reactivity to aeroallergens in children. ${ }^{16}$ Martinez et al. ${ }^{17}$ recently reported that children of lower socioeconomic status may be at considerable risk of developing asthma if their mothers smoke 10 or more cigarettes a day.

The data for the present study originate from a cross-sectional survey on respiratory health in 1968 Dutch primary school children. Exposure to passive smoking was evaluated by a written questionnaire, completed by the parents. Impedance characteristics of the respiratory system were measured using the forced oscillation technique (FOT), according to Làndsér ${ }^{18}$ The FOT yields values of the total resistance and reactance of the respiratory system. ${ }^{19}$ Because the measurements are independent of effort and require little or no cooperation from the subject they can easily be performed in children. In addition to the commonly used on-line impedance parameters: resistance at $8 \mathrm{~Hz}\left(\mathrm{R}_{\mathrm{rs}}\right)$, reactance at $8 \mathrm{~Hz}\left(\mathrm{X}_{\mathrm{rsg}}\right)$, resonant frequency $\left(\mathrm{f}_{0}\right)$ and frequency dependence of resistance (FD), the curve parameters obtained by linear and quadratic regressions used to describe individual resistance and reactance curves as a function of frequency, were studied. In the present report the effects of ETS exposure (acute and cumulative) on respiratory impedance are evaluated. Effects of maternal, paternal and parental smoking were studied independently and the existence of a dose-response relationship was investigated. In order to find out whether a gender difference in susceptibility to ETS exposure exists, the analyses were performed for boys and girls separately. 


\section{METHODS}

From March to June 1993 we conducted a survey on respiratory health in 1968 primary school children living in two different regions of the Netherlands. In the present report the data concerning ETS exposure on respiratory impedance will be discussed.

\section{Population}

In cooperation with two local health services 1968 children aged 6 to 12 years, were approached by their primary schools. 1281 children living in the south of the Netherlands (Limburg) and 687 children living in the north (Groningen).

Informed consent to measure the children's lung function, using the forced oscillation technique, was obtained from $226(95.7 \%)$ parents in Limburg and $658(95.8 \%)$ parents in Groningen, resulting in a total response of $1884(95.7 \%)$ children.

\section{The Questionnaire}

Information on the parental smoking habits was obtained by means of a written questionnaire, completed by the parents of the children. These questions are part of the Dutch version of the children's questionnaire of the World Health Organisation published by Florey and Leeder. ${ }^{20,21}$ The questions concerning active smoking. pertained to whether father and mother smoked $(y / n)$ " when they started or stopped smoking (date) and the number of cigarettes, cigars or pipes they smoked inside the house (=number of smokes). Information was also obtained about age and gender of the child, parental educational level, and several relevant indoor sources of pollution such as the presence of gas appliances (sources of nitrogen dioxide) and home dampness. The major questions discussed in this report are described in the Appendix. The questionnaires were distributed in the participating schools, two weeks before the team who performed the lung function measurement visited the school. At the time of the lung function measurement the questionnaires were collected.

\section{The Forced Oscillation Technique}

The mechanical characteristics of the respiratory system were measured using the technique of forced oscillations, according to the method developed by Landser et all. ${ }^{19}$ The technique has been described in detail previously. ${ }^{22,23}$ Briefly, a pseudorandom noise signal consisting of sinusoidal pressure oscillations containing all harmonics of $2 \mathrm{~Hz}$ up to $48 \mathrm{~Hz}(4,6,8, \ldots .48)$, was applied at the mouth of the seated child. During the measurements the child breathed quietly and wore a nose clip. The cheeks and the floor of the mouth were supported with the hands of either the investigator or the child itself. Mouth pressure and mouth flow are measured with identical differential pressure transducers (Validyne MP 450), and fed into a Fourier analyzer, dividing pressure by flow: the system calculates an impedance value for each of the investigated frequencies. The impedance is partitioned into a real part, resistance and an imaginary part or reactance. The real part $\left(\mathrm{R}_{\mathrm{rs}}\right)$ is the equivalent of the total resistance in a resistance-inductance-capacitance $(R-L-C)$ circuit. The reactance $\left(X_{\mathrm{rs}}\right)$ depends on the elastic and inertial properties of the respiratory system. The frequency al which $X_{r s}$ equals zero is called the resonant frequency $\left(f_{0}\right)$. To evaluate the rellability of the measurement a coherence function is estimated at each frequency. This indicates the amount of noise generated by the child's spontaneous breathing, present in the measured signals. 
In adults negative frequency dependence of resistance (FD), i.e. a decrease in resistance with increasing frequency, is considered an abnormal finding and together with increased $\mathbb{R}_{\mathrm{rs}}$ and $f_{0}$ values and decreased $X_{\mathrm{rs}}$ values is considered a marker of aifflow obstruction. ${ }^{24,25}$ In young children this negative frequency dependence of resistance is a common finding, but tends to disappear with age and growth and does not necessarily implicate pulmonary pathology. 23,26,27

Each child performed at least five valid impedance measurements according to recommendations, recently set up by an international working group on standardization of impedance measurements in childiren. ${ }^{28}$

\section{Analyses}

In the present analyses exposure to maternal, paternal and parental smoking were each categorized into four groups:" (a) never smoked (b) stopped smoking. (c) smoking less than 10 smokes per day inside the house, (d) smoking 10 or more smokes per day inside the house, (smokes = cigarettes + cigars + pipes). Besides, ETS exposure was expressed by wo interval variables, the total dose = the total number of smokes, smoked per day inside the house, and pack-years (cumulative dose) = (total dose $x$ years of passive smoking)/25 (1 pack-year $=$ exposure to 1 pack of 25 cigarettes per day, during 1 year).

In the analyses only impedance values with a coherence function $>0.95$ were retained. Landser et al. ${ }^{29}$ have demonstrated that in measurements with a coherence function exceeding 0.95 the error of the measurements due to the presence of noise or nonlinearities is less than $10 \%$. Using linear (I) and quadratic (q) regressions, individual resistance $\left(\gamma_{R}=\beta_{I R} f+\alpha_{1 B}\right.$ and $\left.\gamma_{R}=\gamma_{q R} f^{2}+\beta_{q R} f+a_{q A}\right)$ and reactance curves $\left(Y_{X}=\beta_{\mid X} f+\alpha_{1 X}\right.$ and $\left.Y_{X}=\gamma_{q X} f^{2}+\beta_{q X} f+\alpha_{q X}\right)$ were described as a function of frequency. From these curves, for each child, the following additional impedance parameters were obtained: $\beta_{I R}, \alpha_{I R}, \beta_{I X}, \alpha_{I X}$ (linear curves, for the frequency ranges $4-$ $48,2-28$ and $4-12 \mathrm{~Hz}$ ), $\gamma_{\mathrm{qR}}, \beta_{\mathrm{qR}}, \alpha_{\mathrm{qR}}, \gamma_{\mathrm{q} X} \beta_{\mathrm{qX}}$ and $\alpha_{\mathrm{qx}}$ (quadratic curves, frequency range $4-48 \mathrm{~Hz}$ ).

The effects of ETS exposure were studied using linear regression analyses with the individual impedance parameters $\left(R_{r s s}, X_{r s a}, F D, f_{0}\right.$ and the additional parameters) as dependent variables. The three different ways to quantify ETS-exposure (categories, total dose, and pack-years) were studied independently, for mother, father and parental smoking separately. All analyses were performed for boys and girls separately. In the regression of parental smoke exposure on respiratory impedance we controlled for influences of height and weight and for confounding factors such as home dampness (=reported damp spots inside the house), educational level of the father (low or high), and unvented kitchen geysers (=gas-heated hot-water supplies without flue, located in the kitchen, which is an important source of nitrogen dioxide in Dutch homes). The analyses were performed using SPSS-X statistical package. ${ }^{30}$

\section{RESULTS}

For 1884 of the 1968 children $(96 \%)$ informed consent was obtained from the parents for performing the impedance measurements. Finally, for $1776(90 \%)$ children the combination of a fully completed questionnaire and valid impedance measurements was obtained. The present analyses were restricted to this group. General characteristics are shown in Table 1. 
Table 1. Average age, height and weight ( \pm sd) of the 1776 investigated children.

\begin{tabular}{lcc}
\hline Characteristics & Boys, $n=906(51 \%)$ & Girls, $n=870(49 \%)$ \\
\hline age, $y r$ & $9.8( \pm 1.8)$ & $9.7( \pm 1.7)$ \\
height, $\mathrm{cm}$ & $1.42 .0( \pm 11.5)$ & $140.9( \pm 12.1)$ \\
weight, $\mathrm{kg}$ & $33.6( \pm 8.1)$ & $34.1( \pm 9.1)$ \\
\hline
\end{tabular}

Of all children $44 \%$ were exposed to parental smoking (one or both parents), $8 \%$ were exposed to less than 10 smokes per day inside the home and $36 \%$ to 10 or more smokes per day inside the home. Of the fathers as well as of the mothers $30 \%$ were current smokers. Of the mothers $9 \%$ (161) smoked less than 10 smokes per day inside the house, of the fathers $16 \%$ (277) did so. The percentage of parents smoking 10 or more smokes per day inside the house was higher in mothers $21 \%$ (379) than in fathers $14 \%$ (252). The reported 'dose' ranged from 1 to 40 smokes per day when fathers and mothers were studied separately, and from 1 to 60 when the data of both parents were combined.

Table 2. Regression coefficients resulting from the linear regression analysis, using maternal smoking to quantify ETS exposure, and the individual impedance parameters ('on-line', linear and quadratic) as dependent variables, for boys and girls separately.

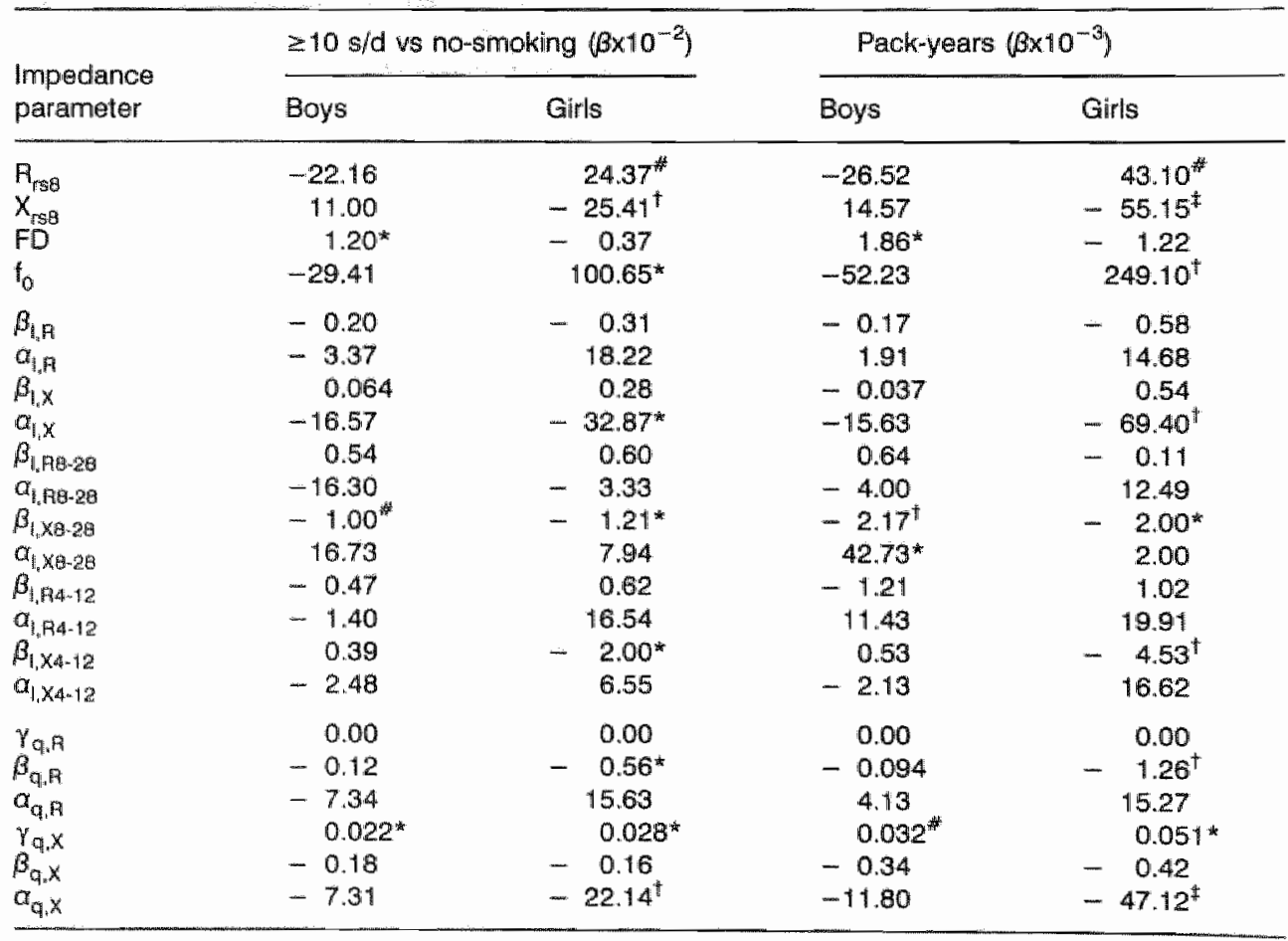

* $p \leq 0.10 ; * p \leq 0.05 ;+p \leq 0.01 ; p \leq 0.001 ;$ all values $<10^{-5}=0.00$ 
When the maternal categorical values were used to quantify ETS-exposure, small significant effects were observed on about half of the investigated impedance parameters in girls, whereas in boys only three impedance parameters were significantly affected. The most obvious effects were found in the highest smoking category (10 or more smokes/day). When mothers had stopped smoking, significant effects were found on $\alpha_{\mathrm{VR} 4-48}, \mathrm{R}_{\mathrm{rs} 8}, \alpha_{\mathrm{RR} 4-12}$ and $\gamma_{\mathrm{gR}}$ in girls, but not in boys. When the mother reported to smoke less than 10 smokes/day, only an effect on $\gamma_{\mathrm{qP}}$ in girls was found (data for these two categories not shown). Independent of how exposure to maternal smoking was quantified (categorical $\geq 10$ smokes/day, total dose or cumulative dose), in each case almost the same impedance parameters were affected. To reduce the large number of data and because of the similarity in results, Table 2 only contains the regression coefficients for the highest maternal smoking category ( $\geq 10$ smokes/day compared to never smokers) and the maternal cumulative dose (pack-years), for girls and boys separately. It appeared that the significantly affected impedance parameters mainly were parameters of respiratory reactance (Table 2). The effects were most consistent in girls and became more significant when cumulative dose (pack-years) was used to quantify ETS exposure, in stead of the categorical variable ( $\geq 10 \mathrm{smokes} / \mathrm{day})$.

Table 3. Regression coefficients resulting from the linear regression analysis, using paternal smoking to quantify ETS exposure, and the individual impedance parameters ("on-line", linear and quadratic) as dependent variables, for boys and girls separately.

\begin{tabular}{|c|c|c|c|c|}
\hline \multirow{2}{*}{$\begin{array}{l}\text { Impedance } \\
\text { parameter }\end{array}$} & \multicolumn{2}{|c|}{$\geq 10$ s/d vs no-simoking $\left(3 \times 10^{-2}\right)$} & \multicolumn{2}{|c|}{ Pack-years $\left(\beta \times 10^{-3}\right)$} \\
\hline & Boys & Girls & Boys & Gir's \\
\hline$R_{\mathrm{rsB}}$ & 20.24 & -6.81 & $44.20^{\#}$ & -14.17 \\
\hline$x_{r s a t}$ & $-18.13^{3}$ & -8.22 & -26.37 & -12.27 \\
\hline $\mathrm{FD}$ & 0.40 & 0.44 & 6.79 & 1.07 \\
\hline$f_{0}$ & 87.13 & 27.75 & 140.26 & 9.57 \\
\hline$\beta_{\|, \mathbb{R}}$ & 0.13 & -0.17 & 0.72 & -0.072 \\
\hline$a_{1, A}$ & -2.20 & 9.70 & -23.85 & 3.51 \\
\hline$\beta_{1, x}$ & 0.082 & 0.14 & 0.86 & 0.27 \\
\hline$a_{1, x}$ & -15.12 & 1.39 & $-55.52^{*}$ & 36.16 \\
\hline$\beta_{1, P Q-2 B}$ & 0.77 & -0.13 & 0.63 & -0.096 \\
\hline$\alpha_{i, 18-28}$ & -8.42 & 10.10 & 6.87 & 26.55 \\
\hline$\beta_{1, \times 2-20}^{r_{1}}$ & -0.52 & $-1.23^{*}$ & -0.61 & $-1.85^{*}$ \\
\hline$a_{1,18-28}$ & 5.47 & 15.59 & -6.03 & 15.93 \\
\hline$\beta_{1, \mathrm{~A} 4-12 \mathrm{C}}$ & 0.14 & $-\quad 0.24$ & -0.61 & $-\quad 1.04$ \\
\hline$a_{1, A 4-12}$ & 5.52 & 16.66 & 10.92 & 36.89 \\
\hline$\beta_{1, x-12}^{1,44-12}$ & 0.49 & -1.17 & 0.67 & $=1.18$ \\
\hline$a_{1,3,4-12}$ & -6.11 & 0.038 & -9.46 & -11.62 \\
\hline $\mathrm{Yg}_{\mathrm{g}} \mathrm{n}$ & 0.016 & 0.013 & 0.025 & 0.019 \\
\hline$\beta_{9, A}$ & -0.10 & -0.41 & -0.36 & $-0.90^{*}$ \\
\hline$a_{\mathbb{q}_{1} \mathbb{R}}$ & 7.78 & $9.3 \|$ & 14.28 & 24.95 \\
\hline$V_{q, x}$ & 0.019 & 0.00 & $0.064^{\sharp}$ & 0.00 \\
\hline$\beta_{\mathrm{C}_{\mathrm{F}} \mathrm{X}}$ & 0.00 & $-\quad 0.070$ & 0.078 & -0.11 \\
\hline$a_{a_{0} x}$ & -9.89 & -13.50 & $-25.28^{3}$ & $-26.55^{*}$ \\
\hline
\end{tabular}

\# $p \leq 0.10_{;}^{*} p \leq 0.05 ;+p \leq 0.01$; all values $<10^{-5}=0.00$ 
Effects of paternal smoking are presented in Table 3. As with maternal smoking, the results were almost independent of the way in which exposure to paternal smoking was quantified, thus again only those for the highest paternal smoking category ( $\geq$ 10 smokes/day versus never smokers) and the paternal cumulative dose (pack-years) are presented. Less impedance (reactance) parameters were significantly affected than with maternal smoking, and this time somewhat more pronounced in boys rather than in girls.

For fathers who had stopped smoking significant effects were observed on $X_{\mathrm{Ts} 8}, \beta_{\mathrm{XX} 4-12^{\prime}}$ $\alpha_{i \times 4-12}$, and when fathers reported smoking less than 10 smokes/day inside the house, significant effects were observed on $\mathrm{R}_{\mathrm{rs} 8}, \mathrm{X}_{\mathrm{rSB}}, \mathrm{f}_{0}, \alpha_{\mathrm{IX8}-28}$ and $\alpha_{\mathrm{XX}-12}$, in boys but not in girls (data not shown). The results in Table 3 show which of the impedance parameters were significantly affected with paternal pack-years, in boys: $\alpha_{1, X}, R_{r s 8^{:}} \gamma_{\mathrm{q}, \mathrm{X}}$ and $\alpha_{q, X}$, and in girls: $\beta_{1, \times 8-28^{*}} \beta_{q, R}$ and $\alpha_{q, X}$. In addition to these effects, using dose in stead of cumulative dose, resulted in significant effects on $X_{\mathrm{rs} 8}, f_{0}$ and $\gamma_{\mathrm{qR4} 4-48}$ in boys.

Table 4. Regression coefficients resulting from the linear regression analysis, using the combination of maternal + paternal smoking to quantify ETS exposure, and the individual impedance parameters ("on-line", linear and quadratic) as dependent variables, for boys and girls separately.

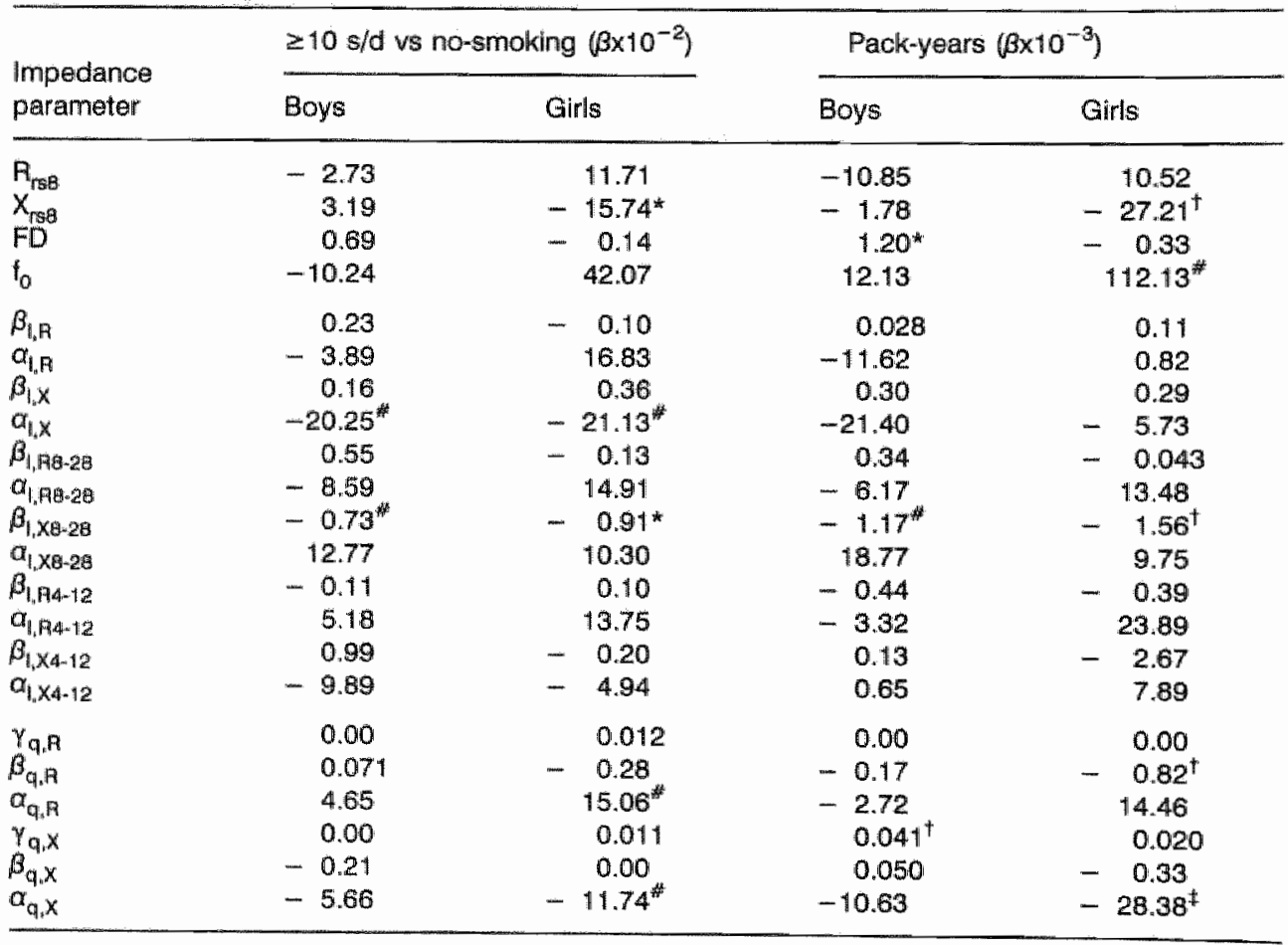

\# $p \leq 0.10 ; * 0 \leq 0.05 ; \uparrow p \leq 0.01 ; \neq p \leq 0.001$; all values $<10^{-5}=0.00$ 
When the data on maternal and paternal smoking habits were combined (parental smoking) the results were quite comparable to those obtained with maternal smoking, although the total number of affected parameters was somewhat smaller. Again, the majority of the effects were found on respiratory reactance, were more significant with cumulative dose (pack-years), and effects were most pronounced in girls (Table 4). If father and/or mother had stopped smoking significant effects were found on $\alpha_{1 \mathrm{R} 4-48}$, $R_{\mathrm{rS} 8}, \beta_{\mathrm{IX8}-28}, \alpha_{\mathrm{IX8}-28}, \alpha_{\mathrm{IRA}-12}$ and $\gamma_{\mathrm{qR}}$, in girls but not in boys.

\section{DISCUSSION}

In the present study we found parental smoking to be significantly associated with respiratory impedance abnormalities, especially respiratory reactance, in primary school children. The effects of maternal and (combined) parental smoking were most pronounced in girls, whereas with paternal smoking a small number of the impedance parameters was significantly affected in boys rather than in girls. Most of the effects were observed if father and/or mother smoked more than 10 smokes per day inside the house, and these results are comparable with those obtained with 'dose' and 'cumulative dose'. These findings may suggest that the 'dose of smokes' the child is exposed to is important in inducing the effects.

We used the technique of forced oscillations to measure respiratory input impedance. The measurements were rapidly and easily performed by the child as well as the investigator. In a previous study ${ }^{23}$ we found input impedance values in children to differ from those reported in adults. ${ }^{24,25}$ In small (young) children reactance values are more negative and resistance values are higher than those found in adults, and negative frequency dependence of resistance (i.e. a decrease in resistance with increasing frequency) appeared to be a common finding. During growth, reactance becomes less negative, resistance decreases, negative frequency dependence of resistance disappears, and values approach those reported in adults. In children reported to suffer from asthma-like symptoms, compared to symptom-free children, reactance and frequency dependence of resistance were significantly more negative, and resistance was significantly higher, although in absolute terms differences were small. ${ }^{34}$

In the present study, the affected impedance parameters were mainly measures of respiratory reactance, which was more negative in children exposed to parental smoking. Reactance depends on the elastic and inertial properties of the respiratory system, including central gas and tissue inertances and a peripheral compliance representing the lung tissue. ${ }^{31,32}$ Reactance is furthermore known to be influenced by lung volume. 33 It has been demonstrated that in adult patients with airflow obstruction, and in children who report asthma-like symptoms, reactance values are more negative than in healthy subjects. ${ }^{25,34}$ The results reported by Collins et al., ${ }^{35}$ using an animal model (rat fetuses) to study maternal smoking effects during pregnancy, suggest that prenatal smoking may induce structural changes (alter lung elastic properties) and reduce lung growth of the fetal lung. In several studies larger FVC values, in children of smoking mothers have been found, along with decrements in other spirometric parameters. ${ }^{36,37}$ Our impedance data can partly be explained by progressive contribution of the compliance of the airways as expanding structures mechanically in parallel with the airways which they supply, as a secondary effect of an increase in the resistance of peripheral airways. However, an increase in lung compliance in 
series with the compliance of the thorax wales does not influence the reactance of the respiratory system. In the present study significant effects were found on several impedance parameters in girls of whom the parents stopped smoking, suggesting persistence of the effects. An effect of maternal smoking on lung development in utero, which may even persist throughout childhood is supported by findings recently reported by Wang et al. ${ }^{15}$

The effects of parental smoking on their children's lung function are likely to depend on several factors, including the amount of time spent by the parent with the child, the number of cigarettes smoked and the child's susceptibility. To explain the predominance of the maternal smoking effect, it has been speculated that mothers compared to fathers smake significantly more cigarettes when they are at horne, in the presence of the child. This statement is supported by the data of the present study. Although the total number of smokers was equal for fathers and mothers, more mothers than fathers were reported to be "heavy inside" smokers (i.e. smoking more than 10 smokes per day inside the house). Furthermore, if maternal smoking already affects lung development in utero, ${ }^{15}$ this may, at least in part, explain the predominance of the maternal smoking effects.

We found that maternal and combined parental smoking mainly affected impedance parameters in girls. Differences in life-style between boys and girls, may result in differences in the time spent with their parents. We have no clear explanation for the fact that when paternal smoking was studied separately, affected impedance parameters were abserved in boys rather than in girls. The fact that in these analyses no account was made for the influences of maternal smoking (which on the whole seems to be more important) may in part be responsible for these observations. However, the mechanism of association between a child's lung function and maternal and/or paternal smoking remains unexplained.

Available data from the literature do not show a consistent gender specific pattern in the effects of passive smoking on lung function. Results vary between larger susceptibility in boys, ${ }^{6-8}$ larger susceptibility in girls ${ }^{1,9,10}$ and no gender differences. ${ }^{12,14,15}$ It has been pointed out that girls seem to be more affected by maternal smoking than boys when the middle and proximal portions of the flow-volume and time-volume curves are used as a measure of lung function, whereas FEV, has been reported to be more sensitive in detecting effects of maternal smoking in boys. ${ }^{8,13}$ Part of this inconsistency with regard to the gender difference in susceptibility to ETS exposure, may be due to the specific methodology applied to determine exposure and effect, used in the different studies. In a previous study we found that spirometry and impedance parameters were significantly affected when children were during their entire life exposed to parental smoking. ${ }^{38}$ The effects were most pronounced in boys, suggesting larger susceptibility. Based on the higher incidence and prevalence of childhood asthma observed in boys, ${ }^{39}$ it has been suggested that the increased susceptibility may have a physiologic basis. The present results, however, do not support this hypothesis, since the majority of the effects were found in girls.

Our data suggest the existence of a dose-response relationship. Impedance, especially reactance parameters in girls, were significantly affected with maternal smoking of to or more smokes per day and with the "total dose" of maternal smoking. Until now the existence of such a relationship is uncertain. Recently, it has been reported that knowing who smokes (father, mother or both) is more important than knowing the number of cigarettes smoked. ${ }^{40}$ Furthermore, the minimal dose at which an effect of parental smoking can be detected remains unclear. The results of our previous study 
suggest the importance of (cumulative) dose (=duration of exposure), since the effects on lung function were the largest and most consistent in children exposed during their entire life. ${ }^{38}$ Similar results have been reported by Murray et al. ${ }^{41}$ in asthmatic children, who found pulmonary function in both boys and girls to be progressively impaired with duration of exposure. That in the present study effects became even more significant when 'pack-years" was used instead of "dose' to quantify maternal smoking, again supports the importance of cumulative exposure.

The question about the longterm consequences of the observed small deficits in pulmonary function that have been attributed to ETS exposure, also remains to be answered. However, the results from several longitudinal studies which found reduced rates of development of lung function in children, exposed to parental smoking "do suggest that on a longer term respiratory health may be impaired in these children. $12-15,37$

Several factors from the indoor environment, like home dampness and sources of nitrogen dioxide (combustion appliances), have been demonstrated to affect respiratory health in children. ${ }^{42,43}$ Furthermore, lower socioeconomic status has been suggested to increase the risk of developing childhood asthma. ${ }^{17}$ For this reason these variables were entered into the regression analyses to adjust for their possible confounding effects. For the majority of the additional impedance parameters, obtained from the individual linear and quadratic regression curves, significant associations were observed with home dampness. Exposure to unvented kitchen geysers significantly affected impedance parameters in girls only, which is in agreement with the findings of our previous study. 38 Some of the impedance parameters were significantly associated with the educational level of the father. All these associations are, however, only indicative as the analyses were designed to adjust sufficiently for confounding variables rather than to investigate these rellationships directly.

The concliusions to be drawn from the present study are restricted by its crosssectional design, findings may be subject to bias since exposure of interest and disease status are examined at one moment in time. Furthermore, parents may underreport smoking, especially in the case of symptomatic children, which would result in bias to the null. At present, however, we were not able to control for these kinds of biases nor for ETS exposure outside the house (on schools, with family and/or friends). In future studies more objective measures of exposure, such as measurements of salivary or urinary cotinine levels could probably give more insight in the existing dose-response relationship.

In summary, in this study we found parental smoking to be associated with respiratory impedance abnormalities in Dutch primary school children, with some evidence of a dose-effect relationship. The effects were more pronounced with maternal and (combined) parental smoking than with paternal smoking, and were found to be more consistent in girls than in boys, suggesting them to be more susceptible to parental smoke exposure. The observation that mainly parameters of respiratory reactance were affected, supports the proposed mechanism of action with passive smoking, namely that it may influence peripheral airway characteristics during the development of the child's lung. However, further studies will be needed to clarify this issue. Given the still relatively large number of parents who are smokers ( $44 \%$ of the children are exposed to parental smoking), more action should be taken to convince parents to quit smoking on behalf of their children's respiratory health. 


\section{ACKNOWLEDGEMENTS}

We thank the teachers of the cooperating schools, the children and their parents for participating in the study. We thank Jos Slangen for his valuable contribution to the statistical analysis and René Cardynaals for his help to handle the impedance data files. This study was conducted in a successful collaboration of the Department of Public Health, Regional Services of Roermond, Groningen and the University of Maastricht.

\section{APPENDIX}

Smoking habits:

* Does the mother of the child smoke at the moment?

1) No, never smoked.

2) No, stopped smaking in 19..(fill in date)

3) Yes, started smoking in 19.. (fill in date)

* How many does the mother, on the average, smoke per day inside the house? (number of smokes/day).

* Does the father of the child smoke at the moment?

1) No, never smoked.

2) No, stopped smaking in 19. . (fill in date)

3) Yes, started smoking in 19.. (fill in date)

* How many does the father, on the average, smoke per day inside the house? (number of smokes/day).

Confounders:

* Did you ever have damp stains in your home in the past two years? (never, sometimes, often, always).

* How is the hot-water supply arranged in the present house?

Unvented geyser inside the kitchen? $(y / n)^{\dagger}$

* What is for the father the highest obtained school (leaving) certificate? (eight possible levels).

t one of the possibilities

\section{REFERENCES}

1. Tager IB. Health effects of 'passive smoking' in children. Chest $1989 ; 96: 11611-1164$.

2. Fielding JE, Phenow Kul. Health effects of involuntary smoking. New Engl I Med 1988; 319: $11452-1460$.

3. Meister R. Environmental Pollutants and passive smoking (Allgemeine Umwelimoxen und Passivrauchen). Pneurnologie 1990" 44: 378-386.

4. Spitzer WO, Lawrence V, Dales R, Hill G, Archer MC, Clark P, Abenhaim L, Hardy J, Sampalis $J$, Pinfold SP, Morgan PP. Links between passive smoking and disease: a best evidence synthesis. A report of the working group on passive smoking. Clin Invest Med 1990; 13:17-42.

5. Wright AL, Holberg $C$, Martinez FD, Taussig LM, Group Health Medical Associates. Relationship of parental smoking to wheezing and nonwheezing lower respiratory tract illinesses in intancy. J Pediatr 1991: 118: 207-214. 
6. Rona RJ, Chinn S. Lung function, respiratory illness, and passive smoking in British primary school children. Thorax 1993; 48: 21-25.

7. Murray AB, Morrison B. Passive smoking by Asthmatics: lis greater effect on boys than on girls and on older than on younger children. Pediatrics 1989; 84: 454-459.

8. Burchfield CM, Higgins MW, Keller JB, Howatt WF, Butler WJ, Higgins ITT. Passive smoking in childhood. Respiratory conditions and pulmonary function in Tecumseh, Michigan. Am Rev Respir Dis 1986; 133: 966-973.

9. Yue Chen, Wan-Xian Li. The effects of passive smoking on children"s pulmonary function in Shanghai. Am J Public Health 1986; 76: 515-518.

10. Vedal S, Schenker MB, Samet JM, Speizer FE. Risk factors for childhood respiratory disease. Analysis of pulmonary function. Am Rev Respir Dis 1984; 130: 187-192.

11. Strachan $D P$, Jarvis $M J$ Feyerabend $C$. The relationship of salvary cotinine to respiratory symptoms, spirometry and exercise-induced brochospasm in seven-year old children. Am Rev Respir Dis 1990; 142: 147-151.

12. Tager IB, Weiss ST, Munoz A, Rosner B, Speizer F. Longitudinal study af the effects of maternal smoking on pulmonary function in children. New Engl J Med 1983; 309: 699-703.

13. Sherrill DL, Martinez FD, Lebowitz MD, Holdaway MD. Flannery EM, Herbison GP, Stanton WR, Silva PA, Sears MR. Longitudinal effects of passive smoking on pulmonary function in New Zeelland children. Am Rev Respir Dis 1992; 145; $1136-1141$.

14. Berkey CS, Ware JH, Dockery DW, Ferris Jr, Speizer FE. Indoor air pollution and pulmonary growth in preadolescent children. Am J Epidemial 1986; 123: 250-260.

15. Wang $X$, Wypil D, Gold DR, Speizer FE, Ware JH, Ferris BG, Dockery DW. A longitudinal study of the effects of parental smoking on pulmonary function in children 6-18 years. Am J Respir Crit Care Med 1994; 149: 1420-1425.

16. Martinez FD, Antognoni G, Marci $F$, Bonci $E$, Midulla F, De Castro G, Ronchetti R. Parental smoking enhances bronchial responsiveness in nine-year-old children. Am Rev Respir Dis $1988 ; 138: 518-523$.

17. Martinez FD, Cline $M$, Burrows $B$. Increased incidence of asthma in children of smoking mothers. Pediatrics 1992; 89: 21-26.

1B. Làndsér F.J, Nagels J, Demedts. M, Billiet L, Van de Woestijne KP. A new method to determine frequency characteristics of the respiratory system. J Appl Physiol 1976; 41: 101-06.

19. Wouters EFM. Total respiratory impedance measurement by forced oscillations: a nonilvasive method to assess bronchial response in occupational medicine. Exp Lung Research 1990; 16: 25-40.

20. Florey C du V, Leeder SA. Methods for cohort studies of chronic airflow limitation, (chapter 3). WHO regional publications, European series No. 12. London, 1982. United Kingidom.

21. Brunekreef $B$, Groat $B$, Rijcken $B_{n}$ Hoek $G$, Steembekkers $A_{0}$ De Boer A. Reproducibility of childhood respiratory symptom questions. Eur Fespir J 1992; 5: 930-935.

22. Wouters EFM, Làndsér FJ, Polko AH, Visser BF. Physiological analysis of exteinded spectrum oscillometry. Fespiration 1988; $54: 263-270$.

23. Cuijpers CEJ, Wesseling GJ, Swaen GMH, Wouters EFM. Frequency dependence of ascillatory resistance in healthy primary school children. Respiration 1993; 60: 149-154.

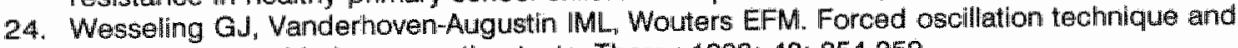
spirometry in cold air provocation tests. Thorax 1993 ; $48: 254-259$.

25. Clement $\mathrm{J}$, Làndser FJ, Van de Woestijne KP. Total resistance and reactance in patients with respiratory complaints with and without airway obstruction. Chest $1983 ; 83: 215-220$.

26. Clément $J$, Dumoulin $B$, Gubbelmans $\mathrm{A}$, Hendriks KP, Van de Woestijne KP. Feference values of total respiratory resistance and reactance between 4 and $26 \mathrm{~Hz}$ in children and adolescents aged 4-20 years. Bull Eur Physiopathol Respir 1987; 23: $441-448$.

27. Stanescu D, Moavero NE, Veriter $C$. Brasseur L. Frequency dependence of respiratory resistance in healthy children. J Appl Physiol 1979; 47: 268-272.

28. Van de Woestijne KP, Desager KN, Duiverman EJ, Marchal F. Recommendations for measurement of the respiratory impedance input impedance by means af the forced oscillations method. Eur Respir Rev 1994; 19: 235-237.

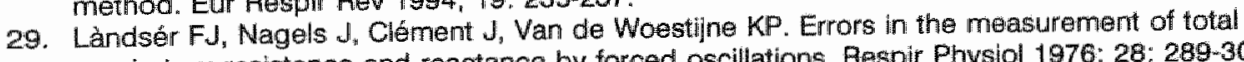
respiratory resistance and reactance by forced oscillations. Pespir Physiol 1976; 28: 289-301.

30. SPSS Inc. 444n Michigan Avenue, Chicago, 1990. Illinois 60611.

31. Jackson AC, Lutchen KR. Modeling of respiratory system impedances in dogs. J Appl Physiol 1987: 62: 414-420. 
32. Kappos AD, Rodarte JP, Lai-Fook SJ. Frequency dependence and partitioning of respiratory umpedance in dogs. J Appl Physiol Respir Environ Exercise Physiol 1981; 51: 621-629.

33. Nagels $\downarrow$, Làndsér $F j_{\text {, Var }}$ der Linden $L$, Clément $J$ o Van de Woestijne KP. Mechanical properties of lungs and chest wall during spontaneous breathing. J Appl Physiol 1980; 49: 408-416.

34. Cuijpers CEJ, Wesseling GJ, Swaen GMH, Wouters EFM. Height and gender related impedance values in primary school children. Eur Respir Rev 1994; 4: 150-154.

35. Collins MH, Moessinger AC, Keinerman J, Bassi J, Fosso $P$, Collins AM, James LS, Blani WA Fetal luring hypoplasia associated with maternal smoking: $\mathbb{A}$ morphometric analysis. Pediatr Res 1985: 19: 408-412.

36. Ware $\mathrm{JH}$, Dockery DW, Speizer FE, Ferris BG. Passive smoking, gas cooking, and respiratory thealth of children living in Six Cities. Am Rev Respir Dis 1984; 129: 366-374.

37. Lebowitz $\mathrm{MD}_{n}$ Holberg $\mathrm{CJ}$, Kunudson $\mathrm{P}_{\mathrm{J}}$, Burrows B. Longitudinal study of pulmonary function development in childhood, adolescence, and early adulthood. Am Rev Respir Dis 1987; 136: 69-75.

38. Cuijpers CEJ, Swaen GMH, Wesseling GJ, Sturmans F, Wouters EFM. Adverse effects of the indoor environment on respiratory health in primary school children. Accepted for publication in Environ Research (in press 1994).

39. Godfrey S. Childhood asthma. In: Asthma (3rd edn), eds. Clark TJH, Godfrey $\mathrm{S}_{\mathrm{n}}$ Lee $\mathrm{TH}$. Chapmann \& Hall, London, 1992 (chapter 18, p551-604).

40. Marbury MC, Hammond SK, Haley NJ. Measuring exposure to environmental tobacco smoke in studies of acute health effects. Am J Epidemiol 1993; 137: 1089-1097.

41. Murray $A B$, Morrison BJ. Passive smoking by asthmatics: its greater effects on boys than on girls and on older than on younger children. Pediatrics 1989; 84: 451-459.

42. Brunekreef B, Dockery DW, Speizer $\mathrm{FE}_{\text {" Ware }} \mathrm{JH}_{4}$ Spengler JD, Ferris BG. Home dampness and respiratory morbidity in children. Am Rev Respir Dis 1989; 140: 1363-1367.

43. Samet JM, Utell MJ. The risk of nitrogen dioxide: what have we learned from epidemiological and clinical studies? Tox Indus Health 1990; $6: 247-262$. 


\section{Chapter 7}

\section{ACUTE RESPIRATORY EFFECTS OF LOW LEVEL SUMMER-SMOG IN PRIMARY SCHOOL CHILDREN}

CEJ Cuijpers, GMH Swaen, GJ Wesseling, G Hoek, F Sturmans, EFM Wouters 


\section{ACUTE RESPIRATORY EFFECTS OF LOW LEVEL SUMMER-SMOG IN PRIMARY SCHOOL CHILDREN}

\section{ABSTRACT}

Possible effects on respiratory health of exposure to a summer-smog-episode were studied in 212 school children. At baseline, when air pollutant levels were low, (55 $\mu \mathrm{g} / \mathrm{m}^{3}$ for $\mathrm{SO}_{2}$ and $58 \mu \mathrm{g} / \mathrm{m}^{3}$ for $\mathrm{NO}_{2}$ (max. 24-hour means), and $2-56 \mu \mathrm{g} / \mathrm{m}^{3}$ for $\mathrm{O}_{3}$ (8-hour mean)), acute respiratory symptoms were evaluated by questionnaire and lung function was assessed by spirometry and respiratory impedance measurements. After the episode, characterised by 8-hour $\mathrm{O}_{3}$ levels $>120 \mu \mathrm{g} / \mathrm{m}^{3}\left(163 \mu \mathrm{g} / \mathrm{m}^{3}\right)$ and 1 -hour levels > $160 \mu \mathrm{g} / \mathrm{m}^{3}\left(215 \mu \mathrm{g} / \mathrm{m}^{3}\right)$, the 212 children were re-examined.

No significant effects were observed on the prevalence of acute respiratory symptoms. When individual changes in lung function indices ( $\triangle L F$ ) were regressed on changes in previous day ozone (8-hour mean) and changes in mean dally temperature ( $\triangle M T$ Temp), using multiple linear regression analysis, a significant negative association was observed with $P E F$, but not with other spirometric indices. Although significant associations were observed with $X_{\mathrm{rs} B}, f_{0}$ and FD, the signs of the $\beta$ 's were opposite to the direction expected when $\mathrm{O}_{3}$ adversely affected the impedance outcomes. $\triangle M T e m p$ was positively associated with all spirometric indices, except the PEF, but not with impedance parameters.

In conclusion, in this study short-term exposure to moderately high levels of ozone did not result in clear adverse effects on children's respiratory health. Further research into the applicability of the FOT in this type of field studies still seems to be advisablle.

\section{INTRODUCTION}

In recent years there has been an increasing concern about the possible health consequences of air pollution episodes (smog). Such episodes happen during stagnant weather conditions in summer as well as in winter, though the pollutants of primary concern during these episodes usually differ. For summer-smog, ozone is considered to be the major indicator component of the much more complex mixture of pollutants. In contrast to the pollutants from winter type smog (sulphur dioxide, particulate matter), only little progress has been made in controlling ozone in ambient air." In recent years, 
in the Netherlands, health effects due to photochemical episodes constitute an impor tant public health issue.?

Prolonged exposure of moderately to heavily exercising subjects to ozone concentrations near ambient levels, can result in (transient) lung function decrements, respiratory and other symptoms, increased non-specific bronchial responsiveness and inflammatory reactions. ${ }^{1,3}$ The lung function response to ozone increased with physical exercise and exposure time. ${ }^{4,5}$ Levels at which these effects have been observed are in the range of $160-240 \mu \mathrm{g} / \mathrm{m}^{3}$ ozone. ${ }^{4,6,7}$ Children experimentally exposed to ozone levels in this range, showed lung function decrements comparable in magnitude to those found in adults. In contrast, no symptom responses were observed in children. ${ }^{8.9}$ Epidemiological and field studies have demonstrated that exposure to ambient ozone levels near or below US standards was associated with transient decreases in pulmonary function of children ${ }^{10-15}$ and in two studies the lung function was negatively associated with previous-day ambient ozone. ${ }^{14,15}$ Furthermore, hospital admissions for respiratory illnesses (asthma) were found to be significantly associated with ozone levels lower as those given as guidelines. ${ }^{16,17}$

The present study was undertaken to examine the relationship between acute exposure to ambient pollutants including ozone $\left(\mathrm{O}_{3}\right)$, particulate matter $\left(\mathrm{PM}_{40}\right)$, acid aerosol, sulphur dioxide $\left(\mathrm{SO}_{2}\right)$, nitrogen dioxide $\left(\mathrm{NO}_{2}\right)$ and black smoke $(\mathrm{BS})$ and respiratory function in children, during a summer-smog-episode. Children were studied because cigarette smoking and exposure to occupational lung irritants are not likely to be confounding factors. Furthermore, children can easily be studied at school during their normall daily activities.

Besides current spirometry respiratory impedance measurements, using the forced oscillation technique (FOT), were performed in these children. Earlier studies have demonstrated that the FOT is a suitable tool to evaluate the mechanical characteristics of the respiratory system in (young) children. ${ }^{18-20}$ The measurements are non-invasive and effort-independent, and 3 to 5 valid impedance measurements per child can be obtained in a relatively short time (5-10 minutes). In the present study, the complementary value of the FOT in the early detection of small changes in lung function due to exposure to air pollution episodes, suggested by Peslin et al. ${ }^{21}$ and Wouters, ${ }^{22}$ was investiglated.

\section{METHODS}

\section{Design}

In November and December 1990, baseline health measurements were carried out in 534 children (mean age $8.9 \pm 1.7$ year). Parents of 614 children were approached by a letter given to children from two, randomly selected, primary schools in Maastricht, the Netherlands. Written informed consent was obtained for $534(87 \%)$ children, 251 boys (47\%) and 283 girls $(53 \%)$. After a summer air pollution episode, defined as a time period with 8 -hour average levels of $\mathrm{O}_{3}$ higher than $120 \mu \mathrm{g} / \mathrm{m}^{3}$ on at least two consecutive days, ${ }^{23}$ occurring in July 1991,212 randomly selected children (102 boys, 110 girls) were re-examined (mean age $9.0 \pm 1.7$ year). The lung function measure ments were carried out from 8 to 16 July; on each day on average 30 children were measured. The study was approved by the medical ethics committee of the University of Limburg. 


\section{Air Quality Measurements}

Part of the information about ambient levels of air pollutants was obtained from the nearest site of the National Air Pollution Monitoring Network, Wijnandsrade. The gaseous component $\mathrm{SO}_{2}$ was registered by continuous monitors based on fluorescence and $\mathrm{NO}_{2}$ and $\mathrm{O}_{3}$ were registered by continuous monitors based on chemiluminescence. 24-Hour average concentrations of black smake were measured using the method of the Organisation for European Cooperation and Development (OECD). ${ }^{24}$ Data on the ambient minimum temperature were also collected. Additionall measurements were carried out for particulate matter and acid aerosol. Twenty four hour average concentrations of particulate matter with an aerodynamic diameter less than $10 \mu \mathrm{m}\left(\mathrm{PM}_{10}\right)$ were made with an instrument described by $\mathrm{Liu}^{25}$ with an inlet design similar to the Sierra Andersen 241 dichotomous sampler. No separation in fine $(<2.5 \mu \mathrm{m})$ and coarse particles $(>2.5 \mu \mathrm{m})$ is accomplished with this sampler. Acid aerosol was sampled by an Annular Denuder system, described by van der Meulen et al. ${ }^{26}$ and analyzed for $\mathrm{H}^{+}$, sulphates, nitrates and ammonium. The system consisted of two sodium carbonate coated denuders, one citric acid coated denuder and a filter pack with a teflon and nylon backup filter. The measurements of $\mathrm{PM}_{10}$ and acid aerosols took place every eighth day during the baseline period. During the summerepisode these measurements were taken on a daily basis, between $7.00 \mathrm{a} . \mathrm{m}$. and 7.00 p.m. (12-hour average).

\section{Effect Parameters}

Main health outcome measures in this study are changes in lung function determined by the forced oscillation technique (FOT) and spirometry, and the prevalence of acute respiratory symptoms measured by a written questionnaire. The lung function measurements took place at school during school time hours. Directly after the smogepisode, summer holiday started. Consequently, the parents and their children were difficult to reach and no further measurements were made.

- The questionnaire. During the baseline period the prevalence of acute and chronic respiratory symptoms was evaluated by means of a written questionnaire, completed by the parents of the children. The questionnaire is a Dutch version of the children's questionnaire of the World Health Organisation published by Florey and Leeder. ${ }^{27}$ Except for 'chronic cough' the reproducibility of the answers of the Dutch questionnaire for chronic respiratory symptoms has been found to be good. ${ }^{28}$ During the summersmog-episode a condensed form of the original questionnaire was used, especially aimed at respiratory symptoms in the previous week (see Appendix) and relevant changes in the indoor environment, such as exposure to parental smoking, home dampness, gas appliances and pets. The parents completed these questionnaires between 8-16 July.

- Forced oscillation technique. The technique of forced oscillations (FOT) used in this study was similar to the method described by Làndser et al. ${ }^{29}$ The measurements are performed during spontaneous quiet breathing and enable the assessment of mechanical characteristics of the respiratory system. The technique, extensively described elsewhere, ${ }^{30}$ yields values for the total resistance and reactance of the respiratory system. The total resistance $\left(R_{r s}\right)$ comprises the resistance of the airways, the lungs, and the chest wall. The reactance $\left(X_{r s}\right)$ is determined by the inertial and capacitive properties of the respiratory system. In normal adults, resistance values 
increase slightly with increasing frequency. Reactance is usually slightly negative at lower frequencies and becomes positive at frequencies between 5 and $10 \mathrm{~Hz}$ (resonant frequency, $f_{0}$ ). In the presence of aiway obstruction there is an increase in resistance values especially at lower frequencies, which decrease with increasing frequency (negative frequency dependence of resistance, FD). Reactance values are more negative and resonant frequency is increased in patients with airflow obstruction. ${ }^{31}$ In healthy children negative frequency dependence of resistance, between 8 and 28 $\mathrm{Hz}$, is a common finding, which progressively decreases during growth, advancing to the values found in healthy adults. 18,19

In the present study impedance measurements with a coherence function less than 0.95 at 8 or $28 \mathrm{~Hz}$ or at more than three frequencies were rejected. Landser et al. ${ }^{32}$ demonstrated that for measurements with a coherence function exceeding 0.95 the error of the measurement due to the presence of noise or nonlinearities is less than $10 \%$. All measurement were performed with the child seated, wearing a nose clip and the cheeks and the floor of the mouth being supported with the hands of either the investigator or the child itself. Each child performed at least three valid impedance measurements. Recorded were the mean values for the resistance at 8 and $28 \mathrm{~Hz}\left(\mathbb{R}_{\mathrm{rs} 8}\right.$. $\left.\mathrm{R}_{\mathrm{rs} 28}\right)$, the reactance at $8 \mathrm{~Hz}\left(\mathrm{X}_{\mathrm{rs} 8}\right)$, the frequency dependence of resistance (FD) defined as the difference between the $R_{r s 28}$ and $R_{r s 8}$ divided by 20 and the resoneant frequency $\left(f_{0 ;}\right.$; frequency at which $\left.x_{r s}=0\right)$.

When exposure to elevated levels of air pollution results in ainway obstruction one would expect an increase in resistance and in resonant frequency, more negative reactance values and negative frequency dependence of resistance. ${ }^{22}$

- Spirometry. Spirametry was performed according to the ECCS-protocol, ${ }^{33}$ with the exception that five instead of three acceptable manoeuvres had to be collected out of a maximum of eight attempts. Measurements were performed with the child in standing position using a dry spirometer (Vitalograph Ltd., Buckingham, England). BTPS corrected readings were obtained directly from the spirometer. From the valid manoeurres the highest values for the forced vital capacity ( $\mathbb{F V C}$ ), the forced expiratory volume in one second ( $F E V_{1}$ ) and peak expiratory flow (PEF) were selected. The forced expiratory flow between 25 and $75 \%$ of the vital capacity (FEF $25-75 \%$ ) was selected from the measurement with the highest sum value for the FVC and the FEV " 33

\section{Analyses}

Using the data of the total group $(n=534)$ the cross-sectional association between pulmonary function and age (in days) was calculated, by simple linear regression analysis. This was done for impedance and spirometry, and for boys $(n=251)$ and girls $(n=283)$ separately. The time lag between baseline and summer episode measurements was about 7 months. The associations from the linear regression models were used to adjust for the difference between the first and the second pulmonary function lest result, for the changes in pulmonary function due to the increased age of the children. The growth rates resulting from this model are presented in Table 1.

First, differences in the prevalence of acute respiratory symptoms between baseline and episode were determined. Next, for each child the absolute change in lung function parameters was calculated for FVC, FEV $, P E F, F E F_{25.75 \%}, R_{r s 8} X_{r s 8} f_{0}$ and FD. Therefore the growth corrected baseline values were subtracted from the episode values. Besides, differences in previous day ozone concentrations were calculated (1- 
hour and 8-hour means); by episode value minus baseline value and likewise the changes in mean daily temperature were calculated.

Table 1. Growth rates for spirometry (A) and impedance parameters (B). based on the coefficients of the linear regression analysis of lung function on age (days) $(n=534)$.

A.

\begin{tabular}{|c|c|c|c|c|}
\hline \multirow[b]{2}{*}{ Spirometry } & \multicolumn{2}{|c|}{ Girls $(n=283)$} & \multicolumn{2}{|c|}{ Boys $(n=251)$} \\
\hline & Mean & $\#$ se & Mean & $\pm \mathrm{se}$ \\
\hline FVC & $231 *$ & 14 & 210 & 15 \\
\hline FEV & 204 & 11 & 165 & 13 \\
\hline PEF & 493 & 29 & 438 & 31 \\
\hline $\mathrm{FEF}_{25-75 \%}$ & 237 & 20 & 153 & 21 \\
\hline
\end{tabular}

* $=m \mathrm{~m} \times$ year-1 or $\mathrm{ml} \times \mathrm{s}-1 \times$ year- 1

B.

\begin{tabular}{|c|c|c|c|c|}
\hline \multirow[b]{2}{*}{ Impedance } & \multicolumn{2}{|c|}{ Girls $(n=283)$} & \multicolumn{2}{|c|}{ Boys $(n=251)$} \\
\hline & Mean & $\pm \mathrm{se}$ & Mean & \pm se \\
\hline $\mathrm{A}_{\mathrm{rBB}}$ & $-0.479^{t}$ & 0.050 & -0.362 & 0.058 \\
\hline$x_{r s 6}^{180}$ & 0.181 & 0.028 & 0.470 & 0.025 \\
\hline$f_{0}$ & $-1.47^{ \pm}$ & 0.21 & -1.06 & 0.24 \\
\hline FD & 0.008 & 0.002 & 0.005 & 0.002 \\
\hline
\end{tabular}

$t=\mathrm{CmH}_{2} \mathrm{O} /(\mathrm{L} / \mathrm{s}) \times$ year $-1 ; ;=\mathrm{Hz} \times$ year -1

Changes in the individual lung function parameters were regressed on changes in previous day ozone ( 1 and 8-hour means) and changes in mean daily temperature, using multiple linear regression analysis. If the growth rate was mismodeld the intercept would be expected to deviate from zero, however, the pollution slope would not be affected. In order to investigate differences in sensitivity to ozone exposure, the analyses were performed separately for a group of 43 children who reported one or more chronic respiratory symptoms at baseline. The SPSS-X statistical package was used to perform the analyses. 34

\section{RESULTS}

Air Quality Measurements

At the time of the baseline measurements ambient air pollution levels were low. The highest 24-hour averages for $\mathrm{SO}_{2}$, black smoke and $\mathrm{NO}_{2}$ in that period were $55 \mu \mathrm{g} / \mathrm{m}^{3}$, $54 \mu \mathrm{g} / \mathrm{m}^{3}$ and $58 \mu \mathrm{g} / \mathrm{m}^{3}$ respectively. Ozone levels were low as well. The highest observed 8-hour average was $56 \mu \mathrm{g} / \mathrm{m}^{3}\left(\mathrm{~min} .2 \mu \mathrm{g} / \mathrm{m}^{3}\right)$ and the highest observed 1hour average was $66 \mu \mathrm{g} / \mathrm{m}^{3}$ ( $\mathrm{min}$. $1 \mu \mathrm{g} / \mathrm{m}^{3}$ ). During the baseline period $\mathrm{PM}_{10}$ and acid aerosol were measured on six different days. The mean $\mathrm{PM}_{10}$ concentration over these six days was $65 \mu \mathrm{g} / \mathrm{m}^{3}$. Ambient levels of acid aerosol were low, the highest concentration of $\mathrm{H}^{+}$, expressed as equivalent sulphuric acid was $0.4 \mu \mathrm{g} / \mathrm{m}^{3}$. The 24hour mean ambient temperature in November was $5.9^{\circ} \mathrm{C}$ (range 1.1 to $11.2^{\circ} \mathrm{C}$; max. 
1 hour $13.1^{\circ} \mathrm{C}$ ) and in December $3.2^{\circ} \mathrm{C}$ (range -0.8 to $7.4^{\circ} \mathrm{C}$; max. 1 hour $9.4^{\circ} \mathrm{C}$ ). In calculating these means we included only those days on which baseline lung function measurements of the 212 children were performed.

During the summer episode from July $2^{\text {nd }}$ to July $14^{\text {th }}, \mathrm{O}_{3}$ levels were increased (Table 2). About eleven days the ozone concentration exceeded the $160 \mu \mathrm{g}^{3}$ with a maximum of $215 \mu \mathrm{g} / \mathrm{m}^{3}$. The highest observed 8-hour average concentration was 163 $\mu \mathrm{g} / \mathrm{m}^{3}$. There was a relatively large variation in ozone concentrations between individual measurement days, the highest 8-hour averages during the lung function measurement period occurred on July the $7^{\text {th }}, 10^{\text {th }}$ and $11^{\text {th }}$.

Table 2. Levels of air pollutants during the summer-episode (July 1991).

\begin{tabular}{|c|c|c|c|c|}
\hline Day & $O_{3}(8-h)$ & $P M_{10}(24-h)$ & $\mathrm{SO}_{4}(12-\mathrm{h})$ & $H^{+}(12-h)$ \\
\hline $02 / 07$ & $138 \mu \mathrm{g} / \mathrm{m}^{3}$ & & & \\
\hline 03107 & $163 \mu \mathrm{g} / \mathrm{m}^{3}$ & & & \\
\hline $04 / 107$ & $140 \mu \mathrm{g} / \mathrm{m}^{3}$ & & & \\
\hline 05/07 & $133 \mu \mathrm{g} / \mathrm{m}^{3}$ & & & \\
\hline $06 / 07$ & $130 \mu \mathrm{g} / \mathrm{m}^{3}$ & & & \\
\hline $07 / 07$ & $154 \mu \mathrm{\mu g} / \mathrm{m}^{3}$ & $42 \mu \mathrm{g} / \mathrm{m}^{3}$ & $10.39 \mu \mathrm{g} / \mathrm{m}^{3}$ & 0.00 \\
\hline \multicolumn{5}{|l|}{ Start HM } \\
\hline $\begin{array}{l}08 / 07 \\
09 / 07\end{array}$ & $90 \mu \mathrm{g} / \mathrm{m}^{3}$ & & $5.44 \mu \mathrm{g} / \mathrm{m}^{3}$ & 0.00 \\
\hline $\begin{array}{l}09 / 07 \\
10 / 07\end{array}$ & $80 \mu \mathrm{g} / \mathrm{m}^{3}$ & $24 \mu \mathrm{g} / \mathrm{m}^{3}$ & $1.20 \mu \mathrm{g} / \mathrm{m}^{3}$ & 0.00 \\
\hline $\begin{array}{l}10 / 07 \\
11 / 07\end{array}$ & $136 \mu \mathrm{g} / \mathrm{m}^{3}$ & $54 \mu \mathrm{g} / \mathrm{m}^{3}$ & $8.15 \mu \mathrm{g} / \mathrm{m}^{3}$ & 0.00 \\
\hline $\begin{array}{l}11 / 107 \\
12 / 07\end{array}$ & $1.43 \mu \mathrm{g} / \mathrm{m}^{3}$ & $35 \mathrm{\mu g} / \mathrm{m}^{3}$ & $5.68 \mu \mathrm{g} / \mathrm{m}^{3}$ & 0.00 \\
\hline $\begin{array}{l}12 / 07 \\
13 / 07 \mathrm{~W}\end{array}$ & $94 \mu \mathrm{g} / \mathrm{m}^{3}$ & $23 \mu \mathrm{g} / \mathrm{m}^{3}$ & error & 0.00 \\
\hline $\begin{array}{l}13 / 07 \mathrm{~W} \\
14 / 07 \mathrm{~W}\end{array}$ & $50 \mu g / \mathrm{m}^{3}$ & & & \\
\hline $\begin{array}{l}14 / 07 \mathrm{~W} \\
15,07\end{array}$ & $85 \mu \mathrm{g} / \mathrm{m}^{3}$ & $23 \mu \mathrm{g} / \mathrm{m}^{3}$ & $0.00 \mu \mathrm{g} / \mathrm{m}^{3}$ & 0.00 \\
\hline 15,07 & $50 \mu \mathrm{g} / \mathrm{m}^{3}$ & & & \\
\hline 16,07 & $58 \mu \mathrm{g} / \mathrm{m}^{3}$ & & & \\
\hline
\end{tabular}

* = 12-fiour average (day-time); $H M=$ start health measurements; $W=$ Weekend;

error $=$ measurement error.

The $\mathrm{PM}_{10}$ levels remained low the highest observed concentration was $54 \mu \mathrm{g} / \mathrm{m}^{3}(24$ hour average). There was no increase in acid aerosols, the $\mathrm{H}^{+}$levels were near zero. The concentrations of $\mathrm{SO}_{2}, \mathrm{NO}_{2}$ and black smoke also remained low during the summer-episode, maximum 24-hour values were 23,51 and $24 \mu \mathrm{g} / \mathrm{m}^{3}$ respectlvely. The 24-hour mean ambient temperature was between 20 and $25^{\circ} \mathrm{C}$ and the 1 -hour maximum was $32^{\circ} \mathrm{C}\left(11^{\text {th }}\right.$ of July). Table 3 presents the mean previous day ozone concentrations ( 1 and 8-hour) and the mean daily temperature during baseline and episode, and the mean differences of these variables, between both measurement periods. 
Table 3. Mean ozone concentrations during baseline and during the summer-smog-episode, and means of the maximum 1 -hour temperature during both periods fof the baseline measurement period only those days on which one or more chiddren of the present episode study were measured, were used).

\begin{tabular}{lcc}
\hline Discription & Mean $\left(\mathrm{ug}^{3} \mathrm{~m}^{3}\right)$ & $\pm \mathrm{sd}$ \\
\hline previous day ozone, 1-hour, baseline & 35.67 & 21.47 \\
previous day ozone, 8-hour, baseline & 20.71 & 15.48 \\
previous day ozone, 1-hour, episode* & 119.20 & 40.25 \\
previous day ozone, 8-hour, episode* & 103.84 & 36.43 \\
$\Delta$ ozone, 1-hour, (episode - baseline) & 83.53 & 46.07 \\
$\Delta$ ozone, \& hour, (episode - baseline) & 83.13 & 41.12 \\
mean dally temperature, baseline & $5.2^{\circ} \mathrm{C}$ & $3.3^{\circ} \mathrm{C}$ \\
mean daily temperature, episode & $19.5^{\circ} \mathrm{C}$ & $2.7^{\circ} \mathrm{C}$ \\
$\Delta$ mean temperature (episode - baseline) & $14.2^{\circ} \mathrm{C}$ & $4.7^{\circ} \mathrm{C}$ \\
\hline
\end{tabular}

* July $7^{\text {in }}$ to $15^{\text {th }}$

\section{Effect Parameters}

- The questionnaire. During the summer-episode, adequately completed questionnaires were obtained for 122 af the 212 children (58\%). This low response is due to the fact that directly after the episode summer holiday started so the parents were difficult to reach. Of 10 of the 122 children we did not have a full completed baseline questionnaire. These children were excluded from the symptom analysis, leaving 112 children.

Table 4. Prevalence of acute respirattory symptoms (in the previous week) and medical prescription, during baseline and summer-episode $(n=112)$.

\begin{tabular}{|c|c|c|c|c|}
\hline \multirow[b]{2}{*}{ Respirtory symptoms } & \multicolumn{2}{|c|}{ Baseline } & \multicolumn{2}{|c|}{ Summer-episode } \\
\hline & $\%$ & $n$ & $\%$ & $\mathrm{n}$ \\
\hline Dry throat/hoarseness & 16 & 18 & 13 & 15 \\
\hline Expectorate/cough up phlegn & 17 & 19 & 11 & 12 \\
\hline Wheeze & 6 & 7 & 7 & 8 \\
\hline Situffed nose/rumny nose & 36 & 40 & 25 & 28 \\
\hline Sore throat & 19 & 21 & 19 & 21 \\
\hline Shortness of breath & 5 & 6 & 9 & 10 \\
\hline Tightmess of the chest & 5 & 5 & 5 & 5 \\
\hline Irritated ayes/red oyes & 12 & 13 & 17 & 19 \\
\hline A lot of sneezing & 19 & 21 & 16 & 18 \\
\hline Earache & 11 & 12 & 8 & 9 \\
\hline Feeling of sickness/stomach & 25 & 28 & 21 & 24 \\
\hline Headache & 35 & 39 & 19 & 21 \\
\hline Fever & 6 & 7 & 5 & 5 \\
\hline Medical prescription & 21 & 24 & $1 S$ & 21 \\
\hline Staying ill at home & 12 & 14 & 7 & 8 \\
\hline Doctors consultation & 12 & 13 & 12 & 13 \\
\hline
\end{tabular}


Comparisons were made between the prevalence of acute respiratory symptoms (in the previous week) at baseline and during the summer-smog-episode. The results are presented in Table 4. No statistically significant changes were observed in the prevalence of acute symptoms. Except for shortness of breath and irritated eyes/red eyes the symptom prevalence was higher during baseline. No major changes in exposure to the measured indoor pollutants, such as parental smoking, home dampness, gas appliances, and pets occurred between baseline and episode (data not shown).

Spirometry and Respiratory Impedance. Valid impedance measurements (baseline and episode) were available from $212(100 \%)$ children, and valid spirometry (baseline and episode) from 208 children (98\%). Their mean values during baseline were for spirometry: FVC $2.34( \pm 0.52)$ L, FEV, $2.0( \pm 0.44) \mathrm{L}, \mathrm{PEF} 265.28$ ( \pm 67.10 ) L/min, $\mathrm{FEF}_{25-75 \%} 2.23( \pm 0.62) \mathrm{L} / \mathrm{s}$, and for the respiratory impedance parameters, $\mathrm{R}_{\mathrm{rs} 8} 6.03$ $( \pm 1.59) \mathrm{cmH}_{2} \mathrm{O} /(\mathrm{L} / \mathrm{s}), X_{\mathrm{rsg}}-1.025( \pm 0.69) \mathrm{cmH}_{2} \mathrm{O} /(\mathrm{L} / \mathrm{s}), f_{0} 15.14( \pm 5.84) \mathrm{Hz}$, and $\mathrm{FD}-0.007( \pm 0.047) \mathrm{cmH}_{2} \mathrm{O} /(\mathrm{L} / \mathrm{s})$.

Table 5. Results of the multiple linear regression analysis, $\Delta \mathrm{O}_{3} P D-8+\Delta M T$ Temp together in one modet, $n_{\text {spiro }}=208, n_{\text {imped }}=212$, (lung function indices as dependent variables).

\begin{tabular}{|c|c|c|c|c|}
\hline \multicolumn{2}{|l|}{ Model } & Coefficients & \multirow{2}{*}{ 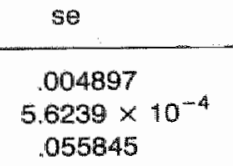 } & \multirow{2}{*}{$\begin{array}{c}\frac{p}{.0001} \\
.1258 \\
.0001\end{array}$} \\
\hline$\triangle F V G$ & $=\beta_{1} \Delta$ MTemp $+\beta_{2} \Delta O_{3} P D-8+C$ & $\begin{array}{l}\beta_{1}=.019994 \\
\beta_{2}=-8.64479 \times 10^{-4} \\
C=-.223571\end{array}$ & & \\
\hline$\triangle F E V_{1}$ & $=\beta_{1} \Delta M$ Temp $+\beta_{2} \Delta O_{3} P D-8+C$ & $\begin{array}{l}\beta_{1}=.014414 \\
\beta_{2}=-4.45513 \times 10^{-4} \\
C=-.200044\end{array}$ & $\begin{array}{l}.004241 \\
4.8711 \times 10^{-4} \\
.048370\end{array}$ & $\begin{array}{l}.0008 \\
.3615 \\
.0001\end{array}$ \\
\hline$\triangle P E F$ & $=\beta_{1} \Delta M T e m p+\beta_{2} \Delta O_{3} P D-8+C$ & $\begin{array}{l}\beta_{1}=3.500892 \\
\beta_{2}=-.451271 \\
C=-4.033821\end{array}$ & $\begin{array}{r}.957132 \\
.109923 \\
10.915364\end{array}$ & $\begin{array}{l}.0003 \\
.0001 \\
.7121\end{array}$ \\
\hline$\triangle F E F_{25.75 \%}$ & $=\beta_{1} \Delta$ MTemp $+\beta_{2} \Delta O_{3} P D-8+C$ & $\begin{array}{l}\beta_{1}=.0220 \\
\beta_{2}=-.0013 \\
C=-.2885\end{array}$ & $\begin{array}{l}20 \\
\times 26\end{array}$ & $\begin{array}{l}.0058 \\
.1413 \\
.0016\end{array}$ \\
\hline$\Delta \mathrm{R}_{\mathrm{rga}}$ & $=\beta_{1} \Delta M T$ Temp $+\beta_{2} \Delta O_{3} P D-B+C$ & $\begin{array}{l}\beta_{1}=5.53555 \times 10^{-4} \\
\beta_{2}=-.002705 \\
c=-.245533\end{array}$ & $\begin{array}{l}.022989 \\
.002606 \\
.264980\end{array}$ & $\begin{array}{l}.9808 \\
.3006 \\
.3553\end{array}$ \\
\hline$\Delta x_{\mathrm{nSB}}$ & $=\beta_{4} \Delta M$ Temp $+\beta_{2} \Delta O_{3} P D-8+\mathbb{C}$ & $\begin{array}{l}\beta_{1}=-.005718 \\
\beta_{2}=. .003815 \\
C=-.185823\end{array}$ & $\begin{array}{l}.012622 \\
.001431 \\
.145488\end{array}$ & $\begin{array}{l}.6510 \\
.0083 \\
.2030\end{array}$ \\
\hline$\Delta f_{0}$ & $=\beta_{1} \Delta M$ Temp $+\beta_{2} \Delta O_{3} P D-8+C$ & $\begin{array}{l}\beta_{1}=.075448 \\
\beta_{2}=-.028079 \\
C=1.491599\end{array}$ & $\begin{array}{r}.103796 \\
.011768 \\
1.196399\end{array}$ & $\begin{array}{l}.4682 \\
.0180 \\
.2140\end{array}$ \\
\hline$\triangle F D$ & $=\beta_{1} \Delta M T e m p+\beta_{2} \Delta O_{3} P D-8+C$ & $\begin{array}{l}\beta_{1}=-.001378 \\
\beta_{2}=2.51437 \times 10^{-4} \\
c=-.006329\end{array}$ & $\begin{array}{l}8.7485 \times 10^{-4} \\
9.9191 \times 10^{-6} \\
.010084\end{array}$ & $\begin{array}{l}.1167 \\
.0120 \\
.5310\end{array}$ \\
\hline
\end{tabular}

$\Delta \quad=$ Difference between episode and baseline FVC. FEV, in L, PEF in Limin, FEF 25 -75\% in L/sec, $R_{r s \theta^{\prime}} X_{r s g^{\prime}} F D$ in $\mathrm{CmH}_{2} \mathrm{O} /(\mathrm{L} / \mathrm{s})$, fo in $\mathrm{Hz}$

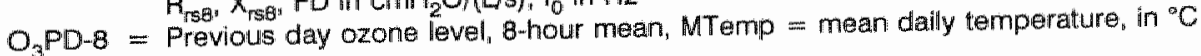


In the unadjusted linear regression analyses, changes in spirometry and impedance parameters, were regressed on changes $(\Delta)$ in previous day (PD) ozone, for $\Delta \mathrm{O}_{3} P D-1$ (1-hour mean) and $\triangle \mathrm{O}_{3} \mathrm{PD}-8$ (8-hour mean), separately. For spirometry, $\triangle \mathrm{PEF}$ was significantly negative related to changes in ozone levels. The associations with $\Delta F V C_{i n}$ $\triangle F E V_{1}$ and $\triangle \mathrm{FEF}_{25-75 \%}$ were not significant with small, positive values for their $\beta^{\prime}$ 's (not plausible). For impedance, significant associations were observed with $\Delta \mathrm{x}_{\mathrm{rs}}, \Delta \mathrm{f}_{\mathrm{o}}$ and $\triangle F D$, but again the directions of the slopes were not plausible. Next, changes in spirometry and impedance parameters were regressed on $\Delta \mathrm{O}_{3} \mathrm{PD}-8$, adjusted by $\triangle M T$ Temp (difference in daily mean temperature). Although the correlation between $\triangle M T e m p$ and $\triangle O_{3} P D-8$ was 0.65 ( $\left.p \leq 0.01\right)$, both variables could be added in the model, simultaneously. The results of these regression analyses are presented in Table 5. For spirometry, $\triangle P E F$ still was significantly negative related to $\triangle \mathrm{O}_{3} P D-8$, indicating a decrease in PEF with increasing ozone concentration. Although no significant associations were found with other spirometric indices, the signs of the observed $\beta$ 's now were plausible (negative). $\triangle M T$ Temp was significantly related to changes in all spirometric indices (positive values for $\beta$ ), except the $\triangle P E F$. The impedance indices $\Delta \mathrm{X}_{\mathrm{reg}}, \Delta \mathrm{f}_{0}$ and $\triangle \mathrm{FD}$ still were significantly related to $\Delta \mathrm{O}_{3} \mathrm{PD}-8$. However, the direction the $\beta^{\prime} s$ is just opposite to what one would expect if ozone adversely affects the impedance outcomes. The present $\beta$ 's indicate an increase in reactance, a decrease in resonant frequency and less negative frequency dependence of resistance with increasing ozone levels. No significant association was observed with resistance parameters. None of the respiratory impedance parameters was significantly associated with $\triangle M T$ Temp.

When for the previous day ozone level the 1-hour mean was used in the analysis, the results were almost identical to those presented for the 8-hour mean. Furthermore, when for the temperature correction the mean daily temperature at baseline (with the hypothesis that low baseline temperature influences PEF rather than high "episode" temperature) was used instead of $\triangle M T e m p$, the results for spirometry were somewhat different. Again only $\triangle P E F$ was significantly related to $\triangle O_{3} P D-8$, but the signs of the $\beta$ 's for $\triangle \mathrm{O}_{3} P D-8$ with $\triangle F V C$ and $\triangle F E V_{1}$ now were nonsignificantly positive comparable to the first analysis without temperature correction, which is less plausible. The associatlons with the impedance parameters were comparable to those observed with $\triangle M T e m p$.

Forty three children (20\%) reported one or more chronic respiratory symptoms at baseline. When the regression analyses were performed for these 43 children separately, similar results were found as those just presented for the total group, although all associations now were nonsignificant (small group).

\section{DISCUSSION}

The acute health effects of exposure to a short summer-smog-episode, with 8-hour average ozone levels exceeding $120 \mu \mathrm{g} / \mathrm{m}^{3}$, were investigated in 212 primary school children. No significant increases in (acute) respiratory symptoms were reported in this study period. Regression of the changes in the individual lung function parameters showed a significantly negative slope for PEF and nonsignificant negative slopes for

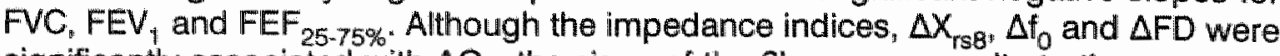
significantly associated with $\Delta \mathrm{O}_{3}$, the signs of the $\beta$ 's were opposite to the expected 
direction of an adverse effect. No significant relation with previous day $\Delta \mathrm{O}_{3}$ was found for $\Delta \mathrm{R}_{\mathrm{rs} 8}$.

A problem in interpreting the data is that the results of a single baseline measurement are compared with episode measurements, performed about seven months later. Especially the comparison in symptom prevalence (between Autumn and Summer) therefore need to be interpreted with caution. The response rate of the second questionnaire was low (58\%), and selection bias may have occurred. The occurrence of bias implicates that the response of parents is related to the ozone exposure. This, however, seems unlikely. In fact, directly after the smog-episode summer holiday started and many parents were difficult to reach. 'Selection' (if occurred) is therefore probably more related to whether the parents and their children already went on holiday or not. Moreover, if bias occurred especially parents of children who respond to the ozone exposure would have returned the questionnaire, which means that we would have observed an effect (= increase in symptom prevalence) but we did not. Other factors which are known to affect the symptom prevalence, for instance indoor exposures or socio-economic factors, can be regard constant over the 7 months period. In part because each child is his/her own control and partly because we measured them and no major changes occurred.

Regression analyses of $\Delta$ lung function on $\Delta$ ozone (previous day) were performed because of the relatively large variation in ozone levels at the different episode days as well as at baseline. Thus, in these analysis individual changes in lung function parameters were related to individual changes in ozone levels. We observed a significant negative association with $\triangle P E F$ only, regression slopes for $\triangle F V C, \triangle F E V_{1}$, $\triangle F E F_{25-75 \%}$ were negative, but not significant. In line with these observations are the results of two epidemiological studies, who also reported negative associations with ozone for PEF only. ${ }^{35.36}$ Very recently, Hoek et $\mathrm{al}^{15}{ }^{15}$ reported responses on changes in ozone exposure to be the largest for PEF, somewhat lower for MMEF and the lowest for FVC and $\mathrm{FEV}_{1}$. Similar results have been reported from clinical studies. ${ }^{4,7}$ In contrast, significantly negative associations with FVC and FEV found in a California summer camp study. "The impedance results do not support the spirometric findings, since no adverse effects on respiratory impedance parameters were observed. If the delta-analyses were repeated without adjusting the lung function data for growth the pollution slopes stayed alomst the same, suggesting that mismodelling of growth does not affect the association between $\triangle \mathrm{LF}$ and $\triangle \mathrm{O}_{3}$.

The coefficients in Table 5 translate into changes of $\mathrm{FVC}_{1}, \mathrm{FEV}, \mathrm{PEF}$ and $\mathrm{FEF}_{25.75 \%}$ of $-4,-3_{n}-20$, and $-7 \%$ associated with a change in $120 \mu \mathrm{g} / \mathrm{m}^{3}$ of the 8 -hour average ozone concentration. These negative (although mostly nonsignificant) slopes are consistent with other epidemiological studies. "The magnitude of particularly the PEF-slope is large. ${ }^{1}$ Based on the SE's of the pollution slopes we calculated that decreases of $6 \%$ in $\mathrm{FVC}_{\text {and in }} \mathrm{FEV}_{1}$ and of $10 \%$ in PEF and in $\mathrm{FEF}_{25-75 \%}$ would have been statistically significant. In contrast, respiratory impedance measurements did not show associations in the hypothesized direction. A nonsignificant change of $-5 \%$ in resistance $\left(R_{r s E}\right)$ and a significant decrement of $-22 \%$ in resonant frequency was found. This might mean that impedance measurements do not demonstrate the type of effects caused by ambient ozone. Further (controlled exposure) research into the applicability of this technique seems necessary. Also, research to determine the dependence of impedance measurements on meteorologic and other potential confounding factors seems necessary, given observed associations opposite to the expected direction. 
In healthy adults exercising outdoors, exposure to ambient ozone resulted in an increase of reported respiratory symptoms. ${ }^{37}$ In contrast, field studies at children's summer camps failed to find increases in symptoms despite decrements in lung function, which were proportional to ambient $\mathrm{O}_{3}$ concentrations. ${ }^{13}$ The results of the present study appeared to be similar. However, the fact that baseline measurements took place in the Autumn and episode measurements in the Summer, could have resulted in a 'downward bias' of the symptom prevalence. Although not significant, we did observe a slight increase in reported eye irritation. Photochemical air pollution is a causative factor in eye irritation, ascribed to non-ozone components of the photochemical mixture and occurring at ozone levels about $200 \mu \mathrm{g} / \mathrm{m}^{3}(0.1 \mathrm{ppm}){ }^{38}$ which is somewhat higher than those in this study. Furthermore, the presence of airborne pollen during the summer season may in part be responsible for the observed increase in the prevalence of eye irritation.

It is not clear whether people who already suffer from respiratory diseases are more sensitive to the effects of exposure to ozone. Indeed, bronchial responsiveness to stimuli such as methacholine has experimentally been shown to be enhanced by exposure to ozone. ${ }^{4}$ On this basis it has been suggested that hyperresponsive subjects are at greater risk of airway narrowing due to irritative or allergic stimuli after exposure to ozone. ${ }^{39}$ Therefore, we also investigated separately, children who reported one or more chronic respiratory symptoms at baseline. No differences were found in this group of symptomatic children compared with the healthy group. These data are in agreement with earlier observations, since similar negative associations with previous day ozone were found for children with and without chronic respiratory symptoms. ${ }^{15}$

During this summer episode, ozone was the only reported pollutant which was increased. There is some evidence that ambient cofactors such as $\mathrm{H}^{+}$in aerosols potentiate the responses to ozone. However, in this study all other pollutants were low and $\mathrm{H}^{+}$levels were near zero. The latter probably results from neutralization by the high ammonia concentrations observed in the Netherlands. This also has been reported by others. ${ }^{14,15}$

The application of the forced oscillation technique in an epidemiological setting with children appeared to be good. Measurements were easily to perform for the child as well as the investigator. In contrast to spirometry, they are independent of the effort made by the child and are therefore less influenced by learning effects. Reported coefficients of variation (CV) of respiratory resistance parameters are about $10 \%$, for healthy as well as asthmatic children. ${ }^{40-43}$ Calculation of $\mathrm{CV}$ values using the data of the present study (SE of the mean difference between baseline and episode divided by the mean value at baseline, maximum estimate) resulted in $(1.17 / 6.03 \times 100=19 \%$ for $\mathrm{R}_{\mathrm{rs} 8}$, which is somewhat higher than for $\mathrm{FVC}$ and $\mathrm{FEV}, 1$, both $12 \%$, but comparable to the CV's found for PEF and FEF $25.75 \%$, both also $19 \%$. Due to the fact that FD and $X_{\text {rs }}$ fluctuate around zero as either a negative or a positive value and consequently their means approximate zero, much larger $\mathrm{CV}$ values were found for these parameters, like has been reported before. ${ }^{43}$

In summary, moderately elevated levels of ozone did not result in an increase of acute respiratory symptoms in primary school children. A statistically significant negative association with ozone was found for $\triangle P E F$ only, not supported by adverse effects on respiratory impedance indices. The data of the present study suggest that exposure to a mild summer-smog-episode, with 8-hour average ozone levels exceeding 120 $\mu \mathrm{g} / \mathrm{m}^{3}$, did not result in clear, adverse effects on the respiratory health of primary school children. 


\section{ACKNOWLEDGEMENTS}

We thank Marcel Severijnen and Arno Scheepers, Department for Research of the Local Government, for their great efforts in performing the additional field air quality measurements, and Saskia van der Zee and Jeroen Douwers of the Department of Epidemiology and Public Health of the University of Wageningen, for preparing and analyzing the air pollution samples. Furthermore, we thank Jos Slangen for his valuable contribution to the statistical analyses. Finally, we thank all the schools, children and their parents for their participation in the study.

\section{APPENDIX}

Questions on acute respiratory symptoms as included in the questionnaire.

Did your child had one of the following symptoms in the previous week (=the week before receiving the questionnaire):

\begin{tabular}{lc}
\hline - dry throat/hoarseness & Yes/no \\
- & Yespectorate/cough up phlegm \\
- stuffed nose/runny nose & Yes/no \\
- sore throat & Yes/no \\
- tightnestness of breath & Yes/no \\
- $\quad$ irritated eyes/red eyes & Yes/no \\
- earache & Yes/no \\
feeling of sickness/stomach & Yes/no \\
headache & Yes/no \\
\hline
\end{tabular}

Has/Did your child in the previous week:

$\begin{array}{ll}\text { - been using medication } & \text { Yes/no } \\ \text { - stay ill at home } & \text { Yes/no } \\ \text { see a doctor } & \text { Yes/no }\end{array}$

\section{REFERENCES}

1. Lippmann M. Health effects of ozone. A critical review. J Air Pollut Control Assoc 1989; 39: 672-695.

2. Aalst van RM. Ozone and oxidants in the planetary boundary layer. In: Schneider T, Lee SD, Wolters G.JP, Grant $L D$, eds. Atmospheric ozone research and its policy implications. Proceedings of the 3rd US-Dutch international symposium. Nijmegen, the Netherlands $1988 ; 573-587$.

3. Tilton BE. Health effects of tropospheric ozone: major effects and related scientific questions. Environ Soi Technol 1989; 23: 257-263. 
4. Horstman $D H$, Folinsbee $L J_{1}$ ives $P J$, Abdul-Salaam $S$, McDonnel $W$. Ozone concentrations and pulmonary response relationships for 6.6-hour exposure with five hours of moderate exercise to $0.08,0.10$ and $0.12 \mathrm{ppm}$. Arn Rev Respir Dis 1990; 142:11581163.

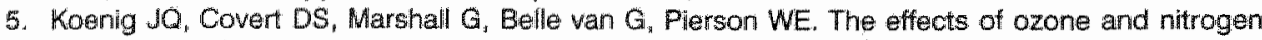
dioxide on pulmonary function in healthy and in asthmatic adolescents. Am Rev Respir Dis 1987; 136: $1152-1157$.

6. Delvin AB, McDonnell WF, Mann R, Becker S, House DE, Schreinemachers D, Koren HS. Exposure of humans to ambient levels of ozone for 6.6 hours causes cellular and biochemical changes in the lung. Arn J Fespir Cell Mol Biol 1991; 4: 72-81.

7. McDonnel WF, Kehrl HA, Abdul-Salaiam S, et al. Respiratory response of humans exposed to low levels of ozone for 6.6 hours. Arch Environ Health 1991; 46: 145-150.

8. Avol EL, Linn WS, Shamoo DA, et al. Short-term respiratory effects of photochemical oxidant exposure in exercising children. I Air Pollut Control Assoc 1987; 37: 158-162.

9. Avol EL, Linn WS, Shamoo DA, et al. Respiratory effects of photochemical oxidant air pollution in exercising Adolescents. Am Rev Fespir Dis 1985; 132: 619-622.

10. Paizenne $\mathrm{ME}$, Burnett $\mathrm{AT}$, Stern $\mathrm{B}$. Franklin $\mathrm{CA}$, Spengler JD. Acute lung function responses to ambient acid aerosol exposures in children. Environ Health Perspec 1989; 79: 179-185.

11. Higgins ITT, D'Arcy JB, Gibbons DI, Avol EL, Gross KB. Effect of expasure to ambient ozone on ventillatory lung function in children. Am Rev Respir Dis 1990; 141: 136-146.

12. Kinney PL, Ware JH, Spengler JD, Dockery DW, Speizer FE, Ferris jr BG. Short-term pulmonary function change in association with ozone levels. Am Rev Rlespir Dis 1989; 139: 56-61.

13. Spektor DM, Lippmann M, Lioy PJ, et al. Effects of ambient ozone on respiratory function in active normal children. Am Rev Fespir Dis 1988; 137: 313-320.

14. Hoek $G_{n}$ Brunekreef $B$, Kosterink $P$, Berg van den $A_{*}$ Hofschreuder $P$. Effects of ambient ozone on peak expiratory flow of exercising children in the Netherlands. Arch Environ Health $1993 ; 48$ : $27 \times 32$.

15. Hoek $G_{n}$ Fischer $P$, Brunekreef $B$, Lebret $E$, Hofschreuder $P$, Mennen MG. Acute effects of ambients ozone on pulmonary function of children in the Netherlands. Am Rev Respir Dis 1993; 147: 111-117.

16. Bates DV. Sizto R. Felationship between air pollutant levels and hospital admissions in southern ontario. Can J Public Health 1983; 74: 117-122.

17. Ponkä A. Asthma and low level air pollution in Helsinki. Arch Environ Health 1991; 46: 262-269.

18. Stanescu $D$, Moavero NE, Veriter $C$, Brasseur $L$. Frequency dependence of respiratory resistance in healthy children. J Appl Physiol Respirat Environ Exercise Physiol 1979; 47: 268-272.

19. Cuijpers CEJ, Wesseling $G$, Swaen GMH, Wouters EFM. Frequency dependence of oscillatory resistance in healthy primary school children. Respiration 1993; 60: 149-154.

20. Duiverman EJ, Clëment J, Woestijne van de KP. Neijens $H J_{i}$ Bergh van den $A C M$, Kerrebijn KF. Forced osicillation technique. Reference walues for resistance and reactance over a frequency spectrum of $2-26 \mathrm{~Hz}$ in heatthy children aged 2.3-12.5 years. Bull Eur Physiopathol Respir 1985: 21: $171-178$.

21. Pestin R, Gallina C. Teculescu D, Pham QT. Respiratory input and transfer impedances in children 9-13 years old. Bull Eur Physiopathol Respir 1987: 23: 107-112.

22. Wouters EFM. Total respiratory impedance measurement by forced oscillations: noninvasive method to assess bronchial response in occupational medicine. Exp Lung Research 1990; 16:2540.

23. Lebret $E_{1}$ Hoek $G_{n}$ Aardema JB. A study on the effects of air pollution episodes on pulmonary function and respiratory symptoms in school children and adults. In: Brasser LJ and Mulder WC. eds. Man and his ecosystem. Proceedings of the 8th World Clean Air Congress 1989, The Hague. The Netherlands, 19-24 vol. 1.

24. Elskamp HJ. National Air Quality Monitoring Network. Technical description. Bilthoven, the Netherlands: Niational Institute of Public Health and Environmental Protection, 1989, report no. 228702017 .

25. Liu BYH, Puil DYH. Aerosol sampling inlets and inhalable particles. Atmos Environ 1981; 15: 589-600.

26. Meulen van der $A$, Elzakker van BG. Waidman JM, Hoek G. Results of a year long study of atmospheric acidity in the Netheriands. In: Brasser LJ, Mulder WC, eds. Proceedings of the World Clean Air Congress 1989. The Hague 1989; 3: 569-574.

27. Florey $G$ du V, Leeder SR. Methods for cohort studies of chronic airflow limitation, (chapter 3). WHO regional publications, European series No. 12. London, United Kingdom 1982. 
28. Brunekreef $B$, Groot $B$, Rijcken $B$, Hoek $G$, Steenbekkers $A$, Boer de A. Feproducibility of childhood respiratory symptom questions. Eur Respir J 1992; 5: 930-935.

29. Làndser $F J$, Nagels $d$, Demedts $M$, Billiet $L$, Woestijne van de KP. A new method to determine frequency characteristics of the respiratory system. J Appl Physiol 1976; $41: 101-106$.

30. Wouters EFM, Làndsếr FJ, Polko AH, Visser BF. Physiological analysis of extended spectruinn oscilliometry. Respiration 1988; 54: 263-270.

31. Làndsér FJ, Clément $J$, Woestijne van de KP. Normal velues of total respiratory resistance and reactance determined by forced ascillations. Influence of smoking. Chest 1982; 81: 586-591.

32. Làndser $F J$. Nagels $J$, Clément $J$ "Woestinne van de KP. Errors in the measurement of total respiratory resistance and reactance by forced oscillations. Respir Physiol 1976; 28: 289-301.

33. Quamjer PhH. Standardized lungtunction testing. Bull Eur Physiopath Resp 1983; 19(suppl.5): $1-95$.

34. SPSS@ Inc., 1990, 444n Michigan Avenue, Chicago, Illinois 60611.

35. Lioy PJ, Wollmuth TA, Lippmann M. Persistance of peak flow decrements in children following ozone exposure exceeding the national ambient air quality standard. J Air Pollut Control Assoc 1985; 35: 1068-1071.

36. Berry M, Loy $P J$, Gelperin $K$, Buckler $G$, Klotz J. Measurement of health effects in children and conselors at two summer camps. Environ Research 1991; $54: 135-150$.

37. Spektor DM, Lippmann $M$, Thurston GD, at al. Effects on ambient ozone on respiratory function in healthy adults exercising outdoors. Am Rev Respir Dis 1988; 138: 821-828.

38. World Health Organisation. Air Quality Guidelines for Europe. WHO regional publications. European series mo. 23, Copenhagen, 1987.

39. World Health Organisation. Acute effects on health of smog episodes. WHO Regional Publications, European series No.43, "s Hertogenbosch, the Netherlands, 1990.

40. Solymar L, Aronsson PH, Bake B, Bjure J. Respiratory resistance and impedance magnitude in healthy children aged 2-18 years. Pediatr Puimonoll 1985; 1: 134-140.

41. Hordvik NL, König P, Morris DA, Kreutz C, Russell, Pimmel L. Narmal values for forced oscillatory respiratory resistance in children. Pediatr Pulmonol 1985; 1: 145-148.

42. Konnig $P$, Hordvik NL, Pimmel RL. Forced random noise resistance determination in childhood asthma. Chest $1984 ; 86$ : 884-890.

43. Duiverman EJ, Neijens HJ, Snee-van Smaalen van der M, Kerrebijn KF. Comparison of forced ascillometry and forced expirations for measuring dose related responses to inhaled methacholine in asthmatic children. Eur Physiopatholl Respir 1986; 22: 433-436. 



\section{Chapter 8}

\section{INTERREGIONAL DIFFERENCES IN THE PREVALENCE OF ASTHMA AMONG PRIMARY SCHOOL CHILDREN IN THE NETHERLANDS}

ME de Kak, PLJM Mertens, CEJ Cuijpers, GMH Swaen, GJ Wesseling, J Broer, F Sturmans, EFM Wouters 


\section{INTERREGIONAL DIFFERENCES IN THE PREVALENCE OF ASTHMA AMONG PRIMARY SCHOOL CHILDREN IN THE NETHERLANDS}

\section{ABSTRACT}

A crossisectional study was conducted to investigate the possible influence of indoor and outdoor environmental factors on interregional differences in respiratory health in primary school children living in two different towns of the Netherlands, Melick/HerKenbosch Asenray MHA $(n=5 \| 1)$ and Leek $L K(n=612)$. The prevalence of asthma and asthma-related symptoms was determined by means of a questionnaire, and respiratory impedance was measured using the forced oscillation technique (FOT). Asthma-like symptoms were reported consequently more often in MHA than in LK: chronic cough ( $17 \%$ MHA versus $5 \% \mathrm{LK})$, shortness of breath $(15 \%$ versus $8 \%$ ), wheeze (17\% versus $14 \%)$ and attacks of shortness of breath $(10 \%$ versus $7 \%)$. However, doctor-diagnosed asthma was reported $7 \%$ in MHA and $6 \%$ in LK.

Adjusted odds ratios of the prevalence rates of MHA versus LK were $4.5(C l=2.7-7.7)$ for chronic cough, $2.5(\mathrm{Cl}=1.6-3.9)$ for shortness of breath, $1.3(\mathrm{Cl}=1.0-1.8)$ for wheeze, $1.6(\mathrm{Cl}=1.0-2.5)$ for attacks of shortness of breath with wheeze, and $1.4(\mathrm{Cl}=1.0-2.2)$ for asthma. Living in MHA appeared to be a statistically significant determinant of the symptom prevalence. Furthermore, the child's age, maternal smoking ( $>10 \mathrm{cig} . / \mathrm{day}$ ), and educational level of the father were significantly associated with one or more asthma-like symptoms, whereas no clear associations were found with damp spots and unventilated kitchen geysers. Calculating adjusted differences in respiratory impedance between the regions resulted in a small but statistically significant difference in resonant frequency, LKK being slightly at a disadvantage.

Measured outdoor air pollution levels of $\mathrm{SO}_{2}, \mathrm{NO}_{2}, \mathrm{O}_{3}$ and $\mathrm{PM}_{10}$ were in general somewhat higher in MHA. In both regions, however, the average levels remained below the present $\mathrm{WHO}$ guidelines, except for $\mathrm{NO}_{2}$ in MHA where the guideline was slightly exceeded.

In conclusion, in this study statisticaly significant but small interregional differences in respiratory impedance values were found between children living in MHA and children living in LK. It can, however, be doubted whether these small differences have clinical importance. However, prevalence rates of key symptoms of asthma were found to be significantly higher in children living in MHA, several well-known (indoor) risk factors for respiratory disease could not explain the observed differences in symptom prevalence between the regions. 


\section{INTFODUCTION}

Asthma is the most common chronic disease in childhood. Under the age of 10 the prevalence among boys is one to two times that among girls of the same age. ${ }^{~}$ Asthma can be defined as reversible airway obstruction occurring in attacks, characterized by the key symptoms wheeze, shortness of breath and cough. ${ }^{2}$ Most epidemiological studies identify asthma by means of a questionnaire evaluating life time and/or period prevalence of the key symptoms for asthma. Often these questions are followed by a question whether or not the asthma has been confirmed by a doctor. ${ }^{2}$ During adolescence the prevalence decreases, although it is difficult to predict in which individuals the symptoms will fully disappear. Factors which have been proposed to influence the prognosis are symptom score, lung function level during childhood and gender. ${ }^{3}$ The prognosis for female subjects has been demonstrated to be less favourable than for male subjects. ${ }^{3}$ It has been suggested that the prevalence of asthma is increasing, in particular among young children. ${ }^{4-7}$ it is not yet clear whether this is a result of a change in severity or in incidence of the disease ${ }^{5}$, or a shift in the balance of care.

Various factors have been suggested to contribute to the increased prevalence of asthma, one of them being outdloor air pollution. Historical air pollution episodes have clearly demonstrated the detrimental effects on health in general and asthma in particular. ${ }^{8}$ More recently epidemiological studies have demonstrated that air pollutants, even at ambient concentrations, are related to increased respiratory morbidity and mortality. ${ }^{9-14}$ These results suggest that air pollution could act as a causative agent as well as a trigger for pre-existing asthma. However, the evidence is incomplete as most studies did not address this topic directly. Geographical variations in the prevalence of asthma often can not be linked to differences in air pollution between study areas: Von Mutius et al. ${ }^{15}$ did not find differences in the lifetime prevalence of asthma, wheezing and bronchial hyperresponsiveness between children living in western Germany (less polluted) and eastern Germany (polluted). However, they did find a higher lifetime prevalence of bronchitis in eastern Germany, but lower prevalence rates of allergic disorders. In general "marked changes in the prevalence of asthma over time have often occurred in places where air pollution is not a problem. ${ }^{14}$

Several sources of indoor air pollution which have been reported to be important risk factors in the development of childhood asthma are environmental tobacco smoke (where maternal smoking appeared to be more important than paternal smoking), home dampness, nitrogen dioxide (mainly produced by gas appliances), and allergens as produced by house dust mites and pets.

In the present study, the possible influence of indoor and outdoor environmental factors on interregional differences in the prevalence of asthma was studied by evaluating respiratory health in 1123 primary school children living in two different regions of the Netherlands: the province of Limburg and the province of Groningen, about 350 kilometres apart (Figure 1). In Limburg we investigated all children in the relevant agecategory living in Melick/Herkenbosch Asenray (MHA), and in Groningen children living in Leek (LK) were invited to take part in the study. For several years, parents and general practitioners in MHA have been concerned about the respiratory health status of their children in respect to the local air pollution situation. Therefore, respiratory symptoms and lung function characteristics of children aged 6-12 years living in MHA were compared to children living in $L K$, a less polluted region in the north of the Netherlands. Possible respiratory differences were evaluated by measuring impedance 
characteristics of the respiratory system using the forced oscillation technique (FOT), and the prevalence of asthma and asthma-related symptoms was evaluated by means of a questionnaire.

\section{METHODS}

\section{Population}

The study population consisted of children aged $6-12$, because children of this agecategory can easily be approached in primary schools and they generally do not smoke themselves nor have occupational exposures. Assuming a relative risk of MHA versus $L K$ for asthma of 1.5 and $a=0.05$, power calculations pointed out that a minimum of 600 children per group was needed. In cooperation with the regional Health Services 541 children in MHA and 687 children in LK were approached. In both regions children in the relevant age-category of in total 10 primary schools were all invited to take part in the project. At school children received a self-administered questionnaire which had to be filled out by the parents. About two weeks later the school was visited by a team of trained technicians to perform the lung function measurements. The questionnaires were collected and children for whom a written informed consent was obtained to perform the lung function measurements, were measured by the forced oscillation technique. Data collection took place from March to June 1993, by two teams of technicians working simultaneously.

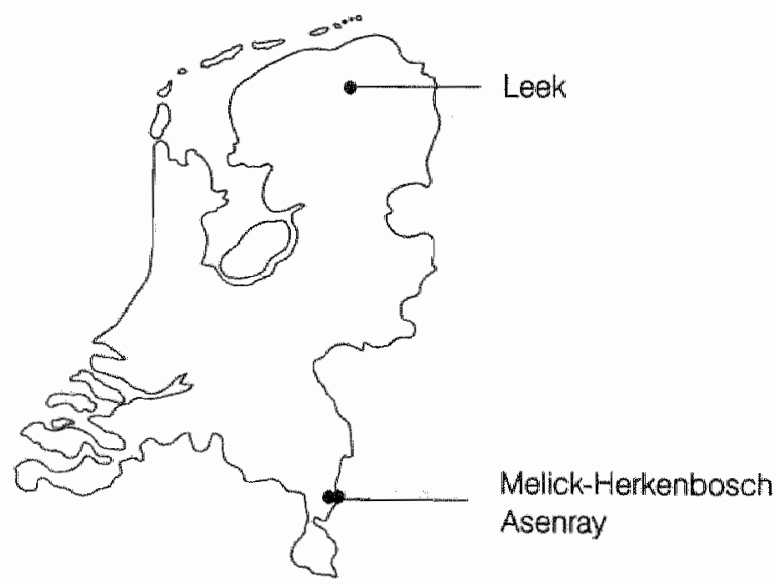

Figure 1. Location of the cooperating municipelities: Leek (province of Groningen) and Melick/Herkenbosch Asenray (prowince of Limburg).

Air Pollution

Table 1 summarizes the information about the local outdoor air pollution situation, concerning the indicator pollutants sulphur dioxide $\left(\mathrm{SO}_{2}\right)$, nitrogen dioxide $\left(\mathrm{NO}_{2}\right)$, ozone $\left(\mathrm{O}_{3}\right)$ and particulate matter with an aerodynamic diameter less than 10 micrometer 
$\left(\mathrm{PM}_{10}\right)$. The data were obtained from several stations of the National Air Pollution Monitoring Network ${ }^{20}$, except for $\mathrm{PM}_{10}$ in Limburg additional measurements were performed by the Department for Research of the Local Government. During the study period outdoor levels of $\mathrm{SO}_{2}, \mathrm{PM}_{10}$ and $\mathrm{O}_{3}$ did not exceed the present WHO guidelines of air quality, although it is to be reminded that the standard of $P M_{10}$ is subjeat to discussion in regard to its safety for human health. ${ }^{21}$ The average $\mathrm{PM}_{40}$ concentration during the study period ( $22^{\text {nd }}$ of March to $6^{\text {th }}$ of June, 1993 ) was $36 \mu \mathrm{g} / \mathrm{m}^{3}$ in Limburg: The present annual guideline is $40 \mu \mathrm{g} / \mathrm{m}^{3}$. In Limburg the air quality guideline for $\mathrm{NO}_{2}$ $\left(135 \mu \mathrm{g} / \mathrm{m}^{3}\right.$, 1-hour average) was exceeded. However, because of the relatively short monitoring period (less than three months), these air pollution data must be regarded

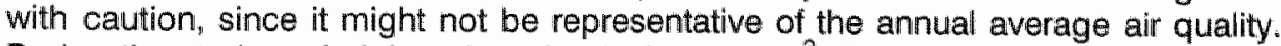
During the study period the 1-hour level of $160 \mu \mathrm{g} / \mathrm{m}^{3} \mathrm{O}_{3}$ was exceeded three times in Budel (Limburg). Air pollution levels were, in general, higher in MHA as they were in $L K$.

Table 1. Average air pollutant levels during March-June 1993, National Air Quality Monitoring Network ( $\mathrm{SO}_{2}$ and $\mathrm{PM}_{10}$ 24-hour averages, $\mathrm{NO}_{2}$ and $\mathrm{O}_{3}$ i thour averages).

\begin{tabular}{lcc}
\hline Component $\left(\mu \mathrm{g} / \mathrm{m}^{3}\right)$ & Limburg (station Budel) & Groningen (station Kollumerwaard) \\
\hline $\mathrm{SO}_{2}$ & 10 & 4 \\
$\mathrm{PMO}_{10}$ & $36^{*}$ & - \\
$\mathrm{NO}_{2}$ & $29^{\text {* }}$ & 14 \\
$\mathrm{O}_{3}$ & $186^{\text {\# }}$ & $139^{*}$ \\
\hline
\end{tabular}

* Measurements Province of Limburg March $22^{\text {nd }}$ to June $6^{\text {th }}, 1993$

* Maximum 1 -hour level; the 1 -hour level of $160 \mu \mathrm{g} / \mathrm{m}^{3}$ was exceeded 3 times at Budel.

\section{Health Measurements}

- Questionnaire. The questionnaire used in this study is a Dutch version of the children's questionnaire of the World Health Organisation published by Florey and Leeder. ${ }^{23}$ The reproducibility of the answers of the Dutch questionnaire for the asthmalike symptoms has been established, Cohen's kappa values range from 0.60 to 0.96 , except for chronic cough ( $\mathrm{kappa}=0.28$ ). ${ }^{24}$ Information of acute and chronic respiratory symptoms was obtained (chronic cough, shortness of breath, wheeze and attacks of shortness of breath with wheeze) as well as information concerning doctor-diagnosed asthma and bronchitis, damp housing, smoking habits of relatives inside the house, domestic animals, presence of indoor nitrogen dioxide sources (gas appliances) and parental educational level of the father. Life-time prevalence as well as the prevalence in the past 12 months of the key symptoms for asthma were evaluated. Current asthma was defined as reporting at least two of the key symptorns, to include wheeze or attacks of shortness of breath with wheeze, in the past 12 months. The questions of chronic respiratory symptoms discussed in this report are summarized in the Appendix.

- Concentrations of $P M_{10}$ have been systematically underestimated with $20-30 \%{ }^{22}$ Comparing the measured concentrations with the air quality standards is therefore uncertain. 
- The forced oscillation technique. The mechanical characteristics of the respiratory system were measured using the forced oscillation technique, according to the method described by Ländsér et al. ${ }^{25}$ The technique has been described in detail previously. ${ }^{26}$ Briefly, a pseudo random noise signal containing all harmonics of $2 \mathrm{~Hz}$ up to $48 \mathrm{~Hz}$, is applied at the mouth of the seated child. During the measurements the child breathes quietly and wears a nose clip while the cheeks and the floor of the mouth are supported with the hands of either the investigator or the child itself. Mouth pressure and mouth flow are measured with identical differential pressure transducers (Validyne MP $45^{\circ}$ ), and fed into a Fourier analyzer, dividing pressure by flow: the system calculates an impedance value for each of the investigated frequencies. The impedance is partitioned into a real part, resistance $\left(\mathrm{R}_{\mathrm{rs}}\right)$ and an imaginary part or reactance $\left(X_{r s}\right)$. The real part $\left(R_{r s}\right)$ is the equivalent of the total resistance in a resistance-inductance-capacitance $(R-L-C)$ circuit. The reactance $\left(X_{r s}\right)$ depends on the elastic and inertial properties of the respiratory system. The frequency at which $X_{\mathrm{rs}}$ equals zero is called the resonant frequency $t_{0}$. To evaluate the accuracy of the measurement a coherence function is estimated at each frequency, which indicates the amount of noise generated by the child's spontaneous breathing, present in the measured signals.

In normal adults, resistance values increase slightly with increasing frequency. Reactance is usually slightly negative at lower frequencies and becomes positive at frequencies between 5 and $10 \mathrm{~Hz}$ (resonant frequency, $\mathrm{f}_{0}$ ). In the presence of airway obstruction there is an increase in resistance values especially at low frequencies, which decreases with increasing frequency (negative frequency dependence of resistance, FD). Reactance values are more negative and resonant frequency is increased in patients with airflow obstruction. ${ }^{27,28}$ In healthy children negative frequency dependence of resistance between 8 and $28 \mathrm{~Hz}$ is a common finding. During growth FD progressively decreases, advancing to a resistance versus frequency relationship as found in healthy adults. ${ }^{29,30}$

Impedance measurements with a coherence function below 0.95 on more than 3 frequencies, or a coherence function below 0.95 on 8 or $28 \mathrm{~Hz}$ were not accepted. Landser et al. ${ }^{28}$ have demonstrated that measurements with a coherence function exceeding 0.95 have an error due to the presence of noise or nonlinearities less than $10 \%$. In the present study, each child performed at least five valid impedance measurements out of a maximum of 8 attempts. ${ }^{34}$ Recorded were the average values for the resistance at 8 and $28 \mathrm{~Hz}\left(\mathrm{R}_{\mathrm{rs} 88}, \mathrm{R}_{\mathrm{rs} 2 \mathrm{~B}}\right)$, the reactance at $8 \mathrm{~Hz}\left(\mathrm{X}_{\mathrm{rs} 8}\right)$, the frequency dependence of resistance (FD) defined as the difference between the $R_{r s 28}$ and $R_{r s 8}$ divided by 20 and the resonant trequency ( $f_{0}$ : frequency at which $X_{r s}=0$ ).

\section{Analyses}

First, using simple cross tabulation differences in current and lifetime prevalence of the asthma-related symptoms between MHA and LK were expressed in crude adds ratios. A multiple logistic regression analysis was used to determine the independent effects of several determinants of asthma-related symptoms such as gender, age, and indoor factors (dampness, passive smoking, unventilated kitchen geysers, pets) as well as the effect of living in MHA versus living in LK (dummy factor: 'region').

Because the subject has to get familiar with breathing via the mouthpiece of the FOT, every first impedance measurement was excluded from analysis. Differences in average impedance values between the regions have first been tested using unpaired t-tests. Multiple linear regression analysis was used to determine possible inter-regional 
differences in respiratory impedance, taking into account differences in exposure to several factors from the indoor environment, physical characteristics and ambient outdoor temperature and humidity. For the comparison MHA versus LK again a dummy factor 'region' was defined. Risk factors that were not significant in the stepwise analyses $(p>0.05)$ were deleted by means of backward elimination. The analyses were performed using the SPSS-X statistical package. ${ }^{33}$

\section{RESULTS}

1190 Parents returned the questionnaire (MHA 98\%, LK 96\%), and 1138 (MHA 96\%, LK $90 \%)^{\text {" }}$ of the children performed a respiratory impedance measurement. For a total of 1123 children (MHA 91\%, LK 89\%) a combination of a completed questionnaire and valid impedance data was available.

The age distribution between the regions is similar (Table 2). The proportion boys and girls is equal in MHA, but in LK $53 \%$ were boys.

Table 2. Age distribution (\%) of the children in MHA and $L K$.

\begin{tabular}{lcc}
\hline & MHA\% & LK\% \\
\hline 6 years & 5 & 6 \\
7 years & 16 & 18 \\
8 years & 17 & 17 \\
9 years & 16 & 13 \\
10 years & 18 & 17 \\
11 years & 16 & 17 \\
12 years & 11 & 12 \\
13 years & 1 & 1 \\
\hline
\end{tabular}

Table 3 presents the frequencies of the investigated indoor factors. Damp spots, unventilated kitchen geysers and pets are reported more frequently in LK than in MHA. Parental smoking and the average education level of the father were comparable between the regions.

Table 3. Frequency distribution of the indoor factors according to the questionnaire in $M H A(n=531)$, and in $L K(n=659)$.

\begin{tabular}{lccc}
\hline & MHA (\%) & LK (\%) \\
\hline damp spots in house & 21 & 34 \\
unventilated geyser in kitchen & 2 & 17 \\
pets in the house & 52 & 62 \\
family smoking in the house & 48 & 49 \\
average educational level father & 5 & 5 \\
\hline
\end{tabular}

- Due to technical problems the last 26 children in Groningen could not be measured. 
The period prevalence ( 12 months before receiving the questionnaire) as well as the life-time prevalence of the key symptoms for asthma are systematically higher in MHA compared to LK (Table 4).

Table 4. Life-fime and period prevalence of asthma related symptoms, doctors diagnoses and allergy in MHA ( $n=531)$ and in $L K(n=659)$, for boys and girls separately.

\begin{tabular}{lrrrrr}
\hline & \multicolumn{2}{c}{ MHA (\%) } & & LK (\%) \\
\cline { 2 - 3 } \cline { 5 - 6 } & Boys & Girls & Boys & Girls \\
\hline ever cough in the morning & 21 & 17 & 9 & 7 \\
ever cough in the evening & 36 & 39 & 24 & 27 \\
chronic cough & 18 & 15 & 6 & 4 \\
ever had shontness of breath & 20 & 16 & 13 & 9 \\
shortriess of breath & 15 & 15 & 3 & 8 \\
ever wheeze & 32 & 29 & 29 & 21 \\
wheeze & 17 & 16 & 14 & 13 \\
ever had attacks of shortness of breath with wheeze & 21 & 12 & 17 & 11 \\
attaciks of shortmess of breath with wheeze & 13 & 7 & 8 & 6 \\
ever doctor-diagnosed asthma & 7 & 6 & 8 & 4 \\
ever doctor-diagnosed bronchitis & 40 & 29 & 29 & 27 \\
present asthma medication use & 4 & 3 & 5 & 3 \\
definition of asthma & 14 & 11 & 10 & 7 \\
allergy for house-dust & 18 & 13 & 12 & 8 \\
allergy for pollen & 15 & 10 & 7 & 5 \\
\hline
\end{tabular}

The relatively high prevalence of reported symptoms in MHA is supported by a likewise high prevalence of bronchitis diagnosed by a doctor. No apparent differences between the regions exist in the prevalence of asthma diagnosed by a doctor, nor did the use of anti-asthma medication differ between the regions. Differences in the key-symptom prevalence of asthma expressed as crude Odds Ratios are presented in Table 5 . The highest OA is observed for chronic cough, which is reported significantly more often by children in MHA than by children in LK. The OA for asthma according to our symptom based definition is $>1$ in boys and girls and (borderline) significant. Statistical significant higher OR's were also observed for shortness of breath and attacks of shortness of breath with wheeze, most pronounced for boys in MHA compared to $L K$. The adjusted OR's resulting from the logistic regression analyses are shown in Table 6. The adjusted OR's for the key symptoms of asthma all were $>1$, significantly $(p<0.05)$ for chronic cough, shortness of breath and attacks of shortness of breath with wheeze, and borderline significant $(p<0.10)$ for wheeze and asthma (according to our definition). The results from the multiple logistic model confirm the assumption that the child's age and smoking of the mother were important determinants of the reported respiratory symptoms. Chronic cough was reported more often in the younger children (5-9 year) than in the older children (10-12 year) $(\mathrm{OR}=2.2, \mathrm{Cl}=1.2-3.8)$. Maternal smoking of more than 10 cigarettes a day was significantly associated with chronic cough $(O R=1.7$, $\mathrm{Cl}=1.0-2.8)$, shortness of breath $(\mathrm{OR}=1.4, \mathrm{Cl}=0.8-2.2)$, wheeze $(\mathrm{OR}=1.6, \mathrm{Cl}=1.1-2.4)$, attacks of shortness of breath with wheeze $(\mathrm{OR}=1.5, \mathrm{Cl}=0.9 .2 .6)$ and asthma according to our definition $(\mathrm{OR}=1.5, \mathrm{Cl}=1.0-2.5)$. 
Table 5. Crude odds ratio"s and confidence iniervals for asthma and asthma-related symptoms, MHA compared to $L K$, boys and girls separately.

\begin{tabular}{lllll}
\hline & \multicolumn{4}{c}{ MHA varsus LK } \\
\cline { 2 - 5 } & OF, Boys & C.I. & OP, Girls & C.I. \\
\hline chronic cougth & $3.6^{*}$ & $2.1-6.2$ & $3.8^{*}$ & $2.0-7.3$ \\
sthortness of breath & $2.0^{*}$ & $1.2-3.3$ & $2.1^{*}$ & $1.2-3.6$ \\
wheeze & 1.3 & $0.8-2.0$ & 1.3 & $0.8-2.1$ \\
attacks of shortness of breath with wheeze & $1.7^{*}$ & $1.0-2.9$ & 1.2 & $0.6-2.3$ \\
asthma & 1.4 & $0.9-2.3$ & $1.5^{*}$ & $1.0-2.2$ \\
\hline
\end{tabular}

$* p \leq 0.05$

For almost all asthma-like symptoms, significant OR's were found when people reported to have had pets in the past, except for wheeze, whereas the associations with the presents of pets at the time of the study was less pronounced. For none of the asthma-like symptoms a clear association with damp spots or with unventilated kittchen geysers was observed.

Table 6. Adjusted odds ratio's and confidence intervals of asthmarrelated symptoms, MHA compared to $L K$.

\begin{tabular}{lll}
\hline symptom & O.R. & C.I. \\
\hline Chronic cough & $4.5^{*}$ & $2.7 \times 7.7$ \\
shortness of breath & $2.5^{*}$ & $1.6-3.9$ \\
wheeze & $1.3^{*}$ & $1.0-1.8$ \\
attacks of shortness of breath with wheeze & $1.6^{*}$ & $1.0-2.5$ \\
asthma & $1.4^{*}$ & $1.0-2.2$ \\
\hline
\end{tabular}

$*=0<0.05, * 0<0.10$

The results of the t-test for the respiratory impedance values are shown in Table 7. Significant differences between the regions are found in reactance at $8 \mathrm{~Hz}$ and in resonant frequency. However, no notable differences in $R_{r s s}$ and $F D$ were found between the regions. After correction for physical characteristics, indoor factors, outdoor temperature, and humidity by multiple linear regression analysis, only resonant frequency was significantly lower in MHA compared to $\operatorname{LK}(\beta=0.724, p=0.02)$. Significant correlations for $f_{0}$ were found with ambient temperature, age and education level of the father. 
Table 7. Average differences in respiratory impedance values and height between the regions (t-test)" MHA compared to LK.

\begin{tabular}{|c|c|c|c|c|}
\hline & \multicolumn{2}{|c|}{ MHA } & \multicolumn{2}{|l|}{ LK } \\
\hline & Boys & Gins & Boys: & Girls \\
\hline average height (cm) & $141^{*}$ & $140^{*}$ & 143 & 142 \\
\hline average $f_{0}(\mathrm{~Hz})$ & $12^{\text {*i }}$ & 13 & 13 & 13 \\
\hline frequency-dependence $\left(\mathrm{cmH}_{2} \mathrm{O} /(\mathrm{L} / \mathrm{s})\right)$ & 0.003 & 0.006 & 0.0001 & 0.006 \\
\hline average reactance $(8 \mathrm{~Hz})\left(\mathrm{cmH}_{2} \mathrm{O} /(\mathrm{L} / \mathrm{s})\right)$ & $0.7^{*}$ & 1.0 & 0.9 & 1.0 \\
\hline resigtance at $8 \mathrm{~Hz}\left(\mathrm{cmH}_{2} \mathrm{O} /(\mathrm{L} / \mathrm{s})\right)^{5}$ & 5.8 & 6.1 & 5.8 & 5.9 \\
\hline
\end{tabular}

$=p=0.05$

\section{DISCUSSION}

In this study respiratory symptoms and respiratory impedance were measured in 1123 primary school children living in two different regions of the Netherlands: Limburg and Groningen. The life-time and period prevalence of chronic cough, shortness of breath, wheeze, attacks of shortness of breath with wheeze and asthma (according to a symptom based definition) was significantly higher in children living in MHA compared to children living in LK. The regions were comparable with respect to the reported rates of doctor-diagnosed asthma, but doctor-diagnosed bronchitis was reported more often in MHA. The results of the respiratory impedance measurements showed a statistically significant but small difference in $t_{0}$ between the regions, LK slightly being at a disadvantage. However, since the difference is small and not confirmed by differences in resistance parameters $\left(\mathrm{R}_{\mathrm{rs} 8}, \mathrm{FD}\right)$ it can be doubted whether it is of clinical importance.

Factors from the indoor environment such as parental smoking, unventilated kitchen geysers, home dampness and pets may play an important role in the development of respiratory symptoms and asthma in children. ${ }^{16-19}$ These risk factors were reported more frequently in LK. In the present study, maternal smoking (>10 cig./day) and educational level of the father were significantly related to the reported asthma-like symptoms, whereas unventilated kitchen geysers and damp spots were not. After taking into account the independent effects of these determinants of asthma-related symptoms, still higher prevalence rates were found in MHA.

During the study period levels of outdoor air pollutants were in general somewhat higher in Limburg than in Groningen but below the present national and international air quality standards. However, the $\mathrm{PM}_{10}$ standard is subject to discussion in respect to its safety for human health, since recent epidemiologic studies have demonstrated an apparent adverse effect of particulate matter on mortality and morbidity in concentration ranges under currently tolerated levels. ${ }^{34-36}$ The consistency of these observed associations is certainly suggestive for causality. However, until now the toxicologic evidence to demonstrate biological plausibility is lacking. ${ }^{37}$

Only for Limburg (additional) information about the $\mathrm{PM}_{10}$ concentration during the study period was available. The 24-hour average concentration during the study period was $36 \mu \mathrm{g} / \mathrm{m}^{3}$ ( $\max .24$-hour level of $49 \mu \mathrm{g} / \mathrm{m}^{3}$ ). However, by the measurement technique used, $\mathrm{PM}_{10}$ levels have been systematically underestimated with $20-30 \%,{ }^{22}$ which makes the comparison with air quality standards uncertain. Based on data from the 
National Air Pollution Monitoring Network concerning the previous year, there are no notable differences in the average annual $\mathrm{PM}_{10}$ concentration between Limburg and other regions in the Netherlands. It is therefore unlikely that $\mathrm{PM}_{10}$ is fully responsible for the observed regional differences in prevalence rates. Levels of $\mathrm{NO}_{2}$ did exceed the national air quality standard of annual averages. Taking into account the short monitoring period in the present study, the relatively high $\mathrm{NO}_{2}$ levels not necessarily implicate that the tolerated annual levels will be reached.

It seems that well-known risk factors, which were taken into account in this study, can not explain the observed regional differences in the prevalence of asthma and asthma related symptoms in these children. One or more at present unknown (and unmeasured) risk factors of respiratory health are apparently responsible for the high prevalence rates reported in MHA.

Allergy for pollen and house-dust was reported more frequently in MHA than in LK. Although the allergic status of an individual can only be evaluated by means of a skin test or by assessing blood lgE-levels, it is plausible that the prevalence of reported allergy is closely related to the reported prevalence of asthma-like symptoms. The question whether regional specific allergens, perhaps interacting with certain air pollutants, contribute to the relatively high prevalence of asthma-like symptoms in MHA is interesting, but cannot be answered by the data available in the present study.

Previously we have demonstrated that the forced oscillation technique is well suited for use in an epidemiological setting with children. ${ }^{38}$ Since the measurements are independent of the effort made by the child, they are easy to perform by the child as well as the investigator, and 3-5 measurements can be obtained in a relatively short time (5-10 minutes). In agreement with several other investigators ${ }^{29,30}$ we found respiratory impedance values in children to differ from those observed in adults ${ }^{27}$, and to vary with height and gender. ${ }^{39,40}$ Nevertheless, significantly higher values for resistance and resonant frequency, and more negative values for reactance and frequency dependence of resistance (reflecting airway obstruction) were found in children with chronic respiratory symptoms, compared to symptom-free children. ${ }^{38,40}$ The results of the respiratory impedance measurements obtained in this study do not confirm the high symptom prevalence in MHA, since no clear impairment were found in this region compared to LK. In contrast, a small but statistically significant increase in resonant frequency was observed in LK compared to MHA. The magnitude of this difference is, however, so small that it can be doubted whether it is of clinical importance. Moreover, because $\mathrm{R}_{\mathrm{rs}}$ values did not differ between the regions.

Characteristic for asthma is that symptoms alternate with intervals of relative or complete freedom from symptoms. ${ }^{4}$ During these symptom-free intervals the lung function can be completely normal. In the present study, the questionnaire derived prevalence rates refer to the previous 12 months, whereas the lung function was measured at one moment. This may, in part, be responsible for the discrepancy between respiratory symptoms and respiratory impedance values.

We therefore investigated whether children who reported one or more asthma related symptoms in the previous 12 months had different impedance values compared to the symptom-free children. After adjusting for gender and height, the symptomatic children showed significantly higher resistance and resonant frequency values and lower reactance values, except for the children with chronic cough. These findings are in line with our previous findings $s^{39,40}$ and may be interpreted as an indication for airway obstruction in the symptomatic children, although in absolute terms the differences were small. In part of the children, chronic cough may be due to irritation of the higher 
airways, which can probably not be demonstrated by respiratory impedance measurements. In the present study children were not asked to refrain from use of any medication before the impedance measurement. By excluding children who were using asthma-medication according to the questionnaire from the analyses, differences in respiratory impedance values between the groups became smaller, suggesting that children presently using medication have more severe asthma.

According to our symptom-based definition for asthma about $12 \%$ of the children in MHA and $9 \%$ of the children in LK were classified as asthmatic, whereas the doctordiagnosed asthma prevalence was $7 \%$ and $6 \%$ respectively. This may suggest underdiagnosis of the disease in children, as has been previously suggested by several investigators. ${ }^{42-44}$ Part of the discrepancy between our symptom based asthma prevalence and the prevalence of doctor-diagnosed asthma may be due to misclassification of the disease, since a relatively high prevalence of doctor-diagnosed bronchitis was found in MHIA. Similar findings have been reported before. $45-48$

The estimated asthma prevalence of $12 \%$ in the present study is comparable to that found in our previous study among 482 children living in the very south of Limburg. Maastricht. ${ }^{38}$ In this study we found a symptom based asthma prevalence of $11 \%$. Taking the results of both studies together and comparing them to nationall rates of childhood asthma, the prevalence of asthma-related symptoms is found to be systematically higher in the southern region. ${ }^{49-51}$ Most strinkingly chronic cough in younger children (5-9 years) differs among the regions. It has been suggested that chronic cough in young children may be an early and sometimes the only manifestation of childhood asthma. ${ }^{\prime}$ Although the reproducibility of the question for chronic cough is low, its prevalence rate in Limburg is consistently high. ${ }^{38}$ The relatively high prevalence of chronic cough in MHA is confirmed with the likewise high prevalence of doctor-diagnosed bronchitis in this region as reported by the parents, suggesting that regional general practitioners confirm the chronic cough problem.

Compared to international studies, prevalence rates in the present study were relatively high for chronic cough, ever wheeze and bronchitis diagnosed by a doctor, especially in $\mathrm{MHA} .{ }^{42,44,52-54}$ The prevalence of wheeze in the previous year and asthma diagnosed

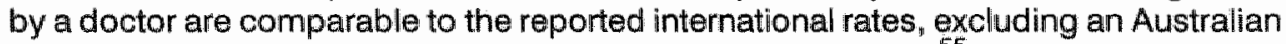
study reporting higher prevalence rates of childhood asthma. ${ }^{55}$

Because of their subjective nature, questionnaire data are subject to bias. Public interest towards the respiratory health of their children may differ between regions, which may influence people's attitude towards their responses to questionnaires. By the questionnaire used in the present study also symptoms occuring in the previous week were investigated (a week before receiving the questionnaire). Besides respiratory symptoms these questions refer to "irritated/red eyes', "headache", 'earache', "nausea' and 'fever". Again reported prevalence rates were higher in MHA compared to LK. "Medication use', 'staying ill at home' and 'visiting a hospital' in the previous week also were reported more frequently in MHA. In contrast, the life-time prevalence of 'pseudocroup", "otitis" and "have the child's tonsils out' was reported equally in both regions. The fact that the main part of the non-respiratory sylmptoms also were reported more frequently in MHA, may suggest the occurence of reporting bias in this region. However, since the above named questions were not developed specifically to control for reporting bias, it is difficult to $j$ udge whether the obsenved high prevalence rates for chronic respiratory symptoms in MHA, were caused by reporting bias only. At least the data are illustrative for a general perception of illness of the inhabitants in MHA. 
In summary, in this study we found a relatively high prevalence of asthma related symptoms, especially chronic cough, in MHA compared to LK. The observed differences in respiratory impedance were small and it can be doubted whether these have clinical importance. Taking into account the independent influence of several wellknown determinants of asthma-like symptoms, the interregional differences in prevalence rates persisted. A determinant which has not been taken into account in this study may differ between the regions, and may in turn be responsible for the higher prevalence rates found in $\mathrm{MHA}$.

\section{ACKNOWLEDGEMENTS}

The authors wish to thank the teachers of the cooperating schools, the children and their parents for participating in the study. This study was conducted in a successful collaboration of the Department of Public Health, Regional Services of Roermond and Groningen and the University of Maastricht. We further wish to thank Marcel Severijnen and Jacob Pijnenburg of the Province of Limburg, Department for Research, for their efforts to provide the additional air quality data.

\section{APPENDIX}

6 Did your child cough on most days, for at least 3 months a year?

7 Has your child ever been troubled by shortness of breath when playing outside or climbing the stairs?

8 Has your child been troubled by shortness of breath when playing outside or climbing the stairs, in the previous year?

9 Has your child's chest ever sounded wheezy?

10 Has your child's chest sounded wheezy, in the previous year?

11 Has your child ever had attacks of shortness of breath with wheeze?

12 Has your child had attacks of shortness of breath with wheeze, in the previous year?

16 Has the child ever had asthma diagnosed by a doctor?

18 Is your child at this moment using anti-asthma medication?

19 Has the child ever had bronchitis diagnosed by a doctor?

\section{REFERENCES}

1. Godfrey S. Childhood asthma. In: Asthma (3rd edn), eds. Clark TJH, Godfrey S, and Lee TH. Chapmann \& Hall, London 1992, (chapter 18, p551-604).

2. Burney PGJ. Epidemiology in: Asthma (3rd edn), eds. Clark TJH, Godfrey S, and Lee TH. Chapmann \& Hall, London 1992, (chapter 9. p254-307).

3. Roorda Rul. Features of the outcome of childhood asthma. Thesis 1992, Groningen, The Netheriands.

4. Mitchell EA. is current treatment increasing asthma montality and morbidity? Thorax $1989 ; 44: 81-84$.

5. Anderson HR. is the prevalence of asthma changing? Arch Dis Child 1989; $64: 172-175$.

6. Fieming DM, Cromble DL. Prevalence of asthma and hay fever in England and Wales. Br Med J 1987; 294: 279-283. 
7. Yunginger $J W$, Reed CE, O'Connel EJ, Metton LJ, O'Fallon WM, Silwerstein MD. A community-based study of the epidemiology of asthma. Incidence rates, 1964-1983. Am Rev Respir Dis 1992; 146: B88-804.

8. Brimblecombe P. The big smoke. A history of air poltution in London since medieval times. Methuen and Co. London, 1987.

9. Hoek $G$, Brunekreef $B$. Acute effects of a winter air pollution episode on pulmonary lunction and respiratory symptoms in children. Arch Environ Health 1993; 48: 27-32.

10. Roemer $W$, Hoek $G$, Brunekreef $B$. Effect of ambient winter air pollution on respiratory health of children with chronic respiraltory syiriptoms. Am Rev Respir Dis 1993; 147: 118-124.

11. Hoek $G$, Fischer $P$, Brunekreef $B$, Lebret $E$, Hoifschreuder $P$, Mennen MG. Acute effects of ambient. ozone on pulmonary function of children in the Netherlands. Am Rev Respir Dis 1993; $147: 111-117$.

12. Pope CA, Dockery DW. Acute health effects of $P M_{10}$ pollution on symptomatic and asymptomatic children. Am Rev Respir Dis 1992; 145: 1123-1128.

13. Schwartz J. Particulate air pollution and daily mortality: a synthesis. Public Health Rev 1991-92; $(1-4): 39-60$.

14. Wardlaw AJ. The role of air pollution in asthma. Review. Clin Exp Allergy 1993; 23: 81-96.

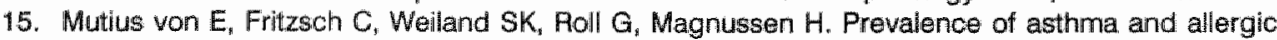
disorders among children in united Germany: a descrpitive comparison. Br Med J 1992; 305: 1395. 1399.

16. Tager $\mathrm{BB}$. Health effects of 'passive smoking' in children. Chest 1989; 96 : 1161-1164.

17. Brunekreef B, Dockery DW, Speizer FE, Ware JH, Spengler JD, Ferris BG. Home dampness and respiratory morbidity in children. Am Rev Respir Dis 1989; 140: 1363-1367.

18. Samet JM, Utell MJ. The risk of nitrogen dioxide: what have we learned from epidemiological and clinical studies? Tox Indus Health 1990; 6: 247-262.

19. Dekker $\mathrm{C}$, Dales $\mathrm{A}$, Bartlett $\mathrm{S}$, Brunekreef $\mathrm{B}_{n}$ Zwanenburg $\mathrm{H}$. Childhood asthma and the indoor environment. Chest 1991; 100: 922-926.

20. Elskamp HJ. National air quality monitoring network. Technical description. Bilthoven, the Netherlands. National Institute of Public Health and Environmental Protection. 1989, report no. 228702017 .

21. Utell MJ, Samet لIM. Particulate air pollution and health. New evidence on an old problem. (Editoriali). Am Rev Respir Dis 1993; 147: 1334-1335.

22. Meulen van der A. Improvernents in the design and operation of a sampler for the measurement of suspended particulate matter in the ambient athmosphere. 1990, FIVM, Bilthoven.

23. Florey $C$. du $V_{n}$, Leeder SR. Methods for cohort studies of chronic airflow limitation, (chapter 3). WHO regional publications, European series No. 12. London, United Kingdom 1982; 112.

24. Brunekreef B, Groot B, Rijcken B, Hoek $\mathrm{G}$, Steenbekkers A, Boer de A. Reproducibility of childhood respiratofy symptom questiong. Eur Respir J 1992; 5: 930-935.

25. Làndser FJ, Nagels J, Demedts M, Billiet L, Woestijne van de KP. A new method to determine frequency characteristics of the respiratory system. I Appll Physiol 1976; 41: 101-106.

26. Wouters EFM. Total respiratory impedance measurement by forced oscillations: noninvasive method to assess bronchial response in occupational medicine. Exp Lung Pesearch 1990; 16: 25 40.

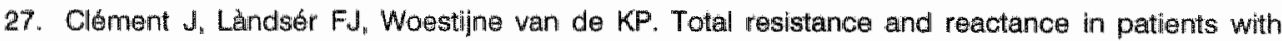
respiratory complaints with and without airway obstruction. Chest $1983 ; 83: 215-220$.

28. Làndser $\mathrm{FJ}$. Clement $J$, Woestijne van de KP. Normal values of total respiratory resistance and reactance determined by forced oscillations. Infiuence of smoking. Chest 1982; 81: 586-591.

29. Clément $J_{4}$ Dumoulin $B$, Gubbelmans $R$, Hendriks KP, Woestijne wen de KP. Reference values of total respiratory resistance and reactance between 4 and $26 \mathrm{~Hz}$ in children and adolescents aged 4-20 years. Bull Eur Physiopathol Respir 1987" 23: 441-448.

30. Stanescu D, Moavero NE, Veriter C. Brasseur L. Frequency dependence of respiratory resistance in healthy children. J Appl Physiol 1979; 47: 268-272.

31. Woestijne van de KP. Desager KN, Duiverman EJ, Marchal F. Recommendations for measurement of the respiratory impedance input impedance by means of the forced ascillations method. Eur Respir Rev 1994 (4); 19: 235-237.

32. Làndsér FJ, Nagiels $\mathrm{J}$, Clément J, Woestijne van de KP. Errors in the measurement of total respiratory resistance and reactance by forced oscillations. Respir Physiol 1976; 28: 289-301.

33. SPSS Inc., 1990" 444n Michigan Avenue, Chicago, Illinois 60611. 
34. Pope CA III. Dockery DW. Acute effects of $P M_{10}$ pollution on symptomatic and asymptomatic: children. Am Rev Respir Dis 1992; 145: 1123-1128.

35. Pope CA III. Kanner RE. Acute effects of PM 10 pollution on pulmonary function of smokers with mild to moderate chronic obstructive pulmonary disease. Am Rev Respir Dis 1993; 147: 1336-1340.

36. Schwartz J. Particulate air pollution and daily mortality: a symthesis. Public Health Rev 1991-92; $19(1-4): 39-60$.

37. Schenker M, Air pollution and mortality. (Ediotorial). New Engl J Med 1993; 329: 1807-1808.

38. Cuijpers CEJ, Wesseling $G_{8}$ Swaen GMH, Sturmans $F$, Wouters EFM. Asthma nelated symptoms and lungfunction in primary school children. J Asthma 1994; 31: 301-312.

39. Cuijpers CEJ, Wesseling G, Swaen GMH. Wouters EFM. Frequency dependence of ascillatory resistance in healthy primary school children. Respiration 1993; 60: 149-154.

40. Cuijpers CEJ, Wesseling G, Swaen GMH, Wouters EFM. Height and gender related impedance values in primary schoolchildren. Eur Respir Rev 1994; 4(19): 150-154.

411. Clark TJH. Definition and clinical categories of asthma. In: Asthma (3rd edn), eds. Clark TJH,

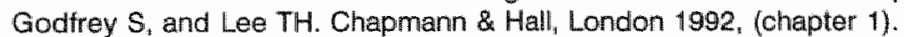

42. Chifford RD, Radford M, Howell JB, Holgate ST: Prevalence of respiratory symptoms among 7 and 11 year ofd schoolchildren and association with asthma. Arch Dis Child 1989; 64: 1118*1125.

43. Speight ANP, Lee DA, Hey EN: Underdiagnosis and undertreatment of asthma in childhood. Br Med J 1983; 286: 1253-1256.

44. Hill RA, Standen PJ, Tattersfield AE: Asthma, wheezing, and school absence in primary schools. Arch Dis Child 1989; 64: 246-251.

45. Lee DA, Winslow NR, Speight ANP, Hey EN. Prevalence and spectrum of asthma in childhood. Br Med J 1983; $286 ; 1256-1258$.

46. Williams $\mathrm{H}, \mathrm{McNicol} \mathrm{KN}$. Prevalence, natural history, and relationship of wheezy bronchitis and asthma in children. An epidemiological study. Br Med J 1969; 4: 321-325.

47. Wilson NM: Wheezy bronchitis revisited (controversy). Arch Dis Child 1989; 64: 1194-1199.

4B. Jones $A$, Sykes $A$. The effect of symptom presentation on delay in asthma diagnosis in children in general practice. Respir Med 1990; 84: 139-142.

49. Akkerman I, Dijkstra L, Houthuijs D, Brunekreef, Biersteker K. Evaluation of a questionnaire on respiratory symptoms in children. I Reproducibility of the answers. T Soc Gezondheidsz 1989;67: 183-187 (in Dutch).

50. Steenbekkers $A$, Boer de $A$, Brunekreef $B$, Hoek $G$, Rijcken $B$, Groot B: A comparison of two questionnaires on respiratory symptoms in children. 1 Comparison of the prevalences. $T$ SoC Gezondheidsz 1990; 68: 478-482 (in Dutch).

51. Rijcken B: Two questionnaires on respiratory symptoms for epidemiological studies in the youth health service. T Soc Gezondheidsz 1989; $67: 271-274$ (in Dutchl).

52. Ninan TK, Russell $\mathrm{G}$ : Respiratory symptoms and atopy im Aberdeen schoölchildren: evidence from two surveys 25 years apart. Br Med J 1992; 304: 873-875.

53. Johnston IDA, Bland JM, Anderson HA. Ethnio variation in respiratory morbidity and lung function in childhood. Thorax 1987; $42: 542-548$.

54. Sennhauser FH, Güntert BJ. Prävalenz des asthma bronchiale ilm kindesalter in der Schweiz: Die bedeutung won symptomatik und diagnose. Schweiz Med Wschr 1992; 122: 189-193.

55. Robertson CF, Heycock E, Bishop J, Nolan T. Olinsky A, Phelan PD. Prevalence of asthma in Melbourne schoolchildren: changes over 26 years. Br Med J 1991; 302: $1116-1118$. 



\section{Chapter 9}

\section{GENERAL DISCUSSION AND CONCLUSIONS}

\section{Asthma}

In this thesis we investigated the prevalence of chronic respiratory (asthma-like) symptoms and asthma in Dutch primary school children. Because there is no generally accepted definition of asthma in epidemiology, it is difficult to give valid estimates of it's prevalence. In our prevalence studies we defined asthma as reporting at least two of the four key symptoms suggestive for asthma, to include wheeze or attacks of shortness of breath with wheeze, in the previous year. In the studies presented in chapter four and eight we found the symptom-based asthma prevalence to be $11 \%$ and $12 \%$ respectively. In contrast, the doctor-diagnosed asthma prevalence in these studies was found to be $6 \%$ and $7 \%$ respectively. The data are in agreement with the statement that childhood asthma is probably substantially underdiagnosed. ${ }^{1-3}$ Furthermore, we found that about one-quarter of the doctor-diagnosed bronchitis children met the symptom-based criteria for asthma, suggesting that some of the children are misclassified. Similar results have been reported before. ${ }^{4}$ Diagnostic labelling by a doctor as either asthma or bronchitis apparently determined whether anti-asthma medication was prescribed. The observation that about half of the symptomatic children are not recognized as having asthma and about one quarter are (mis)classified as having bronchitis suggests that undertreatment is still a problem in these children.

However, problems inherent to the use of a symptom-based definition of asthma are the heterogeneous clinical picture by which the disease presents and the poor specificity of wheezing symptoms for asthma. In addition to the determination of prevalence rates, we performed lung function measurements, using spirometry and the forced oscillation technique. Statistically significant, but small impairments in spirometry and oscillatory impedance values were found in children reporting asthma and asthma-like symptoms, compared to symptom-free children. Furthermore, we found lung function impairment to be larger in children with the key symptoms suggestive of asthrna (symptom-based asthma) than in children previously diagnosed as having asthma. The lung function data therefore support the observed, relatively high, prevalence rates of the asthma-like symptoms and confirm the earlier statement that asthma in these children is probably underdiagnosed.

It has been suggested that the incidence of asthma is increasing, in particular in young children. ${ }^{56}$ Although part of this increase may be attributed to enhanced recognition 
and diagnostic transfer, the provided evidence suggests that the increase in childhood asthma is real. ${ }^{7,8}$ This increase has been suggested to be associated with changes in environmental exposures (especially indoor exposures) and changes in host susceptibility (e.g. the increase of low birth weights). ${ }^{7}$ However, what there relative contributions are awaits further clarification.

\section{Environmental Risk Factors}

- Indoor. In the present thesis we investigated the influences of several factors from the indoor environment, such as parental smoking, unventilated kitchen geysers, home dampness and the presence of pets, on the respiratory system of children. With respect to lung function impairments, parental smoking was found to be the most important indoor risk factor. When the relationship between parental smoke exposure and impairments in respiratory impedance was studied in more detail the results suggest the existence of a dose-response relationship (chapter six). So far, such a relationship has not yet been substantiated, and the minimal dose at which an effect can be determined remains unclear. As far as our data were differentiated we found predominance of the maternal smoking effect. Similar results have been reported before. ${ }^{9}$ The predominance of the maternal smoking effect may, in part, be due to smoke exposure during pregnancy ${ }^{10}$ and partly because mothers in general spend more time with the children. The largest effects of parental smoking were found on parameters of respiratory reactance and on the $F F_{25-75 \%}$ (chapter 5 and 6 ), suggesting that especially the peripheral airways are affected by parental smoking. This is in line with the results of Strachan et al. ${ }^{11}$ who found the flow rates in the terminal part of the spirogram to be the most sensitive to passive tobacco exposure. Although not in all cases statistically significant, maternal smoking also appeared to be associated with the asthma-like symptoms (chapter eight and five). The observation that the associations were more pronounced if the mothers smoked $\geq 10$ smokes per day inside the house than if the mothers smoked $<10$ smokes per day inside the house, again suggests the existence of a dose-response relationship.

Of the other indoor risk factors we investigated, the associations were less consistent than with passive smoking. Unventilated gas household appliances, especially unventilated kitchen geysers are potential sources of nitrogen dioxide inside Dutch homes, ${ }^{12}$ which may be associated with respiratory symptoms in children. ${ }^{13}$ In agreement with earlier reports, ${ }^{12,13}$ we found unventilated kitchen geysers to be related to most of the asthma-like symptoms, without clear effects on spirometry. However, statistically significant effects on part of the impedance parameters (respiratory reactance) were found in girls, butt not in boys. For home dampness, in the past, significant associations have been reported with asthma-like symptoms, especially with chronic cough and wheeze, ${ }^{12,14.16}$ with no clear association with lung function parameters. We found damp stains and mould growth to be related to the asthma-like symptoms, although not in all cases significantly. Furthermore, in boys small impairments in spirometry and impedance parameters were found. Of the pets studied only the presence of a dog was associated with attacks of shortness of breath with wheeze, but not with any of the lung function parameters. However, a clear association may have prompted parents to remove the pet(s), resulting in underestimation of the effect.

By investigating the effects of indoor exposure on respiratory health of children, we performed the analyses stratified for gender. Differences in effect between boys and girls were observed with passive smoking, unventilated kitchen geysers and home dampness. However, no consistent pattern emerged. In chapter five, boys appeared 
to be more susceptible to (undifferentiated) parental smoke exposure, whereas in chapter six the most consistent effects of maternal smoke exposure were found on respiratory reactance in girls. Furthermore, part of the impedance parameters were significantly affected in girls exposed to unventilated kitchen geysers, but not in boys. In contrast, with exposure to home dampness lung function impairments were found in boys, but not in girls. Based on the higher incidence and prevalence of childhood asthma observed in boys, ${ }^{17}$ higher susceptibility of boys has been suggested to have a physiologic basis. However, the inconsistency in the data do not allow supporting this hypothesis.

The conclusions to be drawn from these studies are restricted by their cross-sectional design. Findings may be subject to bias as exposure of interest and disease status are examined at one moment in time. Furthermore, since information on the exposure variable as well as respiratory morbidity was obtained by means of questionnaire, responder bias can not be ruled out as a possible cause for the observed associations.

- Outdoor. In chapter 8 , the observed interregional differences (Limburg versus Groningen) in the prevalence of asthma and asthma-like symptoms could not be explained by differences in the distribution of indoor risk factors, like the ones we just discussed. Other risk factors, such as genetic susceptibility, viral infections and outdoor air pollutants may have contributed to the observed interregional differences in prevalence rates of asthma and asthma-like symptoms. What data on outdoor air pollution levels were available, differed only marginally between the regions and did in general not exceed the air quality standards. It is therefore unlikely that the observed interregional differences in prevalence rates were caused by differences in outdoor air pollution levels, solely.

The potential role of air pollution on respiratory health in general and asthma in particular, has received a lot of attention in the past few decades. The occurrence of smog-episodes offers unique opportunities to study (acute) adverse effects of shortterm exposure to moderately and high levels of air pollutants, in humans. Recently, several Dutch studies have demonstrated acute adverse effects on children's respiratory health, occurring during winter as well as summer-smog-episodes. ${ }^{18-20}$

In the study presented in chapter seven of this thesis we investigated the acute effects of a summer-smog-episode, characterized by ozone levels (8-hour average) $>120$ $\mu \mathrm{g} / \mathrm{m}^{3}\left(\max .163 \mu \mathrm{g} / \mathrm{m}^{3}\right)$ and 1 -hour levels $>160 \mu \mathrm{g} / \mathrm{m}^{3}\left(\max .215 \mu \mathrm{g} / \mathrm{m}^{3}\right)$, on symptoms and lung function in 212 children. We found no significant increases in acute respiratory symptoms, which is in agreement with previous findings. ${ }^{21}$ Of the investigated lung function parameters, only changes in PEF were significantly negative associated with changes in ozone levels, indicating a decrease in PEF with increasing ozone levels. Similar results have been reported before, although the literature on which spirometric parameter is most obviously affected by ozone exposure is not consistent. ${ }^{20,22-25}$ None of the impedance parameters appeared to be significantly adversely affected by exposure to ozone, and the signs of the changes in some of the impedance measures were opposite to the expected direction of an adverse effect. From our data there are no indications that children already suffering from respiratory diseases were more sensitive to the effects resulting from ozone exposure, confirming earlier findings ${ }^{20}$ Our results suggest that short-term exposure to a mild summer-smog-episode, with 8-hour average ozone levels exceeding $120 \mu \mathrm{g} / \mathrm{m}^{3}$, does not result in clear, adverse effects on the respiratory health of primary school children. However, the lack of clear adverse effects on respiratory health may, in part, be due to the relatively short 
exposure time and the relatively low ozone levels during the episode and to the fact that the number of measurements was restricted to the two cross-sectional examinations of the 212 children.

\section{The Forced Oscillation Technique}

In the studies presented in this thesis we used the forced oscillation technique (FOT) in open populations of school children. In chapter two we studied respiratory impedance in 371 symptom-free children. We found the values to vary with height and gender. Resistance values decreased and reactance values increased with increasing height, in boys as well as in girls. Below $160 \mathrm{~cm}$ of height statistically significant gender differences were found in values for resistance and reactance. Negative frequency dependence of resistance (FD of $R_{\text {mich }}$ ), which has been suggested to be a sensitive index of airflow obstruction in adults, ${ }^{26}$ was a common finding in all height categories, which disappeared during growth. Significantly more negative $F D$ of $R_{r s}$ was found in boys than in girls. Similar results on impedance values in children have been reported before, although not all investigators observed negative $\mathrm{FD}$ of $\mathrm{A}_{\mathrm{rs}}$ and in the majority of the studies data were not presented for boys and girls separately. ${ }^{27-30}$ The finding of neglative FD of $\mathrm{R}_{\mathrm{rs}}$ in presumably healthy children suggests that in children the resistance of the peripheral airways makes up a larger part of the total respiratory resistance than in adults. This is in line with reported observations that the peripheral airways are disproportionally narrow in the early years of life. ${ }^{31}$ In contrast to adults this means that in children negative $F D$ of $R_{r s}$ does not necessarily implicate pulmonary pathology. The observation that negative $F D$ of $\mathrm{A}_{\mathrm{rs}}$ longer exists in boys, may implicate that small alterations in the impedance pattern, due to environmental exposure or existing disease, will be more difficult to detect in boys than in girls. The differences in respiratory impedance values between boys and girls of the same age we observed may, in part, be explained by gender differences in growth patterns. Different growth rates of the smaller airways result in differences in airway diameter and consequentlly in different values for resistance.

In chapter four we found statistically significant, but small "differences in respiratory impedance values between children with and without asthma (-like symptoms). These differences were supported by comparable differences in spirometric values. In chapter three we distinguished four groups of children: symptom-free, chronic cough, asthma and rest-symptoms. Statistically significant differences in impedance values were found between symptom-free and asthmatic children, in girls but not in boys. No clear differences were observed in children with chronic cough or rest-symptoms, compared to the symptom-free chilldren. Again the results suggest gender differences in impedance values. Interaction between gender and disease status was found to be statistically significant, which means that differences between asthmatic and symptom-free children were different for boys than for girls. These results support the assumption that in boys smiall alterations of impedance patterns, due to existing disease, are more difficult to detect than in girls.

The diagnostic value of the individual impedance parameters appeared to be low, since for none of the investigated parameters a cut-off point was found with acceptable values of sensitivity and specificity, discriminating between symptom-free children and children with chronic respiratory symptoms. One possible explanation for these results is that, based on a cross-sectional measurement, the FOT is not sensitive enough to identify children who suffer from chronic cough, asthma or any other (chronic) respiratory symptoms. However, the questionnaire deals with symptoms within the 
previous 12 months whereas impedance values were obtained at one moment in time, namely when children were at school and probably free of symptoms. On the other hand the absence of differences in respiratory impedance between symptomatic and symptom-free children may reflect absence of baseline physiopathological changes. This underlines the importance of questionnaires adding to the use of functional measurements.

Thanks to computerization of the impedance data more sophisticated analyses could be performed (chapter three and five). Using linear and quadratic regressions, individual resistance and reactance curves were described as a function of frequency. The impedance parameters characterizing these curves were used in addition to the on-line impedance parameters. We found that the sophisticated impedance parameters gave no additional information over the on-line parameters. These findings support the use of on-line indicator parameters, and allow comparisons of the present with our previous results.

In the studies presented in chapters five through eight respiratory impedance values were used as outcome variables in evaluating the potential health effects of environmental exposures. Measurements were rapid and easy to perform for the child as well as the investigator. In contrast to spirometry they are independent by the effort made by the child and are therefore less influenced by learning effects. Studying the effects of indoor exposures (chapter five) the results obtained by spirometry and FOT showed good agreement. The observation that in girls part of the impedance parameters was significantly affected by exposure to unventilated kitchen geysers was not supported by spirometry. In chapter six respiratory impedance was used as the only outcome measure to determine the effects of passive smoking into more detail. Mainly respiratory reactance was affected by parental (maternal) smoke exposure. The results suggest the existence of a dose-response relationship between parental smoke exposure and respiratory impedance (reactance).

The effects of exposure to a summer-smog-episode on respiratory health (chapter seven), were less consistent. Impairments in spirometric parameters were not supported by impairments in impedance parameters. On the contrary, significant alterations in the opposite direction were found. This might mean that impedance measurements do not demonstrate the type of effects caused by ambient ozone. Further (controlled exposure) research on the applicability of this technique and on the dependence of impedance measurements on meteorologic and other potential confounding factors, is needed.

In summary, of the investigated children $14-12 \%$ reported two or more of the asthma. like symptoms. A major part of these children was not diagnosed as having asthma (-like symptoms) and consequently undertreatment of the children still is an important problem. Of the investigated indoor risk factors, parental smoking was the most obvious related to lung function impairments. Sensitivity of the FOT to detect effects of indoor pollution on the respiratory system was found to be quite comparable with spirometry, whereas it was less sensitive in detecting effects of exposure to a summersmog-episode. However, the present results are restricted by the cross-sectional design of the studies. Future studies with a longitudinal design are needed to obtain more insight in validity and reproducibility of the impedance measurements in children, their diagnostic value in children and the associations of the impedance values with various (relevant) confounders. 


\section{REFERENCES}

1. Clifford PD, Radford $M$, Howell JB, Holgate $S T$. Prevalence of respiratory symptoms among 7 and 11 year old schoolchildren and association with asthma. Arch Dis Child 1989; 64: $1118-1125$.

2. Speight ANP, Lee DA, Hey EN. Underdiagnosis and undertreatment of asthma in childhood. $\mathrm{Br}$ Med d 1983; $286: 1253-1256$.

3. Hill PA, Standen $P J$, Tattersfield $A E$. Asthma, wheezing, and school absence in primary schools. Arch Dis Child 1989; 64: 246-251.

4. Jones $\mathrm{A}$, Sykes $\mathrm{A}$. The effect of symptom presentation on delay in asthma diagnosis in children in general practice. Respir Med 1990; 84: 139-142.

5. Yunginger JW, Reed CE, O'Connel EJ ${ }_{i}$ Melton Lل, O'Fallon WM, Silverstein MD. A community-based study of the epidemiology of asthme. Incidence rates, 1964-1983. Am Rev Respir Dis 1992: 146: 888-894.

6. Burney PGJ, Chinn S, Rona RJ. Has the prevalence of asthma increased in children? Evidence from the national study of health and growth 1973-1986. Br Med J 1990; 300: 1306-1310.

7. Gergen PJ, Weiss KB. The increasing problem of asthma in the United States. Am Rew Respir Dis 1992; 146: 823-824.

8. Britton J. Asthma"s changing prevalence. Establishing the true figures is difficult. Br Med $\mathrm{J} 1992$; 304: $857-858$.

9. Tager IB. Health effects of 'passive smoking' in children. Chest 1989; 96 : 1161-1164.

10. Wang $X$, Wypil D, Gold DR, Speizer FE, Ware JH, Ferris BG, Dockery DW. A longitudinal study of the effects of parental smaking on pulmonary function in children $6-18$ years. Am $J$ Respir Crit Care Med 1994; 149: 1420-1.425.

11. Strachan DP, Jarvis MJ, Feyerabend $C$. The relationship of salvary cotinine to respiratory symptoms, spirometry and exercise induced brochospasm in seven-year old children. Am Rev Respir Dis 1990; 142: $447 \cdot 151$.

12. Dijkstra $L$, Houthuijs D, Brunekreef $B$, Akkerman I, Boleij SM. Respiratory health effects of the indaor environment in a population of Dutch children. Am Rev Respir Dis 1990; 142: 1172-1178.

13. Neas LM, Dockery DW, Ware $J H$, Spengler JD, Speizer FE, Ferris jr BG. Associations of indoor nitrogen dioxide with respiratory symptoms and pulmonary function in children. Am J Epidemiol 1991; 134: 204-219.

14. Strachan DP. Damp housing and childhood asthma: validation of reporting of symptoms. Br Med J 1988; 297: 1223-1226.

15. Dales RE, Zwanenburg $H$, Burnett $A$, Franklin CA. Respiratory health effects of home dampness and moulds among canadian children. Am J Epidemiol 1991; 134: 196-203.

16. Brunekreef $\mathrm{B}$. Associations between questionnaire reports of home dampness and childhood respiratory symptoms. Sci Total Enwiron 1992; 127: 79-89.

17. Godfrey S: Childhood asthma. In: Asthma ( $3 r$ rd edn), eds. Clark TJH Godfrey S, and Lee TH. Chapmann \& Hall "London 1992, (chapter 18 "p551-604).

18. Hoek $G, B r u n e k r e$ f $B$. Acute effects of a winter air pollution episode on pulmonary function and respiratory symptoms in children. Arch Environ Health 1993; 48: 27-32.

19. Roemer $W$, Hoek $G_{1}$ Brunekreef $B$. Effect of ambient winter air pollution on respiratory health of children with chronlic resplratory symptoms. Am Rev Respir Dis 1993; 147: 118-124.

20. Hoek G. Fischer P. Brunekreef B, Lebret E, Hofschreuder P. Mennen MG. Acute effects of ambient ozone on pulmonary function of children in the Netherlands. Am Rew Respir Dis 1993; 147: 111-117.

21. Spektor DM, Lippmenn M, Lioy PJ, Thurston GD, Citak K, James DJ, Bock $N$, Speizer $F_{\text {, Hayes }}$ C. Effects of ambient ozone on respiratory function in active normal children. Am Rev Respir Dis $1988 ; 137: 313-320$.

22. Lippmann M. Health effects of ozone. A critical review. J Air Pollut Control Assoc 1989; 39:672-695.

23. Higgins IT, D'Arcy JB, Gibbons DI, Avol EL, Gross KB. Effect of exposure to ambient ozone on ventilatory lung function in children. Am Rev Respir Dis 1990; 141: 136-146.

24. Lioy PJ, Wollmuth TA, Lippmann M. Persistance of peak flow decrements in children following ozone exposure exceeding the national ambient air quality standerrd. I Air Pollut Control Assoc 1985; 35: $1068-1071$.

25. Berry $M_{*}$ Lioy PJ, Gelperin $K_{*}$ Buckler $G, K$ Kotz J. Measurement of health effects in children and conselors at two summer camps. Environ Res 1991; 54: 135-150. 
26. Clément $\mathrm{J}$, Làndsér $\mathrm{FJ}$, Woestijne van de KP. Total resistance and reactance in patients with respiratory complaints with and without airway obstruction. Chest 1983; $83: 215-220$.

27. Clement $J$, Dumoulin $B$, Gubbelmans $A$, Hendriks KP, Woestijne van de KP. Meference values of total respiratory resistance and reactance between 4 and $26 \mathrm{~Hz}$ in children and adolescents aged 4-20 years. Bull Eur Physiopathol Respir 1987; $23: 441-448$.

28. Stanescu $D$, Moavero NE, Veriter $C$, Brasseur L. Frequency dependence of respiratory resistance in healthy chitdren. J Appl Physiol 1979; 47: 268-272.

29. Duiverman EJ, Clément J, Woestijne van de KP, Neljens HJ, Bergh van den ACM, Kerrebijn KF. Forced oscillation technique. Reference values for resistance and reactance over a frequency spectrum of $2-26 \mathrm{~Hz}$ in healthy children aged $2.3-12.5$ years. Bull Eur Physiopathol Respir 1985; 21: $171-178$.

30. Peslin R, Gallina $C$, Teculescu D, Pham QT. Respiratory input and transfer impedances in children 9-13 years old. Bull Eur Physiopathol Respir 1987; 23: 107-112.

31. Hogg JC, Williams J. Age as a factor in the distribution of lower airway conductance and the pathologic anatomy of obstructive lung disease. New Engl J Med 1970; 282: 1283-1287. 



\section{Hoofdstuk 10}

\section{SAMENVATTING}

\section{Astma}

Dit proefschrift beschrijft onderzoek naar de prevalentie van chronische luchtwegklachten (astma-klachten) en astma bij schoolkinderen, in de leeftijd van 6 tot 12 jaar. Schattingen van de werkelijke prevalentie van astma bij kinderen lopen nogal uiteen, aangezien er verschillende definities van astma binnen de epidemiologie gehanteerd worden. In de prevalentie studies werd astma gedefinieerd als het vermelden van tenminste twee van de vier kern-symptomen voor astma, waaronder in elk geval "piepen" of 'aanvallen van kortademigheid met piepen'. In de studies gepresenteerrd in de hoofdstukken vier ( $n=482$ kinderen) en acht $(n=1123$ kinderen) vonden we, glebaseerd op deze symptoomdefinitie, astma prevalenties van $11 \%$ respectievelijk $12 \%$. Dit in tegenstelling tot de door een (huis)arts vastgestelde astma prevalenties van $6 \%$ respectievelijk $7 \%$, hetgeen suggereert dat een belangrijk deel wan de astma-(klachten)kinderen niet als zodanig wordt herkend en/of benoemd. Verder bleek ongeveer een kwart van de kinderen die bij de (huis)arts bekend zijn met bronchitis, te voldoen aan de op symptomen gebaseerde definitie voor astma, hetgeen zou kunnen worden uitgelegd als misclassificatie. Het al of niet voorschrijven van anti-astma medicatie bleek nauw gerelateerd aan de diagnose 'astma' (meestal wel medicatie) of 'bronchitis' (vrijwel nooit medicatie). De waarneming dat een belangrijk deel van de kinderen met astma-klachten niet als zodanig wordt herkend en/of benoemd, suggereert dat onderbehandeling van deze kinderen nog steeds een probleem is.

Inherent aan het gebruik van een op symptomen gebaseerde definitie van astma zijn probllemen zoals het heterogene klinische beeld van de ziekte en de geringe specificiteit voor astma van symptomen als 'piepen' en 'kortademigheid'. In aanvulling op de prevalentie bepalingen werden longfunctiemetingen verricht met behulp van spirometrie en de geforceerde oscillatie techniek (impedantie meting). Longfunctie waarden voor zowel spirometrie als impedantie, waren significant slechter voor kinderen met astma-klachten vergeleken met klachtenvrije kinderen, hoewel in absolute zin de verschillen klein zijm. De grootste afwijkingen werden gevonden in kinderen met astma volgens onze symptoomdefinitie. De longfunctie data ondersteunen dan ook de relatief hoge op symptomen gebaseerde astma prevalentie bij deze kinderen en bevestigen de veronderstelling dat onderdiagnose (en dientengevolge onderbehandeling) van astma bij kinderen nog steeds de nodige aandacht verdient. 


\section{Milieu-factoren}

- Binnen-milieu. In de in dit proefschrift beschreven studies werden de effecten van diverse risicofactoren van het binnen-milieu, zoals passief roken, afvoerloze keukengeisers, vocht en huisdieren, op het ademhalingsstelsel van kinderen onderzocht. Het roken van de ouders bleek de grootste effecten te hebben op de longfunctie van de kinderen. De resultaten beschreven in hoofdstuk zes, waarin de relaties tussen het roken van de ouders en de impedantie waarden van hun kinderen meer in detail worden uitgewerkt, suggereren het bestaan van een dosis-respons relatie. Roken van de moeder bleek het belangrijkste, hetgeen mogelijk samenhangt met rook-expositie tijdens de zwangerschap en het feit dat moeders in het algemeen meer tijd met hun kinderen doorbrengen dan vaders. Hoewel minder eenduidig dan bij de longfunctie data, wijzen de gegevens beschreven in hoofdstuk 5 en 8 op een relatie tussen het roken van de moeder en de rapportage van astma-klachten bij hun kinderen, wederom met aarwijzingen voor een dosis-respons relatie.

Van de overige onderzochte risicofactoren uit het binnen-milieu, konden effecten op de luchtwegen van kinderen minder consistent worden aangetoond. Er werd een relatie gevonden tussen de aanwezigheid van afvoerloze keukengeisers en een aantal klachten, bij afwezigheid van effecten op de longfunctie bepaald middels spirometrie. Daarentegen werden statistisch significante effecten op een gedeelte van de impedantie parameters (reactantie) gevonden bij meisjes, maar niet bij jongens. Vocht in huis, gemeten als gerapporteerde vochtplekken en/ of schimmelgroei, bleek gerelateerd aan de rapportage van astma-klachten, hoewel niet in alle gevallen significant. In dit geval werden met name bij jongens ook effecten op spirometrie en impedantie parameters aangetoond. De aanwezigheid van een hond bleek significant gerelateerd aan het voorkomen van aanvallen van kortademigheid met piepen. Er konden echter geen relaties tussen het houden van huisdieren en de overige klachten of met longfuncties worden aangetoond.

In de literatuur wordt gesuggereerd dat tussen jongens en meisjes verschillen in gevoeligheid bestaan voor effecten van milieu-factoren op het ademhalingsstelsel. Daarom werden de analyses gestratificeerd naar geslacht. Een consistent patroon kon hierbij niet worden aangetoond. De ene keer leken jongens gevoeliger (passief roken, vocht) terwijl in andere gevallen meisjes gevoeliger leken (afvoerloze keukengeiser, roken moeder).

Het spreekt voor zich dat de conclusies die op basis van de hierboven besproken studies getrokken kunnen worden, beperkt zijn door de cross-sectionele onderzoeksopzet. Het feit dat informatie over de blootstelling als ook over de klachten op één moment in de tijd werd verkregen met éen en dezelfde vragenlijst maakt dat het optreden van informatie-bias niet kan worden uitgesloten.

- Buiten-milieu. In hoofdstuk acht kon het waargenomen inter-regionale verschil (Limburg versus Groningen) in de prevalentie van astma en astma-klachten niet worden verklaard uit de verschillen in verdeling van de risicofactoren uit het binnen-milieu zoals zojuist besproken. Andere factoren, zoals genetische aanleg, virale infecties en risicofactoren uit het buiten-milieu (w.o. luchtverontreiniging) hebben mogelijkerwijs bijgedragen to de waargenomen inter-regionale verschillen in astma en astma-klachten bij de onderzochte kinderen. Voor zover er gegevens over de luchtkwaliteit beschikbaar waren, bleken de verschillen tussen de regio's klein en werden in het algemeen de luchtkwaliteitsnormen niet overschreden. Het is daarom niet waarschijnlijk dat de 
waargenomen inter-regionale verschillen worden veroorzaakt door verschillen in de gemeten buitenluchthwallteit.

De aandacht voor de mogelijke rol van luchtverontreiniging op de respirato ire gezondheid is de laatste decennia flink toegenomen. Het optreden van smog-episoden biedt mogelijkheden om (acute) gezondheidseffecten van kortdurende (piek) exposities nader te onderzoeken. Hoofdstuk zeven van dit proetschrift beschrijft een studie naar de acute effecten van een zomersmog-episode, gekarakteriseerd door ozon concentraties (8-uurs) $>120 \mu \mathrm{g} / \mathrm{m}^{3}$ (max: $\left.163 \mu \mathrm{g} / \mathrm{m}^{3}\right)$ en 1-uurs-concentraties $>160 \mu \mathrm{g} / \mathrm{m}^{3}$ (max. 215 $\left.\mu \mathrm{g} / \mathrm{m}^{3}\right)$, op symptomen en longfunctie bij 212 kinderen. In overeenstemming met resultaten van andere studies, werd geen significante toename in de rapportage van acute luchtwegklachten gevonden. Van de onderzochte longfunctie parameters was alleen de verandering in PEF significant, negatief, gerelateerd aan veranderingen in ozon blootstelling. Vergelijkbare resultaten zijn eerder beschreven, hoewel de literatuur met betrekking tot de spirometrische parameter waarop de effecten het grootst ziln. niet consistent is. Ozon blootstelling bleek geen nadelig effect te hebben op de onderzochte impedantie parameters. De tekens van de veranderingen in impedantie parameters waren tegenovergesteld aan de verwachte richting bij een nadelig effect. Aanwijzingen dat kinderen met chronische luchtwegaandoeningen gevoeliger zijn voor de effecten van ozon dan klachtenvrije kinderen werden niet gevonden, hetgeen in overeenstemming is met eerder beschreven resultaten. Op grond van deze resultaten kunnen we concluderen dat een matige zomersmog-episode met ozon concentraties $>120 \mu \mathrm{g} / \mathrm{m}^{3}$ niet resulteert in duidelijke effecten op de respiratoire gezondheid van kinderen.

\section{De Geforceerde Oscillatie Techniek}

In de studies gepresenteerd in dit proefschrift werd de luchtwegimpedantie gemeten met behulp van de geforceerde oscillatie techniek (FOT), in open populaties schoolkinderen. In hoofdstuk twee zijn impedantiewaarden van 371 symptoom-vrije kinderen nader bestudeerd. De impedantiewaarden bleken te variëren met lengte en geslacht. In alle kinderen namen weerstandswaarden af en reactantiewaarden toe bij toenemende lengte. Beneden een lengte van $160 \mathrm{~cm}$, werden statistisch significante verschillen in weerstands- en reactantiewaarden gevonden tussen jongens en meisjes "Negatieve frequentie afhankelijkheid van de weerstand $\left(F D\right.$ van $\left.A_{r s}\right)$ - bij volwassenen een indicatie voor luchtwegobstructie - bleek een normaal voorkomend verschijnsel bij deze kinderen. Deze FD van $\mathrm{R}_{\mathrm{rs}}$ neemt geleidelijk af met toename van de lengte, en blijt bij jongens significant langer bestaan dan bij meisjes. In tegenstelling tot volwassenen betekent dit dat negatieve FD van $\mathrm{R}_{\mathrm{rs}}$ bij kinderen niet noodzakelijkerwijs een indicatie is voor obstructie, maar hoogst waarschijnlijk kan worden verklaard uit de bouw van het nog onvolgroeide ademhalingsstelsel. Het langer bestaan van negatieve FD van $R_{r s}$ bij jongens zou kunnen betekenen dat kleine patroonveranderingen in luchtwegimpedantie, ten gevolge van blootstelling aan milieu-factoren of door ziekte, moeilijker detecteerbaar zijn bij jongens dan bij meisjes. De waargenomen verschillen tussen jongens en meisjes gaan waarschijnlijk gepaard met verschillen in groeisnelheid tussen beiden, hetgeen resulteert in verschillen in luchtwegdiameter.

In hoofdstuk vier worden statistisch significante, maar kleine, verschillen in impedantie waarden beschreven tussen kinderen met en zonder astma(-gerelateerde klachten). De verschillen werden ondersteund door vergelijkbare verschillen in de spirometrische parameters. In hoofdstuk drie onderscheiden we vier groepen kinderen: symptoom-vrij, chronisch hoesten, astma en rest-symptomen. Statistisch significante verschillen in 
impedantie waarden konden worden aangetoond tussen symptoom-vrije en astmatische kinderen, bij meisjes maar niet bij jongens. Interactie tussen geslacht en ziektestatus bleek statistisch significant, hetgeen betekent dat verschillen tussen astmatische en symptoom-vrije kinderen variëren voor jongens en meisjes. Voor de overige symptoom-groepen konden ten opzichte van de klachten-vrije kinderen geen duidelike verschillen in impedantiewalarden worden aangetoond. Deze resultatentonen wederom aan dat impedantie waarden bij kinderen geslachtsgerelateerd zijn. Daarnaast ondersteunen ze de veronderstelling dat kleine patroon veranderingen in lluchtwegimpedantie ten gevolge van de aanwezigheid van ziekte, bijjongens moeilijker detecteerbaar zijn dan bil meisjes.

De diagnostische waarde van de individuele impedantie parameters bleek laag. Voor geen van de onderzochte parameters kon een afkappunt met acceptabele waarden voor sensitiviteit en specificiteit worden bepaald, met een duidelijk discriminerend vermogen tussen klachten-vrije kinderen en kinderen met chronische luchtwegklachten. Een mogelijke verklaring hiervoor is dat gebaseerd op éen dwarsdoorsnede meting, de FOT niet gevoelig genoeg is om kinderen met chronische luchtwegklachten te identificeren. Echter, in de vragenlijst werd gevraagd naar chronische luchtwegklachten in de afgelopen 12 maanden, terwijl de impedantiemeting werd verricht op één moment, namelijk gedurende schooltijd, waarop de meerderheid van de kinderen waarschijnlijk klachten-vrij was. Een andere mogelijke verklaring zou kunnen zijn dat het ontbreken van duidelijke verschillen in impedantiewaarden tussen kinderen met en zonder klachten, impliceert dat er daadwerkelijk geen functionele verschillen tussen beilde groepen bestaan.

Met name in hoofdstuk drie (en vijf) zijn de impedantie gegevens uitvoerig geanalyseerd. Gebruikmakend van lineaire en kwadratische regressies werden individuele weerstands en reactantie curves beschreven als een functie van de frequentie. Impedantie karakteristieken van deze curves werden gebruikt in aanvulling op de gangbare on-line parameters. De aanvullende impedantie parameters gaven geen additionele informatie ten opzichte van de on-line parameters, hetgeen het gebruik van de an-line parameters ondersteunt en vergelijking van eerdere met huidige resultaten toestaat.

In de studies gepresenteerd in de hoofdstukken vijf tot en met acht zijn impedantie waarden gebruikt als uitkomstmaat in de evaluatie van potentiële gezondheidseffecten ten gevolge van blootstelling aan milleu-factoren. De metingen bleken makkelijk en snel uitvoerbaar zowel voor het kind als ook voor de onderzoeker. In tegenstelling tot spirometrie zijn de metingen onafhankelijk van de geleverde inspanning door het kind, en daardoor minder gevoelig voor leereffecten. Bij de bestudering van effecten van risicofactoren uit het binnen-milieu (hoofdstuk vijf) waren de resultaten verkregen met spirometrie en impedantie evenwel goed vergelijkbaar. De effecten van blootstelling aan een zomersmog-episode (hoofdstuk zeven) waren minder consistent. Afnamen in spirometrische parameters gingen zoals gezegd niet samen met nadelige effecten op de impedantie parameters. Dit zou kunnen betekenen dat de impedantiemeting het substraat van ozon-blootstelling niet kan aantonen. Voor een volledige interpretatie van de data is echter meer onderzoek naar zowel de toepasbaarheid van de FOT als ook de afhankelijkheid van impedantiemetingen van meteorologische factoren en potentiële confounders, noodzakelijk.

Samenvattend, van de onderzochte kinderen rapporteert 11-12\% twee of meer astmaklachten. Een groot deel van deze kinderen lijkt niet als zodanig te worden herkend en/of benoemd, waardoor onderbehandeling van deze kinderen waarschijnlijk nog 
steeds een belangrijk probleem is. Van de onderzochte risicofactoren uit het binnenmilieu bleek het roken van de ouders (met name moeder) het duidelijkste gerelateerd aan longfunctie en klachten. De sensitiviteit van de FOT voor het aantonen van effecten bleek vergelijkbaar met spirometrie wat betreft de risicofactoren in het binnen-milieu, maar dit gold niet voor de aan ozon blootstelling gerelateerde effecten. Met behulp van de FOT konden impedantie metingen snel en eenvoudig worden uitgevoerd in de onderzochte populaties van kinderen. In de toekomst dient echter, door middel van longitudinale studies meer inzicht te worden verkregen in de validiteit en reproduceerbaarheid van de impedantiemetingen bij kinderen, hun diagnostische waarde bij kinderen en de relaties van impedantie parameters met diverse relevante confounders. 



\section{DANKWOORD}

De totstandkoming van dit proefschrift is mede het resultaat van de inzet van, samenwerking met en de begeleiding door velen. Op het risico af sommigen te vergeten is een persoonlijk dankwoord aan de volgende personen hier zeker op zijn plaats. Allereerst wil ik mijn beiden promotores Prof. dr. EFM Wouters en Prof. dr. F Sturmans bedanken voor de manier waarop zij vorm, inhoud en richting hebben gegeven aan het onderhavige onderzoek. Beste Miel, op een cruciaal moment heb jij de teugels van het project ter hand genomen. Met je heldere inzicht in en keninis van de pulmonologie heb je ervoor gezorgd dat we uiteindelijk glansrijk de eindstreep haalden. Jou vermogen om ideeën te genereren en uit te werken zijn van onschatbare waarde geweest voor het huidige eindresultaat. Beste Ferd, als vertegenwoordiger van de epidemiologie in hoogst eigen persoon, was jou zeer kritische, maar altijd opbouwende commentaar, op mijn manuscripten voor mij zeer waardevol. Je scherpe vragen wisten de discussie altijd op een leuke manier te stimuleren en onder het motto: 'beter nu dan dat je daar straks staat", heb je er dan ook heel wat afgevuurd.

Beste Gerard, als een van mijn co-promotoren ben je vanaf het prille begin bij het onderzoek betrokken geweest. Vanuit onze voormalige vakgroep Arbeidsgeneeskunde, Milieugezondheidkunde en Toxicologie (AMT), zijn we begonnen het project op de rails te zetten. Dat niet altijd alles liep als een trein, maar dat we te maken hadden met de nodige tussenstops $s_{\text {, }}$ mleidingen en vertragingen heb jij steeds van dichtbij meegemaakt. Gerard, ik bedank je voor 'de deur die altijd voor me open stond'. Beste Geertjan, voor mij is jou persoon onlosmakelijk verbonden met de hele schrijverij. Je duidelijkheid, directheid en no-nonsens mentaliteit werkten daarbij zeer prettig. Supersnel heb je telkens weer mijn artikelen van grondig en opbouwend commentaar voorzien en met me besproken. Daarnaast hebben jou oprechte belangstelling voor de voortgang van het onderzoek als ook voor mij als persoon en je enthousiasme (VLAAI!!!?) als er weer eens iets leuks was gebeurd (artikel geaccepteerd, prijsje e.d.), voor mij zeer stimulerend gewerkt. Ik had het nodig, Bedankt!

Beste Jos, jij was de spil in mijn analyses. Ten alle tijden was je bereid mij in nieuwe, aanvullende of herhaalde analyses te ondersteunen. Ik ben je geweldig dankbaar voor je inzet. Onmisbaar in de analyse fase was ook jij, Fons. Als geen ander weet jij altijd onvolkomenheden te signaleren en mee te denken over mogelijke oplossingen. In de twee hoofdstukken waar we niet alleen in de analyses maar ook in de schrijverij nauw hebben samengewerkt, heb ik als zeer plezierig ervaren. Ik bedank je voor je vermogen om vaak de geringste onduidelijkheden en tegenstrijdigheden op te sporen, de tijd die je vrijmaakte om een en ander met me door te nemen en je gezelligheid. 
Marliese ook jou wil ik bedanken voor je werkzaamheden tijdens de projecten en de belangstelling waarmee je alles hebt gevolgd. Bedankt ook voor je inzet bij het verzorgen en meedenken over de lay-out van het manuscript, jammer dat je het niet kon afmaken. Die klus werd prima overgenomen door Thum. Nog steeds ben ik verbijsterd van de snelheid waarmee jij aanpassingen en wijzigingen weet door te voeren. Ik weet dat ik niet erg origineel ben als ik zeg: 'Thum geer zeet bedaáank!!! (maar kan ik anders?). Van het secretariaat wil ik verder ook Ellen en Cobie bedanken voor al die keren dat ik een beroep op hun kon doen. Alle collega's van onze voormalige vakgroep AMT en de huidige vakgroep Epidemiologie, bedankt voor het creëren van een gezellige werksfeer, en jullie oprechte, warme belangstelling voor mijn 'proefschrift perikelen', ook toen ik inmiddels een thuiswerkende promovendi was geworden. Met name jou IJmert wil ik bedanken voor je nimmer aflatende belangstelling voor mij en thet reilen en zeilen van mijn onderzoek. Jouw probleemoplossend vermogen, de originaliteit van je ideeën, en de manier waarop je me als directe callega en vriend al die jaren met woord en daad hebt bijgestaan heb ik altijd zeer gewaardeerd. Paul (Borm), jou will ik graag bedanken voor je inspirerende inbreng tijdens de 'stellingen brainstorm".

Beste Paul (Knipschild), vanuit je functie als vakgroep voorzitter heb je, in voor mij niet de meest makkelijke periode, verlenging en ondersteuning geregeld. Ik ben je oprecht dankbaar voor je inzet, je warme belangstelling en je aansporingen.

Ook wil ik graag de mensen uit de Begeleidingscommissies bedanken voor de constructieve samenwerking in de afgelopen jaren. Met name Paul Mertens wil ik bedanken voor zijn inzet vanuit de GGD Midden-Limburg, bij het initiëren als ook bij de uitvoering van de projecten. Gerard Hoek van de Landbouw Universiteit Wageningen, wil ik graag bedanken voor de goede samenwerking met betrekking tot de aanvullende luchtkwaliteits metingen in de smog-studie en voor zijn waardevolle inbreng als mede-auteur van een van de hoofdstukken. Van de Provincie Limburg will ik graag Marcel Severijnen bedanken voor zijn inzet, ondersteuning en samenwerking met betrekking tot het in kaart brengen van de (lokale) luchtkwaliteit en Arno Scheepers bedank ik voor het daadwerkelijk uitvoeren van de aanvullende metingen. Verder wil de medewerkers van het Coördinatiebureau Eerste Lijn (CEL), de huisartsen en de medewerkers van de afdelingen Jeugdgezondheidszorg van de GGD Maastricht en de GGD Midden-Limburg bedanken voor hun inzet bij het benaderen van de onderzoekspersonen. Alle scholen bedank ik voor hun bereidheid tot deelname, en natuurlijk ook alle kinderen en hun ouders. Zonder hun geweldige inzet was dit onderzoek niet mogelijk geweest

Cyrille, als mijn voormalige onderzoeksassistente, en huidige vriendin, wil ik je bedanken voor de vele gezellige uren tijdens de veldwerkperiode. Met je nimmer aflatende optimisme en vrolijkheid wist je ten alle tijden de stemming erin te houden. Monique, ik ben ontzettend blij dat je voor je afstudeer stage bij ons terecht kwam. Jou enthouslaste inzet werkten voor mij ook erg stimulerend. Ik heb onze samenwerking tijdens het project als ook bij de analyses en de schrijveril als zeer prettig ervaren, ik ben blij dat je een van mijn paranimfen wilt zijn. Dat laatste geld ook voor jou, Jeanne. Samen hebben jullie mij in die laatste maanden op een fantastische en heel gezellige wijze met "raad en daad" bijgestaan.

Tenslotte bedank ik al mijn vrienden voor de vele gezellige, sportieve en culinaire uren buiten het promotie gebeuren. Slechts enkele wil ik hier met name noemenlieve Gerda, Serva, Joan, Jeanne, en Ellen ik ben blij jullie te kennen en ik geniet van onze vriendschap. En 'last but not least' bedank in jou mijn lieve Alex voor je steun, je liefde en je nimmer aflatende vertrouwen in mij. 


\section{CURRICULUM VITAE}

Carin Cuijpers werd geboren op 21 oktober 1965 te Venray en groeide op in het noordLimburgse dorpje, Geijsteren. In 1984 behaalde zij het Atheneum-B diploma aan de scholengemeenschap Jeruzalem, te Venray.

Tussen 1984 en 1988 studeerde zij Gezondheidswetenschappen aan de Rijksuniversiteit Limburg (RL), te Maastricht. In november 1988 behaalde zij haar doctoraal diploma in de Biologische Gezondheidkunde (BGK). Na haar afstuderen was zij gedurende een half jaar als onderzoeksassistent verbonden aan de vakgroep Arbeidsgeneeskunde, Milieugezondheidkunde en Toxicologie (AMT). Tijdens deze periode werd onder andere een onderzoeksplan ontwikkeld dat ten grondslag ligt aan de in dit proefschrift gepresenteerde projecten. Van eind 1989 tot begin 1994 was zij als assistent in opleiding werkzaam, eerst bij de vakgroep AMT, later bij de vakgroep Epidemiologie van de AL. Tijdens deze periode verrichte zij de studies die in dit proefschrift beschreven zijn. Vanaf juni 1995, zal zij als epidemiologisch onderzoeker Monitoring Milieucontaminanten werkzaam zijn bij het Centrum voor Chronische ziekten en Milieu-epidemiologie (CCM) van het Rijksinstituut voor Volksgezondheid en Milieuhygiëne (RIVM), te Billthoven. 



\section{PUBLICATIES}

\section{Full Papers}

Cuijpers CEJ, Wesseling GJ, Swaen GMH, Wouters EFM. Frequency dependence of Oscillatory Resistance in Healthy Primary school chlldren. Respiration 1993;60:149-154.

Culjpers CEJ, Wesseling GJ, Swaen GMH, Sturmans $F_{1}$ Wouters EFM. Asthma ralated symptoms and lungfunction in primary school children. J Asthma 1994;31:301-312.

Cuijpers CEJ, Swaen GMH, Wesseling GJ, Hoek G. Siturmans F "Wouters EFM. Acute respiratory effects of low lovel summer smog in primary school children. Eur Respir J, 1995 (in press).

Cuijpers CEJ, Swaen GMH, Wesseling Gd, Sturmans F, Wouters EFM. Acute respiratory effects of low level summer smog in primary school children. Toxicol Lett 1994;72:227-235.

Cuilpers CEJ, Wesseling G.J, Swaen GMH, Wouters EFM. Height and gender related impedance values in primary school children. Eur Respir Rev 1994;4(19):150-154.

Cuipers CEJ, Swaen GMH, Wesseling GJ, Sturmans F "Wouters EFM. Adverse effects of the indoor enwironment on respiratory" health in primary school children. Environ Res, 1995 (in press).

Culjpers CEJ, Kessels AGiH, Mertens PLM, Wesseling GJ, Swaen GMH, Kok ME, Broer J, Sturmans F. Wouters EFM. How does parental smoking affect respiratory imperdance in children? (submitted for publication, Pediatr Puimonol).

Cuijpers CEJ, Kesseis AGH, Mertens PLJM, Wesseling GJ, Swaen GMH, Kok ME, Broer J, Sturrnans F. Wouters EFM. Respiratory impedance in $\$ 776$ Dutch primary school children, with and without chronic respiratory symptoms. (accepted for publication by the Eur Respir $\mathrm{d}$ ).

Kok ME, Mertens PLUM, Cuijpers CEJ, Swaen GMH, Wesseling G, Broer ل, Sturmans F, Wouters EFM. Interregional differences in the prevalence of asthma among primary school children in the Netherlands. (submitted for publication. Eur J Pedeatr).

\section{Abstracts}

Cuijpers CEJ, Swaen GMH, Wesseling GJ, Kessels F, Sturmans F, Wouters EFM. Differences in respiratory impedance values between symptom-tree and asthmatic children. The European Respiratory Ulournal vol. 7 (suppl 18), $1235,1994$. 
Culpers CEd, Swaten GMH, Wesseling GJ, Kessels F, Sturmans F, Wouters EFM. Effects of parental smoking on respiratory health in Dutch primary school children. The European Respiratory Journal wol. 7 (suppl 18), 176s; 1994.

Kok ME, Mertens PLلM, Cuippers CEJ, Swaen GMH, Wesseling GJ, Broer J, Sturmans F, Wouters EFM. Regional variations in respiratory health in primary school children in the Netherlands. The European Respiratory Journal vol.. 7 (suppl 18), 351s, 1994

Culpers CEJ, Wesseling G., Swaen GMH, Wouters EFM. Chbonic cough in school children, more than a symptom? The European Respiratory Journal wol. 6 (suppl 17). 222s, 1993.

Cuipers CEJ, Wesseling GJ, Swaen GMH, Wouters EFM. Acute health effects af smog in children. The European Respiratory Journal vol. 6 (suppl 17), 345s, 1993.

Cuijpers CEJ, Swaen GMH, Wesseling GJ, Wouters EFM. Diagnosing asthma in primary schoolchildren. The European Respiratory Journal vol. 5 (suppl 15), 34s, 1992.

Cuijpers CEJ Swaen GMHH, Wesseling GJ, Wouters EFM. Forced oscillation technique in primary schoof children with and without respiratory complaints. The European Respiratory Journal wol. 5 (suppl 15), $108 \mathrm{~s}, 1992$.

Cuijpers CEJ, Swaen GMH. Gesseling GJ, Wouters EFM. Frequency dependence of osciNlatoryresistance in dutch primary school children. The European Respiratory Journal vol. 5 (suppl 15), 109s, 1982.

\section{Overigen}

Meijers JMM, Cuijpers CEJ, Vliet van $\mathrm{C}$, Swaen GMH. Respiratoire aandoeningen bij langdurige blootstelling aan Man-Made Vitreous Fibres (MMVF). T Soc Gezondheidsz. 66 (1988) 284-290.

Cuijpers CEJ, Jorna THM. Vroege diagnostiek van long- en luchtwegaandoeningen ten gevolge van blootstelling in arbeid en milieu. Lucht \& Longen juni 1991, nr. 2.

Cuijpers CEJ. Luchtwegklachten bij basischoolkinderen in Midden-Limburg. Limburgs Milieu, uitgave wan de stiohting milleufederatie Limburg, maart $1989 \mathrm{nr} .1$. 